Linköping Studies in Science and Technology

Dissertations, No. 1895

\title{
Adopting Information Systems \\ Perspectives from Small Organizations
}

\author{
Özgün Imre
}

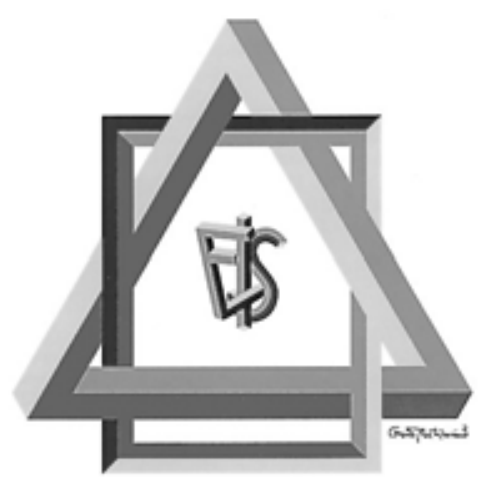

Department of Management and Engineering Linköpings Universitet, SE-581 83 Linköping, Sweden 
(C) Özgün Imre, 2017

Adopting Information Systems - Perspectives from Small Organizations

Linköping Studies in Science and Technology,

Dissertations No.1895

ISSN 0345-7524

ISBN 978-91-7685-389-4

Printed by:

LiU-Tryck, Linköping, 2017

Distributed by:

Linköping University

Department of Management and Engineering

SE-581 83 Linköping, Sweden Tel: +46 13281000 


\begin{abstract}
Why do organizations adopt information systems? Is it just because of financial reasons, of concerns for efficiency? Or is it due to external pressures, such as competitor pressure, that an organization adopts an information system?

And, how does the adoption take place? Is it a linear process, or is the process one of conflicts? Does a specific person govern this process, or do we have multiple parties involved? What happens if these conflicts occur among those involved? How does the organization move on and achieve a successful information system adoption?

By investigating two organizations, one international academic journal and one South American manufacturing company, this thesis aims to investigate the whys and hows of information system adoption, and aims to contribute to the discourse on information system adoptions in small organizations - an often underrepresented segment in information system adoption literature.
\end{abstract}

By adopting different theoretical lenses throughout the five research papers included, this body of work suggests that even when seemingly simple, information system adoptions can become rather complex. The cases reveal that the role of information systems and issues related to information system adoptions are often not well thoughtout in the early days of the organization. The actors' understandings of adoption and consequences mature and the information systems become more intertwined.

Common use of stakeholder theory introduces general stakeholders and their interaction with the focal organization. The cases reveal that the adoption process involves multiple actors, even within what would initially appear as a stakeholder, and that those actors can be in conflict with each other. These conflicts often lead to negotiations, and the cases reveal that these negotiations are opportunities of learning; the actors engage with the information system and with each other, gaining new knowledge about the issues at hand.

The dissertation argues that there are various social worlds in information system adoptions, and various factors - ranging from organizational structure to social norms that often affect why and how the organization undergoes an adoption process. The multiple power relations and divergent interests of stakeholders in these adoption processes, and how information systems affect other parts of the organization, reinforce the need for a well thought-out, flexible and reflexive approach to information system adoptions. 



\section{Preface}

Economic Information Systems

Our main focus is where management and IT meet, not least the new, fast-growing, ITintense organisations. More specifically, we deal with how information is transferred from, between and to people, and with the potential in and consequences of the use of IT. The area includes research on business development, management control, and knowledge and competence development, especially in organisations where use of IT plays an important role.

We study the roles that strategies and information systems play in the collaboration between people in organisations in different sectors (public, private and non-profit), networks and coalitions, and the interaction with the surrounding ecologies. Perspectives management - perceiving and handling the perspectives of different stakeholders - is an important part in the striving for a deeper and more nuanced understanding of the phenomena we study.

Our PhD students also participate in the Swedish Research School Management and IT, a collaboration between a dozen Swedish universities and university colleges. In line with its name, the research school organises courses, $\mathrm{PhD}$ conferences and supports $\mathrm{PhD}$ candidate within Management and IT, thus providing a wide network.

The present thesis, Adopting Information Systems - Perspectives from Small Organizations, is written by Özgün Imre. He presents it as his doctoral thesis in Economic Information System at the Department of Management and Engineering, Linköping University.

Linköping in November 2017

Alf Westelius

Professor

Economic Information Systems 



\section{Acknowledgement}

I guess the first group of people to acknowledge in this dissertation would be you, the reader, who has taken time out of your hectic life and is now browsing through the pages of this text. I am eternally grateful, as without you this text would be only splatters of ink on some papers.

Second group would be all the people that became a part of this journey. That began with Eva who was the first one to welcome me, to Emelie, who is the last member to EIS to join us while I am still employed. They, with others - Erik, Fredrik, Margaret, Markus, Susanne, Thomas - are thus acknowledged for their help during the $\mathrm{PhD}$ process. So are the help of Nils-Göran and Carl-Johan, who became my co-supervisor after Nils-Göran decided to prepare for retirement. And of course, Alf Westelius, who gave me the chance to start this process, and even when green with envy for my ability to write never-ending sentences, managed to see the potential in my ideas and encouraged me.

Of people that should be mentioned, I am grateful for the Information Systems division, with whom we shared a corridor for some time, who were very welcoming to me. Malin and Ida who were the first ones to invite me over for lunch and fika, and to this day continue to listen to me and give me advice, I should specifically mention.

As part of the Swedish School of Management and IT, I am grateful for their funding. And I am more grateful for he opportunities it presented to learn about the research process, and make - hopefully - lasting connections with people that I will call my friends. Just like the new division of Industrial Economics we are situated under, their names would be too many to acknowledge, but I should mention Cecilia, as she mentioned mine, and let it never be said I forget to balance the accounts, and Lars Engwall, who was always kind enough to laugh at my jokes - and of course FEKIS, but jokes first. All friends and colleagues that I cannot mention for space purposes, or because I don't want to offend the next person because they think they were nice, but I didn't think so, from Business Administration to Political Science, from Ryd to Istanbul, consider yourselves acknowledged.

I should thank my father, who has died while I was doing my $\mathrm{PhD}$, who had the most amazing advice "do not give me advice, give me money". I wonder what he would be like as a PhD student. And as someone who jumped from the balcony to get to me as quickly as possible when I managed to fall down from that said balcony before I was even able to walk - a mystery if I ever know one - don't you think he deserves an acknowledgement.

And of course to my mom, who has always supported me, in all my endeavours - aside from the time I tried to live on seawater, or wanted to keep a lizard I found as a pet, or decided to follow some girls when I was three years old for a few kilometres on the beach, and when I tried fireworks at home... If it weren't for her, I would not be here now, plain and simple. My heartfelt thanks and gratitude to that lady, who always put me before herself, and still to this day, asks: "how was school today?"

And lastly, I should thank myself, for if not for me, there wouldn't even be splatters of ink on some papers for you to read.

Linköping, Nov 2017

Özgün Imre 



\section{Table of Contents}

1 Introduction 1

2 Reflections on Theories 9

$\begin{array}{ll}2.1 & \text { Some reflections on theory }\end{array}$

$\begin{array}{llr}2.2 & \text { Theories used } & 16\end{array}$

2.2.1 The technology-organization-environment (TOE) framework $\quad 18$

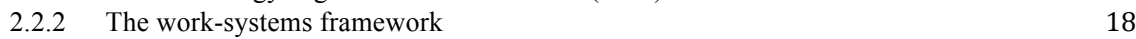

$\begin{array}{ll}2.2 .3 & \text { Stakeholder theory } \\ 2.2 .4 & 20\end{array}$

2.2.4 Social worlds, Negotiated order and Arenas $\quad 21$

$\begin{array}{llr}2.3 & \text { Mapping the theories } & 22\end{array}$

3 Reflections on Research Approach 29

$\begin{array}{ll}3.1 & \text { A qualitative case study }\end{array}$

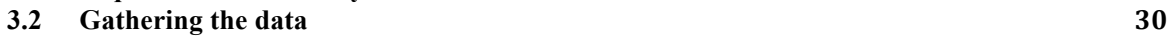

$\begin{array}{ll}\text { 3.3 Analyzing the data } & 34\end{array}$

$\begin{array}{lll}3.3 .1 & \text { Summarizing the analysis } & 43\end{array}$

$\begin{array}{llr}3.4 & \text { Reflecting on quality } & 44\end{array}$

4 The Research Papers $\quad 49$

4.1 Paper 1 - Stake and Salience of Stakeholders $\quad 51$

4.1.1 Introduction to Paper 1 51

4.1.2 Learning by Negotiation - Stake and Salience in implementing a Journal Management System 53

4.1.4 Reflections on Paper $1 \quad 68$

$\begin{array}{lll}4.2 & \text { Paper } 2 \text { - Social Worlds and Negotiated Orders } & 73\end{array}$

$\begin{array}{lll}\text { 4.2.1 Introduction to Paper } 2 & 73\end{array}$

4.2.2 Learning by negotiation - Implementing a journal management system $\quad 74$

4.2.3 Reflections on Paper $2 \quad 89$

$\begin{array}{lll}4.3 & \text { Nuancing the Stakeholder Model } & 97\end{array}$

4.3.1 Introduction to Paper 3 97

4.3.2 Reshaping the Stakeholder Model: Insights from Negotiated Order Theory 98

4.3.3 Reflections on Paper 3 116

$\begin{array}{lll}4.4 & \text { Paper } 4 \text { - Investigating the work system } & 123\end{array}$

$\begin{array}{lll}\text { 4.4.1 Introduction to Paper } 4 & 123\end{array}$

4.4.2 Trying to Go Open: Knowledge Management in an Academic Journal 124

$\begin{array}{lll}\text { 4.4.3 Reflections on Paper 4 } & 147\end{array}$

4.5 Paper 5 - Factors affecting IS adoption at Kitchen Co. 155

$\begin{array}{lll}\text { 4.5.1 Introduction to Paper 5 } & 155\end{array}$

4.5.2 Adopting Information Systems in a Small Company: A Longitudinal study 156

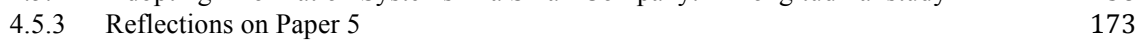

5 Conclusions and Discussion $r 179$

$\begin{array}{llr}5.1 & \text { Concluding the dissertation } & 179\end{array}$

$\begin{array}{lll}5.1 .1 & \text { IS as a non-issue } & 187\end{array}$

5.1.2 Information systems decisions are not standalone $\quad 189$

$\begin{array}{ll}\text { 5.1.3 Conflicts in IS adoption } & 192\end{array}$

$\begin{array}{lll}\text { 5.1.4 Conflict and learning } & 193\end{array}$

$\begin{array}{ll}\text { 5.1.5 Concluding the conclusions } & 196\end{array}$

$\begin{array}{llr}5.2 & \text { Discussing the dissertation } & 200\end{array}$

5.2.1 Reflecting on Future Research 203

$\begin{array}{llr}5.3 & \text { Some words of closure } & 204\end{array}$

$\begin{array}{ll}\text { References } & 205\end{array}$ 



\section{Introduction}

Hello dear readers.

This is Özgün Imre, the author of this dissertation, writing to you from his office in Linköping, trying to foresee what the future holds and adapt his stance accordingly.

I have thought about how to write this wrap $^{1}$ of the dissertation for some time, and had some trials that did not turn out as I intended, which I think is a rather common occurrence when I write, with the text taking a life of its own. In the end I decided to write similar to the essay style, trying to keep my use of references to a minimum as I see the wrap as a moment of reflection on the PhD process. Similar to that, in this wrap, I will try to open some of the black-boxed elements in the research papers in the thesis by providing reflections on them, as well as try to tie the five papers together.

The story of the thesis is a rather long one, with some paths taken that did not end up to anything, with some paths that ended up somewhere - some papers written, but not for the thesis - and some that you are about to read in more detail in the coming pages. And that story began with getting into the $\mathrm{PhD}$ studies with the project aiming to investigate how and why organizations adopt integrated information systems.

There are various ways to investigate an information system (IS) adoption, drawing from different theoretical bases, with different levels of analysis. We have theories and models that deal with IS adoption in particular, such as technology acceptance model (TAM) (Davis 1989) unified theory of acceptance and use of technology (Venkatesh et al. 2003), diffusion of innovations (DOI) (Rogers 1983). We also have perspectives from IS research that did not originate to inspect adoption per se, but can be used to study IS adoption, like sociomateriality (Orlikowski and Scott 2008) when used, for example, in discussing enterprise system adoption and success (e.g. Wagner et al. 2010). Furthermore, we have theories and models from other disciplines that is used to investigate the adoption of IS, such as Gidden's structuration theory that affected the sociomateriality perspective, or institutional theory (Jensen et al. 2009). While there are many venues to follow in an IS adoption study, as the papers in the dissertation show later on, my take is more of an attempt to see how different actors within the setting acted in the adoption process by using different theories. In this way, I tried to keep the focus rather broad and tried to capture the whole adoption process, not focusing only, for example, on how a singular actor - an imaginator, a maverick etc. - managed to convince the others, or how an organization tries to minimize a certain type of risk during IS adoption. I would say, by focusing on how the actors acted in the process as a whole, I was able to provide instances where issues of risk and the power of an imaginator were silently brought into the adoption process.

And furthermore, I see adoption a bit differently than one can find in some parts of the literature taking a project-stage approach, and where adoption is just one of these clearcut stages. Like Rogers (1983) - whose diffusion of innovations (DoI) theory

\footnotetext{
${ }^{1}$ In Swedish, this word would be "kappa" (cloak or wrap), often translated as an "introductory chapter/article" in English publications. However, in those dissertations, the papers are typically appended to this introductory chapter whereas in this dissertation I am employing the Scandinavian, more sandwich-like model, where the articles are both preceded and followed by descriptive, analyzing and discussing texts, all of which are covered by the Swedish term kappa. To go with this sandwich metaphor then, I am using wrap instead of kappa in this dissertation.
} 
influenced technology-organization-environment framework (TOE) that I use - I see the IS adoption more as an on-going issue, that spans various decisions on different levels in an organization. As the cases show later on, one decision to change a part of the organization triggers various responses; a new system acquired has trickle effects through its use, resulting in acquisition of another system. Thus my take on the adoption is a rather different one when compared with the arguments that see adoption just as a clear-cut stage between decision to adopt and implementation. I rather assume a position that sees adoption as an on-going process including decisions and implementation. Similar to Rogers (1983) then I argue that the adoption process will start by first hearing about the innovation to finally adopting it and using it, rather than just arguing it in line with "turning a switch on" or "signing a deal" - that "magic bullet" mentality criticized in literature by likes of Markus and Benjamin (1997) and Davenport (1998). As such, IS adoption or acquisition/investment in parts of the text should be interpreted from this broad definition, a process where different interests clash, where actors act in the way they believe is the best for the organization or in some other way, and where things are complicated.

By having a focus on integrated information system, as Alf Westelius, my main supervisor, would like to argue, me delving into the enterprise resource planning (ERP) systems literature was the logical next step, as they are one - if not the most - of the better-known examples of integrated systems. And even though I haven't followed on the ERP track fully, some of the issues that I encountered while reading ERP literature were rather interesting and influenced this dissertation.

For example, I was rather intrigued by the open-source concept and tried to study open source ERP systems, but due to lack of data, was not able to further that line of research. However, while doing literature research for that, I realised that research on small and medium-sized enterprises (SMEs) is gaining ground and there is a place for further studies on small organizations in particular. This small-organization focus has been carried to the dissertation and all the papers included deal with small organizations.

Similarly, the open-source component can be seen in the papers, though not in the original way I intended for the open-source ERP track, where different logics of open source and proprietary would clash. Instead, the story that will be shown in the following pages will be one of other clashes. It will be about clashes of different stakeholders, clashes among the management group of the organization, clashes among different social worlds. The story will also be about how various factors influence the adoption of information systems, and how these factors work in tandem or against each other, and how the end result has to satisfy different parties. The story will be of two small organizations trying to survive day-to-day while trying to achieve the long-term goal of survival.

These two organizations differ in several aspects: one being a young academic journal, the other being a kitchen manufacturer. One with an international editorial board and clientele, the other situated in South America for a local market. However, all differences aside, they are both small, they are both trying to survive, and they each went through IS adoptions that became the topic of the papers.

During this $\mathrm{PhD}$ process, I have tried my hand at other venues of research that I am not including in this dissertation. Those have involved mostly open source ERPs and various discourses the vendors used. Also in this process, I was the teacher in two 
courses that dealt with ERP systems - their adoption and use. One common thread I could see in these activities was an underlying presence of stakeholders in the processes involved.

Today, we know that having the stakeholders involved with issues is necessary. Some of us have directly related to stakeholder theory thinking, whereas others have used different theoretical lenses to argue for similar things. For example, the customers and owners in soft systems' CATWOE are easy to conceptualise as stakeholders when comparing how similarly they are defined: "owners who could stop the process" "customers affected [...] as victims or beneficiaries" (Checkland and Poulter 2010, p.221) compared with stakeholder defined as "any group or individual who can affect or is affected by the achievement of the organization's objectives" (Freeman 1984, p.46). I could also see similar instances in the course material I used, where issues revolve around stakeholders (for example Scott and Wagner 2003; Westelius 2006), as well as in other parts of literature, from a piece of research on smart cities (Axelsson et al. 2016) to discussing theoretical contributions (Corley and Gioia 2011). It might be that there is an intrusion into the organization that did not take internal stakeholders into account, or an issue of how a manager group that aims for an integrated system is at odds with stakeholders that prefer localised systems, or how various stakeholders have conflicting interests in a smart city project, or how one tries to cater to different stakeholders when doing research. There is a stakeholder understanding that is rather prevalent around us. Thus, looking back, it is no wonder that I have a stakeholder analysis - drawing from Freeman (1984) - as my first step in this dissertation, and to some extent, this dissertation can be placed within stakeholder theory. It has been long recognised that stakeholders are important for the success of IS projects (Lyytinen \& Hirschheim 1987) and stakeholder theory has been incorporated in IS research (Pouloudi 1999), so this dissertation can be argued to fall within the IS domain that draws from stakeholder theory.

But then, as I got involved more into the young academic journal case, some issues popped up that I thought I would not be able to do justice if I only stick with the stakeholder theory. While I can identify the stakeholders, what happens when a central stakeholder has break-ups and perhaps even dissolves? How to account for when the actors within a stakeholder have different agendas? How do these people - or even stakeholders - engage with each other? Is it as Pan (2005, p.175) argues that "the whole stakeholder theory is reducible to this one idea of Freeman's", that will argue for a more instrumental influence/engagement among stakeholders/firm, or can there be issues that will be left in the shadows if using only the Freeman idea of stakeholder theory? These questions I tried to tackle by slowly adding other theoretical streams to my developing tapestry, by conceptualising the issues as clashes of social worlds, by taking the negotiation as how actors engage with each other, by looking for factors that affect the adoption process, that bear on those negotiations, that structure how the adoption pans out. These theoretical streams ranged the TOE framework (DePietro et al. 1990; Thong 1999) to Anselm Strauss' work on social worlds and negotiated orders (Strauss 1978a; Strauss 1978b). Thus, this dissertation, while investigating IS adoption draws from several research streams, even though, as I argue in the next chapter, all of them can be connected to each other.

As I mentioned before, when focusing on ERP systems, I was able to see a shift from large organizations to SMEs in general, and then dividing the S and $\mathrm{M}$. Thus by this dissertation I am adding into that part of literature, IS adoption in small organizations. 
However, having the small organization as my focus also served a purpose. As I mentioned, there was a gradual revelation of what is going on with the case, of seemingly simple situations involving simple actors and acts turning into intricate negotiations, of organizational learning, of balancing their commitment to their small Journal while being employed by their respective universities. Thus, by having rather easy-to-grasp cases provided me a chance of being able to grasp these rather complex issues in a micro-cosmos, rather than trying to solve the Gordian Knot in a large, complex company like ABB. Unlike Alexander the Great, I chose not an unconventional method to solve the problem, but took on, in some ways, a simpler one.

Thus, in the two stories I provide in this dissertation, I have adopted different theoretical lenses to look at the information system adoption in the two organizations from different angles, and to provide different pieces of the puzzle of hows and whys. These two stories are provided in the five papers that I am including in this dissertation:

1- Learning by negotiation - Stake and salience in implementing a journal management system highlights how the academic journal adopted their management system. In this paper, my focus was investigating the various stakeholders that influenced the IS decisions of the editorial board of Business Journal, how their stakes and salience changed throughout the journey, and how these stakeholders' actions played into the IS adoption.

2- Learning by negotiation - Implementing a journal management system, follows the first paper. However, although the studied adoption process is the same, the absence of "stake and salience" in this title is due to a difference in focus. In this paper, I argue that while stakeholders are important in the IS adoption, there are other forces at play, and use a social worlds/negotiated order lens of Anselm Strauss to look at how Business Journal adopted their ISs. The results show that some of the issues that might be missed by only using stakeholder theory can be identified by looking for social worlds and actors instead of stakeholders only.

3- In Reshaping the stakeholder model: Insights from negotiated order theory, I use the insight from the last two papers to design a visual model for stakeholder theory that encourages a nuanced use of the theory. In the analysis of the case, the visual model is used to highlight the dynamism found in the IS adoption of Business Journal, and how individual actors within organizational stakeholders or stakeholder types take different roles when negotiating on issues.

4- Trying to Go Open: Knowledge Management in an Academic Journal is a chapter that again deals with the Business Journal, this time trying to highlight how connected the actors' decisions regarding ISs are to the rest of the organization. To identify these connections, I have adopted Steven Alter's worksystem framework (WSF), and painted a picture that showed how IS adoption issues are not to be taken in isolation from the actors' concerns and aspirations concerning the organization and their relation to it. Due to a longer format, the paper provides a re-narration of the case, providing a comprehensive picture of Business Journal's journey and tying some loose ends in the story.

5- The fifth paper, Adopting Information Systems in a Small Company: $A$ Longitudinal Study, deviates from the others, by providing a case study of a small manufacturing firm in South America, and adopts the technologyorganization-environment (TOE) framework to examine how they opted for a fragmented set-up of standard IS solutions. 
In all of these papers, the topic is similar, covered by the general aim to investigate how and why small organizations adopt their information systems, with the focus changing by the papers. While the first papers aims at identifying the stakeholders and their salience in the IS adoption, the second one aims at identifying the social worlds and their influence at play in that adoption process. The conflict and negotiation focus of the second paper is used to dig deeper to the stakeholder focus in the first paper. By identifying these actors and investigating their interactions with each other, these two papers aim to identify the hows and whys of IS adoption. The third paper is an attempt to combine the insights of the first two and aims to nuance the stakeholder model to reflect issues of temporality, conflict and actor-focused investigation.

The fourth paper attempts to investigate how the various parts of the work-system interacted with each other. Similar to the episodic treatment of adoption in the earlier papers, the various technologies adopted by the organization are used to investigate how an IS-adoption takes place in a small organization by showing how the components of the work system influenced the adoption. The fifth paper uses data from the second case to investigate how the various factors identified in the literature - TOE framework interacted in the IS adoption.

Within that broad topic of investigating how and why an IS adoption occurs, there are some issues that I will now turn to: Was it just financial purposes? Did they begin with something and were locked-in to that decision? Did their ideas emerge under way or were most of them set before the decision process started?

As an analysis of the case material reveals, some of these decisions to adopt the IS are about survival today: can we keep the company going if we don't have this system?; how can I ensure that my production line is reflected in the systems and the accountant understands it?. Some of the issues are of long-term survival: if I were to leave the organization now, will the newcomer be able to understand what I did [and the organization continue its operation]? Some of these decisions are rather rational and straightforward, whereas some are heavily influenced by the environment the organization is in, more aligned with issues of legitimacy and institutional theory thinking. As the issues I picked up from the cases above show, the adoption process is rather hard to pin down to just financial issues, just to a lock-in situation where after adopting a system they couldn't get out due to interdependencies created, just to a preplanned set of actions. It is rather a process of becoming, where the actors and the settings influence each other in various ways, where attachment plays a role, where different worldviews affect decisions.

Some of these connections/influences might be easier to relate to the papers and some have no obvious explicit connections leading to them from the texts. But I think that is one of the purposes of this wrap, to reflect and analyze a body of work and try to make the nuances and issues that didn't make it to the published papers visible.

In the coming pages, in addition to the further exploration of the subject matter related to the papers in general, I reflect on what my theoretical understanding was when writing the papers, the methodological choices I made and how I analyzed my data. In these two chapters first I will provide an overview of the role of the theory in the dissertation and the theories I used and how I think they can provide different pieces to a puzzle, and then I will go over some of the methodological choices made, how the data was gathered and how it was analyzed. Following that, the five papers included in this dissertation are presented. In moving from five papers to a complete thesis, I 
discuss these papers and how they are actually a body-of-work, and what the overall insights of the dissertation are. To do that, in chapter four I introduce the papers, and follow them directly by individual reflections for each - to open black boxes, and close some doors - and then provide general reflections and conclusions in the final chapter.

It is rather hard, I believe, to situate a dissertation to a firm domain that it contributes to - or draws from - if the issues such as IS-adoption or management control are the focus. IS research had a hard time to defend its identity against management, which itself had to fight for its identity against economics and sociology before that. I will delve into the theoretical domains that I draw from in the next chapter; however, there are some domains that this dissertation sits more closely than others that I can briefly mention here.

I have already pointed out stakeholder theory as forming a parcel of this dissertation, thus it can be argued that the dissertation can be placed within the stakeholder domain that deals primarily with issues of identification of stakeholders and their salience - and investigates an IS-adoption case similar to Boonstra and Govers (2009).

One conclusion from that stream is that stakeholders are often conceptualised as monolithic, and might need to be opened up to make justice to the IS adoption in question. To do so, I have adopted social worlds and negotiated order concepts of Anselm Strauss. These concepts have seen use in science and technology studies (Clarke and Star 2008), and have been used to investigate IS-adoptions (e.g. Harvey and Chrisman 1998; Mengiste and Aanestad 2013), thus I can argue that this dissertation falls within that research domain also.

Work-systems and TOE frameworks have been born in the IS field. WSF hasn't seen much use in IS-adoptions to the best of my knowledge, though as Alter (2015) argues, the framework can be used to investigate adoption. However, it also forms a part of the tapestry of this dissertation, and helps in communication with a wider range of audiences. If I were talking with more sociology focused people with Straussian package and managers with stakeholder theory, work-systems theory allowed me to paint the picture that is accessible to both IS- and management-researchers/practitioners. With every new iteration to the IS adoptions, the adaptations of the work system painted a picture that showed how interconnected the IS decisions are to the rest of the organizations. TOE framework (DePietro et al. 1990) on the other, following Thong's (1999) adaptations to fit to the small organization context, showed how a small organizations IS adoption was influenced by various factors, ranging from $\mathrm{CEO}$ /owner characteristics to the environmental influences In that way, this dissertation can be placed among the IS-adoption literature, similar to Gibbs and Kraemer (2004) and Alshamaila et al. (2013).

Thus, it can be argued that the primary audience is the IS and management researchers and practitioners that would see the IS adoption as a process and would like to investigate how the involved actors interacted with each other. However, the data from this dissertation is only from two case studies, so, overall I should put a disclaimer here that there is no emphasis on the generalization from a more positivistic tradition sense of generalization in any of the papers included, or the totality of the dissertation. Similar to that, these two cases are not conducted in a "comparative" design, and thus their benefit stems more from an iterative reading of their combined conclusions - of adding small pieces of the puzzle - rather than comparing the cases to find a definite answer. 
However, the dissertation I believe adds to the literature in several ways. As I will argue later, the IS adoption literature's focus has moved to SMEs as the large organization market became saturated and well researched. In this dissertation I investigate two small organizations, so it can be argued that while covering similar issues, some issues more geared towards a large organizations will be only mentioned as background issues. Or in other words, following the disclaimer of non-generalizability, the insights gained should be thought through from this small organization perspective.

Furthermore, while I will be talking about social structure and its influence on IS adoption, my focus will be mostly of how the actors' interaction was shaped by these social structures, and how this bear upon the IS adoption. Thus while one of the cases comes from a developing country and can be argued to show the differences of developed and developing countries' social structures - thus adding to the IS-adoption literature in that sense - my objective is not in-line with, for example, development economics' of how to change the structure/firm to create further growth, or how to create government policies in accordance to that. It is rather to see how these conditions bear upon the rather micro-interactions taking place during an IS-adoption.

Another aspect to think about when reading this thesis is that while I was able to follow the development of the cases to some extent, I was not able to be present in all the relevant points of interaction, as such, this thesis should not be read as an ethnographic study, but perhaps inspired by an ethnographic mind-set, in trying to see how the actors interacted throughout the IS adoptions.

Another aspect of this dissertation I can mention is my use of discourse analysis to guide my understanding of the phenomena and the material. This means that some issues more pertinent to, for example, rational decision-making model type of ISadoption research, will be backgrounded. That is not to say these issues will not be present, but the decisions to adopt IS will be investigated from how the actors interacted drawing from how they created narrative accounts, not from how they followed an analytical model in making these decisions. 



\section{Reflections on Theories}

As will be shown later on in the research papers, I have used different theories for the papers, and in this section I aim to synthesize my theoretical standpoints for this dissertation. To do so, I first provide an account of how I used theories and then go over the theories I used briefly. This is followed by a section that maps the various concepts used in these theories to each other to show how they fit together, thus how they provide different pieces of a puzzle.

\subsection{Some reflections on theory}

One part of using different theories was an attempt to see the data from different angles, providing different pieces to the puzzle. This, I would also argue, is a result of personal choice, as following only one theory would mean buying into the assumptions of just that theory, thus eliminating the possibility of finding out something that might be interesting, but lying outside the theory's domain. As Walsham (1995, p.76) has put it: "there is a danger of the researcher only seeing what the theory suggests, and thus using the theory in a rigid way which stifles potential new issues and avenues of exploration". Creatively thinking outside the chosen theory box would be one way of doing this. An alternative is to apply different theories to the material. I argue in the following pages that there were issues that data revealed, but I would not be able to do justice with only using stakeholder theory - the first theory I used in this thesis. Thus I extended my theoretical base. As Walsham (1995, p.76) proposes: "It is desirable in interpretive studies to preserve a considerable degree of openness to the field data, and a willingness to modify initial assumptions and theories. This results in an iterative process of data collection and analysis, with initial theories being expanded, revised, or abandoned altogether".

It is in that view that I agree with Avison and Malaurent $(2014)^{2}$ that theory-light research might be a viable option to offset the problems of sticking too much to the theory. They suggest that a "theory fetish" may exist and this might actually stifle the research as the contribution might lie elsewhere but the research might get rejected, as it will not pass the "acid test" of significantly using or developing theory. In this view, like them I agree with Miller's (2007, p.182) suggestion that the value of the research might lie elsewhere: "the discovery of new arguments, facts, patterns or relationships that, in a convincing way, help us to better understand some phenomenon that is of consequence to a social or scientific constituency. Such research may bear little or no connection to pre-existing or future theory, span many theories, or give rise to understandings that only eventually will form the basis of new theories" (Miller 2007, p.182). It is in this manner that I slowly added new theories to my tapestry, to be able to see what lies in data but might be missed by adopting only one lens.

However, similar to others, I do not necessarily fully agree with either Avison and Malaurent or Miller. I don't think my research can necessarily have "no connection to pre-existing theory" as some of their examples are early researchers like Ignaz Semmelweiz, who was ridiculed for arguing for antiseptic procedures, contrary to the conventional medicinal thought of his time. Instead of being outside of a theoretical

\footnotetext{
${ }^{2}$ For a closer look at the debate around the Avison and Malaurent paper, see Journal of Information Technology (2014, issue 4).
} 
domain, I will say I am rather "within" the theories I used, adding a small piece to the discourse by my research. Neither am I fully comfortable with the definition of theorylight papers "those papers where theory plays no significant part in the paper and the contribution lies elsewhere" (Avison and Malaurent 2014, p.330). I agree with their overall position for appropriate emphasis or use of theory and that an overemphasis might be a problem that leads to issues such as reverting to the ideal-types in analyzing and presenting the case or only seeing what the theory suggests. Overall, I don't think they necessarily argue that theory "plays no significant part", but perhaps that the paper does not directly and significantly contribute theoretically. As Silverman (2014) in response to Avison and Malaurent (2014) suggests, it is often an issue of balancing the theory and data, as data doesn't speak for itself without theory. Or as Blumer (1954, p.3) put it, theories " $[\ldots]$ become guides to investigation to see whether they or their implications are true. Thus, theory exercises compelling influence on research-setting problems, staking out objects and leading inquiry into asserted relations. In turn, findings of fact test theories, and in suggesting new problems invite the formulation of new proposals". In this sense I argue there will always be a significant role for theory in our research.

In my papers, I tried to use theories as sensitizing devices. Blumer (1954, p.7) uses the terms definitive- and sensitizing concepts, with the definitive concept defined as "refers precisely to what is common to a class of objects, by the aid of a clear definition in terms of attributes or fixed bench marks". This is akin to the view held by the more positivist approaches, where falsifying the theories is the main concern, whereas in interpretative research the issue is of "using theory more as a 'sensitizing device' to view the world in a certain way" (Klein and Myers 1999, p.75), or as Blumer (1954, p.7) has argued, sensitizing devices "merely suggest directions along which to look". In using theories in this way, I would say I sidestepped some of the issues raised in Avison and Malaurent (2014) that might stem from being too close to the theory, such as reverting to the ideal-types in analyzing and presenting the case or only seeing what the theory suggests. In this way, theories as sensitizing devices provide me with the "background ideas that inform the overall research problem" and "offer ways of seeing, organizing, and understanding experience; they are embedded in our disciplinary emphases and perspectival proclivities. Although sensitizing concepts may deepen perception, they provide starting points for building analysis, not ending points for evading it" (Charmaz 2003, p.259).

Furthermore, I am also in line with the ideas that theories are not just a lens to see per se, but they are actively worked with and through. They influence how we not just "see" but engage in the world. As Sayer (2010, pp.40-1) argues "We develop and use concepts not only through and for observing and representing the world but also for acting in it, for work and communicative interaction; for making and doing as well as speaking, writing, listening and reading, for running organizations and working in them [...]". As such, I agree that the theories do not merely represent or mirror an external reality but enter this external reality and that "... social structures exist only in virtue of the activities they govern, they do not exist independently of the conceptions that the agents possess of what they are doing in their activity, that is of some theory of these activities" (Bhaskar, 1979 cited in Llewelyn 2003, p.666).

Assuming this rather constructionist perspective - that the phenomena under investigation is socially constructed, that this social construction "will involve different configurations of social actors, technologies and objectives" (Butler 1998, p.293), and 
that even the investigation is an interpretative interaction among the researcher and the participants (Klein and Myers 1999) - my next line of questioning was about which theory/theories to use. As Wodak (2001, p.64) puts it: "the first question we have to address as researchers is [...] 'What conceptual tools are relevant for this or that problem and for this and that context?"'. In order of appearance in the papers presented later on, I have begun the journey with stakeholder theory (Freeman 1984), then followed with social worlds/arena and negotiated order (Strauss 1978b), then tried to merge them in a model in the third paper. Stakeholder theory - or more commonly, a stakeholder understanding - is used by various disciplines, and has been used in IS adoption (e.g. Irani 2002; Flak and Rose 2005; Rowley 2011). Similarly, Straussian package has been used to investigate the issues related to IS adoptions (Harvey and Chrisman 1998; Gal et al. 2005; Mengiste and Aanestad 2013), thus I think they are not problematic to study an adoption process. As I will detail in the coming pages, they provide different pieces to the puzzle, first by providing an organizational-level outlook by adopting stakeholder theory and looking into inter stakeholders/firm conflict, and by arguing that stakeholders/firm is not homogenous and that an actor oriented perspective that accounts for the temporality of the situations faced during adoption - the Straussian package - can complement the stakeholder theory.

The fourth paper viewed the issue of IS adoption from the work-systems framework (Alter 2008). The framework, while used in IS adoption (e.g. Figueres-Munoz and Merschbrock 2017) is not commonly associated with adoption studies ${ }^{3}$. However, in line with Alter's (2015) and Dwivedi et al.'s (2015) opinions, I think it can be a helpful framework to study adoption, and similar to Murthy and Marjanovic (2014) that it can help study the transitions the organization undergoes. These transitions are similar to issues of temporality raised in the Straussian package where negotiated orders are created and broken down, but work-systems framework uses different - and more commonly used - terminology to investigate the adoption process. Following worksystem framework's arguments of how the components of the system should be aligned - whereas Straussian package would claim "cooperation without consensus" - this paper provides how the system became misaligned and how it transformed to a new one. The fifth paper adopted the technology-organization-environment (TOE) framework (DePietro et al. 1990), one of the frameworks that directly deal with IS adoptions (e.g. Thong 1999; Alshamaila et al. 2013; Bradford et al. 2014), that aims to investigate the factors that affect the adoption. This framework, instead of proposing alignment of system components or investigating clash of social worlds, argues that

\footnotetext{
${ }^{3}$ In the literature, while scarce, I have found some instances that can be argued as arguments of worksystems framework in IS adoption (e.g. Lindman et al.'s (2013) argument for a research agenda, and Alter's (2015) own work), however this should not be taken as the definitive state of the literature. For example, stakeholder theory is deeply rooted in Scandinavian tradition, even though this fact is often times overlooked (Strand and Freeman 2015). And while IS papers that use "stakeholder theory" from Scandinavia can be found (e.g. Flak and Rose 2005), it doesn't seem as a dominant theory from a brief look in, for example, Scandinavian Journal of Information Systems, with zero hits for the search term "stakeholder theory". However, closely related concepts, such as participatory design (Ehn 1993) or engaged scholarship (Mathiassen and Nielsen 2008) are commonly used. A similar example of different terminology is adopted by Garrity (2001) that talks about "user centered design" as "European tradition", whereas users are also termed as a stakeholder in the literature. Thus, a mere keyword search with "stakeholder theory" does not cover the extent of literature that can be grouped under stakeholder theory, and that might be a case for work systems framework as well: for example Lyytinen et al. (2009) who uses the term "work system" and provides an account similar to work-system framework, but doesn't refer to Alter's work specifically.
} 
several factors impact the adoption process, and in the following pages, my argument is that these factors are also present in other theories, under different labels. Thus, I view the theories I used in this dissertation as complements to each other, providing different pieces that enter into my tapestry, and that they provide a coherent story. And, to be able to argue that these theories provide a coherent story in the thesis they need to be able to map onto each other, and one way of mapping them can be through comparing their levels or types.

One useful way to look at this picture is to use the typology provided by Llewelyn (2003), through which I aim to show how the theories I used cover some different aspects of different theoretical levels in the following paragraphs. As others have argued (Murray et al. 1995; Weber 2003; Gregor 2006; Miller 2007; Avison and Malaurent 2014), just borrowing theories can be problematic, as they might have different assumptions and aspirations. Thus, I believe using such a typology can be a way to show how they connect to each other.

Llewelyn (2003) provides 5 different levels of theorization and suggests some are more appropriate for different settings and research concerns than others (see Table 1). The lower level theorizing often leads to higher level theorizing, and level one, metaphor theorizing, is often a way of picturing the world and giving meaning to the unfamiliar. Creating boundaries in organizations, organizations as systems, people as gatekeepers, are some of the metaphors used to theorize in management research.

Differentiation theorizing, on the other hand, helps us by providing contrasts insider/outsider, public/private, rigor/relevance. Concept-level theorizing occurs to reflect new ways of thinking, and is the " 'highest' level of theorization that can still take the agent as its unit of analysis" (Llewelyn 2003, p.673), with feminism and Giddens' "duality of structure" given as examples of concept level theorizing: Giddens' ideas of the "structure" was a new conceptualization - for that time and for the general audience - to understand how agency engages with the structure, where the structure was conceptualized as a medium and outcome of social activities.

Table 1. Levels of theorizing (Llewelyn 2003, p.687)

\begin{tabular}{|l|l|l|}
\hline Level & Theory & Empirical setting \\
\hline One & Metaphor & $\begin{array}{l}\text { "Micro" reasons, actions; } \\
\text { social production }\end{array}$ \\
\hline Two & Differentiation & "Micro" level processes \\
\hline Four & Concept & $\begin{array}{l}\text { "Meso" agency - how } \\
\text { individuals make things } \\
\text { happen through resources }\end{array}$ \\
\hline Five & Settings & $\begin{array}{l}\text { The social organization of } \\
\text { relationships between } \\
\text { individuals, organizations } \\
\text { and environments }\end{array}$ \\
\hline
\end{tabular}

Level four, settings theorization, is concerned with how the social relations are organized, how the setting (environment) influences the organization. Llewelyn (2003) 
argues that organizational and institutional theories are among these, whereas an application of Latour's ideas (originally a level four theory that focuses on the nature and process of science discovery) to theorize on how an organization changed over time can be thought as structure theorizing, level five, that offers an explanation of enduring social structures.

The argument that I provide drawing from Llewelyn (2003) was not how I began the dissertation process, so it can be taken as a repackaging of my theories. And I cannot say I am fully - or comfortably - embracing some of the opinions she brings up. For example, while I can grasp how Latour's ideas can jump to level five, when I compare it with other examples, like Marx and Habermas, I still find the other examples as more of a level five. Perhaps such a conceptualization is easier as I believe unlike Latour, these others had a grander vision, and have permeated our daily language. However, I will still argue that to categorize the theories I use is a noteworthy exercise to show that I am dealing with issues and research settings that can be relatable. Though my interest in how the actors engaged with each other and how the settings played a role in the adoption process led me to choose my theories, an analysis using the Llewelyn levels shows that they are pretty much compatible, situated in similar levels.

In this manner, I argue that the stakeholder theory, for instance, is a concept theorization, that shifted the focus from the old concept of shareholder to the new concept of stakeholder. By shifting the responsibility of management from shareholders to stakeholders, the theory provided new ways conceptualizing how the organizations should be managed. Also through various categorizations (i.e. Mitchell et al. 1997) elements of differentiation theorization is also found in stakeholder theory: while some are dominant stakeholders, some are not, depending on their power, urgency and legitimacy attributes. The stakeholder theory in this dissertation then provides a way to see the issues at hand by first conceptualizing them as stakeholder issues - not just a shareholder, or owner, or end-user issue. After revealing the relevant stakeholders for the IS adoption, these stakeholders are categorized by their differences - their salience to investigate how they influenced the IS adoption process.

The social worlds/arena and negotiated order theories are in the sense of a metaphor theorization with the metaphor of arena used to express how social worlds engage with each other - they clash and fight - and negotiation - a sense of give and take - as well as differentiation theorization with the focus on how social world exists alongside each other and how they differ from each other. This is not surprising as the negotiated order and social worlds are theories of conflict (Clarke 1991) that would argue that unless proven otherwise, actors would be in conflict; thus there is expectancy that there will be differences among social worlds, and that these differences will result in conflict. Similar to stakeholder theory, these theories are also a parcel of concept theorization as they shift the area of inquiry from a homogenous organizational point of view to social worlds. In this way, the stance adopted by stakeholder paper is shifted: first the conceptualization of stakeholder is amended by arguing that the stakeholder need not be a homogenous actor, but rather consisting of many actors with their own voices, thus a more complex situation when compared with silo-like stakeholders. Following this, the differences of these actors are not just due to their different salience, but also as a result of membership to different social worlds. Thirdly, this package provides a metaphorization that is similar but not quite same to the stakeholder theory: while stakeholder theory is interested in conflicts, Straussian package brings the conflict to intra-stakeholder/firm level, and that these actors fight in an arena. 
The work systems framework also is a metaphor theory, where the information system or an organization - is argued as a work-system, with different parts interrelated and the outcome is a product or a service, and bringing ideas of alignment and harmony of the various parts of the system. While also drawing from the fourth-level theories such as systems theory, work-system framework is more focused on issues within or across organizations. While Straussian package will focus on conflict and clashes of social worlds, this framework is rather alignment-oriented - there might be conflicts, but they need to be minimized, and the components of the system needs to be aligned for successful IS adoption. By showing how one work-system results in realization of new needs and misalignment of the components of the system - and how this might trigger creation of a new work-system - this framework then provides another way to tell the IS adoption story of Business Journal, where the misalignments in the work-system take the front seat, not the social-world conflicts, or stakeholder salience.

The TOE framework also draws from the fourth level to some extent - influenced by theories such as diffusion of innovations - which are settings theorization. TOE as a settings theorization is rather focused on contexts that influence IS adoptions, and can be rather agency free: the constructs of the TOE framework influence the decisionmaker/the adoptee/the adoption process, not the other way around. The conflicts and misalignments are then as a result of these factors, and in this way, this framework adds another layer to the IS adoption by investigating these factors, and how they influenced the interaction of the actors involved in the adoption. The theories used in this dissertation and how they can be mapped to the levels of theories is provided in Table 2.

To use "levels" as an ordering device brings an image of discontinuity; however, as Llewelyn (2003) argues, these levels are permeable, which I agree with, thus theories are mapped on to different levels in Table 2. For example, I have argued that the social worlds/arena and negotiated order mainly concentrate on aspects up to level 3 . However, this theoretical family also includes social structures - it focuses on social worlds and negotiated orders - thus it has element of higher levels of theorization, dealing with how the social structures are created and maintained, how power relations are formed. But often the focus is on the rather micro settings where these "higher" levels play a backdrop to the hands-on issues of the case/field. Similarly, TOE and work-systems draw from higher levels, but they are used in the following papers to show how different aspects of the work-systems and TOE frameworks play a role in IS adoptions, thus presenting a rather "micro" application, where the individuals act on these influences and the adoption process unveils. Thus while these theories have "higher level" concerns, in this dissertation these parts of the theories are often used as a background when investigating how the adoption occurred and how the actors interacted through this adoption.

I have now mentioned the theories I have used and rather briefly sketched the level of engagement they have with the cases, arguing that my focus is mostly on micro-level issues. Before delving into a more specific mapping out of the theories to each other, a few words on them in general can be said. Just as "levels" of theories, other typologies can be used to argue for the fit of the theories. One such typology is provided by Gregor (2006), who proposes 5 categories of theories based on their primary goals. Adopting her typology, most of the theories I have used are theories for analysis and explanation. That is to say, they aim to analyze and describe the situation at hand without aiming for establishing causal relationships among phenomena, and to try to provide an explanation of why and how the situation is the way it is, without providing any 
predictions. This is not surprising, as I did not begin the journey with a claim of predicting, designing or prescribing. My theory choices have been more geared to reveal what the situation is and how it came to be. As such, my position would be more of having a theory of the problem, dealing with why the problem exists and how it creates problematic situations (Majchrzak and Markus 2014).

Table 2. Levels of theories used

\begin{tabular}{|c|c|c|c|c|c|}
\hline & \multicolumn{4}{|c|}{ Theories used } \\
\hline & & TOE & WSF & Stakeholder & Straussian Package \\
\hline \multirow{5}{*}{ 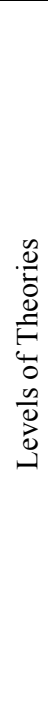 } & Metaphor & \multirow{3}{*}{$\begin{array}{l}\text { TOE contexts } \\
\text { as distinct } \\
\text { from each } \\
\text { other, } \\
\text { influencing the } \\
\text { adoption }\end{array}$} & \multicolumn{2}{|l|}{$\begin{array}{l}\text { Phenomena } \\
\text { (organization, } \\
\text { IS etc.) as a } \\
\text { work-system }\end{array}$} & $\begin{array}{l}\text { Arena to fight, social } \\
\text { order as negotiated } \\
\text { order }\end{array}$ \\
\hline & Difference & & \multirow[t]{2}{*}{$\begin{array}{l}\text { Core work } \\
\text { system vs } \\
\text { context }\end{array}$} & \multirow{3}{*}{$\begin{array}{l}\text { Firm vs } \\
\text { stakeholder; } \\
\text { stakeholder } \\
\text { attributes } \\
\text { Stakeholder } \\
\text { management } \\
\text { instead of only } \\
\text { shareholder }\end{array}$} & \multirow{2}{*}{$\begin{array}{l}\text { Different social } \\
\text { worlds, issues of } \\
\text { power and conflict } \\
\text { Interaction - micro } \\
\text { and macro } \\
\text { influencing each } \\
\text { other }\end{array}$} \\
\hline & Concept & & & & \\
\hline & Setting & \multirow[t]{2}{*}{$\begin{array}{l}\text { TOE contexts } \\
\text { influence IS } \\
\text { adoption }\end{array}$} & \multirow[t]{2}{*}{$\begin{array}{l}\text { Influence from } \\
\text { general systems } \\
\text { thinking }\end{array}$} & & Negotiation context \\
\hline & Structure & & & & Structural context \\
\hline
\end{tabular}

Unlike Llewelyn (2003), Gregor does not provide a level-based scheme, but a taxonomy of different types of theories. However, it is also possible to see theories of analysis as the basic type, as she argues it is necessary for other types of theories (Gregor 2006, p.629), which is similar to Llewelyn's arguments for metaphor theorization. Similar to Gregor's (2006, p.629) take on Kambil and van Heck's work on electronic markets, my attempt resulted in combining these two type of theories, by looking at what is analysis and description - and then looking into what is, how, why when and where explanation. In this way, my intention was to paint a picture of how the IS adoption occurred in my two cases rather by describing and explaining how the process went, rather than trying to provide a theory of the solution (Majchrzak and Markus 2014) where I would have argued about a good solution - a new IT artifact, a new organizational change, a new policy - which would fall on prediction, explanation and prediction, and design and action types from Gregor's (2006) taxonomy.

Combining Gregor's (2006) taxonomy with the arguments of Majchrzak and Markus (2014), the aims and orientations of the theories I used can be depicted as shown in Table 3 below. Similar to Table 2, theories are also mapped on to segments that I haven't used in this dissertation. However due to their underlying aspiration - like how WSF has the aim to help in designing an aligned work system - they were also mapped on to these sections of the table. 
Table 3. Aims and orientations of used theories

\begin{tabular}{|c|c|c|c|}
\hline & & \multicolumn{2}{|c|}{ Orientation of the Theory } \\
\hline & & $\begin{array}{l}\text { Theories of the } \\
\text { Problem }\end{array}$ & $\begin{array}{l}\text { Theories of the } \\
\text { Solution }\end{array}$ \\
\hline \multirow{5}{*}{ 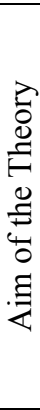 } & Analyze & \multirow{5}{*}{$\begin{array}{l}\text { WSF; TOE; } \\
\text { Stakeholder theory; } \\
\text { Strauss Package } \\
\text { WSF; Straussian } \\
\text { Package (context); } \\
\text { Stakeholder theory } \\
\text { (attributes) }\end{array}$} & \multirow{5}{*}{$\begin{array}{l}\text { TOE } \\
\text { WSF }\end{array}$} \\
\hline & Explain & & \\
\hline & Predict & & \\
\hline & Explain and Predict & & \\
\hline & Design and Act & & \\
\hline
\end{tabular}

\subsection{Theories used}

Now claiming that my choice of theories have been rather geared towards a hands-on level engagement with the cases, and arguing that they are looking for analyzing and explaining the problem(s) in the settings, some words on the theories should be mentioned. I will be rather brief in this section in going over these theories - mainly mentioning a bare-bones version of the theories - as the papers and the following reflections provide a more detailed account of theories. The point here is to be able to indicate how they fit to my reflections above, and to map them out to highlight how they are linked together. But before that, a few words can be said on the process of choosing the theories.

Similar to the whole process of writing the papers and this wrap, the process of choosing these theories is not a linear, clear-cut one. I have already mentioned that the stakeholder theory can be considered as a logical step to begin the research, that it was rather commonly used in several research streams as well as in daily life. But then, why did I choose the other theories?

I cannot say that I had a grand-strategy in mind while choosing these theories, but rather was more engaged with tactics: "What does the theory tell me?" For stakeholder theory, it identifies the stakeholders, their stakes and salience. Thus I can cover the apparent actors in the IS adoption process. "What doesn't it cover?" It doesn't provide me what goes inside the stakeholders/firm that I can see in my data.

One venue to go into these internal issues was the Straussian package, which I was introduced in IS research by a paper that I use in a course I was a part of, a paper by Mengiste and Aanestad (2013) that investigates an open source health care system adoption in Ethiopia. I used that paper to teach, and one critique I had was: "these authors seem to have a naïve idea that politicking will not occur in this situation". Of course, to some extent the aim of their paper is to reveal these highly contested issues that they discovered during their research, so my critique is more of a common-sensical post-hoc comment at most. However, what their paper prompted was to see if I could use the Straussian package, and reveal those internal conflicts in my case. It was logical for me that these clashes of social worlds would occur in their paper, where different 
organizations and government bodies clash. And more interestingly, I could see similar issues in my rather small case, which in my mind would be an add-on to their research stream. Thus if the stakeholder theory was a starting point, Straussian package was an add-on, to see what goes inside the Business Journal.

While I have used the Mengiste and Aanestad (2013) paper for teaching purposes, Alter's work-systems framework was something I first read for a course I took. Worksystems framework, as I mentioned before is not widely used for IS adoption studies. Similar to stakeholder theory, its components are widely used in daily language, so from a communication perspective it enabled me to explain my case to other people more easily - when compared with Straussian package. But furthermore, it provided me a way of putting things into a more structured way: it provided me a set of components to look into, and argued that they need to be in alignment. This meant that, I could now put the actors I investigated into more specific boxes and track how they related to each other, and how their interactions triggered changes to the work-system.

Looking back, one critique I can raise for my choice of work-systems framework can be it is seldom used in IS adoptions, and it seems as if it doesn't add much to the story I am telling. However, from a pedagogical point of view - in layman terms - I believe that that paper serves a purpose for the dissertation by providing an account of the Business Journal's adoption process. Work-system framework, in that manner then helps me in painting the picture from a different angle, with a different perspective and colours. While the stakeholder theory and Straussian package was inherently dynamic perspectives, work-systems framework provided me a way to present the case in static episodes. The changes that occurred were a result of something not going well in the episode - it was not a political stakeholder/firm issue, nor a clash among social worlds, it was a piece of the system that didn't fit well. It provided me a system metaphor to highlight the multiplicity of issues that trigger system-wide effects.

In this way, TOE is also similar. It enabled me to put the IS adoption as an "out there issue". Instead of going over the inherent clashes of social worlds, or stakeholder struggles, this framework enabled me to track something that affects the adoption process. The factors that affect the IS adoption was then a good starting point for me to investigate what this "something" was in my Bolivian case. Just as one reason for using work-systems framework was to pay homage to IS research, TOE was used in a similar way. The process of choosing TOE is rather straight forward: I was already familiar with Rogers' (1983) Diffusion of Innovations, and when I wanted to use it for a case that was from Bolivia, I tried to see if there are instances of where the "environment" context was highlighted more heavily. TOE inherits most of its constructs from DOI, and adds the environment, so in my mind, it was what I was looking for.

Looking back, the story I just provided you can be considered as a journey - a metaphor I use rather frequently, like story or tapestry. As I already mentioned, this journey did not have a grand-strategy. It had a goal - and end-point - and what I have done was mostly to stop at the cross-roads when one theory didn't answer my quarries, take inventory of what tools I have, and ponder on what is the next step to keep this journey going. To that extent, the theories I have used should be seen as small tactical steps that I believe resulted in an assemblage of theories that created an overall story, while not loosing their own stories. To show that, I map these theories in the coming pages, and that mapping starts by a brief account of these theories. 


\subsubsection{The technology-organization-environment (TOE) framework}

The TOE framework (DePietro et al. 1990) is perhaps the most straightforward - and most IS oriented - of the theories I have used. It mainly draws from the diffusion of innovations of Rogers (1983), and argues that the adoption of the IS would be affected by three contexts: technological, organizational and environmental. These three contexts influence how the firm - or rather, actors within the firm - see a need for, searches, and adopts new technology and present "both constraints and opportunities for technological innovation" (DePietro et al. 1990, p.154). One of the reasons I have adopted TOE and not one of the other IS adoption frameworks was the "environment" context. As Hsu et al. (2006) has argued, the addition of this context meant increased explanatory power to the framework when compared with others, and as my case was from South America, I thought it would be prudent to add that "environment" context. One major criticism to TOE was raised by Thong (1999), who has argued that the framework will not be able to account for the rather prominent role of the owner in SMEs, which also turned out to be rather significant for my case. Therefore, I used the Thong adaptation of paying attention to the role of the owner. However, I had to make a slight adaptation to the Thong version of the TOE model, as his model assumed that the "context" would influence the decision making, whereas the original TOE model also argued that the contexts could influence each other. Thus I reintroduced the idea that it is possible for the environment to influence the owner or the organizational context.

As I have mentioned previously, I have adopted the theories as sensitizing devices, and I would say perhaps it is most needed for theories such as TOE to be adopted as such. There are several literature reviews (Jeyaraj et al. 2006; Oliveira and Martins 2011; Jha and Bose 2016) that will give a brief understanding of how TOE - and other frameworks - were used, and how in time some of the factors became more prevalent in the literature. That is one of the reasons I suggested that it is more of a higher-level theorization, and that might result in what Avison and Malaurent (2014) argued as conforming to the ideal types. In the 25 years that it has been used, for example the environment context of the TOE framework has often been expressed as pressures from competitors, and market pressure, which might have resulted in asking questions to look for these constructs only, thereby possibly missing some other relevant issues.

In line with the earlier writings on TOE, I tried to adopt a rather free approach to analyzing my data instead of trying to confirm the established factors of the framework, thus the sensitizing devices. That is not to say I was not influenced by previous studies' findings - for example, I asked the interviewees if/how their competitors affected them. However, I argue that the responses I got were not the same as the more positivist, survey-based research that I have encountered got (e.g Pan and Jang 2008), that lead me to argue that these factors worked in tandem as a composite factor. It was not a direct pressure from competitors, or a direct market pressure that affected Kitchen Co.; it was more of a societal norm that influenced how the business is run in general.

\subsubsection{The work-systems framework}

This framework was created by Steven Alter in several iterations, and draws from general systems theory, which is why I would argue that it is akin to a higher-level theory. WSF was proposed by Alter during the time when issues related to defining what IT, IS and IT-artifacts are (see: Benbasat and Zmud 2003; Orlikowski and Iacono 2001), and has also been linked to other issues related to the IS field, such as rigour vs relevance (see the debate in MISQ's 1999 March issue), with Alter (2003, p.389) 
arguing that adopting the work-systems concept would help the IS discipline, because "as a practical discipline, IS should define itself in a way that facilitates practical applications of its concepts and research. The real world uses IT artifacts but operates through work systems." It is in this way that, though the framework originated in the IS field, there are influences of organizational research owing to the general systems thinking. The organization or the $\mathrm{IS}^{4}$ is conceptualized as a work system, with different parts of it being connected, being influenced by its environment, depending on other actors and structures.

In this way, the work-systems framework is providing another conceptualization on how to view the IS (cf. Benbasat \& Zmud 2003; Orlikowski \& Iacono 2001), as Alter's arguments are often raised from a rather practitioner-oriented view. He argues that instead of taking the IS as a unit of analysis (and considering the organization as its super-system) we should look at the work-systems as the unit of analysis (Alter 2013). Owing to the background idea of use by practitioners WSF adopts a language to communicate with them and provides a simple framing to make mapping the components and highlighting interdependencies easily graspable. This I think is one of the strengths of the framework, thus this framework's simplicity is one of the reasons of why I adopted it.

My use of the work-systems framework was rather in line with Alter's ideas, to identify and map out how the Business Journal viewed as a work system works at this moment. Of course, more often than not, his use of the work systems methodology is also to highlight where there is a mismatch in the work system: "by the system nature of work systems, the components and interactions in a work system should be in alignment, which implies that all components and interactions should be aligned with the work system's goals" (Alter 2013, p.76). The chapter that adopts the WSF reveals the progression of the case that resulted in the work system configuration of Business Journal at the end of the case study, and as such can be argued to show those mismatches in the old work systems that created the situations that resulted in the final work-system. This is similar to what Lyytinen et al. (2009) argued when investigating an ERP implementation, that complex interactions between elements - which I previously argued is rather similar to work-system frameworks' components - can result in unexpected results. This in turn can help in overcoming the problem mentioned by Grover and Lyytinen (2015, p.276) that some models "tell us very little about how and why specific classes of IT tools and technologies are adopted and used, or how an IT tool being adopted might reflect back on the individual's intentions". By investigating how the technology adoption triggered changes to the work-system, and how that resulted in new work-systems, the paper provides some of these hows and whys, and how the technology adopted triggers new work processes, similar to Figueres-Munoz and Merschbrock (2017).

However, as opposed to the way Alter uses the framework - for example for teaching purposes in MBAs - my chapter had the intention to investigate how the components of the Journal's work-system was interconnected to provide a rich case, not to investigate and improve the work-system. This is in line with the ideas of theories of the problem I mentioned earlier, to reveal the problem rather than solve the problem; throughout the

\footnotetext{
${ }^{4}$ ISs are a special type of work system, whose "processes and activities are devoted to information and that produce informational products and services" (Alter 2008, p.451), thus Business Journal, the work system under study, can be conceptualized as an IT-reliant work system, with various ISs investigated as the "technology" construct of the framework.
} 
chapter the various time phases of the Journal reveal how the work-system of that phase led to future problems later on. However, the ideas following from the systems thinking apparent in the WSF are still visible, and one can argue that there is a prescriptive element to the arguments in the end. As one colleague argued, I sound like a "1970s central planning guy", arguing how the problems were a result of the various mismatches in the Journal's work-system and how it should be aligned. While I do not claim to be that 1970 s central planning guy, I will also admit that, perhaps owing to its roots in IS and systems thinking, I believe there can be an overemphasis on alignment. As Ahrne (1990 cited in Llewelyn 2003, p.669) argues, system metaphors often mask discontinuity or emergence, thus even though the discontinuities and emergence and the improvisation exist, they might not be that visible due to the roots of the framework. However, as the case shows, Business Journal has changed its work systems as it evolved, thus I argue that the framework can be used to analyze dynamic situations too.

The longer format allowed by the book chapter genre, as opposed to the brevity of journal articles and conference papers, enabled me to show how the people within the Journal acted on the various issues, thus bringing the higher-level understanding inherited from systems thinking to a more "grounded" level.

\subsubsection{Stakeholder theory}

Stakeholder theory (Freeman 1984) can also be regarded as a higher-level theory. After it was established, it saw a bloom in use that might reflect the ideas of Llewelyn (2003) that the theory is adopted and used in settings different from the research setting it originated in - strategic management - and was found to be applicable to many different research streams, among others IS research (for example, on IS adoption: Irani 2002; Flak and Rose 2005; Pan 2005; Kamal et al. 2011; Rowley 2011). Even in nonacademic settings, the concept of stakeholder, and that stakeholders should be engaged with, managed and prioritized, has become a staple rather than exception. However, as I mentioned previously, for this dissertation stakeholder theory is more of a concept- and difference-theory, rather than a settings- or structure-theory.

In stakeholder theory, there is an inherent dynamism that relates back to the identification of the mutable nature of the stakeholders. Several instances in Freeman's (1984) original text call for caution to not treat the stakeholder issues as static. However, as I argue in the paper, these dynamisms are rather backgrounded in later texts. That is one of the reasons why "dynamism" is a selling point in Mitchell et al. (1997) who specifically dealt with the identification of the stakeholders, arguing that the relationships between the firm and stakeholders need to be constantly assessed. Tennert and Schroeder (1999) was also one of those dynamism-oriented papers that suggested how the stakeholders' position might change and proposed some strategies to manage them. Aspects related to dynamism continues to be a concern, and resulted in proposals of new concepts such as stakeseeker (Holzer 2008) and stakewatcher (Fassin 2012) to provide a different type of categorization to understand the dynamic relations among stakeholders.

One general thread I can see in the theory is that, more often than not, the organization is at the center, often looking at the issues from the firm/management's point of view rather than the stakeholders (Jones and Wicks 1999), thus involving an "inside-out" difference. Friedman and Miles (2002) are also critical to such a stance, and continue to argue that the dynamism - and conflicting nature - of the relations between the firm and the stakeholders are not investigated enough. However, it is noteworthy that their focus 
limits the investigation to the relationship between the organization and the stakeholders, not among the organization and the stakeholders. I can see two reasons why such a firm-/management-centric view can hinder the users of the theory. From a more practical perspective, that might mean that not all the relevant stakeholders are identified, which might hinder the success of the organization/project. From a more analytical point of view, it would reinforce a homogenous/silo understanding of the firm and stakeholders. This is similar to the position of Carney et al. (2011) who argued that conflicts in stakeholder theory is often about inter-stakeholder conflict, and the intrastakeholder conflicts are left out of the picture. My reading of Freeman et al. (2010) who looked back and answered criticisms of stakeholder theory reinforces this view; most often conflicts between the business and the stakeholders - for example due to different ethical standpoints - are taken up by the authors, not conflicts within the business or stakeholders. While I have also put the firm, Business Journal, as the focus of my analysis, later on I tried to broaden my view by adopting the social worlds/negotiated order theory to provide a more nuanced picture. In this way, while the central stage is still occupied by Business Journal, the variations in how individuals behaved and how social worlds interacted were also played out.

\subsubsection{Social worlds, Negotiated order and Arenas}

I think it is rather rational to provide social worlds, negotiated order and arenas together rather than separately, as they are all connected, and all tied to the same person, Anselm Strauss (Strauss et al. 1964; Strauss 1978a; Strauss 1978b; Strauss 1982; Strauss 1997).

As can be seen, all these three are metaphors of some kind; Strauss has argued that all social orders are negotiated orders (Strauss 1978b). This metaphor set the desired stage as one of order, and argued that unless confirmed there will be conflicts among social worlds and they will negotiate in an arena to create a negotiated order. His thinking emphasized the dynamism and temporality of the order, that the order can break down, thus the need to re-negotiate.

For Strauss, negotiation is a key process in this ordering process. For him, social worlds were groups with shared commitments to certain activities, bound by effective communicative means rather than formal memberships (Strauss 1978b), "sharing resources of many kinds to achieve their goals and building shared ideologies about how to go about their business" (Clarke 1991, p.131). These groups are "amorphous and diffuse constellations of actors, organizations, events and practices, which have coalesced into spheres of interest and involvement for participants" (Unruh 1980, p.277). Social worlds are created by actors with their own individual interests and commitments, who often belong to other social worlds. Social worlds then meet in arenas, where "various issues are debated, negotiated, fought out, forced and manipulated by representatives" (Strauss 1978a, p.124) of the participating worlds and subworlds. It is this interaction of social worlds in arenas, how they are represented and how they negotiate with each other, that are the key concerns for Strauss. As Clarke and Star (2008) argue, this package has been used in science and technology studies, in which several IS related papers can be found (e.g. Harvey and Chrisman 1998; Gal et al. 2005; Mengiste \& Aanestad 2013). Furthermore, effects of the terminology and concepts can be seen in papers that do not refer to this interactionist tradition, or the references I have already provided. While for example Garrity (2001) adopts general systems thinking as a driver for his paper, he provides a socio-technical figure, using labels such as "technical design world" "social/technical work world" to depict two 
worlds, with a "communication boundary" separating them with a an unnamed circle that intersects the worlds, thus crossing the boundary. This is, I believe, is very similar to how the Straussian conceptualization will see the situation.

Social worlds and the surrounding concepts have a strong position in the Chicago interactionism tradition ${ }^{5}$, with Mead (1938, cited in Clarke 1991, p.130) describing social worlds as "universes of discourse", which is similar to the definition used by Shibutani (1955, p.566) "universe of regularized mutual response", in turn a definition quoted by Strauss (1978a) when detailing his ideas to continue the "brief" and "overlooked discussion" on social worlds. And just like the Chicago tradition, this package looks into how social actors interact with each other, how they cooperate and clash, how they create meaning.

By focusing on "structure in process" (Glaser and Strauss 1968, p.240), the Straussian theory package deals with "contextual conditions for action and its immediate meaning" (Strauss 2008, p.159), investigating how the more "macro" settings influence and are influenced by the more "micro" relations. This focus of the Straussian package is then applicable for me to show how the IS adoption takes place, how the actors' interactions are influenced by these structural conditions, how these actors represent these social worlds when they begin to discuss what system to adopt - or even more primarily, how they go about their daily business. That is why, the components of the Straussian package are situated in different levels in Table 2, with the "macro" setting of structural context as a structural level, and the "micro" setting of interaction in the arena as a "metaphor level". Whereas the stakeholder theory would put the emphasis on how to manage the stakeholders, this package would rather look into the interaction, and would argue that this interaction will not just involve the "stakeholders" or their representatives, but will involve social worlds that might be mapped into a stakeholder, but would often cross-cut various stakeholders and the firm. Thus, I argue that this package will help in identify what might be black-boxed by only taking the stakeholder and the firm as the issues of interest, and would help reveal the tensions and conflicts that might not be explained by the firm/stakeholder duology.

\subsection{Mapping the theories}

So far, I have provided a brief snapshot of the theories I have used, and reflected on how they can be thought about. I analyzed their level - from micro to macro - and their orientation -problem-oriented vs solution-oriented. I have argued that I was mostly concerned with a rather hands-on theory that aimed to analyze the case to show how the actors interacted with each other during the IS adoption, how the various stakeholders came into play and how contextual factors affected the adoption. Mostly, I aimed to investigate the situation at hand, how it came to be and what the consequences seem to be. In this section I will try to provide a narrative of how these different pieces came together in the dissertation. Figure 1, in this sense both serves as a reminder of some of the concepts I discussed in the previous section, as well as tool to map the different

\footnotetext{
${ }^{5}$ To the best of my knowledge, "social worlds" was first used in Cressey's account of taxi-halls in 1920's New York. (Cressey 1932/2008), to describe peoples' interactions in these taxi halls that was not easily explained by the usual social organizational settings: how the poor and the rich, how the Filipino and the white can all interact in the taxi-halls, how this social world of taxi hall has its own "ways of acting, talking, and thinking," and "its own vocabulary, its own activities and interests," and "its own scheme of life" (p.31).
} 
terminologies used by the different theories. And, this terminological mapping is where I will start in showing how the theories can relate to each other.

To start off, TOE contexts can be argued to fit into several other theories. They can be thought as a part of the firm/stakeholder of stakeholder theory: Owner - thus owner characteristics - is part of the firm, whereas environmental context would contain some of the oft-cited stakeholders - such as customers and competitors. Participants and customers of work-system framework can be seen part of the firm, as internal or external stakeholders. Similarly, the core of the work-system, the first four components in the figure is rather parts of the firm, who has participants, technologies and information that is involved with activities of the firm. Thus these different components of these two frameworks can be argued to relate to stakeholder theory components.

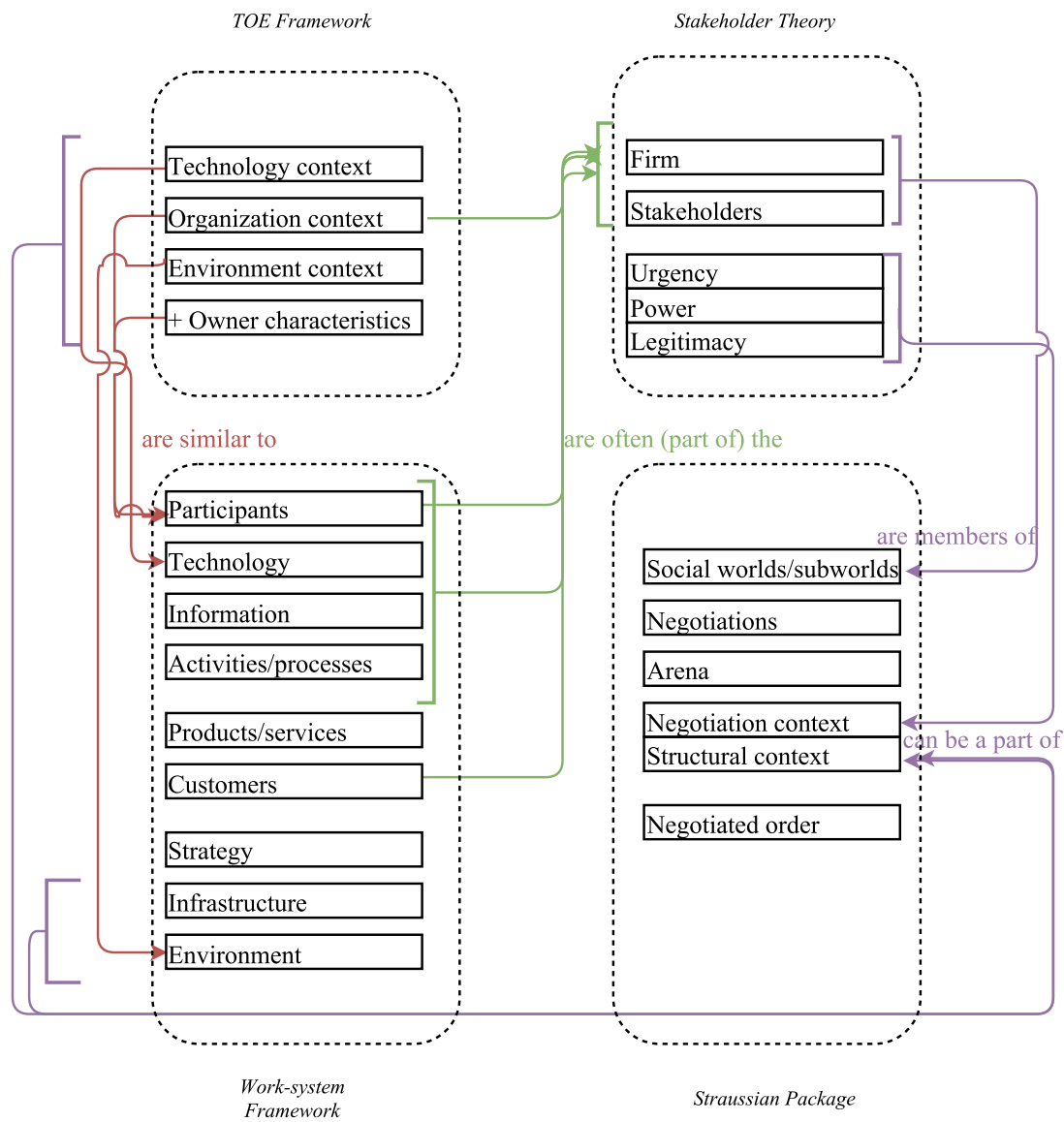

Figure 1. Mapping terminologies

Stakeholders and the firm themselves are members of various social worlds, which negotiate in an arena, affected by the negotiation and structural context. Negotiation context, which would look at power distances, the nature of the negotiations etc. then 
would contain issues discussed in power/urgency/legitimacy attributes of stakeholder theory. Environment and infrastructure of the work-system framework can enter into the structural context, the environment for example can include social norms that will make negotiations with certain parties unacceptable to the wider society, thus will impose a structural hindrance to the issues. Similarly, the technology and environment context can be argued to be a part of structural, and owner and organizational context to be a part of negotiation context.

My aim with this mapping is not to provide an exhaustive account of how all concepts can be mapped. I could for example, in contrast to the ending of the last paragraph can also argue that technology context can be a part of the negotiation context, as the available technologies and the IT capabilities of the participants can easily be thought of as power distance of negotiation context. On the other hand, availability of crucial technologies such as Internet access will have wider implications, thus can be thought of as structural context. The negotiated order, the end result of the negotiations, might also mean a new work-system, with different participants, technologies etc. So, the arrows, while unidirectional for simplicity sake can be conceptualized as bi-directional. That is why, this figure should only be taken as one perspective of how the different terms used in the theories can be related to each other.

After this brief overview, I can now continue to map the theories - and the papers to some extent - in a more thorough fashion. The easiest to map is paper 5, the TOE paper, as it appears to be the outlier. It does not seem have an overt connection to the rest of the theories, and is used to analyze another case than the other papers. Then why was it included in the thesis to begin with?

There are several answers to that question. A rather straightforward one is that the paper provides a second case. While it might make sense to continue with the other theories I used - and perhaps even use the case to "test" my ideas I present in paper three - I felt that I didn't have as good access to that case, I hesitated to employ theories I used in the other papers, and adopted TOE instead. I work in the academia, I play many of the roles discussed in the Business Journal case, I am - to some extent - familiar with the cultures and work practices and thus I can navigate the data, lead the investigation and present the story much more easily. However, for Kitchen Co., a Bolivian case, I can not claim these, but as I have access to the case, and it will provide some chances to investigate issues not found in Business Journal I decided to keep it.

Another answer is that I wanted to use a well-known, IS-related framework since I am talking about IS adoption in the dissertation. This in turn can be opened up. Economic Information System has been described as a division that sits between IS and Management, and adopting TOE, a framework that deals directly with IS adoption would balance the more business oriented stakeholder theory, and sociology oriented Straussian package. In this way, adoption TOE can be seen as an attempt to play both sides. From another angle, adoption TOE would provide me to investigate a wide spread of factors that influence IS adoption process. As I mentioned before, I used it in a sensitizing manner, rather than following the rather positivist research tradition found in IS adoption studies (see: Jha and Bose 2016) of testing the already established factors on my case. For example, as my analysis progressed, the owner became a central figure, and my narration of him changed from an "independent" context factor in the adoption process, to a mediating role among the TOE context factors is in contrast to conceptualizing the owner as an independent variable found in some of the studies. I came to view the owner as a potentially important actor to sensitize me to patterns in the 
data. In the process, I revealed that the other contextual factors can work through the owner, not just have a direct effect in the IS adoption, thus complementing the latter influence path, which is the one proposed in the traditional TOE model. Thus the owner had the role of not just "direct influence" but also as a "mediator" of other contextual factors. Similarly, while the literature mainly talks about competition and market pressure, Kitchen Co. showed that the environmental issues were more of a social norm. Thus while I might have begun the case to investigate a Bolivian case, and adopt TOE that directly investigates the environmental context, the case has provided additional insight to IS adoption that I didn't expect.

Thus, rather than viewing the TOE paper as an outlier, I view it as an extension and complement to the others. In the reflections section on paper 5, I argue that there are lessons to be learned when comparing the two cases - such as how the structure and decision making of the organizations differed, and how that might have impacted the IS adoption. For example, Kitchen Co has an owner-manager, whereas Business Journal has no obvious, and definitely no single, owner, and is run by an editorial board; Kitchen Co pays its employees, whereas Business Journal runs on voluntary work.

I also argue that there are two other ways that a connection can be made. The easiest is with the work-systems framework (WSF). As Alter proposes, the whole work system, not just the "IT" - one type of the technology component in his framework - should be the unit to study. Consonant with such an approach, the factors that affected the adoption of various ISs in the Kitchen Co. can be seen as factors affecting and being part of the work systems. The accumulation of decision making to a single owner provides a different set of participants (WSF) than a decentralized global network of organization with many decision makers (as in the later stages of the Business Journal case), just as being in South America means having a different infrastructure and environment (WSF) than in a Western European (as in the Business Journal case from the start until rather late, when founders started to move to universities in other parts of the world). Thus several of the contexts and factors in TOE have a rather easy matching to WSF: organizational context to participants and processes, environmental context to infrastructure and environment.

The other way of mapping is to the Strauss' theory package, by arguing that the TOE contexts relate to the negotiation and structural contexts found in that package. Issues I related to the environmental context in TOE, such as not adopting a fully integrated system - for now - can be linked to a structural context of a negotiated order; there is a society-wide perspective of how the transparency involved with an ERP-like system can hamper a small company. This in turn resulted in that the option of having an ERP-like system was discarded rather quickly. Similarly, the organizational structure maps rather easily to some of the negotiation context; whereas all parties have their own goals, there is also a rather clear power distribution (owner vs employee), which is tempered by factors such as the owner risking to get a reputation as a bad employer if he uses his owner-manager status to enforce his views and too many problems occur.

Thus, although TOE could be viewed as the outlier, as I mentioned, I view it as an addon and argue that it is possible to connect it to the other theories I have used in the dissertation. However, the others appear to map out in a more tight fashion, to some extent due to being applied to the same case.

If the TOE paper sketches out how various contexts influenced the adoption in Kitchen Co., then the WSF paper provides the story of how different parts connected together in 
Business Journal. These parts that create the work system of the Journal influence each other in various ways, thus a similar argument to the TOE paper can be created. However, while TOE as a framework provides how various factors influence the adoption, the WSF has a prescriptive tendency to argue for an alignment of the parts of the work system. For the work system to function well, parts of the work system have to be aligned with the goals of the work system. Thus if TOE provides how various factors influence the adoption, WSF provides how these components needs to be aligned, and how to maintain the work system, or as in the WSF paper, how the work system was not functioning and how through various iterations the work system evolved to become more aligned over all.

Aside from investigating Business Journal, one of the aims for writing that paper was to provide a longer account of what went on during the IS adoption in the Journal. Thus, I thought a framework that will provide a broad base to delve into the issues encountered during the adoption was necessary, and have chosen WSF, even though it has that prescriptive element of alignment in it. This issue of prescriptiveness is rather against the idea of trying to investigate the problem, as it is more of a solution-oriented thinking. However, I haven't seen much of prescriptive solutions in the WSF literature aside from the already mentioned "alignment" bias, which to the most extent will hold true in discussions of organizations. Similar issues have been brought up by Alter (2013) who argued that inclusion of humans and non-automated tasks results in the systems' indeterminacy and introduces improvisation to the work system. Thus, when taken as a "loose alignment", of different parts being influenced similar to a trigger effect rather than a 1970s central planning guy's road map, WSF was a reasonable tool to use to investigate the Journal case.

I have already provided a mapping of TOE to WSF above. In a similar fashion, WSF can be mapped into the Strauss package, or the stakeholder theory in various ways.

WSF uses the term participants and customers in its terminology, which in stakeholder theory would be easy to term as stakeholders. It is also not a big leap of faith to see most of the participants as internal stakeholders (i.e. employees) and customers as external stakeholders. Similar to that, those different actors/groups can be argued as parties to negotiations, representing different social worlds.

At first glance, some of the more intrinsic issues related to power can also be glimpsed by the work system. There are clear dependencies on the infrastructure, and a reason to be aware of the environment that the work system operates in. However, due to the goal orientation of the work system, these issues related to power are randomly investigated and downplayed. This I have tried to overcome by providing a long narration of the case, but this was also possible, I would argue, as I had used other theories that were more geared towards investigating such issues, and thus knew the Journal's story.

Similarly, by the Strauss package and stakeholder theory I have argued that stakeholders/actors might have different agendas. At this part, I think WSF is rather lacking as its concern is the work system, and some of the activities and processes the participants engage with are not to do with the work system, thus not a main concern of the framework. On this note, my intention is not to argue that WSF does not investigate the hows and why of interaction in an IS adoption investigation, but that how the components of the systems interact during the adoption, and that more hidden agendas of the actors involved might not be an issue for WSF. Thus, to investigate the more "hidden" agendas that the participants have, or to investigate how an inscripted logic 
within the technologies affects the work system, other theories can be of use. I have not looked at the latter part, but actor network theory (ANT) ${ }^{6}$ could provide various ways to look at how inscription occurs and affects organizations. The Kitchen Co. case would then be a story of how the actors involved tried to translate their own expertise/demands to the organization: the owner wanting to adopt a more modern solution that he wasn't able to translate to the organization as the already existing logic - backed up by the accountant - meant a more modern, integrated system, would hinder the survival of the company in the short run. The financial situation and the possible problems arising due to transparency provided by integrated system was used as counters to owners ideas, and to keep the situation - or the network - as it is.

On the other hand, those other theories would provide arguments for the issues with a different terminology - like ANT and inscription and translation - which while useful might also deflect the attention. For example, while the students - or other people were able to understand what I was talking about, the terminology presented by WSF is more attainable to them, and thus provides a common ground to discuss a case. Therefore, I argue that by focusing the investigation on rather well defined small parts, the WSF paper provides additional descriptive power for the dissertation.

So far I have argued that TOE can be mapped into the other theories, and that WSF provides another focus on the Journal case, thus all left is stakeholder theory and the Strauss package.

I began the Business Journal story by applying stakeholder theory, and for most of those involved with the theory, I probably have used it as it became common to use it. I have mapped the stakeholders using the Freeman model, and then I tried to investigate their salience to the central organization. To do so, I had to analyze instances where the respondents argued for the existence of the stakeholders and how they affected the IS adoption. It is in this analysis that I began to utilize the theory as a sensitizing tool and tried to work through the data. As would be seen later on in the papers, various stakeholders are rather logical for an academic journal, like the other journals or indexing organizations, whereas some are more specific to a young journal that is trying to find its place, like the University. This is in contrast to WSF, which provides welldefined components. Whereas universities can be argued to be a weak customer from the WSF perspective or a part of the environment or infrastructure, thus having a rather background role, in stakeholder theory one can argue them as being powerful stakeholders that can significantly affect the organization. In this way, I will argue that stakeholder theory - and the Strauss package - provide more flexibility in conceptualizing the world, and thus in analyzing the data.

Issues related to power, legitimacy and urgency - used to analyze the salience of the stakeholders - can also be put under the Strauss package. These attributes can be argued to be a form of either a negotiation context or a structural context. The indexing bodies like SCOPUS and ISI have a legitimate stake in this case, because of the academic

\footnotetext{
${ }^{6}$ ANT is credited to Michael Callon, Bruno Latour, and John Law, and has been used in science and technology studies (STS), which symbolic interactionism - with Straussian package being a part of that tradition - has also been a key influence (for a review see: Clarke and Star 2008). Though investigating similar issues, among others Star (1991) has criticized ANT for its managerial focus and silencing the invisible work. Blok and Jensen $(2011$, p.49) argue that this criticism has resulted in Latour - while arguing the need for a focus on fact-builders - shifting his political metaphor from "war" to "experimental democracy". In turn, Latour has criticized symbolic interactionism, arguing that it is fit to investigate primate societies but not human societies (Latour 1996).
} 
world's structural composition. However, their power over a journal's IS adoption would be rather limited; its power would be taken into consideration in the negotiation context, but not predominantly.

While stakeholder theory argues that certain individuals can be stakeholders, most of the literature I read often has a group or an organization as a stakeholder. This, similar to the systems thinking bias in WSF, can lead to a diminished emphasis on discontinuities or emergence, which led me to use the Strauss package: that package recognises and emphasises the importance of the individuals who are often members of many social worlds and who represent social worlds.

Thus, I will finish off this chapter by arguing that these theories provide pieces to the puzzle I have in my hands. While stakeholder theory provides a ground to view involved parties in an aggregate level and shows how stakeholders differ in terms of their attributes, the Straussian Package opens up these aggregate levels and brings actors and puts their conflicts in a social-world-oriented picture. This means that the more organizational level analysis afforded by the stakeholder model can now be turned into a more actor-level micro interactionist undertaking, that at the same time keeps track of the macro issues due to structural context's influence on negotiations. The WSF in turn provides a way to think of interdependencies in the IS adoption process, with changes to the actors or the technologies triggering various interactions and iterations of worksystems, whereas TOE provides aggregate contexts that influence IS adoption and help in showing how they were instantiated and interacted within an IS adoption situation. Before using these theories in the papers, however, the next chapter provides a reflection on the methodological choices made in this dissertation. 


\section{Reflections on Research Approach}

Up to now, I have provided a discussion of what the general aims of the dissertation are, and the theories I used, and how I have adopted them to achieve these aims. In this section then, I will go over the choices I made regarding the methodology and how the research approach crystallized.

\subsection{A qualitative case study}

As can be seen later on while reading the papers, I have used qualitative methods throughout this study. My interest was to look at how various actors interact in the settings of these companies, and thus for me having a qualitative case study approach was a logical step.

Much has been written on both qualitative studies and qualitative case studies. Thus, just like I have done in previous sections, I aim to limit myself to a rather brief discussion about these choices with a selective use of references.

In all the papers, I adopt a single-case study approach ${ }^{7}$, and in some, I bring up the usual discussions of what can be gained from such a design. One such discussion is rooted in the arguments of generalizability, where researchers such as Eisenhardt (1989) would argue that a multiple-case study design would be a better way to generalize and create theories. However, others have argued that a single case study design has its own benefits. Davis (2010, p.707), for example, as a concluding remark has argued that even after years of inquiry and documenting a lot of regularities "the nature of the subject matter makes it unlikely to either yield general or precise theories" in organizational research and that it might be a more realistic undertaking to look into "particular processes at particular times." Dyer and Wilkins (1991) also provide an argument of how a single case can provide a richer story - similar to Siggelkow (2007) who has argued a single-case study has a strong potential to provide dynamic processes - and provide a list of such case studies that generated theory by employing only a single case. And while I didn't start this PhD process with the aim of building theory, in paper three I merged my insights from the first two papers and based on the understanding I have from one case, and attempted to nuance the stakeholder model. Thus I think there is potential for use of single-case studies for building theory.

Though himself drawing from four organizations, Dalton's (1959, pp.1-2) position holds true for me too: "the aim is to get as close as possible to the world of managers [focus of the study] and to interpret this world and its problems from the inside [...] we wish to describe both unique and typical experiences and events [...]". With a single case I found it was easier to go deeper, to submerge myself in the case and understand the participants and the organizations better. Thus, the arguments for a richer and more dynamic story, as well as the longitudinal aspects that Yin (2009) suggests as good criteria of selection for single-case study design, speak for the approach I chose.

\footnotetext{
${ }^{7}$ This then would mean for the overall dissertation I have two case studies, a composite case study, the story of Business Journal that I investigate by various theories in papers one to four, and the Kitchen Co. case that uses TOE framework in the fifth paper.
} 
Another topic that needs to be discussed is the choice of the particular cases. Yes, a single-case design is appropriate, but does it mean everything goes? As I would tell my students, unfortunately research is not that easy.

While a more formal list can be deduced from literature (e.g. Yin 2009; Flyvbjerg 2006), some of my choices can be summarized as follows: During the process of this $\mathrm{PhD}$, as I mentioned, I began with ERPs in focus, and even though the focus drifted a bit, the research was about integrated information systems, so my cases should have that component in them. I was getting more and more interested in the interactional aspects of the actors, so the cases I have should enable me to investigate these interactions. As these interactions can be quite complex - and to go with the small organization track I mentioned earlier - the cases should be of organizations of a certain size where they will have the issues I am interested in in a micro cosmos while staying relatable to a potential audience.

In Business Journal case, the story is of an organization that gradually shifts from just using emails to having an integrated management system. In the case, there are relatively few "active" actors. Thus it provides ease of access, and as the papers show later on, even with these few actors it is possible to glimpse the hardships of a larger organization - with different agendas, power plays, divergent stakeholders - in this small organization that survives by voluntary work. Also of particular interest is that I am from academia; thus I have various resources to draw from when engaged with the case, be it from my own experiences or by talking with other people in academia. This criterion is also rather related to the usual audience of a $\mathrm{PhD}$ dissertation: people in academia, who would be rather familiar with some of the issues presented in the Business Journal story.

Kitchen Co., on the other hand, provides a counter case in some instances. Whereas I track a gradual integration in Business Journal, Kitchen Co. has a central figure that thought about an integrated system at the beginning in an organization that seems to survive by using standard ISs without much integration. Thus, after reading about ERP systems that one way or another has an integration (centralization and standardization) focus, it was a nice example of survival without integration. It is a manufacturing company that builds kitchens, which most of the thesis audience can grasp rather easily, with a simple manufacturing process when compared with companies like ABB or Nestle. Counter to Business Journal, it has a central decision maker, the owner, who nevertheless has to balance his authority with concerns about keeping the internal stakeholders happy for the job to be done.

Thus I think both of these cases bring rather important pieces to the table when taken separately. And when taken together, as I do in the general reflections - they complement each other to provide different aspects of how and why a small organization adopts an IS.

\subsection{Gathering the data}

The data collection for the cases is discussed briefly in the following papers. Thus I think, as a general reflection there are other important issues that should be taken up in the following pages. And to start off, gathering the data is where the influence I mentioned in the theory section, that theory plays a role in the co-creation of research, can be seen. 
To start this discussion, I can say that the theories I use are not necessarily a parcel of the daily life of the people I talked with; the Journal people are drawing more from Economics, or from theories like Organizational Theory, with no knowledge of issues related to social worlds, arenas, or even ANT or Structuration. The same case goes for the Kitchen Co.: that aside from the very recognizable instances - e.g. problems of infrastructure - they are not within the language used in most of my theories. And this - except perhaps the more common language of stakeholder theory - I tried to keep that way. As can be seen in Figure 1 in the previous chapter, the concepts that the theories use can be mapped in relation to each other, which helped in being able to analyze the same corpus by different lenses.

By trying to keep the questions free from theories and their concepts - thus to some extent their assumptions - I can say my interview process conforms to our usual ideas of what an interview should be like: of not posing questions that might be "leading", of keeping the interviewee comfortable. However, if I were interested in how the interviewees interact with each other - and others - in their settings, would this strategy fully work? I know that my role as the interviewer is to be attentive, to listen, to give responses to make the interviewee interested in giving me more answers. But would I be missing something if that were all I did? If I claim to follow Klein and Myers (1999) who argue that the research process is one of co-creation between the interviewee and the interviewer, would I be limiting my power of co-creation by giving the "correct" prompts to get the "correct" answers?

I can say I have toed the line with this off-hands view of interviewing. In doing so, I was rather influenced by literature on discursive psychology, chiefly Margaret Wetherell's writings. While sticking to the ethical guidelines that we are socialized in e.g. of not forcing the interviewee, of not revealing sensitive information, of not misleading - in some instances I tried to break from the friendly interview norms. One issue I discuss with my students is to make the interviewees more relaxed, and talking at the interviewee's turf can help in achieving that. But then, it can also be "problematic when interviews take place in people's homes and are seen as an act of hospitality. Complicity, invisibility, and lack of authenticity might be the price one pays for the privileges of the ethnographer" and that perhaps - in some instances at least - the faceless interviewer might hinder the interview process and "it might be highly productive for interviewers to express 'strong views' themselves, rehearse their own opinions in depth, challenge and argue with their participants" (Wetherell 2003, p.28) and become visible.

Just as the theories influence me, my life experiences influence how I see the world, and how I engage with data. Thus by moving from the rather positivist understanding that would argue interview as "raw data gathering", I am more inclined to think that "although we have abandoned the traditional assumption that we can infer from interview talk what actually happens in the social realm under investigation, we nevertheless continue to assume that we can, in a more restricted sense, generalise from interviews to naturally occurring situations. For we are assuming that the interactional and interpretative work occurring in interviews resembles to some degree that which takes place outside the interviews." (Potter and Mulkay 1985, p.269). And for that interaction to more closely resemble what is naturally occurring outside the interview, I sometimes took the role of a friend that agrees, as well as the friend that confronts, in my interviews. 
To some level, I was able to do that because I was rather in close contact with the cases: small organizations that I had an "in" with. Thus to some extent I was able to sidestep some of the issues related to power hierarchy that have been long recognized as an influence of the interviewing (e.g. Oakley 1981). Furthermore I believe in parts opening up what I believe helped in creating a rapport with the respondents, similar to what Oakley (1981, p.49) argued that there will be "no intimacy without reciprocity" necessitated to respond to my interviewees' questions, to laugh with them, and in some parts to agree with or challenge the narrative they provided during the interviews when the occasion called for it. The flexibility afforded by semi-structured interviewing was useful by allowing me to add my questions and comments to co-create this narration.

In preparing for the interviews, one step was creating an interview guide. In doing that, I drew from the discussions in courses like Qualitative Methods at Uppsala University. Aside from the usual references one reads in similar courses, like Bryman (2004) or Patton (2002), I guess one major impact was when I talked with Jaan Grünberg, who came as a guest lecturer for one of the sessions, and opened up how he sets up an interview guide: with lots of white spaces to jot down notes, with questions acting more as points to cover instead of a list of questions. With this "white space" mode, another inspiration was Lofland and Lofland (1995) who argued that it is best to start out with asking "what is puzzling me", and jot down the ideas without much care for coherency. The next step is then to use them to see the issues under investigation and ask, "what do I need to know" to answer this puzzle. So, after several iterations, some themes emerged that came to be an interview guide. The themes revolved around who were involved in the IS adoption, how they interacted, what were their roles, their stakes in the adoption and organization, the IS's effect on the organization and the actors, how the system was chosen, and the technical, financial, organizational issues that they encountered. The semi-structured nature of the interviews allowed me to move back and forward with these themes as the participants' narration evolved.

Another point of the formal data gathering process was observations I made of one of the editors of Business Journal. On those occasions, my take was more to shadow to see what the editor was doing - engaging with the journal system for editorial tasks, communicating with the other editors, and asking for clarification and further insight to the tasks at hand and the other editors' thoughts. However, just as Myers (2013) argues, it is hard to draw a line between observation and participant observation, and I have actively interacted with the editor during the observations. However, this was not done to influence the work practices, as might be the case in action research, but to get a deeper insight into the situation. In this way, I agree with Bryman (2004, p.328) that observations can help in revealing hidden activities and creating an extra sensitivity to the context: while I have worked with conferences, it is not the same as working as a full-time editor. Thus while I was familiar with the tasks, I did not realize how mundane tasks can get in the way of working. This in turn is similar to what prompted researchers in discourse analysis to employ observations, like Phillips et al. (2008) who wanted to complement what they identified in written texts by investigating situations where issues were discursively created and resisted in real time. I was able to track the whole process of an editorial decision - in episodic intervals when the various tasks were finished - to see how the editors engaged with the material, and while not that different from the interview material, it provided an additional data-gathering opportunity for me.

Aside from arguing the need to balance the friendly interviewee with a more confrontational approach to both have the interviewee with me and to have a more 
naturally occurring session, I think the process of gathering the data I presented is not that far from what I often encountered in $\mathrm{PhD}$ dissertations. However, while conducting these two case studies, I was also able to tap into a pool of more informal data sources. I think I was able to see first hand how a revision of a research paper goes, in an accounting course in Uppsala, where we reviewed and discussed an already rejected manuscript, and in various conferences and seminars I was able to participate in settings where I was able to talk with editors, authors and reviewers about the issues I was examining in my Journal case. Thus I can say I have a rather healthy pool of informal informants to draw from for contextualizing the Journal case. Unfortunately, as the Kitchen Co is in South America, the geographical distance provided some obstacles, which I tried to overcome by talking with the group of people that did my mom's kitchen in Turkey - to contextualize a kitchen manufacturer's work processes - as well as scour small kitchen manufacturers' websites to get a "read on" the industry. While this could not fully provide the contextualization I had for the Journal case, it still provided me a common ground to talk to the Kitchen Co. participants and "make sense".

Some of the participants in the $\mathrm{PhD}$ course Den kvalitativa intervjun som forskningsmetod (Qualitative interview as a research method) in Linköping became the unknowing participants in my attempts at trying to find a balance between laughter, agreement, prodding deeper and confronting the interviewees - and with their permission some of that material has been used in an EGOS paper discussing some of the strategies $\mathrm{PhD}$ students use for publishing in academia (Imre 2014b). Of interest was to realize that I made a note of Strauss in one of my course notes from the 20032004 academic year's Introduction to Sociology course, and had forgotten about it until the summer of 2015 when going through some of my old notes during a cleaning session. At that time, following Giddens (2001, p.161), we discussed the various tasks involved in treating illnesses, and thus talked about how a traditional concept of "work" might be broadened in organizations. While Strauss' text was not obviously connected to social worlds in the form mentioned by Giddens, my reading of Strauss while writing this thesis makes me view the management of chronic illness as the issue where different ideas of how to manage it, and thus to some extent where different social worlds, clashed, which in turn can lead to negotiations of divisions of labor (Corbin and Strauss 1985; Strauss et al. 1985).

As mentioned, my two cases are from two rather small and simple organizations. I had an initial "introduction interview" with an editor to set the boundaries, and then continued with the real interviews and observations, accompanied by the "follow-up interviews". With Kitchen Co., it was mostly informal contacts from the beginning with the owner. I kept tabs on his overall progress with Water Co., the company he started and sold before establishing Kitchen Co., and then shifted my focus to Kitchen Co. when it was established. As I broadened the project to include standard non-integrated systems, my contact with Kitchen Co. grew to include some of the other participants of the company during the data gathering process: two engineers, the accountant and an external consultant, all interviewed by Skype or Facetime. Surely, that still is rather different from the first step of this journey, as while I began this journey with largeenough organizations to warrant an ERP system in mind, now I had two small organizations as my case companies. This means that my cases might not provide as much excitement as a case study with a well-known organization like Toyota or IBM will bring, or an obscure company that employs thousands of people. However, as I mentioned before, one impetus to use the Straussian package was my belief that the 
issues Mengiste and Aanestad (2013) sketched in the interactions of health ministries, hospitals and World Health Organization programmes, were also visible in my small organizations. While it is possible to argue that a bigger organization would have provided even more nuances of interactions during an IS adoption, I believe the rather simple, easy-to-grasp settings my two companies provided helped me contrast the complexities of IS adoption more clearly. These two small companies then enabled me to add to the IS adoption literature by providing an account of small enterprises, as well as showing how issues faced by other organizations are reflected in small organizations, which can be as complex as their large counterparts.

Thus, these seemingly simple research settings provided a rather rich data set, and looking back, one of the confessions I need to make for the whole $\mathrm{PhD}$ process was "I wish I was more structured", and had kept a research journal. While I am happy with the end result, I believe a research journal would have helped me keep track of my ideas better and provide another piece of structure to enable a faster writing process for the kappa.

\subsection{Analyzing the data}

Now, after this account of how the data was gathered, it is time to have a glimpse of how it was analyzed. I have hours of interview data - transcribed and/or summarized several hours of observations, and a rather large pool of informal data gathering points to analyze. I will not attempt to go through the analysis process for each piece in detail. However, by providing instances of how the data was analyzed and how it was used, I strive to open "some of the black-boxed issues" that I mentioned before. Thus, in this section I provide some excerpts of the data - interview transcripts are reproduced by permission of the editors - and discuss my analysis of them.

Before beginning this, however, a disclaimer of what "could not be done" should be made. As I have mentioned, both of my cases are small organizations, with the Journal case presenting its own challenges due to the proximity of the interviewees. Thus there are some aspects of the data that could not be put into the papers, as it would be rather easy for them to identify "who said what". Of course, I have anonymised the text, but if you have worked with each other for the last few years and were in conflict in a recent meeting, it is easy to identify the criticized person if one scrutinizes the interview data. Similar precautions had to be made for Kitchen Co., whose participants - though they might not be as interested in reading an academic paper - can still identify the respondents if I am not cautious. For example, there is only one accountant, thus it can be rather easy to track some of his ideas in the text. This perhaps is one of the parts that I felt conflicted, to try to be true to the material I have and to highlight the issues I want to, and to the commitment I made to my respondents to protect their anonymity and integrity. Thus, some of the issues that were brought up in the interviews can not be discussed in the papers, such as an editor blaming another one - with rather strong words - of not doing his share, and always shifting the blame to the others ${ }^{8}$. Where

\footnotetext{
${ }^{8}$ This is similar to the dilemma Walsham (2006) discusses. While I agree with his sentiments that not many respondents would read our papers, and long lead times between submission and publication might mean the organization has moved on, I have worked with small organizations that can identify who the material is coming from, and as such, I am rather dealing with issues that Walsham - from a large organization perspective - won't find too problematic. Furthermore, the situation becomes more complicated as one of the cases comes from an academic journal, thus the assumption that "many respondents won't read our papers" becomes rather dubious.
} 
issues became personal like this, I tried to keep them from the papers, though after a few iterations of the data, I can not say they did not affect how I see the participants of Business Journal and Kitchen Co. In this way, I think the terminology offered by the theories I chose helped, as some of these conflicts, while muted due to taking out the "personal" parts, could still be played by highlighting conflicts of stakeholders and social worlds.

In writing this chapter, I thought about how to best present my analysis. One option was to provide a rather full excerpt - a few pages of uninterrupted interview material - or to pick pieces from different parts of the text to highlight similarities and differences in the interviews and how they were analyzed. Also I had to think about how to best use the data that I can show, and argue for how some of my analysis is as good as an alternative one. To that end, I decided to use small excerpts to highlight similarities and differences instead of a full excerpt, as that would also provide how different participants provided similar-yet-different accounts, and help me establish my conclusions in a more balanced way.

As mentioned, I was influenced by discourse analysis - mostly discursive psychology and particularly interpretative repertoires ${ }^{9}$ - and its effects can be seen in my analysis. However, as will be seen later on, the papers do not have much reference to that line of thinking. There are two main reasons for writing the research papers as they are. The more personal one is stemming from my previous attempts with discourse analysis, and the frustration I felt with the rather loaded question of "so what?" in various venues I presented them at. This "so what" was more of "what is the point of doing this research" rather than the "how can you make your implications more clear" type of questions I got when I presented the research with a more conventional case study design. The more formal, but also connected to that "so what" issue, is to give back to participants of this research process, who are more geared towards a case study design rather than discourse analysis. To be able to speak to the practitioners, and a wider audience, both practitioners and researchers, I decided to present the research with a case study design style. However, as a background analytical framework, I was heavily influenced by the ideas of discourse analysis. I have written several papers where I have used such an analysis (e.g. Imre 2014a), and though they do not form a parcel of this thesis, I found

By asking the respondent what they think of my conclusions from our interviews and giving them the chance to respond to my understanding, my aim was to keep my commitment to preserve the integrity of the respondents. As Saldaña (2009) argues, the other side of integrity is to provide a truthful account of the data, and while I decided to keep parts of the text that seemed too personal - easily identifiable by the respondents - out of the papers and anonymize the data in general, I incorporated both positive and negative accounts of the IS adoption to provide a truthful analysis. On ethical issues and integrity of the scholar and the respondent, also see The Swedish Research Council's Expert Group on Ethics (2011), which provides a broad discussion on these issues, and stresses the importance of the research subjects' and informants' integrity.

${ }^{9}$ Previously I have summarized this perspective as: "IR [interpretative repertoires] constitute a strain of discursive psychology, attributed to the works of Nigel Edley, Jonathan Poter and Margaret Wetherell (Potter \& Wetherell 1987; Wetherell \& Potter 1988; Edley \& Wetherell 1997; Edley \& Wetherell 1995; Wetherell 1998) who drew upon the work of Gilbert and Mulkay (1984/2003) concerning the scientists' discourse. And as a strain of discursive psychology, IR have three core principles as to what discourse is (Wiggins \& Potter 2008): (1) discourse is constructed and constructive: while the discourse is constructed by the people - assembling words, images - the people are at the same time constructed by the very same discourse; (2) discourse is action-oriented, be it to blame, justify, invite or to compliment, discourse is the primary medium to achieve these actions; (3) discourse is embedded in a context." (Imre 2014a, p.3). For a comparison of discursive psychology - interpretative repertoires - and two other forms of discourse analysis, see: Jorgensen and Phillips (2002). 
being experienced in such analysis helped me to tackle this data corpus I had now. I agree with Potter and Wetherell $(1987$, p.168) that analysis is more of a craft and that often words fail us to describe what we have done as "analysis of discourse is like riding a bicycle compared to conducting experiments or analyzing survey data which resemble baking cakes from a recipe. There is no mechanical procedure for producing findings from an archive of transcripts" and that "as the analyst becomes more practised it becomes harder and harder to identify explicit procedures that could be called analysis" (Potter and Wetherell 1994, p.55). Still, in the next pages I will show segments of my analysis process. To begin this, a four-minute extract is provided below. In this part of the interview, we were talking about the cloud system adoption, building on previous discussion on how the journal was set up and the early years.

\section{Extract 1:}

Özgün: You previously mentioned that you guys have asked the university and your colleagues to help. Anything like that in the cloud phase? I mean... with implementation or...

Respondent: Now that you mention... It was not just cloud, but we asked some help from the university. [name of the editor] asked, because he was, erm, friends [hand gesture] $={ }^{10}$ with the higher ups than I was...

$=[$ laughter $]$

$\mathrm{R}$ :

It was more of a general thing, not with Google or something. We wanted to have some backing from the university. Both for IT part, but more for other issues.

Ö: $\quad$ Hmm hmm.

R: When we first began the journal, there was this, "call" to become more international from the university. Trying to attract more funding, researchers, partnership with other universities, you know...

Ö: $\quad$ Hmm hmm.

R: $\quad$ So we thought the journal can actually help the university with that, so we decided to ask for help, as it would raise the university's visibility. Also we were paying for the journal ourselves.

Ö: $\quad$ You mean, like, erm, the server?

R: $\quad$ Yeah. So we decided that "why not ask them to help?". I mean, they earn from the journal, so we can argue that if they helped it can become better.

Ö: $\quad$ Hmm hmm.

R: $\quad$ So, I guess, on the one hand our intention was more of the financial kind, yes, we take our turn to pay for the hosting and server and it is not a full salary, but it adds up. And you have the talk about helping faculty to internationalize, to create awareness of the university and research, and...

Ö: $\quad$ Hmm hmm.

R: $\quad$ And on the other hand, if we had university backing it would have added to the legitimacy of the journal. Now we are a stand-alone new journal, we could have been more if we had Business Journal cooperation with University X. It would have helped to make the journal known better. And we would feel more secure that if something goes wrong it would be our people that we can ask for help.

Ö: And, as far as I understand, you didn't get the university backing, in terms of, erm, sponsorship.

R: No, that didn't work. And looking back, it might have been better, I don't know. Recently, I received an email from [name of publisher] asking if we would like to be a part of them. To be honest, it felt nice, as it means we are doing something good. But in the end we rejected $=$ them

Ö: $\quad$ =Really?

Ö: $\quad$ Why?

R: $\quad$ I am not sure if you have looked up at some of their policies, but it comes to that they can close you down if they want, and you can't say no.

\footnotetext{
${ }^{10}$ In the transcript, the equals sign (=) signals an overlapping talk, whereas ellipsis (...) denotes a silence, and the dash (-) denotes a cut off in utterance. The brackets ([ ] ) are used to signal omitted details in text, or additional information not captured by transcription.
} 


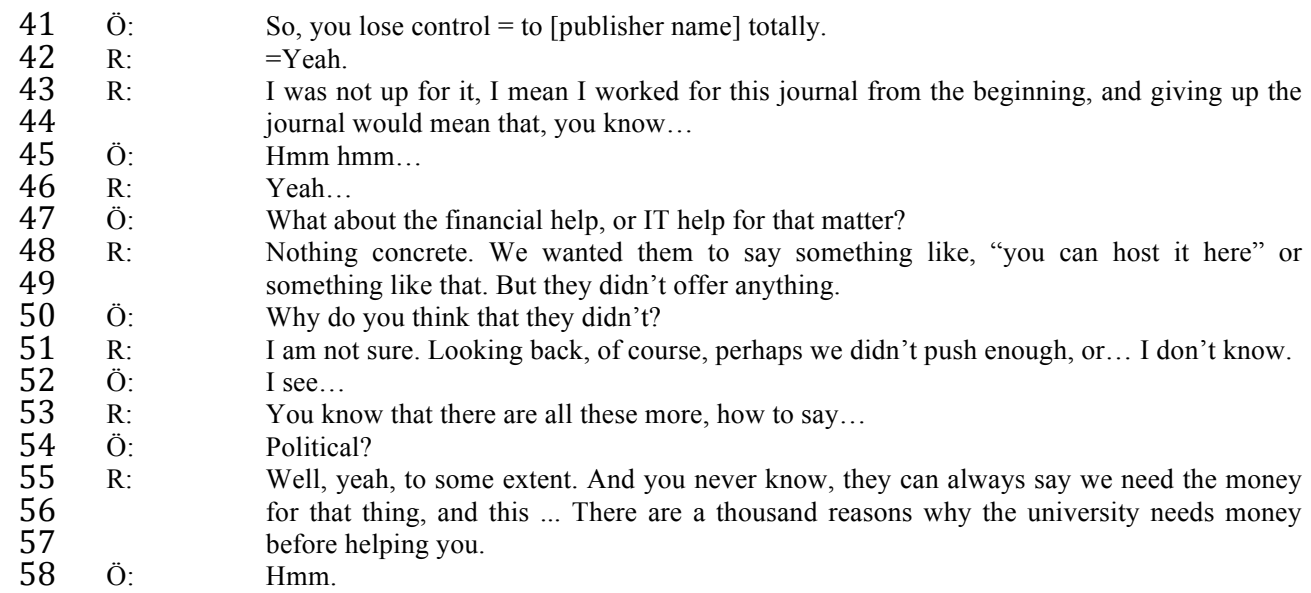

To start off, my question at line 2 builds on an earlier discussion where university and colleagues were brought up - possible stakeholders - and the answer provides an instance where the IS decision was coupled with other issues. This opening of other boxes while discussing IS decisions is what made this material interesting to investigate, as it provides how interconnected the decisions within the organization is.

Response in line 4 begins with a small piece, a moment of spontaneity "now that you [the interviewer] mentioned", an act where the editor can create a sense of credibility by providing an unscripted, compelling account; it is not something that he practiced before. Also of importance is the change in categorizations done, the narration begins we - an indicator of the team/Journal - but then shifts to a specific editor, that was friends with "higher ups". This can be taken in several ways, and I would argue that in this instance it was to allude to how things are "political". I myself bring this word in line 56 after a pause in the respondents' prior account. It receives a luke-warm acceptance by the respondent, and opens up another line of reasoning, of how the university has other things to do. This last piece I related to the concept of urgency in the stakeholder theory in paper one, where in this case the university is narrated as having other projects to support, or as the respondent argued "a thousand reasons", thus lower urgency. My input "political" is one of the instances, which I alluded to previously, where, as interviewer, I added my thoughts of the situation to the conversation, which is a co-creation aspect of the interview form. In this case, my prompt "political" was a spontaneous one, that did not draw from any theory per se, but from how I can conceptualize why the rational decision to support Business Journal from the interview so far - was not taken. It is however curious that my stance aligns well with the "conflict until proven otherwise" assumption of the Straussian package used in papers two and three, that there is a political issue - a conflict - here.

Also of notice is how, by providing an identity to the editor as being friends with "higher ups", the identity of the respondent is also created: he did not participate in these negotiations, because he was not a friend with the "higher ups". This provides first a glimpse of what can be interpreted as part of a negotiation context used in papers two and three: sending someone that has more close ties to the other party can be seen as an attempt to shift the power balance in favor of Journal; and then a glimpse of how the editors can be positioned rather differently within the editorial team, thus introducing 
heterogeneity in a stakeholder (the editor stakeholder category identified in paper one). Of interest is also the possibilities opened by referring to this friendship, as now any "pro university" stance of the editor that is against the editorial team's vision, can be blamed on his relationship to the "higher ups". A very similar reading can be provided for my "political" prompt, which would put any decision made within the university just a "political" issue, eroding the university's valid arguments to mere issues of politicking.

Related to these issues of power, the responses till line 20 mainly draw from a discourse built around fairness, where the Journal and the editors seem to be fulfilling a "call" from the University (a stakeholder in paper one). While this call was not directed to any particular audience or directed for a certain outcome, the editor argues that it would be fair to receive something back, as the university "earns" from the Journal. Thus the journal is construed as an actor that looks for fairness, while the University is positioned as the other: "them". Similarly, the extract also provides instances where the editors/Journal and University is trying to achieve similar things: to internationalize, to be known, to produce. This I took as an example of the rather grand social world of academia, with the editors and the university being members of this world, but also each occupying other sub-worlds.

This categorization of we, $I$ and them occurs throughout the text and serves several purposes. In most cases, it creates a clear separation of stakeholders and the Journal/editors in the first four papers, as stakeholders, as actors, and as parts of the work-system. In other cases, it shifts the blame to others, or creates a moral persona. In lines 43-44, the editor engages with this moral persona, with linking his position as an attachment to the Journal, thus wanting it to succeed. As can be noted, the nature of the attachment is not picked up later on; however, I argue that this was akin to a normative commitment (Meyer and Allen 1991) - of emotional attachment and of reciprocity rather than thinking about what would letting the journal fail costs me, the editor, now. Thus, in this argument, the long-term survival of the journal is wanted because the editor has worked hard on this. When going over the data, to me it rang rather similar to the arguments of entrepreneurs seeing the organization as a "child"(e.g. Cardon et al. 2005), with the feeling of responsibility for the organization's wellbeing a paramount concern. (In the next extract, line 22, the interviewee even uses the word "baby".)

Categorization tools are used to delineate the Journal and a publisher (them), and the editor builds on this moral narrative, that while the editors and the Journal might benefit from entering in an agreement with the publisher, it would be giving control to "them", who might "close down" the Journal, which - apparently - is the product of hard work from the editors. This part of the narrative can be interpreted in different ways, and my line of reasoning went something like this: the publishers share the academic world, but would be closer to some of the Journals sub-worlds, as their practice is publishing, whereas the university was not necessarily sharing as many sub-worlds with the Journal. Thus the situation can be a clash of different sub-worlds and the practices involved with them. "Why would the journal be closed?" is not a question brought up in the interview, but it is somehow taken as a probable threat to the Journal. It can be closed down because "it is not producing enough", "is not fitting to our [publisher] rules", "we don't need it because..." Looking back to how the Journal was set up as a reaction to how the system seemed to leave the editors out, this fear of losing control, of losing agency, is rather interesting, and my reading was that the Journal, just like the editors themselves, is created as something that is threatened by the established 
structure, with the established publisher swallowing the small Journal, subjecting it to the rules set by the established system.

In the next extract with another editor, the focus is a bit different, more involving how the editors engaged with each other during discussions for adopting the system. The editor here draws from discourses of fairness and creates different moral positions for the editors, providing an explanation of why conflict occurred.

\section{Extract 2:}

Özgün: Can you tell me a bit about how the process went among the editorial group then? I mean, now the university said no, and you decided to not go with [publisher name], and you are trying to decide on which system to use...

Respondent: Hmm. Well, I said, we decided to do something that summer. I and [name of the editor] was rather fed up with [name of the editor], as it felt like he was not pulling his weight.

Ö: $\quad$ Hmm hmm

R: I mean, of course we understand, all of us have other things to do. I mean, "I have spent the last week writing this new project proposal, then had to deal with students. I don't have time for the journal”. But I make time for it, I do the same things. I am trying to set up a new PhD course, I am teaching [name of the course] the course full time, but I make the time. So, it was a bit frustrating, you know.

Ö: $\quad \mathrm{Hmm} \mathrm{hmm}$. So it was you and [name of the editor] that drove the process somehow?

R: $\quad$ Yeah, to some extent. I mean, we all decided things together, co=llectively.

Ö: $\quad \quad=$ consensus

R: $\quad$ Yeah. So yes we drove, but not alone [laughes]

Ö: $\quad$ Hmm. I was thinking about some of the things we have discussed, and it is rather fascinating that all of you feel rather passionate about the journal, yet I also get the feeling that things are not that easy-going.

R: $\quad$ True, but I will say that is normal for any group. I mean when we began we were barely out of it. So we started this together, it is like our baby. But, you know it doesn't always go smoothly. You argue and fight.

Ö: $\quad$ Hmm hmm

R: $\quad$ I think if we were still at the same place - or even the same country, it might have been better. It would add another layer so to say.

Ö: $\quad$ Hmm. Wha $=$

R: $\quad=$ like, you know being able to meet and discuss stuff face to face and have a coffee or beer.

Ö: $\quad$ Yeah.

R: $\quad$ And, also, there are other things you have to think of. All of us are trying to rise in our positions, so there is always something new to do. [name of the editor] for example got a new $\mathrm{PhD}$ student, and for that he wrote a project with some other people, so that took serious, serious [emphasis in the voice] time, and it is continuous responsibility. But then you have your commitment to the Journal as an editor, and not just because you started it.

Ö: $\quad$ Hmm hmm.

R: $\quad$ I mean, if we want the journal to become more professional we need to have an editorial vision. And for that you need to set up some time, not squeeze it between other things.

Ö: $\quad$ I understand. Well, I talked with some journal editors around, and one thing that pops up how you won't get much out of it until later on. Would you say that this is that kind of scenario then, that he is not putting enough effort?

R: $\quad$ Yeah. It rings a bell. It is a dilemma, isn't it? If you don't teach the course, you have no job, if you don't do this, the journal won't lift off.

Ö: $\quad$ Hmm

R: $\quad$ So, having the system would force them to work in a more, erm, structured fashion. You know, it is not that the system just sits there but it sends you the alerts, the reminders. And you can see the things that you need to do clearly. We though that will help some of us to get in line, so to say.

Ö: $\quad$ I see. Do you think it worked?

R: $\quad$ A bit too early to say. Now it seems to be going fine, but at this stage it is just the beginning, a pilot. You never know how it will turn out. True. 
R: $\quad \mathrm{Hmm}$.

51 Ö: $\quad$ Erm, one thing that I remember, when I talked with one of your colleagues, he mentioned pocket, it won't work. We do a brief budget to see how much hosting is and this and that. Scholar One was like a full salary. So we discussed it briefly, but everybody felt it was a bit too much.

R: $\quad$ And there was also the, erm... how it looks and how easy to use from all perspectives

Ö: $\quad$ Hmm [questioning stress]

R: $\quad$ I mean, we all have experience as authors or reviewers from these systems. So we had to think about what would we want. It was not too detailed from my perspective, but you don't want a system that is from Windows 95.

[laughter]

$\mathrm{R}$ :

I mean, there was this system that I used when submitting one of my papers. It asked me what my title was, and then there were not correct ones for my position. It is a small thing, but it makes you a bit frustrated. So if I don't want that as an author, then my author would not want that either. So we tried to find something that can accommodate all of these, you know...

Ö: $\quad \mathrm{Hmm} \mathrm{hmm.}$

In this extract, the editor opens his narrative by providing a glimpse of a division - at least he and another editor vs. another editor - in the editorial team. This extract follows a discussion about some of those issues and the editor provides several glimpses of why such differences occur.

In line 6-7, the editor uses the term "not pulling his weight", and this highlights the normative issues mentioned before, that somehow one editor is not doing enough and thus creating a situation that is unfair - we do not know if it is unfair to the editors, or to the Journal yet, as often the editors use "we" to refer to the editorial team and Business Journal interchangeably.

Of notice is the use of various "facts" that creates a factual discourse around the issues. The editor provides names of the editors, mentions time (summer). This type of discourse helps the editor to create credibility of his narrative. He uses others' speech (line 7-9) and admits himself engaging in similar activities (line 9-11). Aside from leveraging these taken for granted facts of life for those of us in academia, then the editor follows the fairness discourse mentioned earlier; the other sub-worlds that the editor belongs to are presented - of teaching, of designing a course - and these are presented as in conflict with the editorial engagements, and as an editor you have responsibilities that you should not shirk. A very similar narration is provided at lines 31-37.

My questioning in lines 41-43 provides another example of using language to position the self. In that line of thought, the question is posed by the remark "I talked with some other editors". This achieves two purposes: the following argument is not from the interviewer, thus any hard feelings due to the (probable) opposing positions in that interaction can be shifted to the "other editors", while at the same time reminding the respondent that the interaction is one of many, a part of a corpus for the research.

Similar to the first extract, this extract contains the rather cliché term: "you know". For example, it is used in line 29 when talking about the spatial issues in relation to communication with other editors. It is noteworthy that that line also contains a rather 
oft-formulated script: if the editors were working in closer proximity, then the editors would be having less communication issues. This is akin to what Edwards (1994) argues as script formulation, formulating the events as "scripted", as typical or routine. Rather than the break up of the communication as a result of distance, the editor creates a narration that presents how close proximity would result in better communication, and takes the interviewer with him "you know".

Of interest is how the role of the IS is discursively created in lines 48-51. Previously, the editor has argued that if they were in close proximity, things might go smoother. Thus one argument can be raised that a system would somehow need to facilitate such proximity. The IS discussed by the respondent, on the other hand, is argued to structure the communication and behavior, to force the editors with alerts to act, to create transparency in roles, thus substituting proximity with formalized communication channels. This is to some extent interesting as a fall back to how things are often done in start-ups, with mostly informal ways of communicating and how in larger organizations more formal methods of communication and action are desired. A similar move of coping with an organization that is becoming more formally organized as time goes by is achieved in lines $36-37$, where the commitment to the Journal is now argued as not just stemming from founding it, but also as a professional commitment. These moves are akin to a slight change in the social worlds, a move from one negotiated set of proper behavior (of being passionate and informal) to another (of being professional and dedicated). This move toward professionalization can further be contrasted with the arguments raised in lines 19-21, where the editor, while providing a narrative that normalizes having arguments among themselves, also positioned the Journal as "our baby", evoking a parent/child metaphor, which later is modified into viewing the Journal as a "professional", giving the Journal an identity separate from the editors - an example of categorization.

The last narrative is once again more about the discussions revolving specifically around ISs. Here, after my prompt, the editor talks about the expense of the systems, and uses a factual discourse. The cost of the system is compared with a salary, the name of the system is provided. Then the discourse shifts and engages with the experience of being an author or a reviewer (social sub-worlds), and how these are turned into considerations when discussing the IS. The negotiations seem to focus on ease of use and on systems appearing adequate or outdated. The concerns related to authors and reviewers are used as reference points to argue for what the system should look like. Thus in these moments, the editors seem take on other roles (author and reviewer), based on the other sub-worlds of academia that they inhabit. As I will argue later on in reflections of the papers, this move will put author and reviewer as an implicated actor from the toolbox of Straussian package.

Before providing a piece of my notes from a non-transcribed interview with Kitchen Co., and then moving to the next section to discuss issues related to research quality, my analysis of the previous excerpts needs a brief moment of reflection. For the more discourse-oriented reader, as it was decided that in the articles I wouldn't be using discourse analysis but follow a case study approach, I didn't transcribe the material with a formal structure, like Jeffersonian style. Also, to keep my analysis clean for the dissertation, I am omitting some of the more discourse-analysis-specific aspects I noted for myself, such as formulation, footing, and stake-attribution. However, one such device I have employed when writing this chapter, rather unconsciously, is externalization. Most of the time, I have used a rather personal account in this 
dissertation, putting myself as an active participant in the process. However, when it came to the analysis in the articles, as well as in the accounts of analysis I provided above, $I$ disappeared. I call this a moment of reflection, as it is rather similar to the arguments raised by Gilbert and Mulkay (1984) of how we, as scientists, present our ideas and how our writings often draw from an empiricist repertoire with its language of naturally occurring phenomena, of universally established rules and facts - the data speaks, the analysis shows, not $I$ interpret.

For Kitchen Co., the interviews were not transcribed. This was a conscious choice, as some parts of the early data was not recorded, thus not able to enter into the later analysis, which would potentially provide a skewed presentation of some of the issues. Thus for these interviews, I took notes. These notes taken during the interview were later on complemented by the recording and were summarized. This summary was then used to analyze why and how Kitchen Co decided its IS set up in the fifth paper. The summary of Extract 3 is presented below in Extract 4, and follows the sequence of notes taken, with indented paragraph showing extra detail provided in the interview.

\section{Extract 3:}

Session with Accountant:

Works at father's company

Long time

Uses old system daily to help with the parent company (ask H and admin?)

The system is fit to handle all the requirements of Kitchen

$10 \%$ or so

$$
\text { (piggybacking) }
$$

Not considered any other system. Knows of Quickbooks through H, very brief look "Why try [to] fix something not broken"

Concern about language issues (more doable) and if the system works with the tax system $>>$ Hugo and consultants concern over tax system as priority (piggybacking=free vs quickbooks license, US comp)

An integrated system can help Kitchen, but if everyone is doing their job as is not necessary now

Not easy integration with other tools in the Kitchen

More integration at Rice. Bigger company (one of the important comp)

Can solve the situation by Excel and formal documents (faktura receipt)

Hasn't found much mistakes

Often if someone new at admin or quick buy-sale (rushed documentation?)

>> Out of recording, issues related to transparency of integrated systems.

\section{Extract 4:}

Interview session with accountant:

Has worked with the father's company for a long time, using a stable accounting system. The accountant is experienced in using the system and feels comfortable in using it for Kitchen Co.

The case of piggybacking is ignored as the Rice Co is family owned, but you would not be able to do that in another organization. One of the reasons is that Quickbooks was overlooked is that this piggy backing is free but with Quickbooks - or others - you need to pay. 
Slight differences in the tax system means that the new "modern" accounting systems from "US" won't be just off the shelf, but needs tinkering. So it seems easier to go with the already existing system. Also was expressed by others that tax issues needs to be looked into more carefully.

The old system does not have the new "modern" functions like the new products, but the accountant doesn't think they are needed so sees no reason to introduce them to Kitchen Co. (or Rice Co.)

At this stage where the tasks are rather simple, and with a limited set of people involved in creating accounting related documents, the work doesn't seem to need an ERP type set up.

Rice Co has a more integrated set up, as the company is bigger with more demand and production (food/retail vs kitchen manufacturing)

In relations, problems occurred when there was a change in the admin asst, as the new girl didn't file some reports correctly. It was solved, but took some time to track the reports.

Small problems pop up if there is an increase in demand.

Doesn't know the particularities of the CAD or any other software used, but can understand the requirement list and costs related. Things are rather easy to match and map into an Excel type file for cross checking if necessary.

>Is not sure if the ERP system would help Kitchen as it means very little flexibility. You leave a paper trail which is not wanted by the customers or the suppliers. I scratch your back you scratch my back type of understanding is eroded by full transparency, which is not how things are done for this type of issues.

I believe the summary does not necessitate for me to provide as detailed analysis as I did for the interview excerpts. One reason is that the summary is already a form of analysis: some of the issues are taken in and expanded, while some others are discarded. Another is that paper five involves less reading between the lines. The analysis stays closer to viewing the Kitchen company situation in terms of the technology, organization, and environment framework, and is less concerned with discourse analysis and with deciphering the stakeholders' social worlds. However, there are issues that can be brought up for reading the fifth paper later on, and even to connect it to Kitchen Co. Here the respondent is an accountant that has worked with Rice Co. - owned by Hugo's family. This means that he has the ability to leverage his expertise in choosing an accounting system - not compatible with the tax system - as well as ability to leverage his familiarity with the Rice Co. and thus to family business in general. The "modern" applications are deemed unnecessary by the accountant, in contrast to Hugo's assessment, where one of the potential benefits of the "modern" was that they would provide more mobile applications. This potential benefit was countered by the fact that Hugo won't have to pay for the old system, but has to pay for the new one. Most of the problems that the accountant encountered are because of basic mistakes, that do not necessitate a more complex integrated system, but more attentive administrative personnel. Of note is that when the recording is stopped, the talk is shifted to the issues related to transparency provided by an ERP-like system, which would mean that the company would be less flexible. As is argued in the fifth paper, this was a common occurrence in all interviews, as especially for smaller organizations, such transparency is deemed hindering for success.

\subsubsection{Summarizing the analysis}

As pointed out in my pre-final seminar, after reading pages of analysis, it can be a nice touch to provide a closure, and as such before reflecting on the quality of research and closing this chapter, I think a very brief summary of the analysis should be made.

In this analysis section my aim was to show how the data was read by me, by providing an analysis that can be referenced to the data directly, and using some of the key concepts that can be linked to the theories to show how they relate to the papers. This was done to provide a more transparent account of the data analysis that was not 
possible to show due to the papers' focus on the story rather than providing a full-blown method discussion, as well as length limitations.

In this way, my aim was to open that black-box of data analysis: even though I agree with Margaret Wetherell and Jonathan Potter that it is rather hard to provide clear-cut explicit procedures that can be called method, by providing data excerpts and my take on them, my reason for providing the data was an attempt to show how the data was used and transformed into the research papers.

By providing this reading, my aim was to reveal the various discursive devices that led me to identify these stakeholders, the social worlds and negotiated orders, the components of the work-system and the influence of various factors on IS adoption in my two cases. To do so, I have provided instances where categorizations have changed (we vs I vs them), where affects were tied to situations (seeing the journal as a child), where the respondents discursively created situations where they were moral heroes that try to keep the Journal afloat, whereas others were either non-entities (some editors) or villains (the University). Through this analysis, I was able to identify the stakeholders, like the University, and their attributes (low urgency for the University) in paper one, and the social worlds and the negotiated orders in paper two - for examples by highlighting the moves between seeing the Journal as a child, and seeing it as a project that needs a formal face, and to seeing it as an administrative burden and a career commitment can be incidents of various social worlds. I attempted to show the various discursive devices that led me to identify these stakeholders and social worlds and negotiated orders. The insights from these papers lead to paper three: my attempt at nuancing the stakeholder model. Paper four used the same interview material to identify the components of the work systems, for example how the resources limited options available - no financial resources to buy a well-known system - and how as the Journal matured, the strategy (from a reaction to the publishing system at the beginning to becoming a good, reputable journal later on) and other components of the system had to change. My summaries of Kitchen Co. case was used to tease the TOE components from the corpus, and identify how they affect the IS adoption in this manufacturing company - like how "modern" systems, a technological context, becomes hard to implement in Bolivia, a different environmental setting than the US from which the modern system stems from.

\subsection{Reflecting on quality}

In this chapter, I discussed my research approach and provided examples of how the data was gathered and analyzed. To some extent, issues related to quality have already been integrated in my narrative about my choices throughout this dissertation. However, before moving on to the papers that make use of this methodological approach, I conclude the methods chapter by specifically reflecting on the research quality. I have already claimed that I conducted interpretative case studies, that I used theories as sensitizing devices, and that I was influenced heavily by ideas related to discourse analysis. Then what are the consequences for this dissertation?

To begin with, I acknowledge that the often-used constructs to discuss the research quality - reliability, validity and replicability - are coming from the positivist/postpositivist traditions (Taylor 2001), and may not be the best tools to evaluate the research I undertook - or qualitative research in general (Steinke 2004). However, they still provide relevant issues of concern, and in this section I aim to highlight how I worked through them. Even the definitions of these concepts are contested from different 
disciplines, and in this chapter I use the definitions provided by Taylor (2001, p.318) as a starting point: reliability as a criterion of if the tools and instruments to be used can be relied upon to measure consistently; validity as a criterion of truth or accuracy of the generalizations of the research; and replicability, a criterion to assess if another researcher can replicate the research and come to the same conclusions.

I view the issue of validity as the aim and attempts of ensuring that one is actually dealing with the intended issue, empirically and theoretically, and that my conclusions are accurate - valid - in line with Taylor's definition above. While conducting this research, I mainly drew from interviews as my main data. I enhanced it with observations for the Journal case. For both these cases I talked with people outside the cases to gather more data about the industry, the concerns of the inhabitants of similar settings. I also contacted the respondents to discuss my initial findings of the material, and thus gave them the chance to make clarifications. I have also conducted follow-up interviews to dig deeper into some of the issues that I thought were pertinent - or came up after the initial rounds of analysis. These more "data-oriented" check-points, I will argue, can be taken as related to the issue of validity. This way of collecting data has served to provide a richer, more thorough empirical basis than any of the sources or any of the steps would have on its own. Similarly, I have tried to use different theories in the Journal case. If my previous comments related to a data-oriented validation can be termed triangulation of data, then my use of theories can be termed triangulation of theory. In the different papers, I employ different, but in my view related, theories to study the IS implementation issue, in order to reach a more solid understanding of the issue.

However, just as the data gathering was not aiming to reach a more universal truth as aimed for in a positivist or post-positivist tradition, my use of theories was also not for that, but more to gather a deeper understanding of the issues I was investigating. In this way, I deviate from the argument put forward by Denzin $(1978$, p.307) that saw triangulation as a way to reduce bias: a tool for validity "by combining multiple observers, theories, methods, and data sources, sociologists can hope to overcome the intrinsic bias that comes from single-method, single-observer, single-theory studies", and am more inclined to agree with his later arguments that suggested that triangulation "reflects an attempt to secure in-depth understanding of the phenomenon in question" (Denzin and Lincoln 2011, p.5), or as Flick (2009, p.445) puts it: "triangulation is less a strategy for validating results and procedures than an alternative to validation [...] which increases scope, depth, and consistency in methodological proceedings".

On that note a few words on generalization can be said. As Potter and Mulkay (1985) notes, like others, I am generalizing the case data to a certain degree. Drawing from discourse analysis, I see the interviews as not just constructing a narrative, but also recreating reality, borrowing from the culture and lived experiences of participants; thus there is an implicit argument that the data can say more than just about the specific setting. Furthermore, I think this stance is coupled with Walsham's (1995) arguments that see providing rich insight as a type of generalization. For me this rich insight emerged as iteration between the concepts of stakeholders, socials worlds, negotiation etc. through an iterative reading of the case material, which resulted in the nuanced stakeholder model, which itself can be argued as a theoretical generalization. In this way, I can say that I have used the case data to provide a rich insight of IS adoption based on the cases investigated - with Potter and Mulkay type generalization inherent and have used theories to sensitize me - and my readers - to the data. Thus while I did 
not begin this journey with an aim of generalization, overall, I will also argue that this dissertation is a piece of work where the results would sit somewhere in between the ideal types of generalization empirical-to-theory and theory-to-theory provided by Lee and Baskerville (2003).

Drawing from discourse analysis once again, some other "criteria for quality" can be discussed to link the issues of validity, reliability and replicability. With keeping in mind that I adopted a single-case approach with small organizations, one issue related to quality would be coherence (Potter and Wetherell 1987): that the set of analytic claims should give coherence to a body of discourse, thus the discourse created in the dissertation should be coherent throughout the text to make claims for validity. This issue of coherence was taken up by Howarth (2000) who argued that only looking at the coherence of discourse might be too internal-looking, and argued that one would have to provide plausible accounts of social phenomena to the community of scholars. In my research, this plausibility construction was to some extent externalized through the publishing process, and also by iteratively working with the papers and presenting them at internal seminars at EIS and at seminars at the Swedish Research School of Management and IT. The aim was to provide meaningful interpretations of the social phenomena I was investigating. Therefore, my rather usual prompt "does it makes sense?" in those sessions helped me assess my degree of success in achieving plausibility and coherence.

In relation to the issue of coherence, one point of further reflection is my close contact with Business Journal due to my position as a scholar. This I took as a beneficial position, as this allowed me to have an "insider status", similar to what Wetherell and Potter (1992) discussed as their nationality providing them with an insider status when talking with New Zealanders on issues related to racism. And just like them, I also acknowledge that this "sameness" does not provide a magical tool to the analyst. I believe it helped me to better understand the setting I was investigating, but it can also have blinded me to some aspects that are too natural and familiar to me to even notice: for example, the fact that the respondent had to apply for research funds was accepted at face value by me, that even though it impacted the case it was not something to delve into. In other settings, with fully state-funded research, the utterance of research funding might have prompted another line of inquiry from the interviewer.

Having an insider status, having an approval from the publishers and colleagues that shows the plausibility of the coherence of my arguments and findings, I argue has lent this dissertation validity. These have also played a role to tackle the issues related to reliability: The arguments are coherent and valid, as multiple data sources were used and different theories were used to check the coherence of the arguments and to provide explanations where inconsistencies occur. And to some extent, this was done through the iterative approach taken throughout the research, keeping in contact with the respondents to present them findings while asking for more information, a type of "member validation" (Seale 1999, p.61). To further the reliability of the research, in this chapter I have provided some extracts from the data and my analysis of them, which in turn increases the transparency of the process, thus extending the reliability of the research.

On the other hand, I should also mention that the issues I see as positive can be construed as issues of concern: insider status and member checks might mean skewed representations, me not mentioning names and omitting some details that reveal the interviewees (to the ones that can identify them) can be seen as problematic. Even 
arguing that these papers have gone through a peer-review process is not that important, as the reviewers also didn't have full access to data.

I have already argued how my stance is a bit different from Walsham (2006) due to the research setting. And, I also believe that even though the two cases are seen as successful IS adoptions, I provide both positive and negative accounts of the IS adoption to be truthful to the data, and not just paint the cases in a preferential perspective. Then following some of the key-terms brought by Lincoln and Guba (2003), I argue that while these issues can be of concern, they have benefits that outscore the potential problems.

I have used the insider status and member-checks to build trust with the respondents. I have negotiated with them what kind of data I am after how I will gather it, and how I will use it. While this might give the respondents more power when compared with a positivist stance - with the researcher speaking with the authorial voice - as I argued before, for me it would be a cornerstone of the cooperative paradigm, which I believe is a parcel of what Klein and Myers (1999) argued. I further tried to ascertain the integrity of my respondents by anonymising the accounts for reasons of confidentiality and privacy, which in turn increased the trust among the participants. Having face-to-face contacts also helped in building trust by providing possible member-checks, where the respondents had the opportunity to discuss my interpretations of their data. In this way, I believe I have followed what Oakley (1981) argued when she said "no intimacy without reciprocity": for my respondents to consent to being participants, I gave them the opportunity to be a part of the research process, not just interview subjects. One reason for me to provide parts of data and how they were interpreted by me in this chapter was also to give you as the readers, who while not having full access, a chance to scrutinize the data and make your own interpretations, thus trying to create a rapport with my readers, and establish a first step of intimacy with you.

At this point, the issue of "replicability" should be opened up, as what I argue as advantages for validity and reliability can hinder the replicability of the research. For example, I mentioned how insider status provided me with advantages in data collection and analysis. This claim de facto means that others - outsiders - will not have the same results that I got. Even the other insiders from academia will not have a guarantee that the results will be the same. One reason for that is the situated character of the interaction between the respondents and the researcher, which makes the arguments of replicability that is "rooted in the realist view of a single external reality knowable through language" (Seale 1999, p.41) hard to attain. However, just as the extracts provided in this chapter serve a purpose to establish the reliability of the data and the analysis, the same arguments can be raised for replicability, that these extracts provide an instance where others can read and analyze the data. While this might not lead to full replicability - if such a thing exists - it leads credence to issues of plausibility and coherence mentioned earlier. Also, by explaining how I gathered data, and what types of data, and how I analyzed it, others with suitable access to other settings could perform similar studies, and possibly come up with similar results. In that sense, I do believe in a kind of replicability, and neither view my data and results as perfectly unique or extreme, nor my analysis to be inimitable.

Another point that can be brought up for validation is related to fruitfulness (Potter and Wetherell 1987, p.171). In this way, I will deviate a bit from Potter and Wetherell's argument: fruitfulness as "the scope of the analytic scheme to make sense of new kinds of discourse and generate novel explanations". As I draw from different theory bases, 
what might be a "novel explanation" in one might not be novel in another. But I agree with them in so far as one theme of this dissertation is to be cautious of homogeneity hidden in stakeholder theory, and that even in small - seemingly homogenous groups of actors - negotiations will involve various social worlds, and that these negotiations might result in learning. Then, this can be argued as an issue of fruitfulness, that the analysis of the material of this thesis re-inserts the heterogeneity to the stakeholder theory and injects social worlds and negotiated order to explain how the various actors interact in an adoption process, and how these interactions can be seen as moments of learning.

Related to this fruitfulness, another point of reference can be made through what Tracy (1995) argued as "helpful problem framing": that the research should help the informants to reflect upon their actions. This was done in two ways, I argue. The first is by the adoption of the case study approach, which is familiar to all the parties, unlike some of the other approaches that can be used. As Myers (2013, p.82) argues, one advantage of case studies is that they represent a real story that most can identify with. Thus the respondents that read the papers can reflect back on their situation. The other way - the main way - of helping the respondents to reflect upon their actions - was done by asking my respondents of their opinion of my initial analysis and keeping in contact with them during the case study period. I attempted to help them by providing my take-aways from their responses, giving them a chance to reflect on what they talked with me about, but also on their actions in general. That is why learning has been a theme in the papers, as with every iteration they went through in their IS adoptions, they went through a process of learning, just as they - and I - went through a process of learning with every point of interaction and reflection.

Now, after discussing my methodological stance, and reflecting on my analysis, in the next section I present the papers included in this dissertation. 


\section{Papers}

The papers associated with this thesis have been removed for copyright reasons. For more details about these see:

http:// urn.kb.se/ resolve?urn=urn:nbn:se:liu:diva-143458 


\section{The Research Papers}

In this section, the five research papers that form the core of this dissertation are presented. The papers are edited to more closely follow the layout of this dissertation (e.g. font and typeface), while more structural components - numbering and style of titles, figures and tables and referencing conventions follow the original publication forms. Some language corrections and editing is done to correct some mistakes in the papers. The accepted pre-final versions of the texts are used to comply with the copyright requirements of the various venues, so small changes in formatting might occur when compared with the published papers' final form.

For every paper, I begin by providing a short introductory section that provides a brief background of the paper, its placement in the thesis, and its conclusions. This introductory section is followed by the paper, which is then followed by a reflection that provides a discussion of the paper. In these reflections I aim to provide a more detailed account of why some choices were made, and how the research process went for these papers.

Before moving on to the papers, though, a few words on the publication outlets can be mentioned. As can be seen, they can be considered an eclectic collection, ranging from IS conference papers to a journal article in a business journal. One reason for having both research areas is, once again due to EIS, which as I mentioned before spans these two research areas - also see, among others, Avgerou (2000), El Sawy (2003), and Hirschheim and Klein (2012) for how this might be a more widespread issue for IS, and Engwall $(1986,1992)$ for Business Education.

The first two papers are conference papers, one from Business (EBES) and the other from IS (EMCIS). They are conferences that are established, and catering to general audiences in their research areas, and thus I saw them as opportunities to speak with these audiences, with the conferences being back-to-back that year presenting an extra chance for quick comparison. The third paper is from a well-known IS conference (ECIS), and was my attempt to see how my own nuanced model will be received by a reputable conference's audience. On that note I am happy to say, a lot of people were able to "make sense" of my ideas.

The fourth paper is a result of me finding a call for chapters for OS-ecosystems for knowledge management. As my case was an OS IS adoption and had elements of knowledge management, I wrote the chapter and after a long review process it was published in an edited book. The journal article was a result of me trying to identify shorter-publication-time journals and getting introduced to Thompson's Emerging Sources index. As my case from Bolivia, I tried to find a journal that will focus on either Latin American cases, or emerging markets, and that might be interested in my case, and the result was a business journal to offset the IS book chapter.

I have already mentioned that I used different theories, thus the focus of inquiry is different for the papers. Similar to that, due to the different foci of these publication outlets, I have focused on some aspects in some papers and sidesteped them in others. However, as I expressed above, I believe these different foci are a strength, allowing me to highlight different aspects of the IS adoption that these two organizations went through, rather than a hindrance. That is one of the reasons why I present the papers 
Papers

within the wrap, and follow them by individual reflections: to offset this eclecticism in the theories and the outlets, and to show how the papers are linked and create a whole. 


\subsection{Paper 1 - Stake and Salience of Stakeholders}

\subsubsection{Introduction to Paper 1}

Background:

After a chance meeting in a fika room with a researcher who was an editor for a small journal, I was introduced to the Business Journal case. This paper focuses on the stakeholders of the Business Journal, and aims to identify their salience to the IS adoption. One background argument of the paper is that as stakeholders can have varying interests, identifying stakeholder salience is an important step to prioritize stakeholder claims.

Placement in the thesis:

By adopting a single-case-study approach, this paper provides a glimpse of why a small organization adopts an IS. By showing how the existing solutions became a part of the problem, the case shows how a more structured IS solution was needed as the organization grew and became more established.

By identifying the stakeholder salience and different stakeholders' opinions of the Business Journal and its IS adoption, the paper also highlights how a round of negotiations took place, and where the diverging interests had to be tackled. This provides a glimpse of how an organization adopts an IS, and how these negotiations can turn out to be instances of learning.

Conclusions:

The paper argues that stakeholder management is a dynamic process, and thus the stakeholder mapping should be updated frequently. As the Business Journal moved from cloud adoption to system adoption, the analysis showed how the editors' ranking of the stakeholders changed, highlighting the need to adopt a dynamic view of stakeholder theory.

The paper also has shown that while there are conflictual interests of stakeholders - also within the editorial board - these conflicts can spur moments of learning that are helpful for the survival of the organization.

Implications:

The paper serves as the first step to reveal the whys and hows of IS adoption in small organizations, and re-affirms that stakeholder management is a hard task to achieve. It argues that problematic situations under the right conditions can turn into situations of learning, thus can be beneficial, thus in line with the implications of situated learning literature in arguing a broader understanding of conflict and learning. A further implication, for this dissertation at least, is how these conflicts might be black-boxed by using a theory that often assumes homogeneous groups as stakeholders. This was the impetus for adopting the Straussian package for the second paper.

Originally appeared as:

Imre, Ö., 2015. Learning by negotiation - Stake and salience in implementing a journal management system. In 16th EBES Conference - Istanbul, 27-29 May. Istanbul, Turkey. 
Papers

Later published as:

Imre, Ö., 2017. Learning by Negotiation: Stake and Salience in Implementing a Journal Management System. In M. Bilgin et al., eds. Financial Environment and Business Development. Eurasian Studies in Business and Economics, vol 4. Cham: Springer, 369-383. 


\subsubsection{Reflections on Paper 1}

As I have already mentioned in the articles, me stumbling on the case was mostly my luck - being at the right place at the right time. Being from the academia, I was able to delve quickly into the worlds of the editors, however, this also comes with a bunch of possible problems: will I be able to disentangle what they are saying from what I think? Am I influenced too much by the first person of contact - since I was able to observe one editor while working, whereas I did not have the same opportunity for the others? There are several reflections that I think can shed light into my thought processes that will hopefully answer such concerns, and in this reflection I group them in two broad categories: reflections on methods and data, and reflections on the theory. In the following reflections, however, I will mostly delve more into my moves within and across theories.

\subsubsection{Reflecting on method and data}

As I have written in the papers, I am influenced by the ideas of Klein and Myers (1999), and two of their principles are connected to the problems I stated above. As they argue, I also believe that data does not just sit there, but is constructed within the interaction of the participants. In this case, I think being from academia enabled me to talk the language of editors and thus made the data collection and interpretation easier. However, as I had easier access to one editor, I might be more influenced by one key informant's point of view.

To balance this I interviewed other editors - though two of them declined - and tried to see where the 3 interviewees I got are in accord - or disagreement - when I was analyzing the data. Also, I have talked with other people in academia and colleagues that went through IS adoptions - such as the adoption of Easychair - a conference management system - by my research school, MIT, to handle our biannual seminars to see if the data I gathered from the case was similar to what I will get from more informal but similar settings.

In discussing how such an adoption went, one divergence from the research school and Journal was the more technical perspective that became apparent. "In other systems I need to click once, with this system three times, so why is it so?" was an argument quoted by an interviewee from the research school, and such an argument did not come in the Journal. This shows that there are various concerns, and stakeholders and relations in every different setting, even if it is an academic setting adopting a more systemized IS to manage their work processes. This helped in contextualizing the Journal case better in my mind, as I was able to see how the generic stakeholder "university" played different roles and became the "University" in journal case, but was only mentioned sporadically in the research school case.

My reading of the data was also influenced by my ideas of discourse analysis. As often mentioned when talking with discourse oriented colleagues, discourse is both a theory and a method, and thus I was influenced by how I see power - how various discourses were utilized to achieve something - as well as how to identify these discourses in the material.

I have brought up the discourse as theory also to highlight another principle of Klein and Myers (1999), the principle of suspicion. In this principle the researcher is advised to be sensitive to biases and distortions in the narratives from participants. As the examples provided by them show, the principle of suspicion is often worked in by revealing the political/economic interests, and juxtaposing alternative viewpoints. In 
that sense, the influence from the discourse analysis in general, and interpretative repertoires of Wetherell and Potter (1988) in particular was useful and these biases were seen as positive elements of the data - as glimpses of how in this case identities were created and decisions were justified.

Due to space limitations in conference papers, only limited accounts of the editors were provided, for example only Editor 1 is expressly mentioned in this paper. Such instances of contrasting identities and decisions occurred when one editor, for example, mentioned how one editor argued that with a formal management system the Journal will look better and be able to attract more authors and readers. I have understood this issue as an attachment to the Journal - primarily an emotional one - with the editor arguing how this is needed for our journal to become successful.

This issue became a bit more colorful when the editor mentioned he is in a tenure track, and thus cannot spend as much time as he wanted with the Journal. Thus for me it was a clash of interests, of trying to balance obligations - if I were to use one of my favourite terms, the editor was a moral hero - of trying to do his best to help Business Journal he established when countered by his obligations to his employees. However, the story became further nuanced when another editor argued how some see the Journal as just as a career step to go further in the hierarchy, while at the same time using this as an excuse to not do their part in managing the Journal.

I expected there to be post-hoc rationalizations, as well as posturing to be on the winning side. As the case has shown, in the end the Journal decided to adopt a management system, so why would the editors claim they were against it when it is already established, and be the loser in front of my eyes? However, as can be seen, within their narratives - and with their narratives vis-à-vis others - the editors painted a rather colorful setting where my understanding of the case evolved. Whereas in the earlier account the editor was the hero, now he was the villain who used excuses to not pull his weight.

In this sense, it was useful to have access to other editors to see how they position themselves vis-à-vis others. One can see uses of various rhetorical tools in the text. For example, most of the time, the editors have used "we" to refer to themselves and "they" to others (University, Ebsco etc.) even while talking about their personal experience. In some ways, this was a membership categorization device (Edwards 1995, p.581) where the editors were creating an identity, discursively creating a unity among themselves. I would argue that you as a reader would be rather familiar with this sort identity creation.

As with other tools of discourse analysis, however, the story of membership categorization doesn't end this clearly. This category memberships were more nuanced later on when the person from the IT department that helped them was termed as the "IT guy", creating a sense of legitimacy of his opinions, similar to an account of "I was asked by the CEO" that would show the listener that the speaker was acting on behalf of someone with knowledge and authority. "IT guy" also connotes the value the editors have attributed to that person: as they have sent feelers to various IT departments for help, only one has helped them fully, with this person acting as a go-to-person.

While presenting the "IT guy", the editors at the same time were creating a sense of "hero" in their accounts as they triumphed against the more corporate ideas (financial pressure) to realize how listening to the expert advice that can save the Journal (see: Whittle et al. 2009). This of course holds true as long as the final point is the adoption of the system, as the moral hero would be the villain if the decision were not to adopt. 
Related to this moral hero that the editors played out, another tool that is noteworthy to mention is formulation (Antaki et al. 2007). We use formulation to present a package by using some parts of the prior accounts, disregarding some while keeping some of what has been said. I would also argue that you as the reader would be familiar with formulations, and one occurrence of formulation was when I summarily asked "So you would have adopted Scholar One if you had money?" where I discredited all other relevant factors - usability, relevance etc. - that affected their decision but only used the financial problems as the driving factor.

I decide to term my question as a formulation, even though it probably would be called a summation at best, or a leading question at worst by a more positivist research approach. And I think it was useful to see how my questions and "summations" during the interview could affect the interview, as such a formulation made the interviewer to take a position, thus was more inline with the active role the conversationalist takes in a conversation. Often times, such formulations resulted in the respondent adding to the narration.

\subsubsection{Reflecting on the theory}

One aspect that drove this and other papers was the inherent dynamism of stakeholder management. Due to the space limitations of the conference, I was not able to provide more tables that more clearly showed how the attributes of stakeholders have changed, and this frustration of visualizing dynamism lead to the ECIS paper - the third paper in this dissertation - that I will present later on.

Such dynamism, as I mentioned, is inherent in stakeholder theory. And similar to (Mitchell et al. 1997) I have used power, legitimacy and urgency to map out how the editors view their stakeholders, and attempted to show that these view - or perceptions, beliefs, ideas - are mutable. The University was the only one of the universities that the editorial board made an official call for help, and I have argued that this was an important stakeholder. However, with their rejection to help the Journal, the editors argued that they do not see the University as "viable" as before for the Journal. This made, to use the terminology of Mitchell et al. (1997), the University move from a dominant stakeholder to a dormant stakeholder position.

Such dynamism became apparent with the IT department of the University becoming a stakeholder. Whereas it was not even considered when cloud system was adopted $-1^{\text {st }}$ round of negotiations - it became an important stakeholder. Thus the stakeholder analysis of any organization has to be an ongoing process - which is not necessarily easy to do. As the case has shown, the editors were able to deal with their stakeholders in a rather direct fashion - sometimes they even saw one person to represent the whole stakeholder - for example the University - and based their opinions on that. However if they have gone to another set of people, or used other ways of communication, the results of their interactions might have been different.

As such, the paper adds a piece to the stakeholder theory by highlighting how a dynamic understanding is needed by showing the changes to the salience of the stakeholders as well as how new stakeholders come to play. The case shows how the power of the University is eroded as the Journal establishes itself more, as well as how the various stakeholders that were not involved previously had to be considered as the issues evolved.

As a further reflection, looking back, I also think that the idea that the stakeholder analysis should be based on an issue was one of the underlying assumptions I had, and 
thus tried to show throughout the Journal case. The oft used overall definition provided by Freeman (1984, p.46) of a stakeholder "can affect or is affected by the achievement of the organization's objectives" becomes too broad and messy. As can be seen, the reviewers were not deemed as stakeholders in the cloud adoption phase, as the editors did not deem a very internal back-office work-process to be affected or affecting the reviewers. Looking back, it is clear that they have affected and are affected by what goes on within the Journal, which resulted in the adoption of issue arena in the ECIS paper as a focus to identify and manage the stakeholders.

Up to now, I have talked about dynamism and the changing character of stakeholders. However, I have not necessarily argued why this dynamism occurs and how it is handled. Thus in the next paper I will try to dig a bit deeper to the case, and use social worlds and negotiated order theory to explain some of the shifts I have talked about in this paper. 



\subsection{Paper 2 - Social Worlds and Negotiated Orders}

\subsubsection{Introduction to Paper 2}

Background:

This paper was written concurrently with the EBES paper, presented just days apart, and shares much of the story with it. During the analysis of data to identify stakeholders and their salience, the divisions within the Editorial Board and stakeholders resulted in a shift from stakeholder theory towards a more nuanced lens, thus this paper has adopted a negotiated order perspective. Similar to EBES paper, with learning seen as notconflict-free, the paper attempts to analyze how the Business Journal adopted their IS.

Placement in the thesis:

This paper opens up the black-box of stakeholders, and argues that assuming stakeholders as homogenous groups can hinder the dynamism inherent in stakeholder management. By showing how fractured the editorial group was on the IS adoption, the paper argues that IS can play the role of a boundary object and reveal the social worlds that are at work in Business Journal.

Having the social worlds in mind, and conceptualizing the decision as a negotiated order play in to understanding how and why a small organization adopts an IS, and adds to the EBES paper by providing additional insight to the IS adoption in Business Journal.

Conclusions:

The paper argues that IS can play the role of a boundary object, so that while the various parties negotiate they reveal their similarities and differences. In addition to mediating communication, this revelatory role of the boundary object can be understood by theoretical lenses that are open to investigating power struggles.

Adopting social worlds and negotiated order, the paper has shown that how the editorial board was fractured, and how different social worlds created struggles. This provides a more nuanced understanding than a naïve stakeholder model that might conceal how heterogeneous stakeholder can be.

Implications:

Following the EBES paper, one implication of this paper is that the need to look into the stakeholders - to identify the diverging interests - is important for achieving organizational goals. By investigating how different social worlds and negotiated orders come together, a more nuanced approach to achieve these goals - like IS adoption - can be conceived, and instances where IS triggers conflict, which in return can initiate learning can be used to sensitize how to enable such learning opportunities.

Originally published as:

Imre, Ö., 2015. Learning by negotiation - Implementing a journal management system. In K. Lambrinoudakis, V. Morabito, \& M. Themistocleous, eds. 12th European, Mediterranean and Middle Eastern Conference on Information Systems (EMCIS 2015), 1-2 June. Athens, Greece. Available at: http://emcis2015.emcis.eu/EMCISfiles/Proceedings.pdf. 


\subsubsection{Reflections on Paper 2}

As can be seen, this paper shares a lot with the previous EBES paper, as they were written concurrently. While they have similar aspirations, and indeed similar conclusions, I would still argue that it was an opportunity to have them as separate papers, and in this reflection I will first reflect on my shift towards the Straussian package. This I think is important as a follow up to the theory chapter where I argued how these theories can complement each other, by directly linking the issues I investigated while conducting the research. Then a reflection on my understanding of it, the Straussian package follows this one, as I believe there are certain parts of the package that I need to more explicitly position myself within.

\subsubsection{Reflecting on the move from stakeholder theory to Straussian package}

One reason that led me to shift my view to social worlds was an attempt to reveal the more fractured view of life I have than the one I was able to present with only the stakeholder model. While once again recognizing the fact that the heterogeneity of stakeholders, and that the models should be taken as a simplification was already mentioned in literature - for example Freeman (1984, p.25) argues how the figure he provides is "enormously oversimplified, for each category of stakeholder groups can be broken down into several useful smaller categories" - how to break this oversimplification resulted in me trying to visualize the stakeholder model, which is shown in the ECIS paper that I will talk about later.

However, aside from this more "research" oriented perspective, the need to open up the stakeholders was also from a more daily-life oriented view. For those of you were interested, during 2014, the Swedish parliament amended a law that granted the $\mathrm{PhD}$ students right for residency. For me, as a $\mathrm{PhD}$ student, that was a rather significant, and while I was following the debates and the concomitant voting, I was able to see how the fractures happened in the parliament, with the parliament being a stakeholder.

We have coalitions, and some of them are more visible when talking about coalitions. Those can be visible, as was the case for the law change, or they can be more tacit. And the fact that the "firm" should be aware of how to look for these coalitions have been argued before, for example when Freeman (1984, p.135) provided a section on coalition analysis, arguing not taking these into consideration might not be the best way. However, there have been several problems on how to go with these suggestions.

As noted in an earlier paper, Lyytinen and Hirschheim (1987) argue that in literature stakeholders are often identified to convey role descriptions, and conflicts within the stakeholders are not opened up. This I would say might be one of the reasons of why the editors were surprised of being rejected help by the University. The Journal fits to the mandate of the University to be more international, so how come they do not help us? The editors have assigned a role - and thus a way of acting - to the University management, so why didn't it work out?

This rejection is rather against the shared mandate, thus from a basic application of the stakeholder theory, is rather puzzling. Though it is easy to say in hindsight that the university has more than one mandate, and helping the Journal is only one of many ways to fulfill a mandate, the Journal and the university was likely to reach a coalition. 
I have already used Mitchell et al. (1997), and looked at issues of power, legitimacy and urgency. With the dependence on the university resources - a type of utilitarian power - and normative power of providing a quality stamp the University had power. However, as Mitchell et al. (1997) argued, the attributes are variable, and thus when the University rejected the editors, its likely to shift from one classification to another. Thus if others have already attempted to provide more dynamism, more nuance to the stakeholder analysis, why did I change my lens and not stick with the stakeholder theory?

One argument is that even with all the add-ons, I felt something rather lacking on how to apply this theory on a grounded basis that will look for the issues that I feel led to fractures within the Journal case. Yes we have forms of power, urgency and legitimacy, but why do we have them? Or in another way, why are they expressed as they were?

As a result of my review of social worlds/arena and negotiated order theory, I make some claims that go similar to this: all social orders are negotiated; this order can break down, thus needs to be re-negotiated; individuals belong to social worlds - groups with shared commitments to certain activities; social worlds are intersected with other social worlds and are further divided into sub-worlds; the representatives of social worlds engage in arenas and negotiate, drawing from the discourses of their social worlds.

I will argue that this set of arguments is rather close to what Mitchell et al. (1997) has argued about their recommendation on stakeholder salience identification: 1 . Stakeholder attributes are variable, not steady state. 2. Stakeholder attributes are socially constructed, not objective, reality. 3. Consciousness and willful exercise may or may not be present.

The temporality aspect of the social order was a key point in Strauss' arguments, just as how the reality is "objective" through the interaction of the actors. Similarly, the issues of consciousness and willful exercise [of power] was an issue that was tackled in how sometimes the negotiations were coercive, whereas in others the "taken for granted" rules influenced the decisions. Thus, in an MIT seminar ${ }^{11} \mathrm{I}$ have argued - in a tonguein-cheek way - that I am turning back to basics by adopting the social worlds/arena/negotiated order theory. I recall that I was discussing how I see the world from this perspective and getting the comment that argued this was done in actor network theory (ANT) - things break down and rebuilt again, the network needs to be sustained, people actively working on that, enrolling other actors, the importance of objects in translation and the active role they can take. And my reply was along the lines of arguing if what I am saying and what ANT is saying is so similar, why does no one refer to the work I am using, which was published before ANT. I guess the following silence spoke for how the audience saw my tongue-in-cheek reply...

Another reason for me to diverge from the stakeholder model was the issue I had with the implicated actors. While it is an accepted notion that implicated actors be present in an analysis of social worlds, I haven't seen that much of use a concepts as such in

\footnotetext{
${ }^{11}$ In the MIT research school, we have biannual research seminars, where the PhD students are obligated to present their research to the research school. As the members of research school has a diverse background and research interests, we are often put into tracks that are aimed to have a common denominator - such as business models, IS adoption and use etc. These seminars can be seen as a stepping-stone where the $\mathrm{PhD}$ students air out their ideas to an internal audience and get feedback to improve their research.
} 
stakeholder theory. However, in my case, several of the stakeholders were not present at the negotiations, they were not even consciously asked to give their opinions.

This issue of who to include in the analysis has been recognized in stakeholder literature, as most of the stakeholder identification problematique can be pinned down to this: who should be counted as a stakeholder. Phillips (2003), for example, has argued how some stakeholder have derivative legitimacy: a radical activist group that might be representing other normative stakeholders, or that might not be representing them but pose as a "dangerous stakeholder" a la Mitchell et al. (1997). However, as the previous paper (EBES) has shown, the authors are not a dangerous stakeholder - and their situation might not change for better if there are more papers in the pipeline - and they do not represent some other stakeholder. They are just not there in the daily life of Journal.

In this way, the concept of an implicated actor seems fitting to explain the role of these stakeholders. Clarke and Star (2008, p.119) argue that "there are at least two kinds of implicated actors. First are those who are physically present but are generally silenced/ignored/made invisible by those in power in the social world or arena [...] Second are those implicated actors not physically present in a given social world but solely discursively constructed and discursively present; they are conceived, represented, and perhaps targeted by the work of arena participants". In this sense, how the editors have used the authors and readers to argue for/contest the journal management system, resulted in me conceptualizing them as implicated actors ${ }^{12}$.

And these implicated actors were also useful to paint the structural and the negotiation context during the analysis. I have used these contexts in the analysis, however, due to space limitations was not able to delve into how they were used. Thus, before closing this reflection, I think it is prudent to delve a bit into how the concepts from negotiated order was used.

\subsubsection{Reflecting on the Straussian package}

To start off, the formal definition of structural and negotiation context, which was taken out from the paper due to space limitations can be given. These two terms come from Strauss (1978b, p.98-100), who argues that:

The structural context is that within which the negotiations take place, in the largest sense. For each case of negotiation, it will be necessary to bring out some of the salient structural properties that bear on the negotiation. Thus, the structural context for covert negotiations engaged in by a corrupt judge includes features of the American Judiciary system and of marketplaces, while the hospital includes the properties of American medical care, the subspecialty of psychiatry, specialization among the caring professions, and the division of labor in mental hospitals.

I distinguish between that larger, structural context and a negotiation context. The structural context bears directly on the negotiation context, but the latter refers more specifically to the structural properties entering very directly as conditions into the course of the negotiation itself. There are many specific kinds of negotiation contexts pertaining to interaction among negotiating parties.

\footnotetext{
${ }^{12}$ It is also of interest that such a discursive use has been investigated in discourse analysis, such as by Goffman (1974) who uses the term "ventriloquizing", and building on that "voicing" by (Lauerbach 2006).
} 
The latter types are related to permutations of the following properties of any negotiation context. [...]

As can be seen, while the structural context can be taken as a social structure bearing upon the negotiations, the negotiation context can be argued as a more direct structure that influences the negotiations. Some dimensions of the negotiation context to think about while conducting the analysis is to identify the goals, values and interest of the parties, to see if the issue at hand is complex, if the negotiations are one-off or continuous and how they influence each other, to evaluate how the balance of power among the parties are distributed.

It is in identifying the structural context that being a member of the academia was most helpful. Even if I don't have experience out of Sweden and Turkey as a researcher, I would argue that some - if not most - of our problems over the world are rather similar. So I will try to briefly paint a picture of what the academia looks like at the moment, which of course will be open to interpretation as my knowledge comes from certain branches of academia.

In Sweden, to the extent that I can see, we are pressured to finance our research by finding financing from specialized government bodies and private sector as opposed to the old-school idea of government grants. This means an added burden, as writing projects takes time and effort, which might not bring any returns - unfortunately not all of our projects get funding. This also adds another layer of stress: most of the time, the people within the field - our colleagues - are competing for the same grant. In addition to that, we are expected to conduct teaching, as well as contribute to the public good by science outreach programs - the so called "tredje uppgiften" in Swedish.

The most important outlet of the researcher seems to be journal articles, the higher quality - assessed by use of various bibliometric tools - the better ${ }^{13}$. With most high ranked journals taking a rather long time to process a paper, this adds a time perspective to the researchers stress. With new journals and conferences appearing everyday, the spectrum of outlets increases, bringing more issues of quality.

The collaborations with other researchers adds another layer, as this adds issues of how to collaborate, how to arrange meetings etc. and how to write something together. The time needed to collect and analyze the data are always an issue.

I can go on for sometime about what I think the academic world looks like at the moment, however, as can be seen from my very brief reflection, we have different

\footnotetext{
${ }^{13}$ This in itself can be a contested issue: who conducts these bibliometric analyses, and how they decide on what is quality. It is not my intention delve into these issues, thus very briefly I should mention that the strong push for journal articles was expressed in the MIT PhD course "Seminar and Thesis Work", and in various different venues writing journal articles was expressed as contributing to the discourse, whereas books was, apparently not. I can create one argument why journal articles might be more sought after: Swedish Research Council, argues that it is the citations that the work gets are important in some research funding (The Swedish Research Council's Expert Group on Ethics 2011, p.91), however, does not call for open-access for book chapters, and as book chapters might be behind a pay wall, they might get fewer citations, thus lowering their impact for the researcher. See contributions in Blockmans et al. (2014) for the use - and abuse - of bibliometrics in research performance. While expressing how their list will not fit every situation, Association for Information System (AIS) still argues that their intention with the "basket of eight" journals is to help in tenure and promotion cases, which can also be considered as a push for publications in certain outlets.
} 
logics and roles that are at play here ${ }^{14}$. Our time is rather limited, taken up by the formal tasks that come with being a university employee, our future jobs depending on these tasks, our research funding providing finance to the projects we are researching on $-\mathrm{a}$ market-logic. Our contribution counted by the research publications on quality journals, on how many students graduated - and evaluated us well - a production-logic. In our daily lives, we take the role of a teacher, a researcher, an administrator, a public speaker, and sometimes, we take on those roles at the same time.

How does this structural context play out for the Journal case? As was mentioned in the papers, one of the issues raised was how time pressed these editors are. They are obliged to fulfill their tasks to the universities, and thus their editorial engagements are a voluntary one. While they have created the Journal together, they can not be forced to take on an extra task, or can use the university tasks as an excuse to not deliver what they agreed before. This also means that they have to do the editorial work in addition to their assigned university tasks, meaning the editorial work will eat from their personal time, thus adding another type of stress.

With the focus on the academia to publish in high quality journals, the goal of becoming a high quality journal, however, means that these editorial tasks can take considerable effort. To find the relevant reviewers - who will also do their tasks voluntarily - for example, often takes time, as well as the editorial proofing after the whole peer-review process is done.

As for the negotiation context, it is easy to see how some of the concepts I mentioned previously would work. For those of us that have limited contact with university governance, the negotiation between the University and the member of the editorial board would be a rather straightforward process. It is most likely a one-off or a few set of negotiations, with clear power distance between the members. The Journal is attempting to have support from the University for financial/technical issues, as well as hoping that the University helping them would also turn-into a sponsorship-type deal, thus legitimizing the Journal even more. The editorial teams' belief that the University mandate of becoming more internationalized would be satisfied by setting up the Journal however is not matched by the University when the University representative argued that the Journal was not a University project. This rather simple negotiation context becomes more complicated when it comes to the negotiations among the editors in how to continue. Their previous "informal" talks resulted them in choosing the University to be approached formally, and the end result was a rejection. All of them are trying to further their careers, with some arguing that Journal is a career step whereas others mentioning it as a burden. The negotiations are on going, affecting their daily life, unlike the one-off they had with the University. They are engaged with the Journal on a voluntary basis, meaning they can not force the others to do a task in the same way a firm can do using contractual obligations.

Further within the complexity construct, comes another point that was one of the leading arguments in the case, the learning aspect. The negotiation with the University was useful, for better or worse things were decided upon. However, with the editorial board negotiating among themselves, the learning aspect was even more important. It was during these negotiations the preferences of the editors regarding the Journal (as a career step vs a burden) and how they actually work within the Journal was aired out.

\footnotetext{
${ }^{14}$ For some interesting read on these issues see: Wedlin (2006); Lucas (2006); Whitley et al. (2010); Engwall \& Scott (2013); Blockmans et al. (2014)
} 
One of the reasons why the cloud solution did not work was due to the work practices not being aligned with the aspirations of the editors and capabilities of the cloud system. The cloud system did not offer much in the way of forcing the editors than the email system. It was these negotiations, and the complexity involved in creating a consensus or a workable solution if not full consensus - among these various roles and aspirations and limitations that resulted in the learning that I argued occurred in the Business Journal case.

Such differences also occurred with the issue of financing the system. As most of us know, without going into details of data security concerns, having Google or Dropbox type solutions are either free, or with a rather negligible cost. However, when it comes to a journal management system, the solutions are not that easy to handle. Financing issues was one of the complex negotiations, as the editors would have to finance the systems themselves. This eliminated the more well-known options like Scholar One rather quickly, which would cost approximately $\$ 3500$, whereas the open source solution would have the basic option beginning from $\$ 650$. Just as the future support and compatibility of the system was an influential factor for not attempting an in-house system, how to finance the system was also posed as a question of continuity. For one year, or two the editors seemed to be willing to pay, but for future either the system needs to be brought to Journal servers - which they do not have - or one of the universities should help, or they should find extra financing for it. All these questions were to most extent left open when I left the case, signaling how the negotiations would continue for some time. That will also mean a negotiation about which option to choose, whom to ask for financing, who shall write the funding application etc.

Another thing that needs to be opened up is what "negotiation" means in my cases. As it was raised in various instances - internal seminars and MIT conferences - I think it should be said that while it is heavily used by Anselm Strauss, it is not clearly defined (Allen 1997). Perhaps when Strauss (1978b) talked about "trade-offs" it was closer to the common use of the term negotiation, however the issue became further complicated when he introduced "silent bargains" or "implicit negotiations", which opened up the questions of how to define and analyze negotiations. However, as Allen (1997, pp.51415) provides, "negotiation can refer to 'bargaining, compromising, brokering, mediating or collusion' (Maines 1977), 'making a deal (an explicit compromise), trading off, reaching a formal agreement (say with respect to each others' turf), or reaching more formal agreements signified by contracts and other signed arrangements' (Strauss 1978). Negotiations can range from tacit understandings (Strauss et al. 1964) to explicit contracts". In similar vein, later research has also provided a broad spectrum of definition for negotiations. As Clarke (2003, p.560) put it "Negotiations of many kinds from coercion to bargaining are the 'basic social processes' that construct and constantly destabilize the social worlds/arenas [...]", opening up what can be studied under negotiations. For example, when asked, an MIT respondent said she would not count what we were doing at the time - discussing my submission with her asking and me answering - as negotiation. However, while there is not a clear-cut definition provided, how previous outcomes of negotiations become taken for granted as time moves on - a process of sedimentation that results in creation of a social structure has been argued before (Busch 1982), how our histories shape what we might argue as negotiation (Hall and Spencer-Hall 1982). As such, it is not that strange while she would argue that this is not a negotiation, I will - especially when considering that some of the discursive psychology work that influenced me from Margaret Wetherell and Nigel Edley (Edley and Wetherell 1997; Wetherell and Edley 1999) was on negotiating 
masculine identities, where the respondents were talking about their everyday life and situations, not "negotiating" in the way taken by a "bargaining" view that most of us assume when we hear negotitate. What these respondents did, at least in my opinion, was to carve their stance among numerous stances by drawing from various discourses. They "negotiated" their identity among the many other identities they hold, by using various interpretative repertoires.

While there are no clear definitions provided, there are some threads that can be found through out the texts to help in understanding what is a negotiation. As social worlds and negotiated order are theories of conflict, a negotiation presumes tension between parties. Similarly, to some extent conscious (or perhaps even openly-declared) antagonistic interests are to be assumed in negotiations. And thirdly, there is to be a give and take as a result of the negotiations - a trade-off. (Nadai and Maeder 2008, p.12). Similar to this Maines and Charlton (1985 cited in Nadai and Maeder, 2008) argue that "a degree of consensus (somewhere between complete consensus and complete disagreement), a degree of exchange (which varies in frequency, intensity and duration), and the use of strategies" are to be found in negotiations.

In this sense, I think it would not be amiss of me to say that I see our exchange as a negotiation, with me representing a bunch of ideologies of what negotiation is, and she questioning what a negotiation is. By using various resources (repertoires) we tried to understand the other and argue for our points, and to some extent we have come to an agreement. This kind of exchange is what I will consider to be an example of negotiation then.

Before ending this section, one last remark I should make is how while useful, the suggestion of Mitchell et al. (1997) that builds the salience of stakeholder in three attributes can also hinder our understanding. As Phillips (2003) has argued, for example, legitimacy is often taken as moral legitimacy, which doesn't cover all aspects. Similar to that thinking, if we take a more Foucaldian idea of power - as not only coercive but also enabler, the border between power and legitimacy is further blurred. I think in that sense, having a negotiated order perspective was a useful endeavor. In cases such as the IT-guy, their legitimacy was expressed as power, the editors did not have power over each other, but the discourses they drew upon - their various memberships to social worlds - enabled them to maneuver each other. In this way, talking about shared ideas/ideologies, work objects, identities instead of terming the issues in power/urgency/legitimacy provided more freedom and deeper understanding.

Up till now, I have argued that there are different stakeholder in the case, that they are not as easy to handle as the editors thought it would be, that there are different social worlds at play with different ideas and power structures and a need for negotiation to establish a workable solution for all involved. In the next paper I will attempt to put these arguments in a visual model, and will suggest that by a nuanced model, we can overcome some of the issues I encountered by using the classical stakeholder model. 



\subsection{Nuancing the Stakeholder Model}

\subsubsection{Introduction to Paper 3}

Background:

While writing the stakeholder and social worlds papers, I began to think about how to combine the various insights I gained from them. While stakeholder theory continues to be immensely popular, social worlds/negotiated order seemed to be forgotten, however it provided a useful lens to investigate how an organization works. With this in mind, I began my attempt to visualize a merged version of these theories.

Placement in the thesis:

By adopting a hermeneutic approach, this paper provides a visualization of an updated stakeholder model by using insights gained from the use of social worlds/negotiated order theory. The Freeman model is updated in various stages to provide a visual representation according to these insights. In this way, the paper serves as a theoretical conclusion to the Business Journal case as well as providing how such a model can be applied to by employing the model to analyze the Business Journal case.

Conclusions:

The paper argues that the proposed visualization enables a more nuanced investigation than the classical stakeholder model. By updating the stakeholder model by using insights from the negotiated order theory, some of the critiques against stakeholder model is worked through. The paper thus claims that the new model is better suited to highlight the heterogeneity of the stakeholders, as well as reminding the user of the temporality of the negotiated orders and how the analysis should be done with an issue at focus to tie the negotiations.

Implications:

Following the two previous papers, one implication from updating the stakeholder model is the shift of focus from stakeholders/firm to a more granular form of analysis. This necessitates one to investigate the actors within these stakeholders/firms to be able to achieve organizational goals. By putting an "issue" as he focus of investigation, the model calls for mapping the situation in relation to the issue, with an end result of more finely detailed analysis, revealing the diverging interests of actors.

Originally published as:

Imre, Ö., 2016. Reshaping the stakeholder model: Insights from negotiated order theory. In Twenty-Fourth European Conference on Information Systems (ECIS), Istanbul,Turkey, 2016. Available at: http://aisel.aisnet.org/ecis2016_rp/21/. 


\subsubsection{Reflections on Paper 3}

How does one provide a dynamic visualization? I am not that sure of it myself, and to some extent I think I was not able to make justice to my thoughts by the model that I present in the paper. I perhaps have fallen to a trap that Pouloudi and Whitley (1997, p.5) tried to sidestep: "In order to ensure that this approach leads to drawing a dynamic picture of the domain, we avoid creating a model which would be more likely to reveal only static instances of stakeholder topography".

So, I open this further reflection part by providing some thoughts about the visualization of the model, and how issues like negotiation context and structural context enter into the model in a more concrete way. Thus, similar to my theory chapter, my argument is that these two theoretical streams can be combined. Then I continue by discussing how the model can be used in other settings drawing from my discussions with various colleagues and providing a re-reading of an article by Boonstra and Govers (2009), to show that the model can be used to sensitize issues that can reveal some aspects overlooked by using only the original stakeholder model.

\subsubsection{Reflecting on the model - visualization and Straussian package}

First and foremost, I should say that I agree with Pouloudi and Whitley (1997), that my attempt, too, provides instances of stakeholder topography. However, I will also argue that it still provides a more dynamic and nuanced picture than the original model. I have already argued about the stakeholder model, and how the model proposed is better poised to provide a more nuanced analysis in the paper. To sum up, some of the issues I had with the original model was the use of different shapes for stakeholders and firm denoting centrality and uniqueness of the firm, use of only direct and uniform relations between the firm and the stakeholders, the homogeneity assumed within the stakeholders and the static/durable understanding of the stakeholder relations.

To begin the discussion, once again, I will say that some of these concerns have been aired by Freeman (1984) himself. For example, he never argued that only direct relationships exist. However, he has very scantly referred to the indirect relations, only 4 times if the word-search function is to be believed. Most of the indirect relationships are talked about when he discusses coalitions. The idea behind his argument is that these indirect coalitions are consciously used to influence the firm. However, do we always have such conscious strategies? Do we always act in such an instrumental way?

I would argue that for some parts this might be true, that there are these indirect links among the stakeholders, and they might be formed and leveraged consciously. However, I will also say that some of these links are there, and they are not used in the way that Freeman has argued, but perhaps as what Phillips (2003) would call derivative.

To keep the figure clean, I have not added social worlds to the model. However, the idea of putting little actors ${ }^{16}$ inside the stakeholders has definitely been influenced by them - as I have already mentioned, they are members of the social worlds, negotiating

\footnotetext{
${ }^{16}$ On that note, we can also place actants in the figure. Actants - nonhuman actors - have been recognized as an important part in negotiated order theory (Clarke and Star 2008). The term "actant" is mostly associated with ANT, and Latour's (1987) Science in Action is expressly thanked by Clarke and Star for the term. While, Clarke and Star's treatment of implicated actants concerns only "nonhuman" actors, ANT uses actant for both nonhuman and human actors. However, as I haven't seen the term actant used in stakeholder theory, for simplicity's sake I decided to keep them out from the model.
} 
on behalf of them. As members of the social worlds, we share common interests and goals, and as argued in the literature, an organization can as well be a social world. However, it is more likely that the organization is at an intersection of various social worlds with the members having memberships to different social worlds. This would then mean that the members of the organization are likely to have different agendas than each other. The fact that people have their own agendas, as well as that members of an organization are not homogenous is well known, however, providing only a collective figure deviates the attention from these actors that we negotiate with on a day-to-day basis. Thus, if we follow the coalition-building idea of Freeman, then we need to remind ourselves that the organizations have actors within. Also, even without this rather practice-oriented coalition idea, visualizing the organizations as entities presents a homogeneous organization, which would be problematic. If we argue that changes occur despite the stabilizing effects of the organization, having a homogenous entity would mean that change can only occur as a result of an outside force.

One key argument that Mitchell et al. (1997) drove in their article was that their typology provided a more dynamic understanding of the stakeholders than the older model. While I agreed to that, I had the problem that their attributes can be used as a static tool. With a Venn diagram, the user of the typology can easily put the stakeholders in assigned places. One way that I have seen that Venn diagram providing dynamism was Boonstra and Govers' (2009) treatment of ERP implementation in a hospital. They also placed their stakeholders within the diagram, but they provided arrows to indicate that the placement of the stakeholders changed over time.

Such a change also occurs with the proposed model, where the University, for instance has lost some of its salience. Its high salience was signaled by using bold in the Cloud adoption (figure 6), whereas in the next figure, it was denoted by normal font. This is, unfortunately, a bit more complicated to read than the Venn diagram provided by Boonstra and Govers (2009). However, on the other hand, I would argue that the Venn diagram itself is not that good to support new stakeholders that come to play, necessitating a new Venn diagram to represent the change from to to $t$.

As can be seen, while I am not that happy with my proposed visualization, I am still thinking that it actually serves a purpose. And perhaps one of my reasons for commitment is the issue arena. As mentioned in the papers, arenas are places where different social worlds interact with each other. It would also mean that these social worlds, at that specific time, are interested in an issue that correlates with their own common goals. And this common interest, rather than any and all that are covered by the rather broad definition of any who is affected or affects goals is an important aspect that is overlooked in the old model. In the daily life of the organization, where interactions are on-going, it is often more hands-on issues that are debated rather than the strategic decisions that Freeman often talks about. Thus, having the negotiations tied to an issue and assuming an issue arena where the various parties interact with each other, I would argue, will provide a more nuanced understanding of what goes on within an organization.

Adoption of an IS can be seen as a strategic decision. However, it was not necessarily posed as a strategic goal within the organization. However, it was more or less deemed as a tool to get out of a work-system/communication problem. The issue at hand was to adopt a system to manage the Journal, not consciously tied to an overarching goal. This is in contrast to some ideas of what strategy is found in strategic management literature - which stakeholder theory is based upon. For example strategy defined as "the pattern 
of objectives, purposes, or goals and major policies and plans for achieving these goals, stated in such a way as to define what business the company is in or is to be in and the kind of company it is or is to be" (Learned, Christensen, Andrews, and Guth 1965: 17 in Freeman et al. 2010) is not how the Journal dealt with these decisions. The impetus was to get over the problem they were facing at the time; the solution was not necessarily a major policy or plan. Thus, my argument is not that the on-hand issues in general are not strategic, or might not flow from strategic decisions, but that for this case it was not. What their story reveals is more of an emerging strategy similar to what Mintzberg (1978) argues, that intentions get modified as they are worked with, resulting in an emerging strategy.

In the previous paper's further reflection section, I have talked about the negotiation and structural context in more detail; thus I will not provide what they mean in this section. However, I will argue that a stakeholder model should have those two contexts in consideration to more easily map out the various stakeholders and strategies to manage them.

Similar to what I mentioned earlier, I must say that the issues that I am raising, most often not, are the things we do when in such a situation. We try to gather data so as to ascertain how the competitors, the government, the customers etc. will view our undertakings. Depending on how complex the issue, the resources we will allocate will differ. How we will negotiate with a stakeholder will differ depending on the balance of power. However, as we can see from the initial Freeman model, these issues are not mentioned, and thus run the risk of being overlooked. The stakeholders are treated as homogenous, the history that shaped the situation missing, the importance of the individual actors not visible.

Similar to this problem of overlooking the direct variables that interact with the negotiation, the structural context is not mentioned in the stakeholder model. How we will negotiate, or manage our stakeholders, will differ if we are in a stable industry context that depends on established rules and authorities or if we are in an industry that is undergoing crisis, or is in the process of organizing. Even if we are talking about stable industries, how we will conduct ourselves will change depending on which country/region we are in, what kind of organizations are involved etc.

Thus, the relatively equal power of editors within the editorial board should be taken into account when discussing how they will negotiate with each other, just as the rather powerful position of the University should be mentioned. It is by these annotations to the stakeholder model that a more nuanced understanding can be achieved. There is no indication of any difference between the stakeholder in figure 5, however, if we take into consideration that the University has formal power and has little to no dependency to the Journal, it is not that strange the Journal was not able to negotiate a more amicable end result. A treatment of how these contexts can impact the organizations can be seen in Hall and Spencer-Hall (1982), who for example argue how winning extracurricular interscholastic competitions as well as having newly graduated doctoral students as teachers changed how the negotiations pan out. Thus, I would argue having these issues as reminders in the model is an important aspect.

Though I haven't consciously thought about it at the time I was writing, I think the additions made to the Freeman model can also help with providing a brief historical aspect to it. One chief argument is that structural context is important. However, as Strauss has argued, these structures are results of negotiations themselves. Thus 
indicating the structure - even briefly - will also provide a glimpse of the historical baggage the issue has, rather than assuming an ahistorical stance the Freeman model does. The account of editors not getting published and not feeling encouraged by the faculty is a piece of history that can reveal why they acted as mavericks and created a new journal, which would also reveal some of the negotiation context: a negotiation among friends is different than a negotiation with an unknown person.

\subsubsection{Reflecting on the model's further use}

The last issue I think should be raised is how the model can be used in other cases. To do so, I will provide an alternative reading of the earlier mentioned Boonstra and Govers (2009) paper. This is not the best way to apply the model, as I don't have access to their data, and surely some of their argumentations I will take issue with are a result of their empirical study. However, as a case that investigates IS adoption at a hospital setting, it can be a fruitful endeavor to re-analyze their case with the model proposed in mind. To separate this re-reading from the reflections, it is presented with a smaller font.

\section{Re-reading Boonstra and Govers}

In their paper, Boonstra and Govers (2009) look at how an ERP system was implemented in a hospital setting in the Netherlands, and aim to show how the stakeholder salience and their attached meaning to ERP system affected the adoption of the system. This research was chosen for several purposes: unlike my Business Journal case - small organization investing in systems that would primarily affect its own organization - ERP adoptions involve high costs and often more actors are involved, with the effects in a hospital causing severe lapses in healthcare provided if adoption goes wrong. This change of magnitude can be useful to see if the model can be of use in other contexts (small vs. large organization, internal vs. external system, publishing vs. healthcare setting). Secondly, Boonstra and Govers (2009) derive their model from the stakeholder theory, thus provide a theoretical match to investigate the proposed model. A third reason to choose this study was to investigate an IS adoption in a healthcare setting with rather high risks if things go wrong - a setting from which Strauss has drawn heavily from while creating his ideas of social worlds, arenas, negotiated order and work in general.

In this case, the effect of the wider social structure is not given much attention. While this might be a result of an empirically driven analysis, one can still find some instances where such glimpses of social structures influence the implementation process. One example is provided when the fact that ERP vendors are aiming for the healthcare market is mentioned. That has implications of how the adoption process can occur. While in the presented case they had the misfortune of having a not-experienced-enough consultant, the fact that there are consultants around signals that overall there is an acceptance of ERP system in healthcare settings, thus such an adoption is to some extent acceptable. This is in contrast with the Ivy-league case of Scott and Wagner (2003), which tells similar problems in addition to ones caused by attempting one of the first ERP implementations in a higher-education setting. Similarly, non-IS trends can also play a role in the adoption. One trend identified in healthcare is "going lean" (Brandao de Souza 2009) which when put in an IS setting might argue that the double billing process in the hospital is a wasteful one, which can be solved by adopting an ERP system.

The use of Mitchell et al.'s (1997) Venn diagram to track the process of how the stakeholders salience during the ERP implementation progressed is something that is similar to what is argued in the proposed model. In Boonstra and Govers (2009), when the attributes of the stakeholders change the placement of the stakeholder in the Venn diagram changes. In the proposed model of this paper, such an analysis is conducted iteratively and is presented by using bold typesets and highlighting. As the conditions bearing on the negotiations change and the issue arena develops, the perceived salience of the stakeholders have to updated, and while the 
Venn diagram is useful to showcase the changes, the reasons for the changes are not provided in such a model.

In their paper, referring to Freeman (1984), Boonstra and Govers (2009) argue that stakeholders have their own subjective views on the issues, and while arguing that views can differ their paper also argue that the views were rather homogenous within the stakeholders "the level of consistency in perceptions within these stakeholder groups, was relatively high" (Boonstra \& Govers 2009, p.186). This view of homogeneity can be rather dangerous as it hides the various ideas within the stakeholder that might not be revealed unless further questioned. In their analysis one identified stakeholder is "physicians (medical staff)". While this might be a result of how they sampled their interviewees - snowball sampling - it is curious that no other medical staff is present in their analysis - nurses, laboratory personnel etc. This is very similar to the criticism of the division of labour raised in Strauss et al. (1985), who argued that such profession-based arguments forget the temporal aspects of the negotiated order, which might break down in times of change, or that there is invisible work that needs to be considered (Star and Strauss, 1999). Such a broad profession might also hide the various differences of opinion. As shown by Strauss et al. (1985), there can be differences in how a surgeon and an anaesthesiologist would provide healthcare and how their needs, priorities and boundaries are different - which in Boonstra and Govers (2009) would fall under the broad term physicians. Putting actors within a stakeholder would then visually remind that there might be differences within the stakeholders, and that negotiations are done by individuals acting on behalf of stakeholders. A similar case occurred for the Business Journal, when the editorial board had an internal split when pondering upon their various IS options. Another issue of not having an actor-based understanding can be revealed with some further reasoning. Doctors and nurses are also known as holding administrative jobs in the hospital. In such a scenario, how these people should be placed in a stakeholder would be problematic. They would most likely be under the medical staff, but their identities as administrators will influence how they conduct themselves in negotiations.

Figure $\mathbf{2}$ below is how they conceptualize the change in the stakeholder salience in their case. As can be seen, the moves of the stakeholders is more easily depicted than the proposed model. However, the other issues I mentioned are not visible in their figure. Can we really reduce IT staff, external consultancy, external project leader and administrators to one representation - one legend? Can we really assume that they haven't changed their placement? Can we see any reasons of how and why these stakeholders changed their attributes?

I would argue that a figure such as mine would be more conductive to begin the analysis of the stakeholders of projects. Though it would be known for us doing the analysis, the Venn diagram does not show the issue at hand - why these stakeholders are there. This would also help the analysis in revealing some stakeholders that might not have a direct stake in the IT implementation: perhaps some of the missing stakeholders I mentioned are such stakeholders and thus weren't placed in the Venn diagram. Also showing what the interactions among the stakeholders - their negotiations - would reveal how and why the attributes have changed: the external consultancy was argued to be incompetent, and later was sued, however, their placement in the figure didn't change, thus looking at the negotiations of the various parties might be a way to identify why such placement still holds. Similarly, the Venn diagram makes it difficult to place the stakeholders vis-à-vis each other, and if we were to follow the stakeholder model, the question arises: where is the firm, the central figure? 


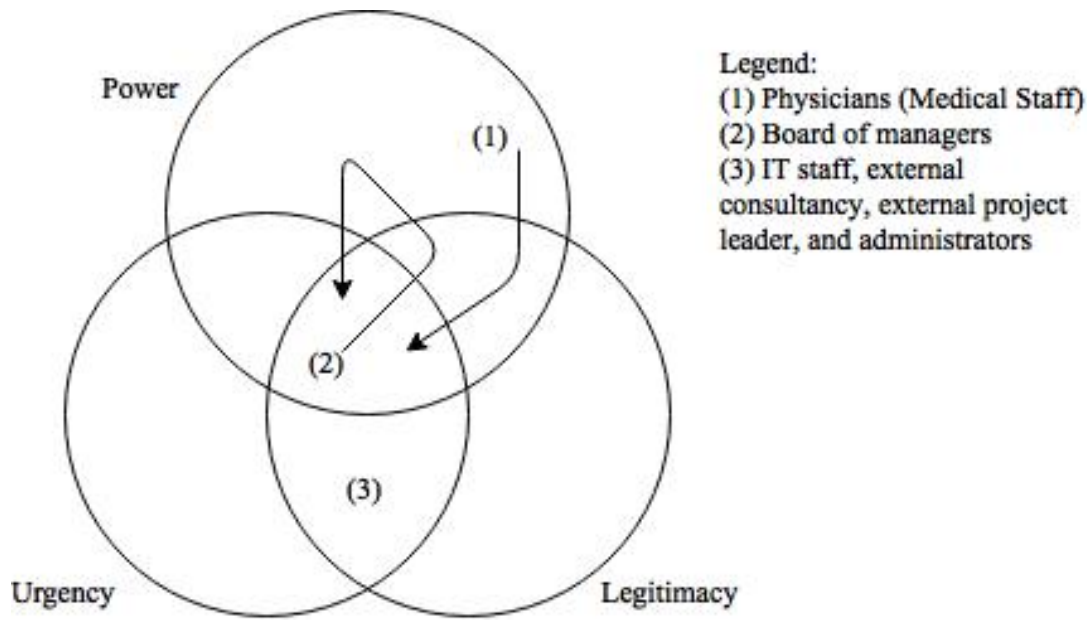

Figure 2. Hospital IT implementation stakeholders (Boonstra \& Govers 2009, p.187)

Before ending this discussion, reflecting on the figure from a more stakeholder vs. negotiated order theory perspective, I summarize and highlight why I used the term "going back to the basics".

As I mentioned some - if not most - of the issues I raise are already covered in stakeholder theory. For example the fact that stakeholders are not monolithic is already recognized; that for example "shareholders are far from being a monolithic, homogeneous group, differing widely in terms of interests, involvement/sophistication, and influence capacity" (Winn 2001, p.136), and that "researchers ignore many differences within stakeholder groups" (Harrison \& Freeman 1999, p.484). This issue has been taken up within the negotiated order theory long before, for example in Strauss et al. (1964) where the hospital is shown as not only vertically but also horizontally segmented, with the physicians negotiating with nurses and technicians and administration, as well as among themselves to carve out their areas of work and legitimacy.

As Winn (2001) argues that might be problematic for stakeholder theory, which while aims to manage diverging interests, doesn't take the diverging interests within the stakeholders as a core part of the analysis. The issue of diverging interests has already been raised in social worlds/negotiated order theory, that individuals participate in a number of social worlds simultaneously (Strauss 1978a; Unruh 1979 cited in Clarke 1991 ) and that social worlds can intersect each other as well as include sub-worlds. This is similar to the criticism raised in Pesqueux and Damak-Ayadi (2005), or to the observations of Freeman (1984, p.58) who argues the importance of these individuals and stakeholders that have more than one role in influencing behavior and creating coalitions. All these concerns and arguments resulted in my attempt to nuance the stakeholder model.

So far, I have argued for conceptualizing IS adoptions as a series of negotiations that involve various actors and social worlds. In the next paper, the IS adoption of Business Journal is conceptualized as a change to the work system of Business Journal, I thus here use a different lens to investigate how these negotiations occur and what their effect is. 



\subsection{Paper 4 - Investigating the work system}

\subsubsection{Introduction to Paper 4}

Background:

This chapter was written as a grounding paper for the Journal story, and thus shares most of the story with the previous papers. Using a single-case study approach as before, the chapter looks at the adoption from a work-systems perspective with conclusions that mostly overlap the earlier papers presented. One reason to adopt a more descriptive theory stems from the need to more clearly identify the parts that create the whole, how various parts of the Business Journal affected each other in the decision making process.

Placement in the thesis:

This chapter serves several purposes for the thesis. The underlying idea was to have a paper that will showcase how various parts of the Journal affect each other in the decision making process. By using the work-systems framework the chapter highlights how various parts of the Journal's work system affected each other. In addition to this, the chapter also provides a richer description of the case than the previous papers, thus presenting some of the issues discussed in a more in-depth format. This in-depth look is useful to understand how individual parts of the Journal create a whole and to see how the IS adoption is reflected in the system, as well as to provide a backdrop to the issues discussed previously in the conference papers.

Conclusions:

The case shows that the IS decisions were done in an ad-hoc manner, and this contributed to some problems during the evolution of the Business Journal. By not recognizing that the IS adoptions were multifaceted, the Business Journal often showed tendency to treat IS decisions as merely technical issues. The case argues that an inclusive perspective such as the work-systems framework can help overcome this tendency and help in side-stepping some of the problems. The story of how IS decisions moved from a non-issue to an issue that needed to be tackled more systematically also shows how formalization in a small organization affects the work-system of the Business Journal.

Implications:

As discussed in earlier papers, IS adoption was not given a priority, and thus caused some problems. Based on that story, this paper calls for being attentive to small changes in the work-system by linking how these changes can result in misalignments later on. One key implication is to consider the IS adoptions in relation to other parts of the organization and move away from the magic-bullet idea of IS solving problems on its own.

Originally published as:

Imre, Ö., 2017. Trying to Go Open: Knowledge Management in an Academic Journal. In F. J. Garcia-Peñalvo \& A. García-Holgado, eds. Open Source Solutions for Knowledge Management and Technological Ecosystems. Hershey, PA: IGI, 222250. 


\subsubsection{Reflections on Paper 4}

The writing process for the chapter was a bit different from the conference papers that I have discussed before. One primary reason for that is the rather limited space one has while writing a conference paper. While keeping the text neat, this unfortunately meant that I was not able to provide some of the details of the case in the way I wanted, or provide a more balanced view on theories. While not necessarily affecting the results, that meant some sacrifices had to be made, which the reflections in this dissertation aim to overcome. Secondly, I thought I should provide a rich description of the case to both offset this space limitation, but also show the issues encountered in the case in a format that can complement the story I was already writing for the other papers.

I have already provided a piece of this story by identifying the stakeholders, by highlighting how negotiations occurred and how the IS played a role that lead to increased understanding within the Journal. However, those episodes were not necessarily played out to the extent that I would have liked. Thus I began to write a case description based on the theoretical frameworks I used before. However, how to put the case together and not just repeat what I have already written?

To do that, I chose Alter's work-system framework. He has argued that while the term work-system has been used before (e.g. Bostrom and Heinen 1977), it could also be used as a central concept to investigate IS. He has proposed the framework as a way to recognize and understand how the current set up of a system operates, and in the paper I have used the framework to investigate the work-system of the Business Journal. However, while attempting to provide this story, the chapter took a life of its own and looking back I can see in some instances it feels like a narrative. So, in this reflection piece, I will try to provide some examples of how I used the work-systems framework in a direct way to shed light on the analysis process by reflecting the use of the framework, and reflecting on the Journal's work-system.

However, before doing so, I should perhaps talk about the issue of knowledge management, and how it rather lacks in the present form of the text in general. While writing the chapter and throughout the revisions, as I mentioned previously, the text took a life of its own, but since the title was set and adding more text to the chapter was not an option, the knowledge management issues are not that visible in the text. However, that is not to say learning and knowledge management are absent in the case. I have already mentioned in earlier papers that learning took place by different actors coming together and negotiating with each other, and how IS can be considered as a boundary object for that. To some extent then the problems the Journal faces were also conceptualized as a knowledge management issue. The email chains - and how it frustrated the editors - were one of the reasons why they began to think of how to reorganize the Journal, and the end result of the journey is a management system. The affordance of this system is the connection to the knowledge management for the case, as now the editors can more easily track the process, see how the decisions were done, who is contributing - or inversely using an earlier phrase from the methods chapter, not pulling their weight. Having the information regarding submissions - the reviews, the decisions, the extra documents etc. - then helps in passing on the torch to newcomers. This is rather similar to continuity management found in knowledge management literature (Beazley et al. 2002), similar to creating an organizational memory. Similarly, the system results in a more streamlined way of working, limiting the email chains, and 
thus eliminates wasted time and provides transparency in the publication process. Thus the management system also provides an affordance to compete with other journals by preserving and revealing some of the competences in the Journal, similar to what Earl (1997) has argued. Thus while the knowledge management aspects of the case was not that visible, they still are a part of the tapestry that makes the Journal case. Or as someone else has put it in one of the internal seminars, the knowledge management plays a practical role in the paper, not a theoretical one.

\subsubsection{Reflecting on the use of the work-system framework}

As I have said before, one reason of writing this reflection is to show some examples of how the work-systems framework is used, and now I will do that. To begin with, some of the components are rather easy, and even unproblematic to identify. I think I can easily claim that the main participants of the work system are the authors, the reviewers, and the editors, with the editors having the most oversight and power to affect the worksystem. The readers are also easy to spot as external customers.

Also easy to identify was the technology aspect of the work-system ${ }^{17}$, with the emails, the cloud system, and the journal management system being the most relevant ones for the analysis. I have already provided a narrative about their use, and how the earlier ones resulted in problems in the work-system. However, as the framework argues, technologies are general and not only the IS used. The easiest technology to spot was the use of Skype to connect to each other when extra communication was needed - or to discuss some Journal issues when talking with the others for other purposes. Already mentioned in the paper, emails also were a technology used. Another technology was the archiving one of the editors does for herself, in which the papers and the reviews she has on them are printed and kept in folders, with the rejections compiled in another folder. This rather primitive technology does not enter into the work-system per se, but provides a management tool for the editor.

Similar to the Journal case in general, my experience from academia helped to delve into the data easier than perhaps I would do in another context. Some of the components of the work-system for the Business Journal are in fact shared by most of us researchers to some extent. The environment component of the framework, "the organizational, cultural, competitive, technical, and regulatory environment within which the work system operates" (Alter 2008, p.456) is to some extent what we experience in our daily

\footnotetext{
${ }^{17}$ On this issue, I think the WSF see the technology as more of an artefact, a tool to be used. Compared with the system development life cycle, I feel that WSF is more open to the evolutionary aspects of organizational life, and that is one of the goals I had in mind while writing, to show how the system evolves by small iterations. However, I still feel that the definition and treatment of technologies is more limited than what ANT would call an actant. For WSF, the issue would be more of the use and the benefit of these tools for the work-system, similar to Delone and Mclean's IS Success Model (DeLone and Mclean 2003), whereas I, following a more broader perspective would also see how the technologies are bodies of inscriptions, that they are actants, that they are both a human creation and agents of change of human behaviour. Or, to follow my Straussian package's toolkit, these technologies can perform as boundary objects. Thus, Skype can be a way to communicate, or can be taken as a prescription to use as communication tool for problem solving, just as a review guideline can be a problem-framing device and a solution-providing device in peer-review sessions.

Another topic of interest is the materiality of these technologies. While Alter refers to sociomateriality in his texts, he often argues that WSF and sociomateriality can be linked to provide a better understanding of the IT-artefact. I haven't investigated these technologies or the IS in question from a sociomateriality perspective, but as if I claim that they can play the role of boundary object, and that they afford the users certain interpretations, then similar to Doolin and McLeod (2012), my view of these technologies would be a combination of a sociomaterial perspective with an analysis of boundary objects.
} 
life in the university setting. Thus it was easy for me to see how the environment of the Business Journal would be, and how the editors would most likely mention it. However, it was not necessarily always as clear-cut as that for some other aspects.

As mentioned in the paper, the editors use the University's resources to check the manuscripts for plagiarism. This was included in the infrastructure component of the work-system framework. However, the editors did not necessarily see the use of such university resources as problematic, but more as a taken for granted part of working. And there are at least two ways that this situation is interesting.

Directly related to the work-systems framework, the use of software such as Urkund and Grammarly are parts of the work processes for those of us in the university. For example, I am expected to send the master theses of my students through Urkund, as well as some of the project reports in the courses. This process however is tied to the university resources, and it is expected to be used for university purposes. However, the necessity to check for plagiarism in scholarly publishing is an important aspect, and thus a system to check for plagiarism is needed. Thus I can argue that use of Grammarly in the Journal is a part of the work-processes, with the manuscripts rejected in case of plagiarism. However, I would argue that in this case, the use of Grammarly is also a case of infrastructure, the accounts to provide access to the plagiarism checks were made available and managed by the universities that the editors were employed at. Thus, the process of checking for plagiarism was heavily dependent on the universities' willingness to provide these services - or willingness not to micro-manage the employees.

The other point of interest is related to issues raised in the earlier papers. While the use of such plagiarism checks can be counted as a process of our work-systems, we have also seen the editors' arguing that they haven't received the support they expected from their universities. Thus, we have seen the erosion of the salience of the University in the first paper. Similarly, I would argue that the need for publishing quality papers, free of plagiarism, is an important aspect of the social world of academia. In such a case where we see a strong push for quality in terms of plagiarism, the erosion of the University's standing in the eyes of the editors might have influenced their disregard for the rules for using these programs. Or, as Alf would comment, even though they might not get the official recognition, they might still see their work with the journal tightly intertwined with their positions at the university. In this scenario, it is not a disregard of the rules, but more of a generous interpretation of them.

Another peculiarity of the publishing business is the rather interesting situation of the "customer". While the need to adjust the strategy to the customers has been recognized (Alter 2008), the need for a clearer distinction of the concepts used has also been argued for (Alter 2013). And I also had to think about how to conceptualize the customer for the Business Journal. If I were to follow this customer centricity, I need to clearly identify the customer. Who is the customer of a Journal: the readers, the academic world? But then what is the readers' strategy? How can we realize that and cater for it? Or is it actually the authors that we need to keep in mind while deciding the strategy of the Journal? What about the strategy of the editorial board, or the editors within the board?

To the most extent, the strategy of the Journal was posed as the Journal's strategy, kept distinct from the editors' own aspirations. I have already mentioned how the commitments of the editors were different, and how some of them only see/begin to see 
the Journal as a career step in earlier papers/reflections. However, the Journal's strategy is to provide a quality outlet for the young researchers with a timely response and quick publishing process. Underlying this first line strategy is to create a stable ground to build upon and establish the Journal as a high quality output. This high quality is equated as inclusion to the various scholarly indexes, which can be achieved by following the rules and regulations of scholarly publishing - the environment.

In this regard, the work-systems framework allows for internal and external customers, and thus I was able to position the authors as participants - by providing the input, and re-working their paper according to the reviewers'/editors' comments - as well as internal customers, who benefit from the output of the Journal internally. However, I can not clearly pinpoint if the Journal's strategy was consciously created to cater to customers' needs. As I mentioned in the paper, the establishment of the Journal was triggered by a rather emotional response to their situations as junior researchers, thus the editorial boards perceptions of what is needed was heavily influenced by what they experienced.

However, what was clear was that IS choices have not been thought about in a strategic manner in the Business Journal, which to some extent provided the problems that resulted in my writing these papers. They were mostly small additions to the Business Journal's work system without explicit thinking about how it might further affect the work-system or what kinds of affordances it would bring. To the most extent the IS was a non-issue, and I would argue that - looking back - what the editorial team has done was to improvise while making IS decisions. Even though they took a more structured approach in the end and discussed how the system needs to fit work practices and/or will change work-practices, until that point the editors took a magic-bullet approach to the IS. This magic-bullet belief was what Markus and Benjamin (1997) cautioned about, and to some extent what prompted Alter (2003) to propose work-systems to replace IT artifact as the unit of analysis.

And this non-issue status of the IS affected the other parts of the work-system. We have seen an indication of that when the cloud adoption did not provide the results expected. The cloud system did not provide any significantly new ways of working, and thus necessitated no changes in the behavior of the participants. However, only through living through the experience, reflecting and negotiating the next step were the editors able to realize that the problem might stem from the participants, and that an IS change can not automatically solve their problems.

On another note, the customers of the systems were taken into account when selecting the management system, though I would argue this was not done in a strategic manner. The main customer centricity in the selection was ease of use, and a brief look into the various management systems will show that they are pretty much similar in how they look and behave. The ease of use for the participants was more heavily thought about but the financial constraints the journal had limited the collection, which can be also be linked to the longevity of the system - the editors were not able to use Scholar One, as they could not sustain a $\$ 3500$ bill every year. Though cheaper, other systems were also eliminated: for example Easy Chair, while a conference management system, can be used for the Journal, but any non-standard option would increase the cost - the system is geared towards conference management, not a continuous project like a Journal. And some systems seemed to be not widely used and could thus not be guaranteed to provide support in a few years, e.g. Express Academic Services from University of Missouri-Columbia. Similarly, as the editors themselves do not have the 
knowledge - or the willingness - to play with the system, any additional change to the system would add an extra burden, thus the OJS would be implemented as-is.

To sum up, this chapter provided a rich description of what happened in the Business Journal - from the editors' eyes - and has shown how several problems sprung up. These problems were mostly woven around the IS-related issues for the purposes of the thesis; however, they also contained pieces of underlying and interconnected issues. One issue was the problems connected with the IS (technology), which as the case has shown affected several parts of the work system. It affected how the participants worked (the processes), what kind of information was collected and disseminated (information). The problems of IS can be linked to the overall lack of strategy concerning IS (strategy), while a pressure to create a more streamlined management was felt both as a result of internal dynamics, as well as external pressures (environment).

One way that I summarized the work system while doing the analysis was to use the work-system snapshot (Alter 2013) format, as can be seen in Figure 3 in which the latest work-system of the Journal is depicted.

\begin{tabular}{|l|l|}
\hline \multicolumn{1}{|l|}{ Business Journal Work-system snapshot - Management system } \\
\hline Customers & Products/services \\
\hline Readers & Scientific publication \\
Authors \\
$\begin{array}{l}\text { Scientific index bodies } \\
\text { Universities }\end{array}$
\end{tabular}

\section{Figure 3. Business Journal Work System Snapshot}

The work-system snapshot is part of the methodology used by Alter, who defines it as "a formatted, one-page summary of the work system in terms of six elements of the work system framework: processes and activities, participants, information, 
technologies, products/services produced, and customers of the work system. Used for summarizing the "as-is" work system and the recommended "to-be" work system" (Alter 2013, p.83), and has been used by practitioners to discuss and design their work systems in organizations (Alter 2010). The other three components of the work-system framework are left out for the sake of simplicity, and often are discussed in more detail as the analysis of the work system goes. The snapshot is often used to provide a quick summary of the work system, and then used to identify the opportunities and problems.

\subsubsection{Reflecting on Business Journal}

After this detailing of the various components of the work-systems and which parts of the Business Journal's work-system coincides with them, perhaps I can provide some further reflections on Business Journal.

As someone who has thought - and enquired - about establishing his own journal while in a Masters programme, I should begin by saying I empathize with the editors. The frustration of not getting published, of not being supported while seeing (or more diplomatically, perceiving) others being supported is something that I think most of us have felt in one part of our careers. However, it is also rather interesting to see how the situation pans out in the end: what began as a response to the establishment becoming more entrenched in the norms and rules of academic publishing, is now an organization becoming more formalized the longer it survives.

To begin with the last issue, the formalization, it is curious that formalization is one of the organizational characteristics of the diffusion of innovation theory of Rogers (1983). The more formal the organization becomes, the harder it is for out-of-mainstream innovations to be adopted. The rather classical notion that as the organizations grow they tend to adopt more administratively oriented control approaches, involving higher degree of formalized roles and communication patters (Bruns and Waterhouse 1975; Merchant 1984) seems to hold for the Journal. As Merchant (1984, p.291) argues, the IS adoption pattern also reflects that formalization, that the organization uses "a more highly developed and formal budgeting system, with greater standardization of information flows and greater operating manager involvement". This formalization, however, should not only be taken as the organization becoming more hierarchical or bureaucratic - for example most organizations encourage team work - the formalization occurs along the lines of becoming in line with the norms and regulations of the environment (Drori and Meyer 2006; Ahrne and Brunsson 2006).

The more the Journal continues to operate, and the more editors sustain the goal of becoming a quality journal, I will also argue that this formalization will continue. This sounds rather familiar to the arguments raised in situated learning, where the learning occurs as a result of socialization and imitation, with the newcomers participating in simple tasks to become part of the community (Brown et al. 1989; Lave and Wenger 1991). It is through this participation that the Business Journal moved, from being an emotional response of the editors, to a legitimate part of scientific publishing community. While it might have been $O K$ for an editor to step in as a reviewer in the beginning, the further in the process of becoming a quality journal, such shift in roles becomes more unacceptable. While at the beginning it might be $O K$ to not have an ethics declaration, the further along the line it becomes more unacceptable - especially if we look at the increased discourse, at least in Sweden, dealing with academic misconduct after the Macchiarini case at Karolinska. 
Similarly, the existence of the Journal, and the editors' ambitions and the behaviors around - to establish a more streamlined management system, to look for a more formal front page of the Journal etc. - are also rather reminiscent of institutional work. As argued in literature (Suddaby and Greenwood 2005; Lawrence and Suddaby 2006; Suddaby 2010) the agency of the individual is important to understand how the institution is sustained. If we argue that the institution of scholarly publishing - with its values around scientific ethics, reliance on peer-review - is to be sustained, the individuals have to adhere to and uphold these values and processes. I have already talked about such issues when discussing the negotiated order papers, thus I won't discuss them further. However, I still think the case provides a nice example of how the existence of the Journal - whose legitimacy is based on the acceptance of the scientific community - along with many other journals and organizations legitimizes the already existing set-up. The issues of legitimacy is often linked with institutional theory, e.g. Meyer and Rowan (1977), DiMaggio and Powell (1983), however the fact that one adopts innovations for legitimacy purposes has also been long established in the adoption literature, e.g. Rogers (1983), where the more the innovation is adopted the more the pressure for non-adopters to adopt it grows, and the more the innovation is used, the more pervasive it becomes ${ }^{18}$. And how the initial idea of resistance to the system - we were not getting supported, we couldn't publish, we created the Journal to support young scholars - necessitated to play within the rules of the game: if the editors wanted to be taken as legitimate actors, they needed to act similar to the established journals.

Taking one step deeper into the case, we can also see the editors' institutional work (Lawrence and Suddaby 2006) sustaining the Journal's work system. By not adjusting their work processes while doing the cloud adoption, the editors continued to sustain the already institutionalized ways of working in the Journal. It took some time for the editors to realize that the work processes they had were becoming un-sustainable in the move towards a management system that will enforce new work processes in a more direct way. By reading the case through this lens, I can open up some points for further discussion of how work-systems framework can be further used:

A work-systems framework can be useful to highlight the macro institutional logics: we have seen how some issues - increased competition - resulted in a need for a more professional front for the Journal, as well as how the Journal tried to become indexed in several scientific indexes.

A work system framework can be useful to highlight the micro-institutional mechanisms - and how they interact with the macro logics: we have seen how during its journey, the Journal became more organized to succeed in achieving the accreditation by scientific indexes, how this organization created the necessity and paved a way - to some extent - for the adoption of a management system.

Throughout the Journal case story, I have moved from analyzing their stakeholders and their salience, how they changed over time, to investigating the various social worlds at play. I have conceptualized the adoption of the IS as negotiations among social worlds

\footnotetext{
${ }^{18}$ I have previously mentioned Engwall's $(1986,1992)$ work on the establishment of business schools, which I think provides another example of this legitimation process. The more external support these schools got for teaching the more resources they had for teaching, the more they taught, the wider their ideas could reach, and the more demand they would have for teaching. A similar account of university rankings can be discerned in Wedlin (2006).
} 
and tried to show how their differences played a role, and how the adoption process was also one of learning. I also attempted to merge some of the insights I have gained from these two streams to update the visualization of the stakeholder model. In the worksystem chapter, some of these issues were still visible for the readers to follow, even if studied under different terminology. And as can be seen, some aspects of can still be analyzed and used to highlight other issues. However, I think it is time to stop the Journal case, and jump to another case before finishing the paper section of the dissertation. 


\subsection{Paper 5 - Factors affecting IS adoption at Kitchen Co.}

\subsubsection{Introduction to Paper 5}

Background:

This paper deviates from the rest of the papers by looking at the second case, the Kitchen Co. The contact with the company was made a few years ago when I met the owner of the company before he established the company. He at the time was thinking of possible options for the company and how to run it and was interested in IS for his company. Thus we kept in contact throughout the years and in the paper I investigate the case by using the TOE framework.

Placement in the thesis:

Once again adopting a case study design, the paper follows another case than the rest of the papers, so in some sense it provides a totally different story. However, by using different terminology and trying to identify the various factors that affected the IS adoption in Kitchen Co the paper continues on several themes from the other papers why a small organization adopted their IS solutions, and how these factors affected the adoption. The Kitchen Co case provides an IS adoption from a developing country, thus provides breadth to the thesis when coupled with Business Journal, an international undertaking built on voluntary work in developed countries. Similarly, adoption of the TOE framework - widely used for IS adoption - makes some of the insight from the case more easily contrastable to the wider IS adoption literature, broadening the immediate audience of the dissertation.

Conclusions:

The results of the case study, to most extent, reflects what earlier research using TOE has argued for. However, the results diverge in certain aspects: competitive pressures seem to not influence the adoption process, unlike how they are argued to be influential in IS adoptions. This to some extent might be related to the size and the fact that the organization is still young. The case has also shown that the IS adoptions are influenced by social norms, which in the case have influenced the decision to adopt a nonintegrated system. The case also shows that such non-integration might be used as a tool for control.

Implications:

One implication from this research is that the environmental context matters. By showing how the possible benefits of integration and transparency do not suit the environment, the paper reveals that some norms that drive IS adoptions might be paradoxical in different environmental settings. Coupled with how factors that affect IS adoption can work in tandem and form new factors, this suggests that more qualitative investigations from diverse environmental settings can provide important nuances to IS adoption literature.

Originally published as:

Imre, Ö., 2016. Adopting Information Systems in a Small Company: A Longitudinal Study. Journal of Applied Economics and Business Research, 6:4, 269-283. 


\title{
4.5.2 Adopting Information Systems in a Small Company: A Longitudinal study
}

\section{Adopting Information Systems in a Small Company: A Longitudinal Study}

Özgün Imre, Linköpings Universitet, ozgun.imre@liu.se

\begin{abstract}
For some time there has been an increase in adoption of enterprise systems by small companies. With well-documented potential benefits, there are a lot of reasons to adopt them. In this study however the choice to adopt smaller pieces of information systems by a small organization is investigated to provide a counter example to the integratedsolution literature. With the intention to adopt an enterprise system at the beginning, the case provides a dynamic story of a small organization and how various factors impacted on the intention and resulted in an assemblage of information systems instead. By adoption the technology-organisation-environment framework and a single case study design, the case indicates that in addition to the oft-cited factors such as organisational size and IT readiness, social norms and the characteristics of a central individual, such as the owner, play a prominent role in information systems adoption, and highlights how these factors are connected to each other.
\end{abstract}

\section{Introduction}

For some time, it has been argued that small and medium-sized enterprises (SMEs) can use information technologies (IT) as a tool for competitive advantage. One development in this area is the adoption of enterprise systems - such as enterprise resource planning (ERP) systems - by the SMEs. Once a domain of large enterprises, today enterprise systems are used by SMEs as well. This move to some extent has been the result of saturation of the large-enterprise market, as well as the changing technology that enabled the vendors to offer solutions to SMEs.

The ERP systems literature argues that there are various benefits for adopting such systems: cost reduction, productivity improvement, quality improvement, customer service improvement, better resource management, improved decision-making and planning, and organizational empowerment (Shang \& Seddon 2000). Based on these benefits (e.g. Karimi, Somers, and Bhattacherjee 2007; Morton and $\mathrm{Hu} 2008$; Uwizeyemungu and Raymond 2012) it might be expected that many organization adopted an ERP-like information system? However, many organizations do not adopt ERP-like systems. Then the question arises: why do not some organization adopt such systems?

In this paper, the decisions of a small organization regarding their information systems (IS) choices to adopt small off-the-shelf ISs are investigated. By focusing on identifying which factors influence IS adoption in a small organisation context and how they interact with each other, this paper aims to answer the research question "how does a small organization adopt an IS?" 
A small company is chosen for this study for several reasons: while the ERP literature began to include SMEs, the differences between small- and medium-sized companies are often missing (Laukkanen et al. 2007; Iskanius et al. 2009). By focusing only on a small company then the study would add to the literature by providing a perspective to balance out the medium-sized enterprise perspective. Similarly, by focusing on a small company, the study would also reveal how the often taken for granted assumptions that govern SMEs in general - resource deficiency, short-term focus ${ }^{19}$ - play in IS adoption. Thus the main objective of this study is to contribute to the information systems adoption literature by studying a small business' IS adoption process.

As noted by Jha and Bose (2016), IS adoption studies often assume a European or American setting, and do not assume a longitudinal perspective. This skewed representation means that social and behavioural differences in other settings are not investigated, thus eroding the generalizability of the findings of research outside the specific geographies of developed countries. The case for this paper, Kitchen Co., is a manufacturing company in South America that builds kitchens for both private individuals - more of a bespoke design - and supplies kitchens for housing projects. The study adopts the technology-organization-environment framework (TOE) (DePietro et al. 1990). With its explicit emphasis on environmental context, TOE provides a useful lens to analyse a non- American or Europe setting. .

The case provides a glimpse of interrelated IS decisions: the owner of the company had experience with ERP systems before setting the company up and had the intention to use one. However 4 years down the road, the company has no ERP system in the pipeline, even though recent talks with the owner revealed that the idea of adopting an ERP system is still in his vision of the company. The company, on the other hand adopted smaller standard-off-the-shelf systems to create their IS. The adoption of IS that helps in running the company during these 4 years still has to satisfy various stakeholders and play various roles within the organization. The case has been followed over this time and such a longitudinal view and similar to Cho and Mathiassen (2007) and Kietzmann (2008) contributes by exploring the stages that the organization has passed in adopting.

After this introduction the next sections provides a brief literature review on ERP adoption and discusses the theoretical framework. The research approach is detailed next, followed by the case description and analysis, with the paper closing with a discussion and conclusions.

\section{Enterprise systems in SMEs}

ERP systems have originally been geared towards large enterprises, and have been associated with various benefits over the years (Davenport 1998; Shang \& Seddon 2000; Yusuf et al. 2004; Uwizeyemungu \& Raymond 2012; Nwankpa 2015). However in recent years, as Sedara (2009) argues, the market became saturated and the vendors shifted their focus towards SMEs, and as a result -the ERP literature began to include SMEs (Laukkanen et al. 2007; Iskanius et al. 2009).

\footnotetext{
${ }^{19}$ As Zammuto et al. (2007, 752) argues, a resource-poor organisation might have a different experience than a leading edge manufacturing organisation. However, as research on born -global organisations shows resource-constrained organisations can still leverage their capabilities and achieve success, e.g. by using network relationships (Sullivan Mort \& Weerawardena 2006).
} 
Similar to large organisations, the strategic value of ERP systems have been investigated for SMEs, and Yen and Sheu (2004) argues that they are as strategic for SMEs. Buonanno et al. (2005) claims that structural and organizational reasons were cited as the main reasons for not adopting an ERP system among SMEs - not financial ones as assumed in the previous literature. Similarly Federici (2009) has cautioned against considering an SME-ERP implementation as a scaled down implementation. ERP systems' potential benefits often arise from efficiency and legitimacy gains (Son \& Benbasat 2007), and it has been argued that SMEs can level the playing field against large enterprises by employing enterprise systems (Awa et al. 2016), and use them for competitive advantage (Koh \& Simpson 2007).

However, achieving these benefits is not straightforward. Peculiarities of SMEs - e.g. family owned, single person owned, tight budgets - might necessitate further research to evaluate how SME setting impacts ERP implementations. The literature documented the impact of several organizational and context factors on SMEs information system preferences. For example Federici (2009) found that some factors such as size were not significant, however SMEs preferred local ERP companies. Cereola, Wier, and Norman (2012) identified importance of top management support. Buonanno et al.'s (2005) study showed that organizational complexity is not a significant factor in SME ERP adoptions.

\section{Technology-Organization-Environment (TOE) framework and IS adoption}

There are a myriad of ways to explain how and why an IS is adopted. There are some specific theories that directly address the issue - such as technology acceptance model (TAM) (Davis 1989) unified theory of acceptance and use of technology (Venkatesh et al. 2003), diffusion of innovations (DOI) (Rogers 1983) and TOE (DePietro et al. 1990) which this study adopts.

In this paper the TOE framework is adopted. The TOE framework is a widely used IS adoption frameworks that has empirical support and has been used in various IS adoption decisions. It has been claimed as a generic IS adoption/diffusion theory that only suggests different sources of influence without specifying variables of each (Zhu \& Kraemer 2005).

In TOE framework, decisions are influenced by three contexts ${ }^{20}$. Organisational context denotes descriptive measures about the organizational characteristics such as top management support, size, organizational readiness and employees' IT expertise (Awa et al. 2015; Jeyaraj et al. 2006; Zhu \& Kraemer 2005; Iacovou et al. 1995; DePietro et al. 1990). Technological context refers to existing technologies in use and new technologies relevant to the firm. In this context research has shown that characteristics such as complexity, compatibility, relative advantage, ease of use, IT infrastructure play a role in the decision to adopt IS. (Rogers 1983; DePietro et al. 1990; Jeyaraj et al. 2006; Oliveira \& Martins 2011; Oliveira \& Martins 2010).

Environmental context on the other hand refers to the arena in which the firm conducts its business - its industry, competitors, and dealings with the government. While the technology and organization contexts of TOE closely follow the characteristics investigated in DOI of Rogers (1983), this environmental context adds extra explanatory power to the TOE framework (Hsu et al. 2006). Research has focused on

20 See Jha and Bose (2016), Oliveira and Martins (2011) and Jeyaraj, Rottman, and Lacity (2006) for a review of the constructs within these contexts. 
how government regulations, competitive pressures supplier support impact on IS decisions. (DePietro et al. 1990; Zhu \& Kraemer 2005; Jeyaraj et al. 2006; Oliveira \& Martins 2011; Alshamaila et al. 2013; Awa et al. 2015).

While TOE has been recognized as a versatile tool of inquiry, one criticism against it has been raised by Thong (1999) that it might not be the most suitable to be used in small organisations. Claiming that in small organizations the CEO is the owner/manager of the organization and has a role in determining the innovativeness of the organization, Thong (1999) has argued that CEO characteristics should be considered as a fourth context in TOE framework, and were found significant (Jeon et al. 2006; Shiau et al. 2009). In most IS adoption literature however, Thong's (1999) CEO characteristics is missing even though there is a strong emphasis on the effect of size and top management support in the organizational context.

Several reviews (Jha \& Bose 2016; Oliveira \& Martins 2011; Jeyaraj et al. 2006) highlight the predominance of quantitative methods in IS adoption research, which might be one of the reasons why similar constructs have been validated as significant in IS adoptions. However TOE has been adopted in qualitative research that also seems to validate the same constructs (e.g. Alshamaila, Papagiannidis, and Li 2013; Bradford, Earp, and Grabski 2014).

Also, as Jha and Bose (2016) argues, there is a lack of non-American and European adoption research. Adopting TOE, with its emphasis on environment, would highlight how a South American setting would effect the IS adoption. Similarly, they argue that there is a technological determinism in some theories used within the field. As TOE doesn't assume prevalence of any contexts, it can help in providing a more balanced understanding of IS adoptions when compared with other frameworks.

While Thong (1999) has argued adaptation to the TOE model, the model he proposed did not account for the interaction between the different contexts - even though he cautioned that indirect effects might occur. In this paper, the TOE framework is adapted to include the insight from Thong (1999), with the most commonly cited factors are included in their respective contexts - Technology, organization, environment and CEO - provided in figure 1. The mentioned reviews highlight a tilt towards positivistic philosophy in IS adoption research. In this study, the TOE framework is used as a sensitizing device ${ }^{21}$ to analyse the case and highlight how the building blocks of the TOE framework impact the IS adoption and use. By using TOE framework in such a way, the case material then can be used to reveal some other building blocks and linkages among them that might be overlooked due to the design of previous studies, which mostly accounted for direct impact of the factors whereas leaving interaction among factors unattended.

\footnotetext{
21 In his work, Blumer $(1954,7)$ uses the terms definitive- and sensitizing concepts, with the definitive concept defined as "refers precisely to what is common to a class of objects, by the aid of a clear definition in terms of attributes or fixed bench marks".
} 


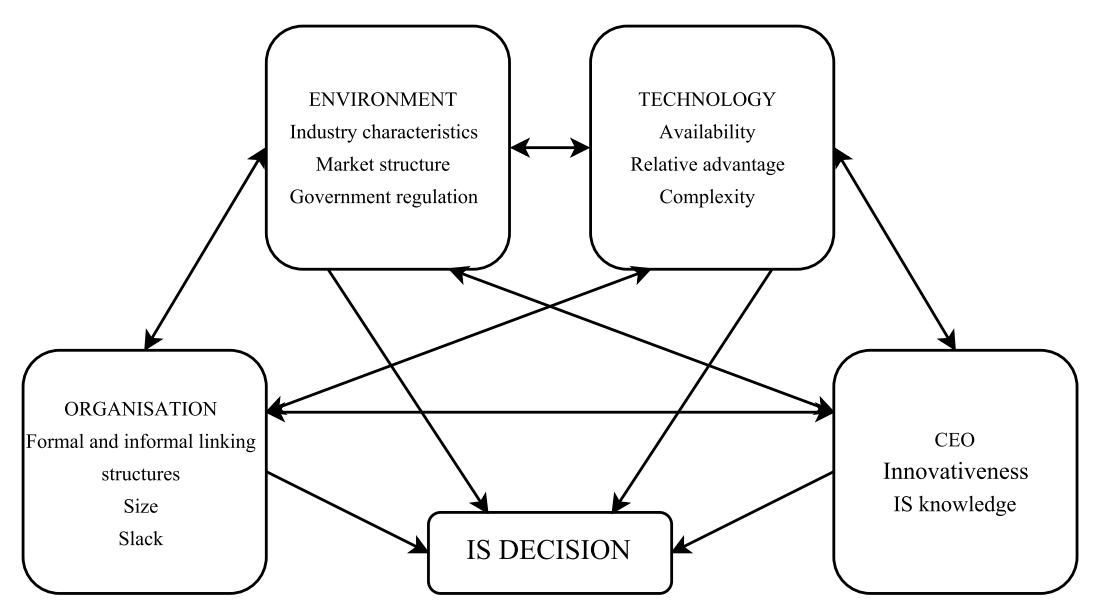

Figure 1. The adapted TOE framework (adapted from DePietro, Wiarda, and Fleischer (1990) and Thong (1999))

\section{Setting and approach}

In this study a qualitative and interpretative single case study design was adopted (Walsham 2006; Eisenhardt 1989; Benbasat et al. 1987). A single case study design was selected for this research, as the contact with the owner of the case organization about various issues was kept from late 2012 to early 2016, providing longitudinal aspects that make a single case study design appropriate (Yin 2009). As Siggelkow (2007) and Flyvbjerg (2006) argues adopting such a design can be valuable to highlight dynamic processes by getting closer to the constructs under study which might be harder with large-sample empirical works.

The study is further informed by the principles laid out by Klein and Myers (1999). During the time period that the author kept in contact with the owner of Kitchen Co. there were instances that changed the understanding of both parties. The author's research project was about integrated systems, e.g. ERP systems, and Hugo, the owner of Kitchen Co was undergoing SAP training. This mutual interest resulted in discussions around why an ERP system can be useful for a company, what kind of options there might be for a start-up. This instance is akin to Klein and Myers' (1999) idea that facts are produced with the interaction among the researcher and the participants. This stance was later adapted as Kitchen Co. was established and no ERP decisions were made, resulting in the "research project" with Kitchen Co to cool down. However, as time went by, the choices made in Kitchen Co to adopt smaller systems became interesting phenomena, an option to highlight an alternative of an assemblage of systems in contrast to a fully integrated system such as an ERP. Thus the passage of time and addition of new data has changed the perspective of the researcher, which might fit with Klein and Myers' (1999) ideas of iterative thinking.

Data gathering has been done in semi-structured interviews. The author has met Hugo, the owner of Kitchen Co., in Sweden, so the first few instances of interaction was on a 
face-to-face basis. Later contact was kept via video conferencing tools - Skype and Facetime - and was later broadened to include 2 members from the engineering team, the accountant, and an external consultant. Notes were taken during the interviews, and used as reference points when summarizing the interviews and examining the data.

\section{Kitchen Co.}

In this section, the case organization is presented, followed by three subsections corresponding to the three contexts of TOE framework used to analyse the IS adoption decisions within the case company. During the analysis the CEO (Hugo) emerged as a central figure. To highlight this predominance of CEO and show how interconnected these contexts are, the fourth context, CEO characteristics, is used in these three subsections rather than presented as a fourth context.

\section{Initial Contact with Kitchen Co.}

The case company for this study is situated in South America. Kitchen Co., designs manufactures and installs kitchen, though their projects so far has mainly focused on the capital and surrounding cities. Their projects have ranged from bespoke kitchens to providing kitchens for housing projects.

The first contact with Kitchen Co was made before it was officially established. The owner of Kitchen Co, Hugo, was a master student that took a course on ERP systems from the division where the author is employed, and through a mutual friend was introduced in 2012. At that time Hugo was thinking of establishing a company in Sweden, but decided to return to his home country, and established a company for digging wells for water provision, Water Co. Two years later that company was sold and Kitchen Co was established.

Before establishing Water Co. Hugo has attended an industry conference in Germany, which SAP, a major ERP vendor, was a sponsor. Coupled with the ERP course he was taking in Sweden, this industry conference resulted in an initial idea of using an ERP or ERP-like - system for his future company. However, neither in Water Co., nor in Kitchen Co. such a system is used, thus providing a story that highlights the contrast between initial ideas and the actual organization.

\section{Organisation}

Kitchen Co. is a small organization, employing less than 30 people. Most of the employed people work in the workshop to create the kitchens - fashioning the cupboards, cutting the kitchen top etc. - and then going to the project sites to install these kitchens. Most of the production is manual, due to the capital costs involved with automated machinery. The workers receive the blueprints that are designed by a CAD tool used by the engineers and manufacture the kitchen according to the specific requirements from the blueprint. After the parts are manufactured they are checked against the requirements list provided in the blueprint, and they are checked once again during the installation.

The CAD is used to create the list of requirements of the projects, and the list is printed out as an Excel file, which is then put into an inventory management software. This job is mostly done automatically, however an administrative assistant first manually has to edit the Excel file and check that the requirement list and the inventory list are the same 
after the file is fed to the inventory system. Hugo has done that task along with the engineers from time to time to ascertain that the lists are the same. Such close contact with the data allows Hugo and the engineers to have a feeling about how the company is doing by keeping track of the projects and people involved with the projects.

Hugo has a small team of engineers that design the kitchens and also work as a sales team. Hugo himself has a background in industrial engineering and manufacturing management, thus has experience from both the engineering and management perspective to help with the daily run of the business. He takes an active role in running the company and spends time both at the office and the workshop. The first housing project they have received was due to his personal involvement and using his network, and in his words "being there at the right time". As the sole owner he has the official power to make decisions, and is mostly involved with the day-to-day running of the company.

Hugo is coming from an entrepreneurial family, and has used some of the resources available from having such connections in both Water Co. and Kitchen Co. One main resource is the accountant, who also takes care of the family owned Rice Co. Jose works part time with Kitchen Co as he has more responsibilities with the Rice Co., and was influential in the accounting software selection, the same that they use in Rice Co. Hugo handles the issues related to human resources himself, and the costs and expenses are reported to the accountant by using simple Excel sheets accompanied with the receipts and order forms, and the accountant has not raised any difficulties in deciphering such documentation.

There is an understanding that a close integration within IS can help to reduce some of the costs and help streamline the manufacturing process. The inventory management system can use barcodes to read the data and keep track of the stocks, which was identified as a future option. However, as of yet Kitchen Co. hasn't felt a need to use barcodes to keep track of inventory and merchandise due to relatively low volumes of production and consistent communication with suppliers. Such a gap, as Hugo admits makes the work a bit tedious. However, it has also provided him an opportunity to check on the actual status of the stocks, as well as having a grasp of what is going on with the company. By managing the payrolls individually he is better able to realize who is working on which days and compare it with the projects they are assigned. He argues that it is provides a more personal feeling when talking with the workers rather than relying on a fully integrated system.

At this moment, a fully integrated system is not fully realizable. The company still operates on short-to-medium term survival and doesn't have the financial resources for an ERP system. When the option of an open source ERP as an alternative was raised by the author, Hugo commented that they don't have the in-house IT knowledge to operate the system so it wouldn't be "free anyway". The workers at the workshop are not trained to use a computer system to assist them in their work - which still relies on manual work processes. As a result, the engineering team and Hugo have a closer interaction with the workshop, visiting them regularly to see the progress of the projects in person. The existing communication channels - sending the blueprints, the list of requirements, calling the foreman among others - are not deemed as problematic even though it not an integrated solution. However respondents suggested that as long as no problem occurs - or they grow exponentially - there is little advantage to complicate the work-system by changing the IS set up. 


\section{Technology}

As already mentioned, there are several systems that are in use at Kitchen Co. This is a deviation from the ERP-like system idea Hugo had at the beginning. While there are various ERP systems that will serve most of their needs, Hugo has decided against such a system.

The engineering team uses a CAD software to design the kitchens and plan the production with the system. It also keeps track of the required material that is needed to produce the kitchen. For standard kitchens, the system derives the materials requirements automatically. For more specialized products, the engineers manually input some of the requirements to the list in the software. One person in the engineering team was familiar with the system from a previous job and has recommended to the team, and the software was adopted rather quickly. There are modules that can be used to integrate such CAD software to an ERP system, however the interviews suggest that at this moment such integration is not needed.

A free inventory management system is used by Kitchen Co. Using a free software has helped in reducing the costs, especially at the kick-off stage of the Kitchen Co. Hugo wanted to have a versatile system to cover any future growth, and decided that keeping everything in an Excel sheet will not work in the long run. One chief reason for choosing the system was that it was created for small and medium-sized organizations, and was easy to set up. The system also offers easy upgrade options if the in-built options do not support the organization, while necessitating minimal support from the vendor, highlighting issues of complexity as well as external support.

One overarching issue in IS selections was the need to be able to operate in Spanish, and being able to work with the country regulations. While the engineering team has English language skills, for any other personnel the IS needs to be in Spanish. Similar to this constraint, issues related to the tax system was the main reason why the accountant's idea to use the familiar accounting system was accepted. Whereas other options were also investigated - such as QuickBooks, which Hugo wanted - they were discarded due to incompatibility with the tax system, and language issues. Whereas the accounting system used does not have modern tools - e.g. cloud applications and being able to generate quotes and invoices from a smart phone - the accountant's experience in using the system has offset some of these issues. Hugo's experience with such mobile apps was broadened while studying in Sweden and he encountered various payment systems. He remembers using applications like Swish and iZettle, and he argues that while he would like to use such applications, they are not widely spread in South America. As most of the customers and suppliers would not use these systems, they will not be able to use these applications with full potential..

Having an education and experience of using such systems in Sweden also provides another point of contrast. Hugo recalls the wide use of mobile internet, and expecting to have wireless connection is most public places in Sweden, However in his country, such technologies can still be problematic. This became apparent while having a Skype interview with the author, which had to be postponed twice due to low quality of internet connection. Such failures in connection makes on-spot quote calculations more difficult. However the sales team is comfortable with using their laptops and giving rough estimates on the spot, and more firm quotes within a few days of initial contact with potential customers. Such a time gap also allows them to discuss what can be 
offered to the customer rather than relying on set-rules written to the system. Rules such as a discount to a returning or premium customer could be decided together before putting into the system. However having a discussion on what the project entails and then deciding upon a cost projection and preparing an offer for the customer - with Hugo and a project responsible from the workshop - seems to be a workable solution for Kitchen Co.

\section{Environment}

In previous studies, one major part of the environmental context was the external threat and the adoption of the innovation by the competitors. In Kitchen Co. the respondents did not provide any indication that the competitors' choice was influential in selection of IS. As already mentioned, the CAD software was suggested by an engineering team member which can indicate that the software is used by others. Similarly the accounting software is suggested by a senior accountant, demonstrating that already existent software are used without much change in new organizations.

As Kitchen Co. is still a small company, Hugo is able to manage the company with the limited IS tools adopted. As mentioned Hugo had the idea to adopt an ERP system early on, however that is not realized yet. In the recent years ERP vendors have shifted some of their services to cloud, and began to offer "reasonably priced" packages. While the external consultant and Hugo seem to be enthusiastic about the idea, they are not sure as not having the right infrastructure can cause problems. Though there is a trend for increasing speed, South American countries lack the internet speed found in North America or Western Europe (Akamai Technologies 2016). This necessitates IS that can work without [stable] internet connection, thus eliminating some of the cloud options that can be adapted to the existing IS in Kitchen Co. Such lack of stable connection necessitated, as mentioned, an interview with the researcher to be postponed twice, and around that period, Kitchen Co. was not able to order supplies as they usually do, but had to phone their suppliers. Similar to the infrastructure problems, all the ISs that have been supplied from the vendors that Kitchen Co. is able to access with minimal effort. This coupled with the familiarity of the employees with the systems used before Kitchen Co. highlights the importance of external support and employees' experience.

Another environmental factor was hinted at previously, being at the right place at the right time. Hugo argues that compared with his experiences in Sweden, USA and Germany, in his country people are more willing to work with personal contacts and back-of-the-envelope calculations. Having an ERP-type system where everything is connected and adheres to a set of rules can be problematic. Kitchen Co. has customers that prefer to use back-of-the-envelope type calculations from time to time. As all respondents have argued, there is a tendency to use paper invoices and paying with cash in the country, thus having such a tightly integrated system might become problematic. Such norms and transactions were contrasted heavily by Hugo, who remarked how in Sweden every cashier was directly connected to Skatteverket, the Swedish Tax Agency.

In Kitchen Co. none of the informants argued that their choices are influenced by competitive pressure. This is counter to most of the literature where competitive pressure plays a significant role. Hugo argued that they are not in a stage where they are "that concerned" about competition, but are trying to survive on short and middle term. Similar arguments were raised by others, however one issue of interest is the choice of the CAD. As two of the engineers have argued they have used the system in their 
education - and one worked with it - there might be elements of normative pressures in this choice. When asked about their knowledge about competitors that might be using an ERP system, while there were no definite answers, there was a basic understanding that similar organisations are not using one whereas bigger organizations might have ERPs.

\section{Discussion}

This paper has the aim of investigating how a small organization adopted ISs, and has employed the TOE framework to identify the factors that affect the adoption. In this part of the paper how these factors worked in tandem to afford and impede some IS choices for Kitchen Co.

Hugo, as the owner of Kitchen Co. has proven to be a central figure in decisions regarding IS adoption in Kitchen Co, similar to Thong (1999). Having education in ERP systems, he has expressly argued for an ERP system and has thought about a cloud-ERP option. However this was countered by organizational realities such as constrained financial resources and non-existing in-house IT capabilities needed for an ERP implementation. In this clash of CEO vs organizational context, several members of the organization has countered Hugo's ideas and was able to influence him to their chosen IS systems. Whereas the idea of an ERP was more predominant in the early talks with Hugo, after Kitchen Co. was set up and production began the prevalence of the idea of an ERP system diminished. To most extent this can be characterised as a result of low need-pull within the organisation: the current set up of the system seems to satisfy the organisational needs, thus the perception of a lower relative advantage of an ERP system. This satisficing is similar to what Teece, Pisano, and Shuen (1997) and Bensaou and Earl (1997) discuss as a Japanese style approach to IT management.

Also of notice is the use of Hugo's network to to secure services of the accountant and external consultant, once again highlighting the importance of CEO's capabilities. This need and ability of the CEO to network is well recognised (Kotter 1982), however in the reviewed TOE-based literature that ability of the CEO is not highlighted. In Kitchen Co. the external consultant was identified by Hugo while studying in Sweden, whereas some of the customers were found when he was attending various expos in Bolivia. Just as attending an SAP sponsored expo has affected Hugo's ideas, the networks that the $\mathrm{CEO}$ is a part of should be considered more thoroughly.

The ISs that were adopted in Kitchen Co. have also shown the importance of compatibility. While some parts of the work-system needs manual assistance, the chosen IS systems complement each other. The inventory management system provides the actual stocks the warehouse has, whereas CAD is used to plan the manufacturing of the kitchens. The blueprints produced by CAD is used at the work-shop to manufacture the kitchen as well as used to check the inventory. An administrative assistant - as well as the engineers and Hugo from time to time - manually check the systems are working well, and transfer the reports created to the accounting software. This rather basic set up, while lacking the potential benefits offered by ERP systems - automation, standardization - allows Hugo to keep track of the company with ease. This is similar to what Orlikowski and Hofman (1997) suggested, that such issues can result in improvisation and can be turned into advantages. Diverging from the ERP idea that Hugo had - that implied automation and meetings to check the progress of projects the current set up necessitates him and the engineers to work closely with the shop 
floor. This bridges the "division of labour" by having both planned and unplanned meetings to discuss the issue. The current set up has thus spurned a more "flat" hierarchy.

Of notice is the effect of technological capabilities provided by the standard IS systems. These systems are standard solutions that have more or less compatibility to work with other systems inscribed to them (CAD can read an Excel sheet with some minor modifications as input for inventory). This allows organizations to assemble them to a work-system bypassing the problems related to non-compatible legacy systems.

Similarly, the chosen IS are not complex, a technology factor. However, this noncomplexity factor is tightly coupled with organizational resources and readiness, as well as environmental factors. QuickBooks, which Hugo was thinking of for accounting purposes, was discarded for Accounts, a system that the accountant has been using for some years. They are of similar complexity in their set-up, however, Accounts is already adapted for the Bolivian regulations, and has readily available support ${ }^{22}$.

These factors have already been validated in other contexts as mentioned before. However, in Kitchen Co. the competitive pressure was not a factor that was taken up by any of the informants, which is against most of the literature, as well as for SME-IS adoption (Hoti 2015). The interviewed people argued that they are on "survival mode" and thus competition's decisions are not taken into consideration for IS choices. A similar non-significance was found in Kuan and Chau (2001) for EDI adoption in small organisations in Hong Kong, Jeon, Han, and Lee (2006) for e-business adoption in South Korean SMEs, Alshamaila, Papagiannidis, and Li (2013) for cloud system adoption in small organizations in South England. The existence of non-significance from different environmental setting for different IS can be interpreted in different ways. One way is to argue that small (and medium) sized enterprises are more prone to be affected by internal pressures. However this interpretation can be problematic: as evidenced by the mentioned reviews, competitive pressure is often significant. As the sources that argued that competitive pressure is a non-significant factor follow either a large-sample survey-based approach or a multiple case study design, they do not problemise why the factor was not significant, but only take it as a finding. In Kitchen Co. however, while competitive pressures were not cited, there may have been a normative pressure that stemmed from the educational and professional background of engineers. This might mean that how the factor is defined in previous research might lead to omissions. In this way, adopting a single case study was useful to identify such a divergence by being able to have possibility to ask the respondents what "doing business" means. After several iterations it became clear that these norms of "back-ofthe-envelope calculations" were not Kitchen Co. specific, but rather social norms, that were not talked of as part of the "competitive pressure" discourse, but more as a taken for granted part of "doing business".

Another interesting - and related - finding are the social norms that seem to be at play. While previous research has identified government regulations/support can be an important factor, "norms" have often been termed as "subjective norms" drawing from theory of planned behaviour (Ajzen 1991). These were used as an organizational factor. Rather than this type of treatment of norms, in Kitchen Co. social norms of dealing with

22 As addressed in community support pages (Intuit 2016), QuickBooks might be missing some modules in international version of its products. 
customers and suppliers informally played a role that resulted in the organization shying away from a fully-integrated system. Such a decision might result in loss of efficiency in the long term, however it also allows the organization to be flexible in conducting business. This is similar to the Peter Pan syndrome (The Economist 2014) where organization choose to stay small in spite of benefits of growing. This is another example of how the gaps within the system can be turned into a strategic tool. While there are opportunity costs associated with the non-integrated systems, for short-term survival an integrated solution might not be an option.

\section{Conclusion}

This paper began with the aim of investigating a small manufacturing organization in South America. The intention behind was to identify the factors relevant to IS adoption by adopting the TOE framework, and highlight how they interact with each other to affect the IS decisions within the organization.

Similar to previous research, the main factors that were important in this case were related to CEO's knowledge and attitude towards IS, organizational readiness, prior IT experience, top management support, size, IT infrastructure, compatibility, non complexity, interpersonal relations. Contrary to most of the existing research, competitive pressure was not significantly pertinent to Kitchen Co.'s IS decisions. This might be a result of the short-term survival focus of the organization which might lead to an internal focus rather than external.

Another interesting finding was the role played by social norms, that showed that having a non-integrated system might lead to improvisation (Orlikowski \& Hofman 1997) that might be more beneficial in the short-run. While an ERP type system might bring efficiency, in Kitchen Co. the points where the ISs that do not integrate have been used are firstly to have insight/control over the organization and secondly to provide flexibility when handling customers and suppliers. The transparency, standardisation and high integration of an ERP system would erode the ability of Kitchen Co. to adapt their transactions to the specific situations at hand. By adopting an affordance lens (Zammuto et al. 2007; Leonardi 2011) future research can compare the affordances provided by an ERP and a set up similar to what Kitchen Co. has and provide a more nuanced understanding of the IS decisions.

There are several venues for future research based on these findings. This study has attempted to answer the calls for IS adoption research from non- American and European settings (Jha \& Bose 2016) and provided a dynamic story that showed how organizational and individual factors can affect each other. The study relied on a single case study design with Skype conference as communication method in this attempt. A more ethnography based research design would be able to bring the dynamic elements, as well as how other elements related to the specific setting - Bolivia, relatively young work-force, manufacturing industry, etc. - to the forefront by providing an in situ narrative.

Related to the choice of method, as mentioned previously most IS adoption research has adopted more or less positivistic philosophies. However, the finding of this research that social norms play an important role has not necessarily been taken up by researchers unless they follow institutional theory. As indicated in the discussion part, the competitive pressure was not relevant for this case whereas social norms played an 
important role. However, this might be a case of different factors affecting each other indirectly. By adopting TOE as a sensitizing device and using it in qualitative case studies - especially in light of how quickly the IS and organizations are changing - can help in identifying new factors as well as defining the existing factors. Whereas this research is a single case study and the investment process it depicts should not be generalized, it suggests factors that can be important also in other cases, and that other cases could reveal yet other factors of importance. The similarities of previous research might be a result of using existing definitions with established methods, calling for a different use of TOE than a strict set of predefined and exhaustive factors.

A final venue for future research is to compare the adoption of older systems with new systems. As argued, in this case the ISs had built in compatibility to some extent, which made it possible for Kitchen Co. to have an assemblage of systems rather than an integrated one. The strategic consequences of these new technologies and how they create new affordances contra old school integrated system can provide insight for would be adopters to realize their organizational goals.

\section{References}

Ajzen, Icek. 1991. "The Theory of Planned Behavior." Orgnizational Behavior and Human Decision Processes 50: 179-211. doi:10.1016/0749-5978(91)90020-T.

Akamai Technologies. 2016. "Akamai's State of the Internet." https://www.akamai.com/us/en/multimedia/documents/content/state-of-theinternet/q4-2015-state-of-the-internet-connectivity-report-us.pdf.

Alshamaila, Yazn, Savvas Papagiannidis, and Feng Li. 2013. "Cloud Computing Adoption by SMEs in the North East of England." Journal of Enterprise Information Management 26 (3): 250-75. doi:10.1108/17410391311325225.

Awa, Hart O., Ojiabo Ukoha, Bartholomew C. Emecheta, and Shaofeng Liu. 2016. "Using T-O-E Theoretical Framework to Study the Adoption of ERP Solution." Cogent Business \& Management 3 (1). Cogent: 1196571. doi:10.1080/23311975.2016.1196571.

Awa, Hart O, Ojiabo Ukoha Ojiabo, and Bartholomew Chinweuba Emecheta. 2015.

"Integrating TAM, TPB and TOE Frameworks and Expanding Their Characteristic Constructs for E-Commerce Adoption by SMEs.” Journal of Science and Technology Policy Management 6 (1): 76-94. doi:10.1108/JSTPM-04-2014-0012.

Benbasat, Izak, David K. Goldstein, and Melissa Mead. 1987. "The Case Research Strategy in Studies of Information Systems Case Research." MIS Quarterly 11 (3): 369-86. doi:10.2307/248684.

Bensaou, M, and Michael Earl. 1997. "The Right Mind-Set for Managing Information Technology.” JOUR. Harvard Business Review 76 (5): 118-28.

Bradford, Marianne, Julia B. Earp, and Severin Grabski. 2014. "Centralized End-to-End Identity and Access Management and ERP Systems: A Multi-Case Analysis Using the Technology Organization Environment Framework." International Journal of Accounting Information Systems 15 (2). Elsevier Inc.: 149-65. doi:10.1016/j.accinf.2014.01.003. 
Buonanno, G., P. Faverio, F. Pigni, A. Ravarini, D. Sciuto, and M. Tagliavini. 2005. "Factors Affecting ERP System Adoption: A Comparative Analysis Between SMEs and Large Companies." Journal of Enterprise Information Management 18 (4): 384-426. doi:10.1108/17410390510609572.

Cereola, Sandra J., Benson Wier, and Carolyn Strand Norman. 2012. "Impact of Top Management Team on Firm Performance in Small and Medium-Sized Enterprises Adopting Commercial Open-Source Enterprise Resource Planning.” Article. Behaviour \& Information Technology 31 (9). 4 PARK SQUARE, MILTON PARK, ABINGDON OX14 4RN, OXON, ENGLAND: TAYLOR \& FRANCIS LTD: 889-907. doi:10.1080/0144929X.2010.528029.

Cho, Sunyoung, and Lars Mathiassen. 2007. "The Role of Industry Infrastructure in Telehealth Innovations: A Multi-Level Analysis of a Telestroke Program." European Journal of Information Systems 16 (6): 738-50. doi:10.1057/palgrave.ejis.3000718.

Davenport, Thomas H. 1998. "Putting the Enterprise into the Enterprise System." Harvard Business Review 76 (4): 121-31. http://www.ncbi.nlm.nih.gov/pubmed/10181586.

Davis, F.D. 1989. "Perceived Usefulness, Perceived Ease of Use, and User Acceptance of." Information Technolog MIS Quarterly 13 (3): 319-340.

DePietro, Rocco, Edith Wiarda, and Mitchell Fleischer. 1990. "The Context for Change: Organization, Technology and Environment." In The Processes of Technological Innovation, edited by L. G. Tornatzky and M. Fleischer, 151-75. Lexington, MA: Lexington Books.

Eisenhardt, Kathleen M. 1989. "Building Theories from Case Study Research.” The Academy of Management Review 14 (4): 532-50.

Federici, Tommaso. 2009. "Factors Influencing ERP Outcomes in SMEs: A Postintroduction Assessment." Edited by Yogesh K. Dwivedi. Journal of Enterprise Information Management 22 (1/2): 81-98. doi:10.1108/17410390910922840.

Flyvbjerg, Bent. 2006. "Five Misunderstandings About Case-Study Research." Qualitative Inquiry 12 (2): 219-45. doi:10.1177/1077800405284363.

Hoti, Erind. 2015. "The Technological, Organizational and Environmental Framework of IS Innovation Adaption in Small and Medium Enterprises. Evidence from Research over the Last 10 Years." International Journal of Business and Management III (4): 1-14. doi:10.20472/BM.2015.3.4.001.

Hsu, Pei-Fang, Kenneth L Kraemer, and Debora Dunkle. 2006. "Determinants of EBusiness Use in U.S. Firms.” International Journal of Electronic Commerce 10 (4): 9-45. doi:10.2753/JEC1086-4415100401.

Iacovou, Charalambos L., Izak Benbasat, and Albert S. Dexter. 1995. "Electronic Data Interchange and Small Organizations: Adoption and Impact of Technology." MIS Quarterly 19 (4): 465-85. doi:10.2307/249629.

Intuit. 2016. "Hi, I'm Using a Trial Version of Global Quickbooks from Bolivia...” 
https://community.intuit.com/questions/1320858-hi-i-m-using-a-trial-version-ofglobal-quickbooks-from-bolivia-i-want-to-add-the-payroll-module-is-it-possible-iwant-to-pay-the-essential-subscription.

Iskanius, Paivi, Raija Halonen, and Matti Mottonen. 2009. "Experiences of ERP Use in Small Enterprises." In 11th International Conference on Enterprise Information Systems, Milan, Italy.

Jeon, Bang Nam, Kyeong Seok Han, and Myung Jin Lee. 2006. "Determining Factors for the Adoption of E-Business: The Case of SMEs in Korea." Applied Economics 38 (16): 1905-16. doi:10.1080/00036840500427262.

Jeyaraj, Anand, Joseph W. Rottman, and Mary C. Lacity. 2006. "A Review of the Predictors, Linkages, and Biases in IT Innovation Adoption Research." Journal of Information Technology 21 (1): 1-23. doi:10.1057/palgrave.jit.2000056.

Jha, Ashish Kumar, and Indranil Bose. 2016. "Innovation Research in Information Systems: A Commentary on Contemporary Trends and Issues.” Information \& Management 53 (3). Elsevier B.V.: 297-306. doi:10.1016/j.im.2015.10.007.

Karimi, Jahangir, Toni M Somers, and Anol Bhattacherjee. 2007. "The Role of Information Systems Resources in ERP Capability Building and Business Process Outcomes.” Article. Journal of Management Information Systems 24 (2): 221-60. doi:10.2753/MIS0742-1222240209.

Kietzmann, Jan. 2008. "Interactive Innovation of Technology for Mobile Work." European Journal of Information Systems 17 (3): 305-20. doi:10.1057/ejis.2008.18.

Klein, Heinz K., and Michael D. Myers. 1999. "A Set of Principles for Conducting and Evaluating Interpretive Field Studies in Information Systems.” MIS Quarterly 23 (1): 67-93. http://www.jstor.org/stable/10.2307/249410.

Koh, S.C. Lenny, and Mike Simpson. 2007. "Could Enterprise Resource Planning Create a Competitive Advantage for Small Businesses?” Benchmarking: An International Journal 14 (1): 59-76. doi:10.1108/14635770710730937.

Kotter, John P. 1982. "What Effective General Managers Really Do.” Harvard Business Review 60 (6): 156-67. ftp://87-104-13-156-dynamiccustomer.profibernet.dk/Qmultimedia/b\%C3\%B8ger/Arbejde/Generel ledelse og strategi/(Ebook Hbr) - Harvard Business School - Effective Managers.pdf.

Kuan, Kevin K Y, and Patrick Y K Chau. 2001. "A Perception-Based Model for EDI Adoption in Small Businesses Using a Technology-Organization-Environment Framework." Information and Management 38 (8): 507-21. doi:10.1016/S03787206(01)00073-8.

Laukkanen, Sanna, Sami Sarpola, and Petri Hallikainen. 2007. "Enterprise Size Matters: Objectives and Constraints of ERP Adoption." Article. Journal of Enterprise Information Management 20 (3): 319-34. doi:10.1108/17410390710740763.

Leonardi, Paul M. 2011. "When Flexible Routines Meet Flexible Technologies: Affordance, Constraint, and the Imbrication of Human and Material Agencies." 
MIS Quarterly 35 (1): 147-67. http://web.stanford.edu/group/WTO/cgibin/uploads/Leonardi 2011b.pdf.

Morton, Neil a., and Qing Hu. 2008. "Implications of the Fit between Organizational Structure and ERP: A Structural Contingency Theory Perspective." International Journal of Information Management 28 (5): 391-402.

doi:10.1016/j.ijinfomgt.2008.01.008.

Nwankpa, Joseph K. 2015. "ERP System Usage and Benefit: A Model of Antecedents and Outcomes." Computers in Human Behavior 45 (2015). Elsevier Ltd: 335-44. doi:10.1016/j.chb.2014.12.019.

Oliveira, Tiago, and Maria F. Martins. 2010. "Understanding E-Business Adoption across Industries in European Countries." Industrial Management \& Data Systems 110 (9): 1337-54. doi:10.1108/02635571011087428.

Oliveira, Tiago, and Maria Fraga Martins. 2011. "Literature Review of Information Technology Adoption Models at Firm Level." The Electronic Journal Information Systems Evaluation 14 (1): 110-21.

Orlikowski, Wanda J., and J. Debra Hofman. 1997. “An Improvisational Model for Change Management: The Case of Groupware Technologies." Sloan Management Review 38 (1): 11-21.

Rogers, Everett M. 1983. Diffusion of Innovations. 3rded. New York: The Free Press. Sedara, Dershana. 2009. "Size Matters! Enterprise System Success in Medium and Large Organizations." In Handbook of Research on Enterprise Systems, edited by Jatinder N. D. Gupta, Sushil Sharma, and Mohammad A. Rashid, 218-31. Hershey, PA: Information Science Reference.

Shang, Shari, and Peter B Seddon. 2000. "A Comprehensive Framework for Classifying the Benefits of ERP Systems." In Americas Conference on Information Systems (AMCIS), 1-11. http://aisel.aisnet.org/amcis2000 \nhttp://aisel.aisnet.org/amcis2000/39.

Shiau, Wen-Lung, Ping-Yu Hsu, and Jun-Zhong Wang. 2009. "Development of Measures to Assess the ERP Adoption of Small and Medium Enterprises." Edited by Yogesh K. Dwivedi. Journal of Enterprise Information Management 22 (1/2): 99-118. doi:10.1108/17410390910922859.

Siggelkow, N. 2007. "Persuasion With Case Studies.” Academy of Management Journal 50 (1): 20-24. doi:10.5465/AMJ.2007.24160882.

Son, Jai-Yeol, and Izak Benbasat. 2007. “Organizational Buyers' Adoption and Use of B2B Electronic Marketplaces: Efficiency- and Legitimacy-Oriented Perspectives." Journal of Management Information Systems 24 (1): 55-99. doi:10.2753/MIS0742-1222240102.

Sullivan Mort, Gillian, and Jay Weerawardena. 2006. "Networking Capability and International Entrepreneurship: How Networks Function in Australian Born Global Firms." Edited by Chris Styles. International Marketing Review 23 (5): 549-72. doi:10.1108/02651330610703445. 
Teece, David, Gary Pisano, and Amy Shuen. 1997. "Dynamic Capabilities and Strategic Management." Strategic Management Journal 18 (7): 509-33. doi:10.1002/(SICI)1097-0266(199708)18:7<509::AID-SMJ882>3.0.CO;2-Z.

The Economist. 2014. "The Peter Pan Syndrome.” The Economist.

Thong, J Y L. 1999. "An Integrated Model of Information Systems Adoption in Small Businesses.” Journal of Management Information Systems 15 (4): 187-214. doi:10.2307/40398410.

Uwizeyemungu, Sylvestre, and Louis Raymond. 2012. "Impact of an ERP System's Capabilities upon the Realisation of Its Business Value: A Resource-Based Perspective." Information Technology and Management 13 (2): 69-90. doi:10.1007/s10799-012-0118-9.

Venkatesh, Viswanath, Michael G. Morris, Gordon B. Davis, and Fred D. Davis. 2003. "User Acceptance of Information Technology: Toward a Unified View." MIS Qarterly 27 (3): 425-78. doi:10.1017/CBO9781107415324.004.

Walsham, Geoff. 2006. "Doing Interpretive Research.” European Journal of Information Systems 15 (3): 320-30. doi:10.1057/palgrave.ejis.3000589.

Yen, H., and C. Sheu. 2004. "Aligning ERP Implementation with Competitive Priorities of Manufacturing Firms: An Exploratory Study.” International Journal of Production Economics 92: 207-20. doi:http://dx.doi.org/10.1016/j.ijpe.2003.08.014.

Yin, Robert K. 2009. Case Study Research: Design and Methods. 4thed. Thousand Oaks, California: Sage Publications.

Yusuf, Yahaya, A. Gunasekaran, and Mark S. Abthorpe. 2004. "Enterprise Information Systems Project Implementation: A Case Study of ERP in Rolls-Royce." International Journal of Production Economics 87 (3): 251-66. doi:10.1016/j.ijpe.2003.10.004.

Zammuto, Raymond F., Terri L. Griffith, Ann Majchrzak, Deborah J. Dougherty, and Samer Faraj. 2007. "Information Technology and the Changing Fabric of Organization.” Organization Science 18 (5): 749-62. doi:10.1287/orsc.1070.0307.

Zhu, Kevin, and Kenneth L. Kraemer. 2005. "Post-Adoption Variations in Usage and Value of E-Business by Organizations: Cross-Country Evidence from the Retail Industry." Information Systems Research 16 (1): 61-84. doi:10.1287/isre.1050.0045. 


\subsubsection{Reflections on Paper 5}

In this last paper of the thesis, there are several issues I want to delve into a bit deeper. One of them is why I added another case to the thesis and broke the story of the Business Journal. By reflecting on this, I aim to provide some rationale of why Kitchen Co was added to the dissertation. Following this reflection, I will also try to cover some theoretical and methodological issues I encountered in the case, and then will reflect upon how I would see this story by using the perspectives I adopted for the Journal case to, once again, show how the perspectives I adopted throughout this journey can complement each other.

\subsubsection{Reflecting on adding the second case}

To start off the reflection, one easy answer to why add a new case is that I have access to data, I have followed Kitchen Co for several years, so "why shouldn't I?" Similarly, an easy answer was that two cases often looks better than one case. However, both of these - tongue in cheek - answers would be selling the story short, and it can always get a prompt, "three is better than two", and following Eisenhardt (1989), the next prompt can be, "four is better than three" as fewer than four means difficulty in generating theory.

I have started my $\mathrm{PhD}$ journey with an aim to investigate the integrated systems - like ERPs - thus for some time, the Kitchen Co. was a non-entity for me. I kept contact with the company, but for some period of time that was in a total unstructured manner without a clear goal of investigating the IS. Also as you might remember Hugo had established another company before Kitchen Co. so I cannot claim that the process was a linear one where everything went nicely.

However, me beginning in the ERP world - and teaching about it - mostly showed that there seems to be a bias towards integration. Thus, after some time, witnessing how a non-integrated system continued to function and serve well the needs of a small organization made me think about including this case in the dissertation. We have seen in the Journal case a gradual organization, a gradual shift from a non-structured way of working to a formal management system. Thus in some ways, the Kitchen Co. serves as a counter example to some of the issues in the Journal case.

Another way that these cases diverge is the set-up of the organization - the organizational structure. Whereas in the Journal case we had a group of editors that have equal say in matters - and can even be argued as friends - in Kitchen Co. we have a single ownership structure, where formally Hugo has the last word on important decisions. This has some implications of how the decision making - or to use a term from the Journal case, the negotiations - will pan out. A similar case can be made for the broader sense: where Kitchen Co. has people that have different roles within the organization, the Journal case provides a group of participants that dabble in each other work practices in their daily lives.

Kitchen Co. is somewhat of an alien for me when I compare it with the Journal case. I know the academic world, I encounter the work practices found in the Journal case in my daily life, I live in a developed country. Thus, it was a rather refreshing deviation from the Journal case on a personal note. However, that deviation also ties with another reason to add the case to the dissertation. By adding this case, one aim I had was to inject the developing world example to the dissertation as well as literature in general. 
As mentioned in the paper, there is a lack of representation of these countries (environments) in the IS adoption literature, and as the Journal case has been from a developed world perspective, I thought it might be interesting to have the case included in the dissertation. This in one sense fulfills Jha and Bose's (2016) call for including different geographies to analyze the factors that influence innovation and adoption ${ }^{23}$. My investigation, on the other hand was more parallel in spirit to Avgerou's (2008) investigation. While my narration at parts suggests that I am testing TOE in a Bolivian case, my attempt is to see how IS adoption takes place in a different embedded setting than the ones often presented. In this way, I am more inclined to the "social embeddedness discourse" that often deals with how the different contextual factors of developing countries play a role: in my case, in IS adoption. And I believe it is that social embeddeddness that was the main factor that rejected the potential benefits of integration and centralisation provided by an integrated system, the social norms that made it unfeasible to adopt a new integrated system.

I would then argue that, the inclusion of the Kitchen Co. case is a valid one. It may not be a planned action that Yin (2009) - or even Eisenhardt (1989) with her emphasis on selecting the cases before entering the field - would want. However, from a more grounded theory approach (Glaser and Strauss 1967), seeing what the Journal case says, analyzing it, and finding another case to add to that analysis is what is needed: selecting the case after entering the field. I cannot claim I followed the grounded theory, but as I have read and used several concepts created/used by Strauss, thus I am to some extent influenced by his overall ideas of how to conduct research. And as I expressed before, I openly admit that there was no grand strategy behind my choices, I mostly tried to see what the story reveals and what it might miss, and try to find resources to fill the gaps of the story.

Due to me adopting TOE instead of continuing with the more social worlds/negotiated order perspective, or my attempt at updating stakeholder model, the language I used is not very similar to the older papers. Following a discourse analysis perspective, that is not surprising: as I am talking to another audience and I have a set of tools - TOE vocabulary - that I should use to be accepted as a legitimate participant of the conversation, my language use shifts. This is similar to having the scripts necessary for publishing in IS journals mentioned by Grover and Lyytinen (2015). I will thus also try to paint a brief picture of how the story can be seen from the Journal case perspectives. However to do so, I should begin by mentioning some of the theoretical and methodological differences between these cases.

\footnotetext{
${ }^{23}$ To some extent, investigating a developing country can shed light on the differences between developed and developing countries. Zhu and Kraemer (2005), for instance has compared two samples and identified that environmental factors are statistically different for developed and developing countries. If we follow the argument that SMEs constitute an important part of economic life in developing countries, then looking at how IS adoption takes place in such companies is important to understand why adoption rates differ between developed and developing countries. The slow adoption rates of e-commerce of SMEs when compared with developed countries is what prompted Rahayu and Day (2015) to conduct their study. Unlike them however, my aim is not to generalize, thus I can not make any claims of my case representing a larger sample - even though of course there is an inherent generalization in the work, as discussed in the research approach chapter. However, I believe that my argument that there is a social norm of not going for an integrated system shows a divergence from how things might work in a developed country, and can be turned into a managerial implication: that if the vendors wants further penetration in these developing countries, they should assuage the concerns regarding transparency and flexibility more clearly.
} 


\subsubsection{Reflecting on method and TOE}

As I have already mentioned, interviews were the main data-gathering tool, which I have already used for the Journal case. However, unlike the Journal case, I was not able to observe the work practices, and had to rely on sometimes not so reliable ways of communicating via Skype and Facetime. Another problem in data gathering was due to time-zone differences, as when the Kitchen Co.'s workday was ending it was around 23:00 in Sweden. While I was able to talk with Hugo during the lunch - almuerzo - due to personally knowing him from Sweden, as lunch was rather important piece of down time - even family time for those that eat at home - for the employees, we often talked after hours, thus I tried to keep the interviews shorter for those interviews. Language barriers also made it hard to express our ideas fully from time to time, especially when it came to talking with one of the engineers and the accountant. Thus, not having as structured data as the Journal case, I thought I would not be able to do justice to the case or to the theories that I could draw from to investigate it.

Coming to the theoretical choice for the study, the TOE framework, I had some ideas behind when looking for which theory to use. First and foremost I had to find a perspective that would be able to show the reader if having this case from South America would make a difference to the IS adoption process. Thus I limited my search for a framework to those that would provide a focus on environment. I also wanted to contribute to the IS adoption literature, thus tried to keep clear from theories that are used in the literature but that are not specifically tied to IS adoptions. I think I can safely say that I have already expressed an interest in institutional theory already in the papers and reflections. And it has been used in IS research (e.g. Teo et al. 2003) and in some instances has been combined with TOE specifically (Gibbs and Kraemer 2004; SoaresAguiar and Palma-dos-Reis 2008). However I decided that the data I was gathering would be rather limited when it comes to explaining the institutional work - if there was - taking place and how it leads to (re/de) institutionalization within the work place, which I would be interested in studying. To the best of my knowledge, the $\mathrm{TOE} /$ institutional theory stream has not followed an institutional work perspective, so this might be a venue for future research ${ }^{24}$.

Thus TOE seems like a rational choice for me. As I have mentioned in the paper, it has been around for some time, and has its roots in earlier theories - like the diffusion of innovations of Rogers (1983) for its technology and organization contexts. Similarly, with some imagination I can also link some of the issues discussed in other theories and frameworks to some aspects of the TOE. For example, it would be possible to present the three contexts of TOE as a locus for different institutional logics, with the IS conceptualized as a carrier of different logics. But as already stated, I tried to keep clear of merging IS adoption with other theories - as some would say, I have tried that enough already.

\footnotetext{
24 A closely related attempt is made by Pishdad et al. (2015), who combines institutional logics with the TOE framework. However, while related, institutional work will delve into a more actor oriented analysis when compared with institutional logics, as Lawrence and Suddaby (2006) define institutional work as "the purposive action of individuals and organizations aimed at creating, maintaining, and disrupting institutions", and argue that by institutional work, they draw from "an understanding of actors as rational in the sense that they are able to work with institutionally defined logics of effect or appropriateness". Thus, once again following a Straussian package, how these logics were first created/negotiated, and how they were sustained to become institutionalized, and how they were introduced to the settings at hand can be an interesting venue of research to supplement TOE, and IS adoption literature in general.
} 
There is enough written about the TOE framework already, so it is rather redundant for me to go through those again ${ }^{25}$. However, what can be opened up a bit more is my attempt in using it as a sensitizing device. I thought I would be able to find a more nuanced understanding of the case if I adopted the theory in that way rather than drawing hypotheses from the literature and test it. Looking back, I can also claim that it might have given very similar results to the ones I have now, but I cannot be so sure for several reasons.

If I were to follow the literature to create hypotheses, I would have to argue that for example, competitive pressures would positively affect the adoption process (the organization will adopt IS if here are more competitors that have a similar system). And while this might hold true, if we are talking about an organization that is still trying to survive, there is also a good chance that the respondent would not possess or actively seek that kind of knowledge. So if I were to follow the hypo-deductive process seemed to be taken by most of the researchers, I would either reject this or call it inconclusive for my case. A similar issue is for example seen in Rahayu and Day (2015), who argue that firm size was not significant in their study of Indonesian SMEs' adoption of ecommerce. They argue that "a possible explanation for this condition is because Indonesian SMEs are mostly still at a lower level in the adoption of e-commerce (Rahayu and Day, 2013), where most have just a static or interactive website or even just e-mail."

In both cases, the reason of why these hypotheses would argue for an insignificant effect is rather logical, thus either I need to adapt the theory by introducing moderators, or I have to adopt a more inductive approach. In my case, I adopted the second option. Though I can be considered well-versed in the literature, I can not claim to be knowledgeable enough with the literature, country or the industry to account for - for those knowledgeable - very obvious moderators. Thus to some extent my line of reasoning was "if I were to refute a hypothesis based on theory, would my results be novel, or would that mean I am overlooking something?" Would I say something like Rahayu and Day (2015), or even if I want to do so, can I really say it with one case?

Thus as the industry and the environment was new to me, and I had access to Kitchen Co. for some time, I decided to adopt the sensitizing approach, and I am not sure the

\footnotetext{
${ }^{25} \mathrm{I}$ believe that the existing literature reviews mentioned before give enough references to have an understanding of TOE framework. A more focused reading of research that wasn't included in these reviews (e.g. Awa et al. 2016; Rahayu and Day 2015; Ghobakhloo et al. 2011; Ramdani et al. 2009) would also provide how the contextual factors were used in the SME setting. However, I believe one of the key aspects that I think deserves attention is that the contextual factors in TOE can be "both constraints and opportunities for technological innovation" (DePietro et al. 1990, p.154), which I think helped with using the framework as sensitizing device as this allowed me to think about possible influences without strict a priori relations.

On another note, it is also interesting that there are other frameworks resembling the TOE framework rather closely, without mentioning the TOE framework, which I argue shows that it has a wide acceptance and applicability, and that it is a good analytical lens to investigate the complex relationships in an IS adoption. For example the model in Iacovou et al.'s (1995) study of electronic data interchange in small businesses can be read as similar to TOE: perceived benefits-technological, organizational readinessorganizational, external pressure-environmental. A similar reading can be made for Parker and Castleman (2009) who argue that mostly the dominant theories do not take into consideration the idiosyncrasies of small firms' e-business adoptions and call for an integrative framework. They provide a descriptive model, which would match rather well with the TOE model - with Thong's personal context added. I will also argue such a match is possible with the factors that influence IT governance identified by Xue et al. (2008), who once again did not refer to TOE.
} 
other option would provide me with the social norms that I found significant in the case. Mostly, the TOE framework focuses on pressure from competitors and/or trading partners and government regulations, however in my case it was a bit different. There was a long-standing tradition among the society as a whole that made adoption of some IS rather problematic. If you were to adopt an ERP-like system, you would be more transparent to the government, and thus you would - potentially - be harmed by paying due taxes. To not have that situation you would need to have a shadow-system that would erode the benefits of an ERP-like system. If I were to stick to the terminology of competitive pressure or trading partner pressure, I would have missed the fact that this use of interconnected but not fully integrated system is how things are done, entangled with the day-to-day practices of informal agreements and deals. Similarly, when these companies receive a project they cannot deliver and therefore refer the customers to a competitor, the line between the competitor and a partner would also be eroded. Nor would the fact that informal ties with the government played a role in the Kitchen Co. be revealed, as the literature would often argue about government regulations and promotions, not about the informal ties that can be found.

Thus, to cut a long story short, I would argue that adopting a sensitizing approach to use the theory has been fruitful for me, giving me the ability to sift through my data and investigate how these different contexts of TOE affected the IS adoptions in Kitchen Co. But why not continue with the social world/negotiated order/stakeholder traditions that I have been following for some time, and instead use another theory?

\subsubsection{Reflecting on other theories and Kitchen Co.}

One reason to begin with is the lack of same quality data. While I was able to have interviews with different people from Kitchen Co. at some instances, the depth of the data would not satisfy my own aspirations to be able to identify the different social worlds, and the negotiations going on. Similarly, while I will argue that my attempt to nuance the Freeman model was a nice endeavor, I did not necessarily do it for "testing". It was more of an attempt to do as Cummings and Angwin (2004) who argued against the rather institutionalized ways to see the organization. If I were to apply my model, then I would have preferred a setting where I can directly observe the participants, and for Kitchen Co. that meant I should speak Spanish.

However, while I can not claim to have sufficient depth of data enough to warrant a full paper, I think I can spend some paragraphs and try to map out the situation in Kitchen Co. in a more stakeholder/negotiated order oriented way. Thus, with a word of caution to not read too deeply into the analysis, here is what Kitchen Co would look like:

There are several stakeholders I can identify in the case, with some internal and external. Internally, we have the top management - Hugo - the engineering team, the administrative team and the shop-floor workers. The external stakeholders are the customers, the competitors, the government and Pasta Co. Some of them have minimal bearing on the issues at hand - adopting various IS products. So they would most likely be left out of the issue arena presented in the ECIS paper. However, they are likely to affect the decisions by their indirect influence - probably, as we have seen, through social norms if nothing else.

Bearing in mind that one of my arguments was to think about the actors within these stakeholders, I can highlight some relations and actors among these stakeholders. The accountant who works at both Kitchen Co. and Pasta Co. is involved in this adoption case, placed within the administrative team, and has a strong say in accounting issues - 
especially when closing the books, his urgency is increased. Similarly, another tie exists between the organizations through familial ties: if Kitchen Co. fails, Hugo's family thus Pasta Co. - will to some extent be affected. However, the affect of such scenario to the whole organization is debatable. Thus, the main actor would be Hugo's father. Government can be broken in two, one where Hugo has a contact, thus can have some help in navigating the water, and the other where the rules and regulations are to be obeyed and has no leeway. In opposition to these more informal relations, the foreman who represents the work-floor workers has a more formal type of relation with the managers, engineers and the administrative personnel. The foreman contributes to the meetings concerning the new projects and issues related to the work floor, and is also in contact with the other internal stakeholders in some form or another; however, the relations he has seems to be more of the traditional/hierarchical character. Thus customers - aside from the off chance big projects - are often small projects and thus the customers do not impact the organization heavily. The competitors are often similar scale organizations, and from time to time they refer the customers to each other - this was expressed as rather seldom for Kitchen Co. and occurred when they had already a full schedule and can not accommodate the customer in time.

The situation for the adoption of the accounting system can be sketched as below. Here we have the negotiation context - with most of the negotiations taking place internal to the organization - that resembles Business Journal to some extent. We have key people that are more prominent, like the Accountant who uses his experience and knowledge of accounting regulations to argue for the adoption of the system. To some extent this was countered rather weakly by Hugo and the engineers who would be more inclined to adopt a more modern system. In this case, I would not expect the administrative assistant to have that much of problems, as both systems would be rather routine from her perspective, whereas for the accountant, the work might entail the bulk of his commitment to Kitchen Co.

In all these internal negotiations, the power is rather skewed to the owner, Hugo. However, he has to balance the issue in several forms: the accountant works for his father's company, so his rejection might lead to problems, and he can not seem too strict as that will cause a "word-of-mouth" effect that might result in not being able to recruit other staff. The structural context imposes a rather clear barrier to the selection of the various systems, due to non-compliance with the government regulations as well as language issues.

The case of Hugo and some of the engineers preferring a more modern system can be attributed to their different stance on the issues. If I were to put them into a social-world context, their education, age and career paths would set them apart from the accountant's social world. While the negotiations might revolve around ease of use and integration for Hugo and the engineers, the discourse used by the accountant will fall on efficiency and familiarity with the system, to the rules of accounting and some other discourses. We might also expect influence from Pasta Co. in an informal manner, to pressure Hugo to go with the accountant's demands, to not shake the boat. 


\section{Conclusions and Discussion}

So now, after writing parts of the dissertation and the papers, in this chapter I sum up my reflections and ideas, and discuss them in their entire form. I have already provided individual reflections on each paper, aiming to help the reader see the process behind and open some of the black boxes, while at the same time helping me to reflect on what I have done. To finish this dissertation then, in this chapter I aim to draw general conclusions from the overall work and discuss them in relation to the general ideas behind this dissertation and provide a general reflection. Thus in the first part of this chapter, I provide some conclusions that I draw from the dissertation. To do so, I will touch upon the main conclusions of the papers and provide a very brief re-cap, and then try to map them to some general themes that emerged throughout the dissertation process. In the second part, I discuss the dissertation in trying to position the thesis in the literature and provide some suggestions for future research venues.

\subsection{Concluding the dissertation}

There are several conclusions I can draw from the dissertation. Some of them are easy to pinpoint in the papers, thus easy to map here in this chapter. Some are less direct, and reflect how I interpret the cases in their totality, similar to what I have done in the last reflection when "reading" Kitchen Co. case through other theories. The general aim of the dissertation is to investigate how and why organizations adopt integrated information systems, and as I mentioned, the part of integrated systems changed while the research evolved. While ERP-like systems was the initial thought, during the research process integrated systems of smaller scope as well as a case of standard nonintegrated systems were investigated in the dissertation. The focus also shifted to small organizations that are seemingly simple to investigate. Reflecting back, some metaphors that I used - or hinted - like "journey" and "tapestry" are a result of this process: to begin with an aim, and to find your own path to the ending point. Thus to some extent, as I argued throughout this dissertation, the cases provided differences in their modus operandi, about their environmental settings, about what they want from an IS. So, to start off this section: why and how does a small organization adopt an IS?

First and foremost, the reasons for adopting an IS are multiple. To some extent, similar to arguments found earlier research, e.g. Davenport (1998); Markus and Tanis (2000), it is done to streamline the operations, to structure the work in the organization, to ease the cooperations, as in the Business Journal story. These reasons are a way to reduce the waste - of unnecessary communications - as well as to ascertain that all parties involved are doing what they should do. On the other hand, adopting ISs is also a way of satisfying various pressures, both from the inside and the outside of the organization - for example not adopting an ERP-like system to escape the potential problems of transparency, as seen in the Kitchen Co. case, similar to pressures identified in literature that followed an institutional theory perspective (e.g. Chatterjee et al. 2002; Teo et al. 2003).

Secondly, the IS adoption can be triggered by various events. Some of them stem from external shifts, such as a rival journal getting established - thus increased competition in the Journal case. Similarly, in a setting where no other similar organization adopts an integrated system, there is a lack of external stimuli to adopt one, as seen in Kitchen Co. 
On the other hand, the impetus to adopt ISs can be an internal issue. With growth and increased complexity, adoption of ISs was seen as a way to structure the work processes, substituting the informal communication style that became unstable as the Journal evolved. This is once again in line with the pieces of research I mentioned previously: most arguments raised by Davenport (1998), Markus and Tanis (2000), Davis (1989) - and even the organizational aspects of Rogers' (1983) DoI or as a more concrete example, the cost-benefit analysis of a CEO of perceived benefits of IS (Shiau et al. 2009) can be thought of as internal/rational pressures, that leads to IT adoption as a solution to the increasing amount and complexity of the work. Similarly, if I were to argue that the pressures mentioned by Teo et al. (2003) - such as extent of adoption among competitors, or customer - as external/imitative, the existence of social norms can be one of these imitative reasons of not adopting the IS. Thus I can argue that the research pieces I provided fall in line with earlier research that also investigated these internal and external factors and argued that they work in tandem (e.g. Gibbs and Kraemer 2004; Son and Benbasat 2007; Salge et al. 2015).

When it comes to how the ISs are adopted, there are also various ways of how the process went. In the Business Journal case, it was a step-by-step process, as a slow progression of new organizational needs were revealed and solved. On the other hand, in Kitchen Co. the decisions were influenced heavily by the participants' - the owner's, the accountant's, the engineers' - previous experience of running businesses. In that case, the pieces of the puzzle were assembled more consciously, using the experience of the participants of Kitchen Co. than the evolution highlighted in the Business Journal case.

Both cases showed that informal contacts provide an important resource to draw from, similar to what has been long recognized in entrepreneurship in small organizations (Birley 1985). It was the informal contacts in the IT department that helped the editors, just as Hugo used informal contacts to get information about various ISs available, as well as securing job contracts. This shows the importance of personal contacts within the industry as well as the general area, and recognizes the expected importance of networking to get the job done in small-organizational settings of this dissertation Similar to what Ostgaard and Birley (1994) discussed, these personal networks turned out to be important in both setting and implementing the strategy in these two organizations. For the IS adoption, the existence of such networks have been recognized for a long time, for example, Rogers (1983) has identified interpersonal networks as an important aspect of information seeking in adoption of innovations. The importance of these networks were also noted in Parker and Castleman's (2009) TOE-like framework for IS adoption that I mentioned previously.

The way of conducting the decision making around IS adoption is not a mandate from above, but a result of the interaction of the various parties within the organization, attesting to the importance of non-hierarchical negotiation in these settings. Both in the voluntary-work-based, equal-standing-among-decision-makers of Business Journal, and the single-ownership, small-manufacturing setting of Kitchen Co., the decision to adopt an IS necessitates inclusion of various voices and negotiating a workable outcome, of cooperation without full consensus. While the organizational structure plays a role in how these workable solutions are attained - where in Business Journal every one is of equal standing vs Kitchen Co. with Hugo holding veto powers - the leveraging of various discourses to offset the official hierarchy - by drawing on the accountant's expertise for instance - was an interesting aspect of the adoption process. 
Thus, in short form, the IS adoption as a process is one that spans several organizational levels, involving multiple actors, that aims to satisfy both internal and external needs, that provides solutions for various needs. This in turn is in line with the socio-technical systems view that argues that all parts of the system are connected and can influence each other, that both external and internal parties need to be considered (Mumford 2006), similar to what Alter argued when creating his work-systems framework. Even though stakeholder theory has mostly been used to manage external stakeholders, similar to the overall pattern, IS research has also revealed that both internal and external stakeholders matter (Pouloudi and Whitley 1997; Pouloudi 1999), and they need to be considered for IS adoptions (Boonstra et al. 2008; Boonstra and Govers 2009). My conclusions are a result of investigating two seemingly simple organizations, adopting seemingly simple ISs for seemingly simple reasons, but as I argued in this dissertation, there is little "simple" about how the IS adoption went. And one implication I can draw from this is the need to be able to analyze these different aspects concomitantly. In this dissertation, I have been influenced heavily by discourse analysis, and broadly followed by an interactionist understanding - following the writings of Anselm Strauss - which enabled me to discuss how various discourses were taken up by actors, how IS - and its effects - were discursively created within the interactions of various actors, how these actors positioned themselves among various social worlds/stakeholders/organizations in micro-settings. To disentangle such complex interactions with only focusing on an organizational level, or only looking at a single actor, I believe, would not do the IS adoption justice. Thus to experiment with various models/theories/methods to investigate those relationships among actors is a worthwhile endeavor.

In, figure 4, an overall look to the dissertation is provided, going from the issues under investigation to some implications that can be drawn from the dissertation. From the rather broad purpose of investigating hows and whys of IS adoption in small organizations, some issues I investigated are presented in clouds. I have not given them any ordering, as I believe they more often than not intersect each other. These issues of investigation then lead to some conclusions that can be more clearly mapped to the individual papers, as shown in Figure 5.

I began this journey with investigating the stakeholders involved in IS adoption in Business Journal. As shown in paper one, this adoption process involved multiple stakeholders. These stakeholders, as suggested by literature have different stakes and salience (Mitchell et al. 1997). This necessitated an analysis of what their stake is in the IS adoptions, and in that paper, I argued how series of negotiations resulted in changes in the salience of the stakeholders. 

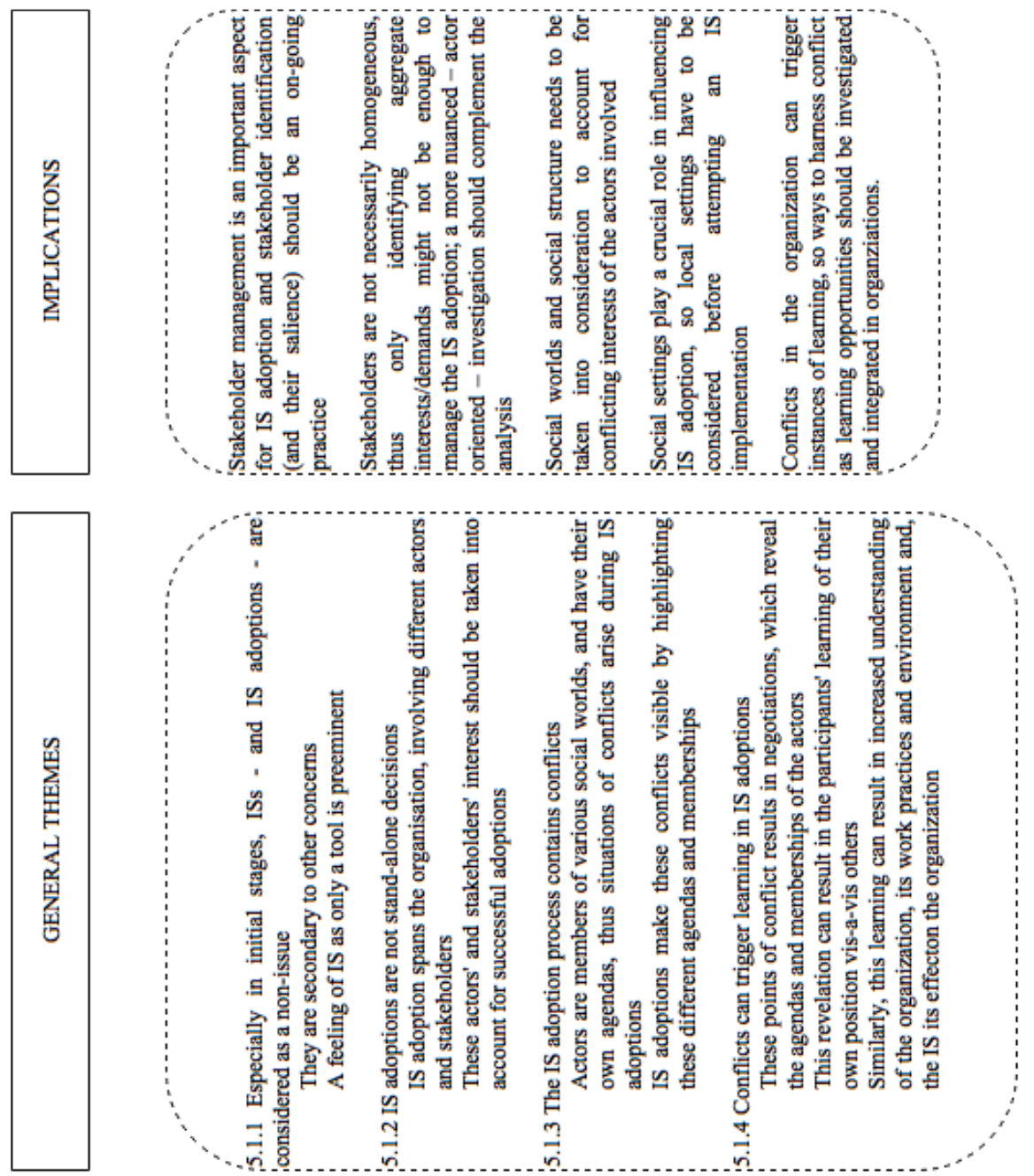
During this process of investigating the stakeholders, the differences within the editorial board showed that adopting a stakeholder-firm perspective might not be enough to investigate how the adoption took place, thus, in paper 2 , I shifted my perspective to social worlds and negotiated order. I argued that there are not just inter-stakeholder/firm conflicts, but due to the actors' membership in various social worlds, there are intrastakeholder/firm conflicts. By using the Straussian package, my investigation focused on how temporally bound the created negotiated order is, and how these conflicting interests of the actors should be continuously assessed for the IS adoption to progress and succeed.

These two papers resulted in my attempt in paper 3, to nuance the stakeholder model of Freeman (1984), by merging the insights I gained by employing stakeholder theory and the Straussian package in a graphical representation. I argued that any analysis should be grounded in the issues at hand, and the social worlds and actors' interests should be taken into consideration during the IS adoptions, which due to stakeholder theory's focus on mostly organizational-level analysis would not be a main concern.

I concluded the Business Journal story by the fourth paper, in which I adopted the worksystem framework of Steven Alter. In that paper, building on the reasons identified in this story - e.g. to streamline the work processes, to compete with other journals, to force the participants to adhere to the established work processes (and help them in working by providing a structured way of working) - this paper showed how the IS that is adopted triggers changes throughout the work system of the Journal. By showing how the work system of the Journal evolved, this paper resulted in my recommendation that these IS adoption decisions should be considered thoroughly to eliminate potential problems that might arise at other parts of the work system.

Paper five provided a story of a small manufacturing company in South America that had the ambition to adopt an ERP-like system, but instead is using several standard systems. This paper adopted the TOE framework as its theoretical lens to answer the call for IS adoption research in non-USA/Western European settings raised by Jha and Bose (2016), so that the influence of these settings - if they exist - can be reflected by the environmental context of the TOE framework. The analysis revealed that the owner plays a significant role, and that various factors that affect the IS adoptions can actually affect each other, and thus act as a composite factor, which often is not stressed in the literature. This composite factor - social norms for the Kitchen Co. - influenced the intention to adopt an ERP-like system negatively, which in another setting would be more feasible to adopt due to different social norms, highlighting that environmental factors can impact IS adoption. The case showed how issues like organizational size and structure - that is already established as important in the literature - affect the IS adoption process, and how social norms - that often is not a part of the environmental context of TOE - play an important role for IS adoptions. 

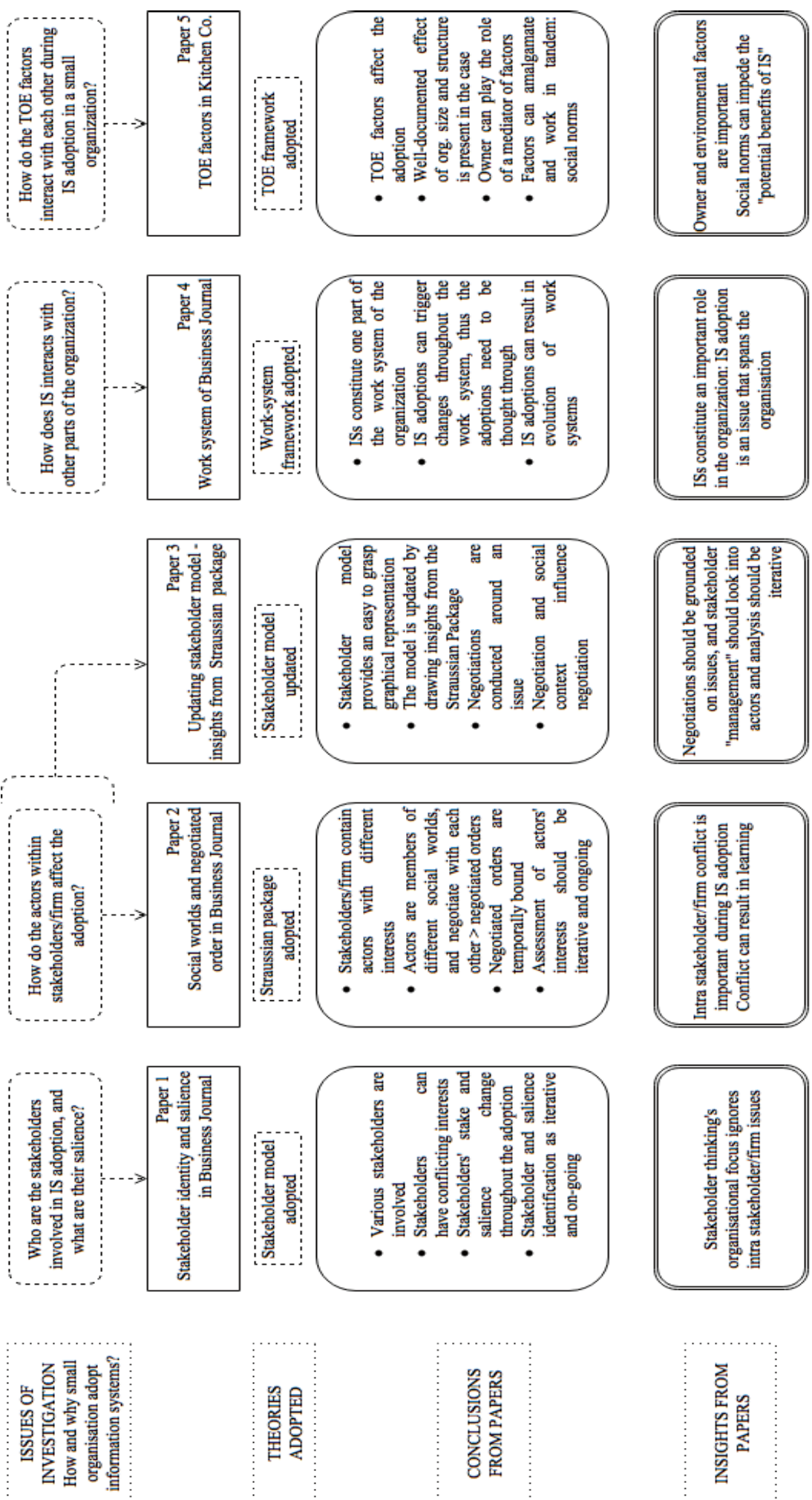

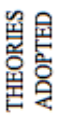
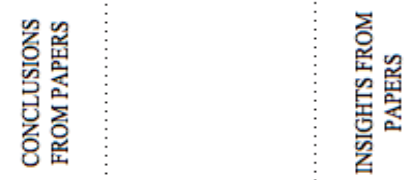
In these two cases, various reasons for why organizations adopt ISs were revealed. The decision to move towards an integrated system in the Business Journal story was to compensate for lack of communication by standardizing work practices. This story also involved issues related to increased competition, and how such an integrated system was intended to be used to bolster the Business Journal's legitimacy vis-à-vis these competitors. The Kitchen Co. case showed how the intention to adopt an ERP-like system - with its potential benefits of standardization and centralization - was halted due to lack of available resources: the need to survive in short-term that meant limited resources for an integrated system. This story also provided the instances where the owner had to balance the interests of the participants in Kitchen Co. and ascertain that the work processes are in line with the social norms. These social norms formed a reason why an ERP-like system might not work where the transparency of such a system can hinder the organization's relations with suppliers and customers.

When it comes to how the adoption process went, these cases highlighted the importance of informal contacts, as could be expected in small, new organizations. In both cases these contacts were used heavily to gather knowledge about the various ISs, and how they might fit the organizations. These contacts were used as helping hands in establishing these two organizations, by providing expert knowledge, by spreading the word, by providing general support. One key aspect of how these IS adoptions took place was the rather improvisational approach taken by these organizations. The existing resources were used to create work systems that, while not perfect, provided enough support so that the organization continued to survive. In that sense, this dissertation fits among a myriad of other works, not least, work originating in Strauss, who revealed how improvisation-based health care is (Strauss et al. 1963; Strauss et al. 1964), and who argued that even in most totalitarian institutions negotiations and improvisation takes place (Strauss 1978). Improvisation today is a parcel of IS research, so this dissertation can also be mentioned as fitting in the research stream of, among others Ciborra (1999), Orlikowski (1996) and Elbanna (2006). Similar to instances of improvisations in these earlier works, in the improvisations investigated in this dissertation, the role of specific ISs and how they can help the organization, how the work should be conducted, and the ISs' and the participants' roles, were negotiated. These negotiations, while revealing the conflicts during the IS adoption, also provided learning opportunities. This theme will be developed further in this chapter.

Aside from these conclusions directly derived from the individual papers, there are several issues that can be brought up from the totality of the work, as can be seen in figure 6. They contain the whys and hows I stated above that are derived from the papers, but also provide some other perspectives that can be put under the themes I investigated in this dissertation. These themes evolved as the research process went on, and can be grouped under four headings. The first is how the IS adoption was seen as a "non-issue" especially at the early stages of the organizations, followed by how interrelated IS adoption is with the "non-IT" parts of the organization. Another general theme revolved around how IS adoptions contain and reveal conflicts among various actors and social worlds, which is closely related to the last theme, that these conflicts can be opportunities for learning. 


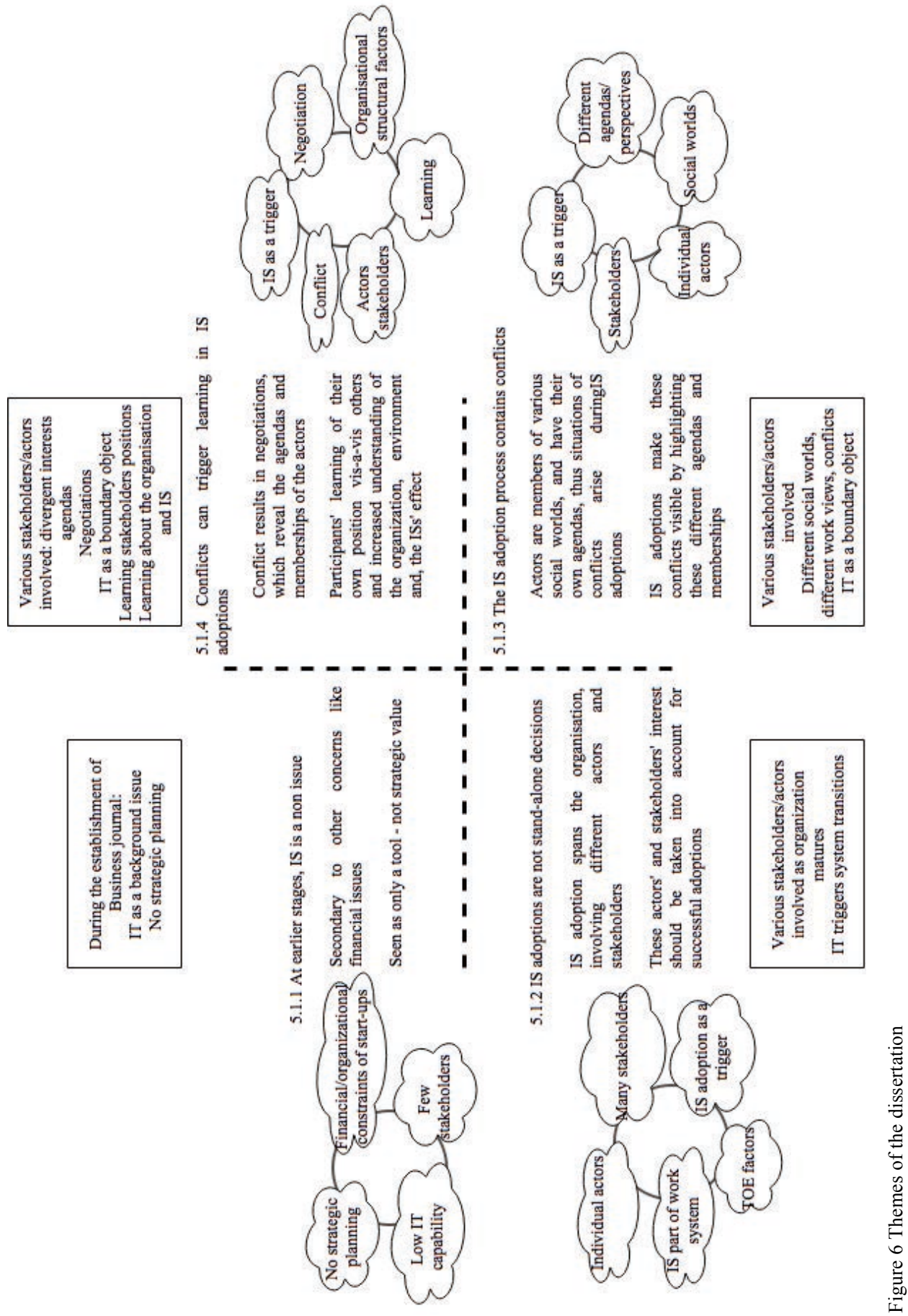


To some extent, the first two themes can be argued to span from the temporal aspects of the IS adoption. Whereas at the earlier stages the organizations - especially Business Journal - did not have IS as a strategic issue in their agenda, which changed as the organizations evolved: the participants realized that IS adoption is interrelated to many parts of the organization. In some respect, my arguments in earlier papers that there are "temporal zones" were a precursor to these first two themes.

The third theme, that there is conflict in IS adoption, is also a recurring theme, as I tried to show in various instances how stakeholders, social worlds, actors had conflicting interests. This theme, as well as relating to the cases, also drew from the Straussian package that would argue that there will be conflict unless proven otherwise. The temporal shifts that spurned the first two themes was also an underlying part of this theme, as there was not much of a conflict when IS was a non-issue, however as it began to affect the participants - to become an issue - conflicts emerged. That learning occurs through these conflicts was a theme I had in the early papers owing to the situated learning literature I drew from. These themes are discussed in the following pages.

\subsubsection{IS as a non-issue}

An interesting aspect of this study is the rather "secondary issue" mentality found around the IS. While in both cases the adoptions were successful - they seemed to be working for the organizations - and the respondents saw the IS as an important aspect of the work system as the organizations evolved, it is rather worrying to attach such a "non-issue" position to the IS. This, I argue, is a result of several circumstances playing together.

First and foremost, it can be argued that a more experienced user is able to realize more value from an IS. Similarly, an argument can be made for the more experienced user being able to see the potential value in adopting such ISs. We have seen such instances where people with experience asked for adoption of new systems in organizations that did not have the same experience or aspirations as they did (Scott and Wagner 2003; Westelius 2006; Boonstra and Govers 2009). Then, if it was these people - champions that drove the process and made the IS an issue, it is not surprising why both my cases, but especially Business Journal, did not see ISs as an important issue; neither case had a strong, determined, convinced champion, a Markus and Benjamin (1997) style change advocate. Kitchen Co. had Hugo at the center, but he was not pushing a specific solution.

Throughout the cases, the ideas of ISs have evolved, and were brought into a stronger position - one that can affect how we perform our work, that can affect how we present ourselves to others. However, before that evolution occurred, the idea of an IS as just a tool was also something that was interesting to notice. It has been long argued not to see the IS as a magical tool to solve problems (Markus and Benjamin 1997). However, it was that type of thinking that resulted in the Business Journal's adoption of the cloud solution, thinking that it will change how things are. This turned out to be wishful thinking for the editors, as their practices did not change, so the cloud solution just added another layer to the organization. It was this disregard for the IS, and realizing that it needs to be worked with, that resulted in the work-system evolutions in paper four.

As another element of influence, it should be noted that these organizations are rather young, and trying to establish themselves. Similar to the oft-heard argument, the 
financial resources in a young, small organization can be rather lacking, and thus limiting their choices. In both of these cases, the central actors asked friends and colleagues for help, using the scarce resources that were available to them: the case of "improvising with what we have". Thus these organizations did not have the chance to devote ample time to put ISs on the agenda; it was survival first and then other issues (such as process improvement and IS adoption). These issues are similar to the lack of IT capabilities as a detriment to adoption process. Following Karimi et al. (2007) it can be argued that the knowledge resources to build IT capability - such as previous ISimplementation experience - and relationship resources where IT-literate people were missing in the organization is akin to the situation of the cases investigated here. This lack of capabilities then can be reflected in the business strategy, which might then mean that the IS will not be ranked high on the priority of the top managers, whose support has been cited as important for IS-adoption (Cereola et al. 2012; Oliveira and Martins 2011) and if they lack the capabilities, this might lead to a strategy that won't take IS into consideration, thus lower IS value (Schryen 2013) thus the issue would become a strategy mis-fit (Yen et al. 2011).

These circumstances, of having little experience, of seeing IS as "only" a tool, and of having scarce resources, have contributed to what I called "IS as a non-issue" in these organizations. One can draw parallels to what I just argued and to the TOE model I used in paper five. The concerns that I think resulted in this "non-issue" status of ISs fits mostly to the organizational context of the TOE framework. The resource scarcity has been long recognized as a complicating organizational context, just as not having the inhouse personnel with IT-expertise. These two, in my perspective, result in the rather problematic issue of "magic bullet" mentality, even though it has been argued to be detrimental to organizations (Markus and Benjamin 1997; Carr 2003).

Thus I argue that even though models like TOE have been used for decades now to investigate IS adoptions, their explanatory power seems to hold true, and the problems identified that can hinder IS adoptions seem to persist. The "non-issue" status that was found in some instances in this dissertation would make these problems persist even more acutely as the organizations evolve. As these frameworks are often based on a wide range of empirical observations, and often cover a broad range of constructs at a rather general level, that their fit to investigate these situations is not diminished over the years can be self explanatory: they have in-built flexibility to account for different IS adoption. However, it is rather surprising for practitioners and students new to such frameworks that the problems identified and cautioned about seem to occur anyway. It was not in this dissertation's aim to find why and how these problems persist. However, one general take-away related to this - similar to what Markus and Benjamin (1997) and Carr (2003) argued - is to get rid of the simplistic - compartmentalized - view of how to identify and tackle problems.

This is related to one issue that needs to be brought up while discussing TOE - or other frameworks for that matter - that of interrelated factors, just as I have argued in the previous paragraphs. In the original TOE framework, the contexts influence the IS adoption and influence each other. However, just as I argued previously, the factors within the contexts can impact each other - IT expertise, champions, financing among others that can lead to an "IT as a magical tool" view. This, in turn, can lead to a composite influence on IS adoption, or would even render ISs a non-issue. Such revelations, as I argued in the dissertation, can become apparent when one takes more of a sensitizing approach to theories. By using theories in such ways - of taking them as 
starting points rather than definitive tools - can help us to infer more about the phenomena we are investigating, and provide us with an extra tool to further our credibility by sharing compelling stories.

Similar to helping in the research endeavor, having a more open view of how to identify and tackle problems can help not do the same mistakes again. While most managers or for that matter, anyone who needs to solve problems in a social setting - would also realize that such solutions are complex, it is rather crucial to not see the models and theories we use as the definitive "truths". This to some extent can be read as an implication of this research, that practitioners should be more vigilant in tackling these problems, which I would then argue would necessitate a shift of education and training methods and the models used to account for this multiplicity. To fall back to my criticisms of stakeholder theory from earlier parts: if stakeholder management is how the issues are framed, then the practitioners are educated to see stakeholders as to be managed, which would take efforts to conciliate with a network view of society that will argue that it is hard to manage the network. As I mentioned before, stakeholder theory has been adopted by many scholar, and one reason is that its simplicity. However, that adoption can also lead to problems, by creating a feedback loop where everything is seen from that - and only that - perspective, eroding the complexity one often finds in social settings. And to some extent, I will argue that this is a result of using a discourse that will posit these models and theories as definitive answers to definitive questions, similar to what Gilbert and Mulkay (1984) argued when they discussed discourses used by scientists - the empiricist repertoire. Thus, either we need to engage in more theory/model building to highlight these interrelations, or we need to be able to use our existing theories/models in a more creative way. This issue has been raised in information systems, for example by Grover and Lyytinen (2015) who cautioned against the "scripted" research, where originality might be lost due to following established norms, similar to Avison and Malaurent's (2014) concerns of theory fetish. In this dissertation, my choice was to add on different theories to identify and tackle the problems I found in the cases, and try to create a compelling story of how and why two small organizations adopted their $\mathrm{ISs}^{26}$.

\subsubsection{Information systems decisions are not standalone}

One piece of creating a compelling story in this dissertation can also be considered as one of the main conclusions that can be drawn from this dissertation: IS decisions are not standalone decisions. This has been already discussed in IS literature, when talking about how integrated systems, such as ERP systems, should be considered more than just IT. The literature has argued that IS adoptions span the organization, that they are political issues (Scott and Wagner 2003; Westelius 2009), that IS have their own logic that affects the adopting organization (Davenport 1998), that they are not mere technical IT exercise (Scapens and Jazayeri 2003). One implication from this dissertation is that

\footnotetext{
${ }^{26}$ To some extent, I would argue that adding different theories was made possible as I was writing a compilation thesis, and as such, I would be able to write this wrap to show how these bits and pieces fit together. If I were focusing on a single project, I would probably have engaged in framework creation in a more integrative sense like I did with the ECIS paper, the third paper in the dissertation. As most of the research is presented as an integrated project, one suggestion I can give to see researchers adding on theories is to look at the research from a historical perspective; for example, following the story laid out by Sahay and Walsham (1996), Walsham and Sahay (1999) and Barrett et al. (2001) one can see how different theories were used for the same overarching story from an Indian GIS implementation.
} 
this still holds, even when the IS under consideration, and the organizations, are small; the IS decisions are not standalone.

In the Journal case, the IS adoption journey went from using small pieces to an integrated system, whereas Kitchen Co.'s story highlighted a case where an assemblage of standard systems was used. In both these cases, the decision to adopt these systems were multi-faceted. One the one hand, the IS selection is primarily a financial one. Both cases have revealed that there were other options that could have been chosen. Scholar One was mentioned for Journal whereas Hugo, the owner of Kitchen Co. wanted an ERP-type system. However, in the short term, these options are not really available to these companies. They are aiming to survive in the short term, with limited resources, thus they cannot choose those systems. However, not choosing them might affect their long-term survival, more so for the Kitchen Co. if they continue to grow, where an ERP-type system can bring efficiency through standardization and centralization ${ }^{27}$. This I argue as the rather typical dilemma of an SME, trying to balance short-term needs with long-term needs.

However, IS adoption is not just a financial issue: I am not sure that Kitchen Co. would be adopting the same systems in the same ways if there were other people employed in the company, or if the owner had another vision or personality. This brings the issues related to the personality, experience and intentions of the members of the organization back to the table, some of which have been shown to impact the decision in the cases investigated.

Drawing from the Kitchen Co. case, the personality and aspirations of the owner is an important aspect for the organizations' IS adoption. This is similar to the arguments of "top management support" as a critical success factor in IS adoptions (Nah et al. 2001; Soja 2006). In small organizations, it is also argued that to achieve success "top management support as well as executive participation in providing clear direction, adequate monitoring, and feedback are required" (Malhotra and Temponi 2010, p.36) and that is why Thong (1999) introduced CEO characteristics to the TOE framework. In the Kitchen Co. case the owner was a central figure that triggered some changes, and acted as a carrier of the others' ideas and inspirations and the other contextual factors. It was through him - and the engineers - that some new systems were brought to the table. He, as the owner, had significant influence over the decisions regarding the organization in general, and the IS adoption in particular. However, he also had to consider what his team of people needed and wanted: working in a small organization meant that decisions will have quick repercussions that might lead to loss of key personnel, or a rejection of the initiative, which would mean loss of resources. In the previous section, I argued how various factors came together to reinforce the magic bullet view of the IS, which is one of the instances where the interrelatedness of factors can be seen. Thus, it is problematic to think about IS decisions regarding IS adoptions as standalone decisions.

Furthermore, the IS adoption for the organizations investigated meant dealing with stakeholders. Some of these stakeholders were prominent influencers in the adoption process, like the University management or the IT department in the Business Journal

\footnotetext{
${ }^{27}$ At this point, I do not think that there are any imminent "threats" to Kitchen Co. in terms of "standardization and centralization". However, bearing in mind that Hugo, the owner had the aspiration to have an ERP-like system. If the organization grows exponentially and he loses the overview to the organization, efficiency losses due to not having such a system can become issues of concern.
} 
case, whereas some were only what we can argue are implicated stakeholders, brought up in the discussions but seemingly having no real influence over the issue at hand, like the publisher that wanted to "buy out" the Journal. What these implicated stakeholders meant, however, was that the IS adoption needed to satisfy not just the internal concerns, but also had to take external concerns into account, similar to what is argued in the literature (e.g. Boonstra et al. 2008; Poba-Nzaou and Raymond 2010; Teo et al. 2011).

This, as often, is easier said than done. In the cases investigated, one can argue that the differences in stakeholder positions were not extreme. When compared to what was at stake, for example in the hospital ERP implementation of Boonstra and Govers (2009) where strong professions and standpoints (management board vs. vendor/implementer vs. healthcare providers vs. administrators vs. IT staff) clashed with the potential failure meaning a broken healthcare system, the issues faced by my two cases are more manageable. However, while that may be true, it does not diminish the need to take the stakeholder consideration seriously. As mentioned in the Business Journal case, the rejection by the University was seen as an affront, and while in the end the editors argue it made them stronger, it created tensions within the editorial board and injected instability into the organization for a period of time. Similarly, while having no apparent power in the IS negotiations, the indexing bodies' importance in the academic journal world, meant that the Journal would not be able to use informal ways of conducting business if they want to be accepted by the indexing bodies. These different stakeholder claims needed to be satisfied while at the same time the short-term survival needed to be ensured and long-term survival of the journal needed to be secured.

The cases investigated in this dissertation can be termed success stories - at least when I conducted my case studies. Both seem to be doing well in general, and do not seem to have to have problems with the latest IS set up. Thus it is hard to criticize the situation in the end. However, to achieve this success, several factors came to play. Both are rather small organizations, with informal channels of communication and conducting business. This de facto differentiates them from examples found in literature on large organizations, where issues and problems are compartmentalized, and can be left to fester. This compartmentalization was one of the reasons why the ERP implementation in the hospital investigated by Boonstra and Govers (2009) failed; the parties that should be involved were not. The healthcare providers did not get involved until a crisis, thus the ERP adoption was only an administrative and a technical issue. Furthermore, the board of directors, after initiating the ERP adoption kept their involvement to a minimum, whereas in the two cases investigated in this dissertation, the "higher ups" in both organizations are personally vested in the organizations. They are concerned with the day-to-day running of the organization, which reduced issues that would be taken as standalone. As the IS issues became more prominent in the organization - as IS became an issue - though not necessarily as a strategic attempt, they were engaged with by these "higher ups". Thus the size and the structure of the organizations played a key role in achieving these success stories.

These factors are taken as important in frameworks such as TOE, used in the fifth paper on Kitchen Co. However, the interrelatedness of the decisions can also be found in other frameworks, such as WSF used for the Business Journal case in the fourth paper. There, the IS adoption was shown to affect - and be affected by - the actual works and processes, as well as the strategy of the Journal. Thus, as a conclusion of this 
dissertation, a need for seeing IS adoption as a long-term strategic issue can be identified.

This then would situate the thesis among a stream of literature that argued how IS change should be conceptualized. To some extent, the changes faced by the organizations through the adoption process are incremental in nature, with small changes occurring, and participants adapting. They were at the same time more radical, when the misalignments between the strategies, work practices, values and technology became wider.

\subsubsection{Conflicts in IS adoption}

Another conclusion that can be drawn from this dissertation revolves around the concept of "conflict" 28 . While the ideas of conflict are inherent in stakeholder theory, one argument in this dissertation was that using the classic stakeholder model of Freeman (1984) might be one part of the problem in tackling conflicts.

In the previous section, I argued that IS decisions are not standalone. One reason why that is so is the nature of social life in general, with many factors bearing on a topic. One such factor is the various stakeholder claims that might be in conflict with each other. One takeaway then is to be attentive to the stakeholder claims in IS adoption.

Oftentimes, the conflict in stakeholder theory is posed as the conflict between the stakeholder and the firm. This idea of conflict was then extended to cover other stakeholders, to pose them as having divergent interests in the issues at hand, and such an argument then often brings connotations of coalition building found in Freeman (1984). While acknowledging such conflicts between the stakeholders and the firm and aspects of coalition building - as seen in the first paper, this dissertation also argued that conflict can lie within these stakeholders and within the firm.

Thus, another takeaway is to also be attentive to what goes on inside the stakeholder and the firm. One argument in this dissertation is that there are various actors in the stakeholders and in the firm, and their considerations and stakes have to be identified if the adoption - or to be more general, any initiative - is to be successful.

The concepts that I used to tease out these identities and stakes are the ones in the Straussian package found in papers two and three, similar to the call made by Beaulieu and Pasquero (2002). I argued that the actors in these stakeholders and in the firm can be considered as members of different social worlds - and sub-worlds - which would engage with each other in arenas and negotiate. Sometimes these negotiations are overt and visible, sometimes they are silent and covert. And while such interaction among actors is rather common to how most understand the world, by focusing on stakeholders and the firm as homogenous entities, stakeholder model can black-box these internal struggles.

In the previous section I argued how the conflicts between the stakeholders in the Business Journal case might not be that extreme. The Straussian package can then be

\footnotetext{
${ }^{28}$ I have been following the Straussian understanding on the issue of conflict that, "[social worlds] typically have diverse moral and political commitments; and they promote conflicting agendas for action. Controversy derives from these worlds having different perspectives on what should happen, when and how. Controversies occur where different social worlds meet" and that "each of these social worlds seeks legitimacy, authority, and power to further its own goals; and seeks to limit and repress other worlds with which it is on conflict. Of course, there is often conflict within worlds as well as among them, not only about strategies and tactics but also about goals" (Clarke 1990, p.19).
} 
used to argue why that is so. As can be noted in papers two and three, these stakeholders and firms - and the actors that constitute them - are mapped into interrelated subworlds, co-habiting rather closely in the social world of academia. That means that they are members of these worlds that aim to achieve similar things. Drawing from discussions of how ideas and actions become institutionalized over time, then one can argue that there will be some common ground in how these actors think and act, and thus a low level of inter-stakeholder conflict seen in the Business Journal.

However, what happens when actors from very different social worlds come to negotiate? What happens when there are multiple voices heard within the firm? These are the questions I argue will not be best answered by only employing stakeholder theory, thus the need to go for a deeper, more situated analysis. This is why I changed my theoretical lens in consecutive steps, to see the adoption process from different angles. Just as these different lenses highlighted that IS adoption is not a standalone process, they highlighted that conflicts can arise during that process, and that conflict might not be easily mapped into a stakeholder-firm model. These concerns of how to grasp this dynamism is similar to issues raised by, among others, Fassin $(2008 ; 2010)$, who has also attempted to visually modify the stakeholder model. However, while his concern was still embedded to the stakeholder-firm perspective, my attempt at paper three also argued taking actors inside these stakeholders and the firm, and their social worlds and negotiations into consideration.

It was that line of thinking that resulted in paper three that adapted the stakeholder model to reflect these issues of intra-stakeholder/firm conflict and to situate the analysis, proposing an issue arena. The reason for developing a visual model was to help the audience engage with constructs that cannot be easily tackled with the original stakeholder model. As Freeman himself argued, the stakeholder model as it has been used is not very sophisticated, and a finer-grained analysis is needed to "see the overall stakeholder relationship as a multifaceted, multiobjective, complex phenomenon" (Harrison and Freeman, 1999 p. 484). My answer to that call for finer-grained analysis was to add different theoretical lenses to make sense of the IS adoption, and see how the interactions occurred during IS adoption. Thus, the intention was to be able to track the actors and interactions along different lines, not just at an organizational level provided by the stakeholder/firm lens. As can be seen in the conditional/consequential matrix of Strauss and Corbin (1998, p.184), there are many levels of interaction, from individual to global. Thus only looking at the organizational level of stakeholder/firm was not sufficient to cover the IS adoptions. It was not my intention to criticize stakeholder theory or stakeholder models when beginning to write this dissertation. However, I also found out that it does not cover other possible conflicts which play a role in IS adoption in the Business Journal case - as it is not in its raison d'etre to delve into those issues. Thus, an inquiry into hows and whys of IS adoption needs to be further elaborated, and in my perspective, a stakeholder analysis is one step in doing so, not the only step.

\subsubsection{Conflict and learning}

One theme in the earlier pieces revolved around learning taking place in the organization. Similar to others, I came to view learning as not a conflict-free, linear process, but as a process of instances where conflict can turn into moments of learning (Contu and Willmott 2003; Mengiste and Aanestad 2013). I argue that there are learning points encountered in the investigated cases that map onto that line of argument. 
All my papers illustrate how the actors learned to interact with each other and the surrounding environments. This can be seen in how various iterations fixed the problems in old work-systems of Business Journal, and how Hugo, the owner of Kitchen Co. realized that an ERP-like system was not applicable even though he had aspired to acquire one.

These learning moments occurred - for these cases - around the IS that was the issue at hand. Like other issues that touch various actors in different ways, the IS thus was useful to reveal the divergent interests of these actors. Some of them were related to the various stakeholders at hand, and to some extent easy to imagine a priori, like the rejection by the University in the Business Journal story. Others were more covert, as when the accountant in Kitchen Co. successfully argued for using the old system, or when the long-term survival of the Journal was put as a career-step instead of an administrative or financial burden.

In Kitchen Co. case, Hugo had several conflicts. His aspirations to have an integrated system were confronted by his team's own ideas of how to run the organization - the accountant being happy with the existing system - as well as the affordance of integrated system for standardization and centralization confronted with the affordance of transparency. While the first instance of conflict - internal -lead to learning by forcing Hugo to re-think how to use what is available and improvise to set up his organization to not lose important manpower, the external conflict forced him to balance his aspirations vis-à-vis the probability of increased oversight by tax authorities and loss of flexibility to deal with suppliers and customers. Similarly, in Business Journal, the editorial team had internal conflicts, where some saw the Journal as a burden - and acted accordingly - whereas others saw it as a career step and complained how others are not pulling their weight. This conflict resulted in learning about how the individual editors see their commitments, whereas conflicts with the University resulted in the editorial team to actively seek support from other sources and thus broadened their network.

I have not employed the concepts "communities", or "sense of self" in this dissertation. However a similar stance to mine has been argued by using that terminology: "Individuals bring to a community a personal history of involvement with workplace, social and familial groups whose norms may complement or conflict with one other. These conflicts need to be negotiated and reconciled at least in part if the individual is to achieve a coherent sense of self" (Handley et al. 2006, p.642). This is similar to the situations where for example newcomers are told to observe and learn, where they are lost and are trying to grasp the situation reported in Guzman (2008). This moment, I argue, is a conflict, and learning will take place by the social interaction of this newcomer with the established actors, that he will negotiate his place within the organization, and by doing that he will go through a process of learning.

That is why I argue that these points of conflict in the cases were instances of negotiations among various parties, and those negotiations spurred instances of learning for the actors involved. The actors involved learned, among other things, what kind of role they want from an IS. From the early IS as a non-issue, to seeing the need of an integrated system in Business Journal, to seeing the benefit of an assemblage of standard not-integrated systems in Kitchen Co., the negotiations of actors lead to new insight into ISs. However, what is more interesting is that these negotiations also meant that the actors learned more about themselves, the other actors they work with and the surrounding settings they are in. 
The members of the editorial board of the Business Journal story came from very similar backgrounds, but treated the Journal - and ISs - in different ways. The negotiations around how to set up the Journal in the beginning was different from the negotiations of how to keep it going at the end. By engaging in those negotiations, the editors' positions vis-à-vis others were revealed. Some saw the Journal as only a burden, others saw it as a career step. Thus, when the next issue came up, the editors negotiated in a manner that stimulated a faster decision process, by playing to what they learned previously, that the new system will ease the burden, that it will help to achieve a better Journal, thus a better chance for a career. A learning process also took place in Kitchen Co. when Hugo's ideas of more modern systems were left behind due to the accountant's emphasis of the suitability of the system they had, and potential loss of flexibility of integrated systems when dealing with informal ways of doing business. In light of these - and more specifically from Business Journal case - one contribution of this research was to follow the situated learning in this more conflict-aware style expressed by Contu and Willmott (2003) applying it in a small organization. Unlike the Mengiste and Aanestad's (2013) investigation of large organizations, my take was to show that even in small organizations with very similar members these conflicts take place and that they can be learning opportunities. Just like how we can expect in Boonstra and Govers' (2009) hospital case that stakeholders have conflicts, we can expect that conflicts will occur in adopting a healthcare system in Ethiopia that will engage WHO, hospitals, federal agencies and ministries. What Business Journal has shown was that these very issues could also occur in a microcosm.

In one way, my take on learning in this dissertation is a rather natural offshoot of the philosophical underpinnings I discussed earlier in the text. Following the Chicago tradition that Strauss forms a part of, an earlier argument by Dewey (1998/1910, p.142) - one of the founders of the tradition - would provide such a link: "Failure is instructive. The person who really thinks, learns quite as much from his failures as from his successes". If, then, we take that every social order is a negotiated one, and that these orders are bound to break down - thus fail - one can see that every negotiation can also be an opportunity for learning. And this learning can be argued to occur along two, for me inter-connected, paths. To follow this failure path, one result of this conflict is learning through reflection, which would follow Blumer's ideas that we reflect on our own actions, as well as on others'. Thus, for the next round of negotiations, we change our stance and our vocabulary. We learn how to negotiate better, by reading cues and readying our arsenal. If the negotiations with the University were of a more continuous nature, perhaps, Business Journal would have succeeded in getting the support they wanted. The other type of learning is about, for our case, IS and its effects on the organization, similar to the learning track that Mengiste and Aanestad (2013) followed. Through various negotiations, the participants have to learn new aspects of the IS, and how it will influence their work-life. The Business Journal moved from using only emails to using an integrated system. These interactions among the actors, how they learn from each other about themselves, about the IS, about the organization and the environment is similar to what Crossan et al. (1999) argued, that learning takes place in both individual, group and organizational level, that these levels interact with each other during a learning process, and as Westelius (2003) argued. that these failures, these errors can lead to learning and improvement.

It is not my intention to argue that every moment of every negotiation - or every conflict - should be seen as a learning point, and neither will I argue that such a view would be feasible as most of the actors in these social worlds are pressured to fulfill 
various roles, and thus have to prioritize some aspects more than other. As I have argued before, the organizational setting helped the actors within these organizations to learn from these negotiations, and thus learning might not be possible in every setting. However, one takeaway from this section is the importance of being open to conflicts in the organization and to try to see the silver lining and see them as moments for learning and improvement rather than just as a burden. In my cases, the small size of the organizations made some of the issues more manageable when compared with large organizations: with Business Journal founded by like-minded people from similar backgrounds, and Kitchen Co. by being set up as a team by the owner. However, having said that, once again I am not suggesting seeking out conflicts - neither of my cases did that - but rather to see them as potentially beneficial instances if or when they occur. And to have them turn into benefits I believe one needs to work on how to set up the organization, perhaps in line with the recommendations argued by Jones et al. (2006), by actively trying out solutions to break down barriers in the organization that hinder knowledge sharing.

\subsubsection{Concluding the conclusions}

Before moving to the discussions, what I have written so far in this section can be rephrased to highlight the conclusions and their implications, and where they might be situated within the larger research traditions. In the papers, I have provided some of the individual conclusions, and up to now, I have provided the overarching themes that emerged through the investigation. Then in this section, I aim to put them in a more general fashion, and link them to the themes I have discussed previously, and infer some further implications. And while at times the language will seem as if I am (over)generalizing my conclusions, it should be kept in mind that the corpus of this dissertation is from two cases, thus the generalizations are more of a rhetorical device, suggesting ideas for sensitization, rather than a generalization from a positivist stance, claiming that a particular pattern will hold true in a type of context or population.

The first conclusion is not anchored to a paper per se, but more to a temporal episode in the cases. At the earlier stage in Business Journal, it can be seen that the organization is rather immature, trying to establish itself. This stage, where most of the inspiration for the "IS as a non-issue" theme comes from. In this stage where the organization is struggling to survive, the reasons for adopting an IS were not substantiated: they were basic pieces of ISs that did not receive any strategic thought. In this stage, the IS acted as a tool to communicate, chosen rather intuitively without thinking of future needs of the organization. The participants were not interested in establishing IS as an important part of the organization, but merely as a tool to communicate. Then as a conclusion from what I saw, I can say that in the early steps of small organizations, IS adoptions are not strategic, that a view of IS-as-a-basic-tool predominates, and the decisions are taken intuitively. I have already established that I see the process of adoption as a series of negotiations, and then in this stage, where things are done intuitively, the IS adoption takes places through series of mostly quick informal negotiations.

If I am mentioning that there is a conclusion for the earlier stages of the organization, that presumes that there is a conclusion for the later stages too. And that to some extent is linked to the general theme of learning in the organization. Whereas in the earlier stages of organization saw intuitive decision-making, the later stages saw an increased role for deliberate thinking and strategizing. I have argued how various reasons contributed to Business Journal participants to see IS as a more strategic issue later on. 
On that note, I see Kitchen Co as a successor to Hugo's struggles with Water Co. - his previous company. Then some conclusions can be drawn, that as the organization matures, the IS takes a more strategic role within the organization, and thus IS adoptions are elevated to strategic decisions rather than intuitive decisions. In this shift of how IS adoptions are made - from intuitive to strategic - the negotiations are more formalized. Similarly, the why has also shifted: in Business Journal it moved from mere communication tools to an attempt to formalize working processes, and to some extent to restructure the organization, whereas in Kitchen Co. the IS were chosen to support the work processes from the start. Thus, as the organization matures the reasons for IS adoptions also shifts, from mere tools to conduct work, to integral aspects of ways of working, taking more of a central role in the work-system.

In similar vein to Contu and Willmott (2003), one argument I had was that there is learning in these cases, and that this learning is not necessarily linear and conflict free. Moving from IS as a non-issue with intuitive decisions, to IS as an important part of the work system with strategic thinking behind, I believe this process of learning took place. One of the key aspects I mentioned in this dissertation is that IS took on the role of a boundary object. This I argued is what triggered some of the conflicts and the learning within the cases. It has revealed how various parties saw the IS and the organization in different ways - using emails as a communication device vs a way to organize the work flow - and resulted in reflection on how to progress from that situation. This role of triggering conflict and learning is an aspect of the "hows" of IS adoptions. Previously I argued there were fewer stakeholders, and that IS did not have a strategic value at the earlier stages. Following from that, I will then argue that as the organization grew, as more stakeholders were engaged - or perhaps as the stakeholders present at the first stages were engaged more thoroughly - as the already existing IS began to cross more boundaries, this learning began to take place. Thus, the more central role the IS has, the more likely that it will play this role of boundary object, and thus reveal and trigger conflicts and learning. This would then imply that how to turn conflict into learning opportunities should be discussed in organizations.

So far, most of the conclusions I mentioned seem to be the coming from Business Journal, with a few sporadic mentions of Kitchen Co. I will argue that the issues I mentioned were also present in Kitchen Co., especially if we remember how Hugo had the intention of an ERP-like system and ended up with an amalgamation of systems. This can be rephrased as clashes of different stakeholders and actors that resulted in a work-system, that involves instances of conflict, negotiations and learning, especially if one takes the longer perspective I enjoyed by knowing Hugo's earlier attempts. However, the Kitchen Co. story also provides an important aspect of why and how of IS adoption.

In the Kitchen Co. case, my attention was on factors that affected IS adoption, and two conclusions can be derived from that. The first one is the important role of the owner as a mediator of various factors. The importance of the owner in small organizations is already an issue that is well established, so I won't go into detail. However, from a TOE perspective, the Thong (1999) model that first incorporated the owner did so as an independent variable, and most of the literature often looks into these context as independent from each other (e.g. Jeon et al. 2006; Yoon and George 2013; Wang and Lo 2016). Then what my case tells is that we need to think about how the contexts of TOE interact with each other. 
The other conclusion is about the importance of environmental context. Unlike the previous TOE research, my case did not reveal a strong competitive push, or market demand for the (non-)adoption of IS. It was argued more as "how things are done" when discussing why an ERP-like system is not adopted, which I termed as social norms under the environmental context. This, I think is important as that shows how the potential benefits of integrated systems - centralization, integration, transparency - can be seen as burdens in another setting, calling more attention to adoption of IS in developing countries. This has implications for the adopters, to see if the system can have various inscriptions that will lead to unforeseen consequences - like technical isomorphism discussed in Benders et al. (2006) - as well as vendors and consultants who need to identify ways to overcome this social resistance to what systems argue as benefits. This environmental influence in Kitchen Co., I believe, can be important to once again show that the innovations should be considered carefully before being transplanted to other settings.

Following these arguments, I can now suggest some conclusions of how and why a small organization adopts ISs. I can now claim that IS adoptions can be conceptualized as a series of negotiations. These negotiations involve various stakeholders, who are in turn made up of actors that have different agendas and interests, which can clash. These negotiations can range from intuitive, informal perspective making - especially in the early stages of an organization - to more formalized negotiations as the organization matures. This maturity also brings changes to the rationale for adopting IS systems, where in earlier stages it seems to solve problems, at later stages it takes a more strategic goal and can be seen as attempts to structure the organization. One reason of this maturity is the learning that took place while adopting the IS, which prompts participants to learn about the IS and the organization, they continue to learn and change their position accordingly throughout the IS adoption. To some extent, this learning is triggered by the conflicts revealed by the IS playing the role of a boundary object, where different parties interpreted the IS differently, e.g. as a tool for communication; as a formalized work structure; as a substitute for face-to-face contact. This learning then makes the IS adoption a long-term process, where even the IS adoptions due to one-off negotiations can affect consecutive but unrelated IS adoptions. I can also now claim that in small organizations the owner plays an important role, and that environmental context can influence the options of IS adoptions in significant ways.

Aside from these rather purpose-oriented conclusions and their implications, I also note some overall aspects of this dissertation. To some extent, as the beginning step was stakeholder theory; I can argue that some of the conclusions and their implications can be made to refer back to that field. My conclusions, mainly from Business Journal case, was that the stakeholder model, while simple and useful, can also black-box some of the issues during an IS adoption - or any phenomena, if I were to generalize. At one portion of the Business Journal story, I attempted to show how even within a firm that seems homogenous, actors can have different ideas/agendas. This can be read as a conclusion, that the agential power of the actors is an important aspect in IS adoptions. The literature has covered the importance of top management, and argued that that the end users needs to be involved in IS adoptions, and here I would argue that we still see the homogenous understanding I criticized earlier. Does everybody in "top management" think and act the same? If so, is it because of some inherent homogeneity, or is it due to a negotiated ordering taking place, which might lead to institutionalized behaviors later on? And if that is so, does that mean nobody at top management will act in differently and resist the change? That is why the conclusions that several stakeholders are at play, 
and that these stakeholders have different interests, that they are heterogeneous and are made up of actors have several implications.

This means that looking into actors - within the firm and stakeholders - and situating them in a broader social structure and a negotiation context is needed to analyze how the IS adoption takes place - at least following the theoretical lenses I adopted. Overall, to some extent this would mean adopting a multi-level analysis that will take into consideration the agential power of the actors, as well as the structuring power of the wider social settings, which would, I believe, provide a more nuanced view of stakeholder theory.

This leads to another conclusion, that the stakeholder analysis should be a dynamic one. I have attempted to nuance the stakeholder model to reflect the issues I mentioned in the last paragraphs. To some extent this need for dynamism can be seen as a process of maturation; during the early stages of the companies, they had relatively few stakeholders, whose number grew as the organizations became more established. Just considering an initial number of stakeholders might mean losing important opportunities for the firm: as the firm evolves, the stakeholder can also evolve and change. Another reason why a dynamic perspective is needed is that the actors have many memberships (to various social worlds), and the social setting is near-always in a flux. So, similar to the arguments raised against stakeholder theory that it is not dynamic enough, my conclusions suggest that the managers - key people in the stakeholder domain - should be on the look out for changes to the stakeholder map. I have further argued that, it is not just that these stakeholders need to be monitored, which would be covered mostly with the more dynamic stakeholder understanding such as Mitchell et al. (1997) and Boonstra and Govers (2009), but the manager has to monitor the wider social changes, and the actors within the firm and the external stakeholders. Pinpointing the social worlds at play, and how they interact with each other, I believe can help to nuance stakeholder theory.

We have seen that stakeholders have different attributes, and we have seen that we should focus more on some type of stakeholders, e.g. definitive stakeholders. But I would argue that, leaving it at that level misses some important elements of organizational life; that, for instance, resistance takes place within the organization. This resistance will take place, with individuals engaging with each other while institutionalization processes are going on within the organization. On the aggregate level, the organization will be in an arena engaging with stakeholders on various issues, trying to further its own agenda, affected by the structural setting. These contestations in the arenas will either further the institutionalization of the structural setting or will act as resistance to it. This is why, once again, I argue that adopting a multi-level perspective that will account for these micro- and macro-interactions is needed to fully - if such a thing is possible - grasp what is happening during an IS adoption. For example, in this multi-level perspective, the vendor of an ERP system will note down that the tax system is different in country $X$, which means there is possible resistance for transparent integrated systems that can be easily connected to a tax-authority as that might reduce the perceived autonomy of the company, and then plan accordingly and act perhaps differently than one would at the parent country.

In this dissertation, the phenomenon was IS adoption, and some of the conclusions can be tied to the IS adoption literature's overall conclusions without the mediating effect of stakeholder theory. If I can argue that the previous paragraphs suggests a take-away as being vigilant of the role of social worlds in IS adoptions, the Kitchen Co. paper has 
shown that we need to be vigilant of the environment. The potential benefits of integration and centralization was eroded by the social norms that argued that such benefits would not be realized in this setting for a small company. That I believe can be important to once again show that the innovations should be considered carefully before being transplanted to other settings. While a centralized and integrated system can benefit an organization, it might mean failure of the company in another. This means that the vendors and the managers have to think about the match between the IS and the social setting the adopting organization is in for a successful IS adoption.

Another conclusion can be linked to the situated learning literature that I have drawn from in the earlier papers. My conclusions from this dissertation are in line with the literature. One additional insight that this dissertation has, compared with Mengiste and Aanestad (2013) who were of similar minds, that the learning through conflict - be it between stakeholders/firm, or as I tried to stress in the dissertation, among actors of different social worlds - can even take place in rather small settings with seemingly homogenous groups. This calls attention to, first, not to discard conflict due to the negative connotations it has, and second, to be attentive even in familiar settings, as oftentimes the visible memberships - stakeholder/firm, community, organization - can black-box more intricate differences of interest and agendas.

\subsection{Discussing the dissertation}

In this dissertation, my focus was to investigate how and why organizations adopt ISs. Now, after a long journey, I claim that there are multiple reasons for why the adoption takes place, ranging from internal reasons of streamlining the process, to external ones of abiding by social norms that will let your organization grow. I also argue that the process involves multiple actors in multiple levels of the organization, who are members of a range of social worlds. The process of adopting an IS is thus a process of negotiations that range from informal intuitive IS adoption negotiations to more strategic-minded formalized ones.

But what does that mean overall? What do my conclusions mean in the general scheme of things? And what can be done as future projects?

There are several ways I can tackle the issue of placing this dissertation in a more general setting. To begin with, I first acknowledge complexity. Recently, while teaching the Enterprise systems course, I was asked how come the practitioners make the mistakes we were discussing. Apparently, everything is clear when we read the literature, and when we think through cases, so it was baffling to that student that the same mistakes are committed over and over again.

During this dissertation, I aimed to show how the seemingly simple settings provided by the cases are actually rather like microcosms that reflect the type of messy interactions we find ourselves in. With every step taken in the IS adoption, the actors had to think of possible scenarios, of various clashing interests, of various alternative ISs. Thus, every small step is a moment where numerous factors combine to influence the actors. A similar stance can be seen in my research process, beginning with a stakeholder perspective, then adding other theoretical lenses to solve the next problem that popped up. Thus, IS adoptions, even the simple IS adoptions, need to be thought out, and realized as complex projects.

This ties in with the stance I have taken with trying to merge the stakeholder model and the Straussian package. The stakeholder model is too simplistic to cover the issues we 
face today, and the Straussian package, though known in some circles, seems to not be used in practice. Thus, their combination, at least to some extent, is an attempt to unravel this complexity I found in my research process. To provide a more fine-grained, a more situated analysis, the complexity of the situation needs to be remembered. My finer-grained stakeholder model helps by pointing at the potential diversity of each stakeholder by highlighting the inherent differences of the actors belonging to different social worlds within these stakeholders, and indicating the potential interaction between stakeholders and at the temporal interconnections and shifts in stakeholders and positions.

In this dissertation, though not always apparent due to the language afforded by the theoretical lenses, the stance taken was the importance of the interaction among the actors. While through my readings for the dissertation I claim to be somewhat knowledgeable in the area of social interactionism, I am also a bit baffled that not many people were aware of the concepts that I used to weave my story, and use other tools to address similar issues. Reading for example Susanne Odar's manuscript for her $\mathrm{PhD}$ dissertation on initiatives in ABB, where she used sense-making in Weick's tradition, I am rather curious of how I would have interpreted her data with my insight in the Straussian package. Her ideas of interpersonal and structural interaction are rather similar to what I argue is the core of social worlds - the structural contexts - and negotiated order and arena - the process of the clash of social worlds and the negotiations - that result in sense-making. Of course, as an author that has been living with these theoretical lenses for some time, I am biased to view the world through those lenses. However, I believe we have something to learn from the Straussian package that seems to have been used in several disciplines, but not necessarily in the ones I encountered during my $\mathrm{PhD}$ life.

I believe that the interaction of these various actors could also be a way to reveal the issues related to power in these social orders and processes. Looking back, in every paper, overt or covert, there were issues of power. Taking Latour's (1986) observation of the paradox of power in potential vs power in use - when someone has power, nothing happens, but when one exerts power, others do something - taking interaction as the place where this exertion happens can be an interesting way to see how power operates. When considering that there are structural conditions that bear on these interactions, looking into these interactions can reveal why perhaps even when no one is exerting power, the wheel keeps turning and people continue to interact and negotiate.

Latour (1996, p.232) has criticized the view that saw structure and interaction as separate, arguing, "Those who believe in social structures always presuppose the prior existence of that sui generis being, society, which is then 'manifested' through interactions. Now the only proof that we have for the existence of this being emerges from the impossibility of carrying out a face to face interaction without the immediate arrival with it of a jumble of relationships with other beings from other places and other times." I find it interesting that this idea of structure and the interaction as being intertwined was argued in works of Anselm Strauss. While Latour's arguments put the "objects" (non-human actants) more at the center than the Straussian lenses do, I argue that social interactionism, and social worlds, negotiated order and arena can still help us tackle how these interactions occur ${ }^{29}$. Two observations from Timmermans and Berg

\footnotetext{
${ }^{29}$ It is noteworthy to highlight the critique raised by Keating and Cambrosio $(2003$, p. 18$)$ that the socialworlds tradition seems to put these non-human actants in a secondary position, whereas "boundary objects" of Star and Griesemer (1989) and thus the highly important interaction with and around them, is
} 
(1997, p.274) on Latour's work can point us in such a direction: that Pasteur "did not raise the world ${ }^{30}$ with just the anthrax vaccine: the world was already raised in many different ways" and that while in principle ANT can be written from the viewpoint of every actor in the network, often it is some central actors that from the focal point, excluding other actors. While ANT is powerful to capture the emerging, the Straussian package provides the "drag of history; the cumulative consequences of commitment and action over time" (Clarke and Star 2008, p.122). Thus, the world that was already raised can bear upon the interactions within the Straussian package. And though it depends on who is using it - and for what purposes - the Straussian package deals with the mundane, the invisible, the many (Clarke 1990; Star 1991), and has consequently often been used to account for more than just the few engineers and scientists.

In this dissertation, I was able to investigate how various sources of legitimacy were used by the respondents. The owner used his formal standing to argue his position, whereas the accountant used his experience to lend weight to his opinion. The editors argued by using a language based on commitments to the Journal, to their other activities, to their careers. All of those, I can see - and do see - as issues of power. The power to achieve something greater by being a part of the editorial group, to create a Journal as a reaction to the status quo. The owner's classical power over the workers to use a system, rather than just fill out a form at the end of the month. Power being stored by using available resources to create a moral persona that battles unfairness, to be used at their discretion (also a display of power, mostly referring to the option of "not to use power") next time in a negotiation. These four approaches to power that Law (1991) investigates (cf. power in potential and use of Latour, 1986) I have seen in various instantiations of interaction: in the editors discussions of how they negotiated with external people and how they solved their internal problems during their IS adoption, as well as in how the accountant's experience and the engineers' education were used to shape the IS adoption in Kitchen Co.

These relations of power that I detect throughout the research process is one of the reasons why I see the individual papers creating a whole. From the overt power (over) of University to covert power (to), seen in editorial board, these issues of power formed a parcel of this research process, affecting how the IS adoption took place. During these IS adoptions, the actors cooperated without a full consensus, they assembled various work systems and adapted to the changes. They negotiated from one step to the other, used their discretionary power to set agendas, and accumulated power (of for example relational capital) to be used in the coming negotiations. With many actors involved in the IS adoptions, this is why the IS adoptions can not be a standalone decision. This is an important reason why the adoption process is complex, when all these actors engage in these power relations in the negotiations.

founded in this tradition. The interaction with the object can then help in investigating how social worlds are (re)created, how negotiations occur, and how the object itself is created, similar to the story of interactions with geographical information systems provided by Harvey and Chrisman (1998). However, also of notice is the definitions these traditions had for the "actant". As I mentioned in an earlier footnote, whereas ANT used actant for both human and non-human actors, the Straussian package used actant for non-human actors.

${ }^{30}$ This is a word play, referring to Latour's (1983) title "Give me a laboratory and I will raise the world", which itself is a reference to a quote from Archimedes "give me a place to stand, I will move the world". Timmermans and Berg (1997) here provide a critique that Pasteur was not alone in "raising the world" and that his vaccine was one step among many, and so that Pasteur "raised the world" not by just an emergence of a new network, but through extension and translation of already existing networks, and thus they argue that these past structures should be taken into account. 


\subsubsection{Reflecting on Future Research}

During the last few paragraphs I have talked about power and its effect on the IS adoption. Consequently, a call for future research on those issues can be a good place to start off this section.

I think one future research venue would be one of investigating these power relations in a more direct fashion. In this dissertation, my focus was on how and why these ISs were adopted, investigating how the actors interacted with each other. I did so through interviews and small observations. However, a more "power"-focused investigation should delve specifically into those interactions. Thus, a group of researchers - or at least a researcher - that immerse themselves in these interactions would have a different - and deeper - take on these power relations and how they play a role in the adoption process. It is in those instances of interaction, where these different actors come together to assemble, to negotiate, to cooperate, that I believe interesting aspects of these power relations and their effect on IS adoption appear, aspects that I began to decipher in this $\mathrm{PhD}$ process.

Putting power aside very briefly, as it never is fully put aside, a second research stream can be argued for. I was able to discuss my ideas at the 2016 ECIS conference with peers that were involved with a more conventional stakeholder perspective, and it was enlightening how most of them saw the issues I brought up, that we might be sacrificing that complexity by narrowly focusing on the static stakeholder model. Thus, as a further research venue, I hope to conduct some further research to use the model I introduced in the third paper, and through workshops to engage with practitioners to see if it "makes sense". I have mentioned how I asked my colleagues and peers if my research "makes sense" as a quality criterion, and I believe by engaging with the practitioners to gauge if the model I created makes sense to them would be yet an important aspect of quality assurance.

On that note, another venue would be to adopt a similar strategy of immersion in the research setting that I argued when discussing power issues. I believe such immersion would provide opportunities to observe how the boundaries of social worlds are (re)created in a more nuanced fashion, how issue arenas take shape, how indirect actors can affect the process. Just as I believe that conducting workshops with practitioners using the model I introduced in paper three can help to test it in the field, I believe that such an immersion in a research setting would provide opportunities to develop the model and fine-tune it. I have already mentioned how I was influenced by discourse analysis, and I suggest that one can argue for a merge of various discourse-oriented theories/methods that can enhance the model. For example, situating various discourses - such as the market vs production discourses I very briefly mentioned while discussing the Business Journal story - in the model would sensitize the user to the underlying messages to these discourses, and can help them reflect more critically on the discourses they adhere to without questioning them thoroughly.

Throughout the dissertation, the actors - be it individuals, stakeholders, or even social worlds - took a dominant position, and thus, following along the lines of sociomateriality, a future research goal should be to adopt a lens that will treat both the "actors" and the technology more equally. One aspect of this dissertation was the increasing centrality of IS as a boundary object as time went. This would align well with the overarching ideas of sociomateriality, of assemblages, and entanglements of social and material. The more important the IS became for the organizations, the more tangible it became. What I think can be an interesting twist, is to investigate if this 
increased boundary object role is a result of learning taking place, or if it is because the IS became a more of a part of the organizational life, and thus can impact more participants. As I think both these factors are at play, thus their entanglement should be an interesting venue to look into. Connected to this, another concept of importance is boundary infrastructures, and looking into why and how - if at all - a boundary object transforms into a boundary infrastructure can be of value.

\subsection{Some words of closure}

I have begun this journey with the aim of investigating how and why organizations adopt integrated information systems. In the papers I included in this dissertation, I attempted to, if not answer those questions, add knowledge to be able to answer them. I argued that there are multiple stakeholders in the adoption process and their stake and salience can change over time. I argued that, furthermore, these stakeholders and the organization under investigation contain numerous actors within, who have diverging interests. This led me to argue for the need of a more nuanced analysis to investigate the IS adoption than offered by stakeholder theory, and that the Straussian package serves well as a basis for extending and complementing stakeholder analyses. I argued that IS adoption is an instance where these divergent interests became apparent; using the tools I propose helped identify a series of negotiations that the actors went through, and that also served as a process of learning. I argued that the reasons for adopting an IS range from securing the future of the organization to surviving in the short run, from satisfying social norms to streamlining internal communication processes, and that there may be individual predispositions and reasons, too. The mix of these reasons, and how they are pursued by different actors, lead to a multitude of negotiations - and potentially to learning.

While writing this dissertation, my aim was to reflect on these individual papers, and show how they interact with each other to argue the points I made. How that IS adoptions should not be taken as standalone, that even small changes to ISs can trigger unexpected consequences. Thus, mine was an attempt to show that IS adoption should not be considered a non-issue, and that there are conflicts in the process and that it is possible to see these conflicts as opportunities for learning instead of as a burden. It was also my aim that through reflecting on those papers, and my theoretical and methodological choices, I would be able to show how these small bits and pieces interact with each other and become something new, this dissertation.

By providing an account of how these stakeholders, actors, social worlds and negotiated orders, how environmental and organizational factors interacted with each other, my aim was to shed light on how the adoption process went in the two investigated cases, and to derive useful insights from that analysis. I hope that through your interaction with this dissertation, I was able to entice you to be a part of the world within this text, and that you recognized your own experiences and thoughts in the world created in these pages, and that when you close the book, you will take a part of it with you.

Sincerely,

Özgün Imre 


\section{References}

Adomavicius, G. et al., 2007. Technology roles and paths of influence in an ecosystem model of technology evolution. Information Technology and Management, 8:2, 185-202.

Ahrne, G. \& Brunsson, N., 2006. Organizing the world. In M.-L. Djelic \& K. SahlinAndersson, eds. Transnational Governance: Institutional Dynamics of Regulation. New York, 74-94.

Ajzen, I., 1991. The theory of planned behavior. Orgnizational Behavior and Human Decision Processes, 50, 179-211.

Akamai Technologies, 2016. Akamai's State of the Internet, Available at: https://www.akamai.com/us/en/multimedia/documents/content/state-of-theinternet/q4-2015-state-of-the-internet-connectivity-report-us.pdf.

Allen, D., 1997. The nursing-medical boundary: a negotiated order ? Sociol, 19:4, 498520.

Alpaslan, C.M., Green, S.E. \& Mitroff, I.I., 2009. Corporate governance in the context of crises: Towards a stakeholder theory of crisis management. Journal of Contingencies and Crisis Management, 17:1, 38-49.

Alshamaila, Y., Papagiannidis, S. \& Li, F., 2013. Cloud computing adoption by SMEs in the north east of England: A multi-perspective framework. Journal of Enterprise Information Management, 26:3, 250-275. Available at: http://www.emeraldinsight.com/doi/abs/10.1108/17410391311325225.

Alter, S., 2003. 18 Reasons Why IT-Reliant Work Systems Should Replace " The IT Artifact" as the Core Subject Matter of the IS Field. Communications of the Association for Information Systems, 12, Art 23. Available at: http://aisel.aisnet.org/cgi/viewcontent.cgi?article=3188\&context=cais [Accessed January 7, 2015].

Alter, S., 2004. Making Work System Principles Visible and Usable in Systems Analysis and Design. In AMCIS 2004, the Americas Conference on Information Systems. New York, NY, 1604-1611.

Alter, S., 2006. Work systems and IT artifacts - Does the definition matter? Communications of the Association for Information Systems, 17, Art. 14. Available at: http://aisel.aisnet.org/cais/vol17/iss1/14.

Alter, S., 2008. Defining information systems as work systems: implications for the IS field. European Journal of Information Systems, 17:5, 448-469. Available at: http://www.palgrave-journals.com/doifinder/10.1057/ejis.2008.37 [Accessed October 30, 2012].

Alter, S., 2010. Work systems as the core of the design space for organisational design and engineering. International Journal of Organisational Design and Engineering, $1: 1, \quad 5-27 . \quad$ Available http://inderscience.metapress.com/index/G5V7127N0W376627.pdf. 
Alter, S., 2013. Work System Theory : Overview of Core Concepts, Extensions, and Challenges for the Future. Journal of the Association for Information Systems, $14: 2,72-121$.

Alter, S., 2015a. A Work System Perspective on Adoption Entities, Adoption Processes , and Post-Adoption Compliance and Noncompliance. In Twentieth DIGIT Workshop.

Alter, S., 2015b. The concept of "IT artifact" has outlived its usefulness and should be retired now. Information Systems Journal, 25:1, 47-60. Available at: http://doi.wiley.com/10.1111/isj.12048 [Accessed January 6, 2015].

Antaki, C., Barnes, R. \& Ivan, L., 2007. Members' and analysts' interests: Formulations in psychotherapy. In A. Hepburn \& S. Wiggins, eds. Discursive Research in Practice: New Approaches to Psychology and Interaction. Cambridge: Cambridge University Press, 166-181.

Avgerou, C., 2000. Information systems : what sort of science is it ? Omega, 28, 567579.

Avgerou, C., 2008. Information systems in developing countries: A critical research review. Journal of Information Technology, 23:3, 133-146.

Avison, D. \& Malaurent, J., 2014. Is theory king?: questioning the theory fetish in information systems. Journal of Information Technology, 29:4, 327-336. Available at: http://link.springer.com/10.1057/jit.2014.8.

Awa, H.O., Ojiabo, O.U. \& Emecheta, B.C., 2015. Integrating TAM, TPB and TOE frameworks and expanding their characteristic constructs for e-commerce adoption by SMEs. Journal of Science and Technology Policy Management, 6:1, 76-94. Available $\quad$ at: http://dx.doi.org/10.1108/JSTPM-04-20140012\%5Cnhttp://\%5Cnhttp://dx.doi.org/10.1108/02635571111170785.

Awa, H.O., Ukoha, O. \& Emecheta, B.C., 2016. Using T-O-E theoretical framework to study the adoption of ERP solution. Cogent Business \& Management, 3:1. Available at: https://www.cogentoa.com/article/10.1080/23311975.2016.1196571.

Axelsson, K., Melin, U. \& Granath, M., 2016. In Search of ICT in Smart Cities - Policy Documents as Idea Carriers in Urban Development BT - Electronic Government: 15th IFIP WG 8.5 International Conference, EGOV 2016, Guimarães, Portugal, September 5-8, 2016, Proceedings. In H. J. Scholl et al., eds. Cham: Springer International Publishing, 215-227. Available at: http://dx.doi.org/10.1007/978-3319-44421-5_17.

Barley, S.R., 2008. Coalface institutionalism. In R. Greenwood et al., eds. The SAGE Handbook of Organizational Institutionalism. London: Sage.

Barrett, F.J., Powley, E.H. \& Pearce, B., 2011. Hermeneutic philosophy and organizational theory. In Philosophy and Organization Theory. 181-213. Available at: http://www.emeraldinsight.com/doi/abs/10.1108/S0733558X(2011)0000032009.

Barrett, M., Sahay, S. \& Walsham, G., 2001. Information technology and social transformation: GIS for forestry management in India. The Information Society, $17: 1,5-20$. 
Beaulieu, S. \& Pasquero, J., 2002a. Reintroducing stakeholder dynamics in stakeholder thinking: a negotiated-order perspective. In J. Andriof et al., eds. Unfolding Stakeholder Thinking: Theory, Responsibility and Engagement. Sheffield, UK: Greenleaf Publishing, 101-118.

Beaulieu, S. \& Pasquero, J., 2002b. Reintroducing stakeholder dynamics in stakeholder thinking: a negotiated-order perspective. In J. Andriof et al., eds. Unfolding Stakeholder Thinking: Theory, Responsibility and Engagement. Greenleaf Publishing, 101-118.

Beazley, H., Boenisch, J. \& Harden, D., 2002. Continuity management: preserving corporate knowledge and productivity when employees leave, New York: John Wiley \& Sons.

Benbasat, I. \& Zmud, R.W., 2003. The identity crisis within the IS discipline: defining and communicating the discipline's core properties. MIS Quarterly, 27:2, 183-194.

Benbasat, I., Goldstein, D.K. \& Mead, M., 1987. The Case Research Strategy in Studies of Information Systems Case Research. MIS Quarterly, 11:3, 369-386.

Benders, J., Batenburg, R. \& van der Blonk, H., 2006. Sticking to standards; technical and other isomorphic pressures in deploying ERP-systems. Information \& Management, 43:2, 194-203. Available at: http://linkinghub.elsevier.com/retrieve/pii/S0378720605000480 [Accessed July 17, 2012].

BenMoussa, C., 2010. Exploiting Mobile Technologies to Build a Knowledge Mobilization Capability: A Work System-Based Method. In 2010 43rd Hawaii International Conference on System Sciences. IEEE, 1-11. Available at: http://ieeexplore.ieee.org/lpdocs/epic03/wrapper.htm?arnumber=5428640.

Bensaou, M. \& Earl, M., 1997. The right mind-set for managing information technology. Harvard Business Review, 76:5, 118-128.

Bird, F., 2001. Good Governance: A Philosophical Discussion on the Responsibilities and Practices of Organizational Governors. Canadian Journal of Administrative Sciences, 18:4, 298-312.

Birley, S., 1985. The role of networks in the entrepreneurial process. Journal of Business Venturing, 1:1, 107-117. Available at: http://dspace.lib.cranfield.ac.uk/handle/1826/5768\%5Cnhttp://www.sciencedirect.c om/science/article/pii/0883902685900102.

Bjerknes, G. \& Bratteteig, T., 1995. User participation and democracy: A discussion of Scandinavian research on system development. Scandinavian Journal of information systems, 7:1, 73-98.

Blockmans, W., Engwall, L. \& Weaire, D. eds., 2014. Bibliometrics: Use and Abuse in the Review of Research Performance, London: Portland Press Limited.

Blok, A. \& Jensen, T.E., 2011. Bruno Latour: Hybrid thoughts in a hybrid world, Routledge.

Blumer, H., 1954. What is wrong with social theory? American Sociological Review, 19:1, 3-10. 
Boland Jr., R.J., 1978. The Process and Product of System Design. Management Science, 24:9, 887-898. Available at: http://dx.doi.org/10.1287/mnsc.24.9.887.

Boland, R.J., 1991. Information Systems Use as a Hermeneutic Process. In H.-E. Nissen, H. K. Klein, \& R. A. Hirschheim, eds. Information Systems Reserach: Contemporary Approaches and Emergent Traditions. Amsterdam: North-Holland, 439-454.

Boonstra, A. \& Govers, M.J.G., 2009. Understanding ERP system implementation in a hospital by analysing stakeholders. New Technology, Work and Employment, 24:2, 177-193.

Boonstra, A., Boddy, D. \& Bell, S., 2008. Stakeholder management in IOS projects: analysis of an attempt to implement an electronic patient file. European Journal of Information Systems, 17:2, 100-111. Available at: http://www.palgravejournals.com/doifinder/10.1057/ejis.2008.2.

Bostrom, R.P. \& Heinen, J.S., 1977. MIS problems and failures: a socio-technical perspective, part II: the application of socio-technical theory. MIS quarterly, 1:4, $11-28$.

Bradford, M., Earp, J.B. \& Grabski, S., 2014. Centralized end-to-end identity and access management and ERP systems: A multi-case analysis using the technology organization environment framework. International Journal of Accounting Information Systems, 15:2, 149-165. Available at: http://dx.doi.org/10.1016/j.accinf.2014.01.003.

Brandao de Souza, L., 2009. Trends and approaches in lean healthcare. Leadership in Health Service, 22:2, 121-39.

Brown, J.S., Collins, A. \& Duguid, P., 1989. Situated cognition and the culture of learning. Educational researcher, 18:1, 32-42.

Bruns, W.J. \& Waterhouse, J.H., 1975. Budgetary control and organization structure. Journal of accounting research, 177-203.

Bryman, A., 2004. Social Research Methods, New York: Oxford University Press.

Brynjolfsson, E. \& Hitt, L.M., 2000. Beyond Computation: Journal of Economic Perspectives, 14:4, 23-48.

Buonanno, G. et al., 2005. Factors Affecting ERP System Adoption: A Comparative Analysis Between SMEs and Large Companies. Journal of Enterprise Information Management, $\quad 18: 4, \quad 384-426 . \quad$ Available at: http://www.emeraldinsight.com/10.1108/17410390510609572 [Accessed July 15, 2012].

Busch, L., 1982. History, structure, and negotiation in agricultural research. Urban Life, $11: 3,368-384$.

Butler, T., 1998. Towards a hermeneutic method for interpretive research in information systems. Journal of Information Technology, 13, 285-300.

Callon, M., 1991. Techno-economic networks and irreversibility. In J. Law, ed. $A$ sociology of monsters: essays on power, technology and domination. London: Routledge, 132-161. 
Camillus, J.C., 2008. Strategy as a Wicked Problem. Harvard Business Review, 86:5, 98-106.

Cardon, M.S. et al., 2005. A tale of passion: New insights into entrepreneurship from a parenthood metaphor. Journal of Business Venturing, 20:1, 23-45. Available at: http://www.sciencedirect.com/science/article/pii/S0883902604000059.

Carey, J.W., 2002. Cultural studies and symbolic interactionism: Notes in critique and tribute to Norman Denzin. In N. K. Denzin, ed. Studies in Symbolic Interaction. Studies in Symbolic Interaction. Emerald Group Publishing Limited, 199-209. Available at: http://dx.doi.org/10.1016/S0163-2396(02)80047-3.

Carney, M., Gedajlovic, E. \& Sur, S., 2011. Corporate governance and stakeholder conflict. Journal of Management \& Governance, 15:3, 483-507. Available at: http://dx.doi.org/10.1007/s10997-010-9135-4.

Carr, N.G., 2003. IT Doesn't Matter. Harvard Business Review, 81:5, 41-49.

Cereola, S.J., Wier, B. \& Norman, C.S., 2012. Impact of top management team on firm performance in small and medium-sized enterprises adopting commercial opensource enterprise resource planning. Behaviour \& Information Technology, 31:9, 889-907. Available

at: http://www.tandfonline.com/doi/abs/10.1080/0144929X.2010.528029 [Accessed April 2, 2013].

Charmaz, K., 2003. Grounded theory: Objectivist and constructivist methods. In N. K. Denzin \& Y. S. Lincoln, eds. Strategies for qualitative inquiry. Thousand Oaks, California: Sage, 249-291.

Chatterjee, D., Grewal, R. \& Sambamurthy, V., 2002. Shaping up for e-commerce: institutional enablers of the organizational assimilation of web technologies. MIS quarterly, 26:2, 65-89.

Checkland, P. \& Poulter, J., 2010. Soft Systems Methodology. In M. Reynolds \& S. Holwell, eds. Systems Approaches to Managing Change: A Practical Guide. London: Springer London, 191-242. Available at: http://link.springer.com/10.1007/978-1-84882-809-4_5.

Cho, S. \& Mathiassen, L., 2007. The Role of Industry Infrastructure in Telehealth Innovations: a Multi-Level Analysis of a Telestroke Program. European Journal of Information Systems, 16:6, 738-750.

Choudrie, J., Papazafeiropoulou, A. \& Lee, H., 2003. A web of stakeholders and strategies: A case of broadband diffusion in South Korea. Journal of Information Technology, 18:4, 281-290.

Ciborra, C.U., 1999. Notes on improvisation and time in organizations. Accounting, Management and Information Technologies, 9:2, 77-94. Available at: http://www.sciencedirect.com/science/article/pii/S0959802299000028.

Clarke, A.E. \& Star, S.L., 2008. The social worlds framework: A theory/methods package. In E. J. Hackett et al., eds. The handbook of science and technology studies. Cambridge, MA.: MIT Press, 113-137.

Clarke, A.E., 1990. Controversy and the Development of Reproductive Sciences. Social Problems, 37:1, 18-37. 
Clarke, A.E., 1991. Social worlds/arenas theory as organizational theory. In D. R. Maines, ed. Social organization and socials process: Essays in honor of Anselm Strauss. Hawtorne, NY: Aldine de Gruyter, 119-158.

Clarke, A.E., 1998. Disciplining Reproduction, Berkeley, CA: University of California Press.

Clarke, A.E., 2003. Situational Analyses: Grounded Theory Mapping After the Postmodern Turn. Symbolic Interaction, 26:4, 553-576.

Cole, M. \& Avison, D., 2007. The potential of hermeneutics in information systems research. European Journal of Information Systems, 16:6, 820-833. Available at: http://www.palgrave-journals.com/doifinder/10.1057/palgrave.ejis.3000725.

Contu, A. \& Willmott, H., 2003. Re-Embedding Situatedness: The Importance of Power Relations in Learning Theory. Organization Science, 14:3, 283-296. Available at: http://orca.cf.ac.uk/2681/.

Corbin, J. \& Strauss, A., 1985. Managing chronic illness at home: three lines of work. Qualitative sociology, 8:3, 224-247.

Corley, K.G. \& Gioia, D.A., 2011. Building Theory About Theory Building: What Constitutes A Theoretical Contribution? Academy of Management Review, 36:1, $12-32$.

Crane, A. \& Livesey, S.M., 2003. Are you talking to me? Stakeholder communication and the risks and rewards of dialogue. Unfolding stakeholder thinking 2: Relationships, communication, reporting and performance, 1-32.

Cressey, P.G., 2008. The taxi-dance hall: A sociological study in commercialized recreation and city life, University of Chicago Press.

Cummings, S. \& Angwin, D., 2004. The future shape of strategy: Lemmings or chimeras? Academy of Management Executive, 18:2, 21-36. Available at: http://wrap.warwick.ac.uk/8258/.

Dalton, M., 1959. Men Who Manage: Fusions of Feeling and Theory in Administration 2013th ed., New Brunswick, NJ: Transaction Publishers.

Davenport, T.H., 1998. Putting the enterprise into the enterprise system. Harvard Business Review, 76:4, 121-31. Available at: http://www.ncbi.nlm.nih.gov/pubmed/10181586.

Davis, F.D., 1989. Perceived Usefulness, Perceived Ease of Use, and User Acceptance of. Information Technolog MIS Quarterly, 13:3, 319-340.

Davis, G.F., 2010. Do Theories of Organizations Progress? Organizational Research Methods, 13:4, 690-709.

De Leoz, G.M. \& Petter, S.C., 2013. Infusing High Performance Teams in Information System Work Environments. In MWAIS 2013. Paper 12. Available at: http://aisel.aisnet.org/mwais2013/12.

DeLone, W.H. \& Mclean, E.R., 2003. The DeLone and McLean Model of Information Systems Success: A Ten-Year Update. Journal of Management Information Systems, 19:4, 9-30. 
Denzin, N.K. \& Lincoln, Y.S., 2011. Introduction: The discipline and practice of qlaitative research. In N. K. Denzin \& Y. S. Lincoln, eds. The SAGE Handbook of Qualitative Research. Thousand Oaks, California, 1-21.

Denzin, N.K., 1978. The Research Act: A Theoretical Introduction to Sociological Methods 2nd ed., New York: McGraw-Hill.

DePietro, R., Wiarda, E. \& Fleischer, M., 1990. The context for change: Organization, technology and environment. In L. G. Tornatzky \& M. Fleischer, eds. The processes of technological innovation. Lexington, MA: Lexington Books, 151175.

Dewey, J., 1998. How we think: A restatement of the relation of reflective thinking to the educational process., Lexington, MA: Heath.

DiMaggio, P. \& Powell, W.W., 1983. The iron cage revisited: Institutional isomorphism and collective rationality in organizational fields. American Sociological Review, $48,147-160$.

Donaldson, T. \& Preston, L.E., 1995. The stakeholder theory of the corporation: concepts, evidence and implications. Academy of Management Review, 20, 63-91.

Doolin, B. \& McLeod, L., 2012. Sociomateriality and boundary objects in information systems development. European Journal of Information Systems, 21:5, 570-586. Available at: http://dx.doi.org/10.1057/ejis.2012.20.

Drori, G.S. \& Meyer, J.W., 2006. Scientization: Making a world safe for organizing. In M.-L. Djelic \& K. Sahlin-Andersson, eds. Transnational Governance: Institutional Dynamics of Regulation. New York, 31-52.

Dwivedi, Y. et al., 2015. Reseach on information systems failures and successes: status update and future directions. Information Systems Frontiers, 17:1, 143-157.

Dyer, W.G. \& Wilkins, A.L., 1991. Better Stories, Not Better Constructs, To Generate Better Theory: a Rejoinder To Eisenhardt. Academy of Management Review, 16:3, 613-619. Available at: http://amr.aom.org/cgi/doi/10.5465/AMR.1991.4279492.

Earl, M.J., 1997. Knowledge as strategy: reflections on Skandia International and Shorko Films n (PRUSAK L, Ed), pp. 1-15,. In L. Prusak, ed. Knowledge in Organizations. Boston, MA: Butterworth-Heinemann, 1-15.

Edley, N. \& Wetherell, M., 1997. Jockeying for position: The construction of masculine identities. Discourse \& society, 8:2, 203-217.

Edwards, D., 1994. Script Formulations: An Analysis of Event Descriptions in Conversation. Journal of Language and Social Psychology, 13:3, 211-247. Available at: http://dx.doi.org/10.1177/0261927X94133001.

Edwards, D., 1995. Sacks and psychology. Theory and Pyschology, 5:4, 579-596.

Ehn, P., 1993. Scandinavian design: On participation and skill. In D. Schuler \& A. Namioka, eds. Participatory design: Principles and practices. Hillsdale: Lawrence Erlbaum Associates, 41-77.

Eisenhardt, K.M., 1989. Building Theories from Case Study Research. The Academy of Management Review, 14:4, 532-550. 
El Sawy, O.A., 2003. The IS Core IX: The 3 Faces of IS Identity: Connection, Immersion, and Fusion. The Communications of the Association for Information Systems, 12, 588-598.

Elbanna, A.R., 2006. The validity of the improvisation argument in the implementation of rigid technology: The case of ERP systems. Journal of Information Technology, $21: 3,165-175$.

Engwall, L. \& Scott, P. eds., 2013. Trust in Universities, London: Portland Press Limited.

Engwall, L., 1986. Mercury Meets Minerva. Scandinavian Journal of Management Studies, 3:2, 121-138. Available at: http://www.sciencedirect.com/science/article/pii/0281752786900241 [Accessed September 10, 2012].

Engwall, L., 1992. Mercury Meets Minerva, Oxford: Pergamon Press.

Fassin, Y., 2008. Imperfections and shortcomings of the stakeholder model's graphical representation. Journal of Business Ethics, 80, 879-888.

Fassin, Y., 2009. The stakeholder model refined. Journal of Business Ethics, 84:1, $113-$ 135.

Fassin, Y., 2010. A Dynamic Perspective in Freeman's Stakeholder Model. Journal of Business Ethics, 96:S1, 39-49. Available at: http://link.springer.com/10.1007/s10551-011-0942-6.

Fassin, Y., 2012. Stakeholder Management, Reciprocity and Stakeholder Responsibility. Journal of Business Ethics, 109:1, 83-96. Available at: http://search.proquest.com.library.capella.edu/docview/1030717525?accountid=27 965\%5Cnhttp://wv9lq5ld3p.search.serialssolutions.com.library.capella.edu/?ctx_v er=Z39.88-2004\&ctx_enc=info:ofi/enc:UTF8\&rfr_id=info:sid/ProQ:abiglobal\&rft_val_fmt=info:ofi/fmt:

Federici, T., 2009. Factors influencing ERP outcomes in SMEs: a post-introduction assessment Y. K. Dwivedi, ed. Journal of Enterprise Information Management, $22: 1 / 2$, $81-98$. Available at: http://www.emeraldinsight.com/doi/abs/10.1108/17410390910922840.

Figueres-Munoz, A. \& Merschbrock, C., 2017. BIM adoption for on-site reinforcement works - a work system view. In eWork and eBusiness in Architecture, Engineering and Construction: ECPPM 2016: Proceedings of the 11th European Conference on Product and Process Modelling (ECPPM 2016), Limassol, Cyprus, 7-9 September 2016. CRC Press.

Flak, L.S. \& Rose, J., 2005. Stakeholder governance: Adapting stakeholder theory to egovernment. Communications of the Association for Information Systems, 16:1, 31.

Flak, L.S., Nordheim, S. \& Munkvold, B.E., 2008. Analyzing stakeholder diversity in G2G efforts: Combining descriptive stakeholder theory and dialectic process theory. e-Service Journal, 6:2, 3-23.

Flick, U., 2009. An Introduction to Qualitative Research 4th ed., Thousand Oaks, California: Sage Publications. 
Flyvbjerg, B., 2006. Five Misunderstandings About Case-Study Research. Qualitative Inquiry, 12:2, 219-245.

Freeman, R.E. et al., 2010. Stakeholder Theory The State of Art, Cambridge: Cambridge University Press. Available at: www.cambridge.org/9780521190817\%5Cn?

Freeman, R.E., 1984. Strategic Management: A Stakeholder Approach, Boston: Pitman.

Freeman, R.E., 2010. Strategic management: A stakeholder approach, Cambridge University Press.

Freeman, R.E., Harrison, J.S. \& Wicks, A.C., 2007. Managing for Stakeholders: Survival, Reputation, and Success, New Haven, CT: Yale University Press.

Friedman, A.L. \& Miles, S., 2002. Developing stakeholder theory. Journal of management studies, 39:1, 1-21.

Gadamer, H., 2004. Truth and Method, New York: Continuum.

Gal, U., Yoo, Y. \& Boland Jr, R., 2005. The Dynamics of Boundary Objects, Social Infastructures and Social Identities. ECIS 2005 Proceedings, 57.

Garrity, E., 2001. Synthesizing User Centered and Designer Centered IS Development Approaches Using General Systems Theory. Information Systems Frontiers, 3:1, 107-121. Available at: http://dx.doi.org/10.1023/A\%3A1011457822609.

Ghobakhloo, M., Arias-Aranda, D. \& Benitez-Amado, J., 2011. Adoption of ecommerce applications in SMEs,

Gibbs, J.L. \& Kraemer, K.L., 2004. A cross-country investigation of the determinants of scope of e-commerce use: an institutional approach. Electronic Markets, 14:2, $124-137$.

Giddens, A., 2001. Sociology 4th ed., Cambridge: Polity.

Gilbert, G.N. \& Mulkay, M., 2003. Opening Pandora's Box: A sociological analysis of scientitst's discourse, Cambridge, UK: Press Syndicate of the University of Cambridge. Available at: http://www.surrey.ac.uk/sociology/people/opening_pandoras_box.htm.

Glaser, B.G. \& Strauss, A.L., 1967. The discovery of grounded theory: Strategies for qualitative research, Chicago: Aldine.

Glaser, B.G. \& Strauss, A.L., 1968. Time for Dying, Chicago: Aldine.

Goldfinch, S. \& Wallis, J., 2010. Two Myths of Convergence in Public Management Reform. Public Administration, 88:4, 1099-1115. Available at: http://www.ingentaconnect.com/content/bpl/padm/2010/00000088/00000004/art00 011.

Gray, B. \& Wood, D.J., 1991. Collaborative alliances: Moving from practice to theory. Journal of Applied Behavioral Science, 27:1, 3-22.

Gregor, S. et al., 2006. The transformational dimension in the realization of business value from information technology. Journal of Strategic Information Systems, $15: 3,249-270$.

Gregor, S., 2006. The Nature of Theory in Information Systems. MIS Quarterly, 30:3, 611-642. 
Grover, V. \& Lyytinen, K., 2015. New state of play in information systems research: The push to the edges. MIS Quarterly, 39:2, 271-296.

Guzman, G., 2008. Sharing practical knowledge in hostile environments: a case study. Journal of Workplace Learning, 20:3, 195-212.

Hall, P.M. \& Spencer-Hall, D.A., 1982. The social conditions of the negotiated order. Urban Life, 11:3, 328-349.

Handley, K. et al., 2006. Within and beyond communities of practice: Making sense of learning through participation, identity and practice. Journal of management studies, 43:3, 641-653.

Harrison, J.S. \& Freeman, R.E., 1999. Stakeholders, Social Responsibility, and Performance: Empirical Evidence and Theoretical Perspectives. The Academy of Management Review, 42:5, 479-485.

Harvey, F. \& Chrisman, N., 1998. Boundary objects and the social construction of GIS technology. Environment and planning A, 30:9, 1683-1694.

Hendry, J., 2001. Missing the target: Normative stakeholder theory and the corporate governance debate. Business Ethics Quarterly, 11:1, 159-179.

Hirschheim, R. \& Klein, H.K., 2012. A Glorious and Not-So-Short History of the Information Systems Field. Journal of the Association for Information Systems, $13: 4,188-235$.

Holzer, B., 2008. Turning stakeseekers into stakeholders: A political coalition perspective on the politics of stakeholder influence. Business \& Society, 47:1, 50 67.

Hoti, E., 2015. The technological, organizational and environmental framework of IS innovation adaption in small and medium enterprises. Evidence from research over the last 10 years. International Journal of Business and Management, III:4, 1-14. Available at: http://www.iises.net/international-journal-of-businessmanagement/publication-detail-255.

Howarth, D., 2000. Discourse, Buckingham: Open Univerity Press.

Hsu, P.-F., Kraemer, K.L. \& Dunkle, D., 2006. Determinants of E-Business Use in U.S. Firms. International Journal of Electronic Commerce, 10:4, 9-45. Available at: http://login.ezproxy.lib.umn.edu/login?url=http://search.ebscohost.com/login.aspx?

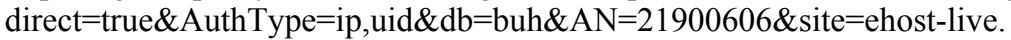

Hunter, B., 2010. Moving Open Access to Open Source: Transitioning an Open-Access Journal into the Open Journal Systems Journal Management System. Technical Services Quarterly, 28:1, 31-40.

Iacovou, C.L., Benbasat, I. \& Dexter, A.S., 1995. Electronic Data Interchange and Small Organizations: Adoption and Impact of Technology. MIS Quarterly, 19:4, 465-485. Available at: http://www.jstor.org/stable/249629? origin=crossref.

Iansiti, M. \& Levien, R., 2004. Strategy as Ecology. Harvard Business Review, 82:3, 68-81.

Iansiti, M. \& Richards, G.L., 2006. Information technology ecosystem: Structure, health, and performance, The. Antitrust Bull., 51:1, 77-110. 
Imre, Ö., 2014a. Constructing an open source ERP sales pitch- In search for interpretative repertoires. In 8th Mediterranean Conference on Information Systems (MCIS 2014), 3-5 September. Available at: http://aisel.aisnet.org/mcis2014/33.

Imre, Ö., 2014b. Repertoires of publishing: A talk with PhD students. In EGOS European Group for Organizational Studies 2014, July 3-5, Rotterdam. 1-25.

Imre, Ö., 2015a. Learning by negotiation - Stake and salience in implementing a journal management system. In 16th EBES Conference - Istanbul, 27-29 May. Istanbul, Turkey.

Imre, Ö., 2015b. Learning by negotiation - Implementing a journal management system. In K. Lambrinoudakis, V. Morabito, \& M. Themistocleous, eds. 12th European, Mediterranean and Middle Eastern Conference on Information Systems (EMCIS 2015), 1-2 June. Athens, Greece. Available at: http://emcis2015.emcis.eu/EMCISfiles/Proceedings.pdf.

Intuit, 2016. Hi, I'm using a trial version of Global Quickbooks from Bolivia... Available at: https://community.intuit.com/questions/1320858-hi-i-m-using-a-trialversion-of-global-quickbooks-from-bolivia-i-want-to-add-the-payroll-module-is-itpossible-i-want-to-pay-the-essential-subscription.

Irani, Z., 2002. Information systems evaluation: navigating through the problem domain. Information \& Management, 40:1, 11-24.

Iskanius, P., Halonen, R. \& Mottonen, M., 2009. Experiences of ERP use in small enterprises. In 11th International Conference on Enterprise Information Systems, Milan, Italy.

Jasperson, J., Carter, P. \& Zmud, R., 2005. A comprehensive conceptualization of postadoptive behaviors associated with information technology enabled work systems. MIS Quarterly, 29:3, 525-557. Available at: http://dl.acm.org/citation.cfm?id=2017272\%5Cnpapers3://publication/uuid/E1BF7 070-F04D-426B-9124-F311A812D8AE.

Jensen, T.B., Kjærgaard, A. \& Svejvig, P., 2009. Using institutional theory with sensemaking theory: a case study of information system implementation in healthcare. Journal of Information Technology, 24:4, 343-353. Available at: https://doi.org/10.1057/jit.2009.11.

Jeon, B.N., Han, K.S. \& Lee, M.J., 2006. Determining factors for the adoption of ebusiness: the case of SMEs in Korea. Applied Economics, 38:16, 1905-1916.

Jeyaraj, A., Rottman, J.W. \& Lacity, M.C., 2006. A review of the predictors, linkages, and biases in IT innovation adoption research. Journal of Information Technology, $21: 1,1-23$.

Jha, A.K. \& Bose, I., 2016. Innovation Research in Information Systems: A Commentary on Contemporary Trends and Issues. Information \& Management, 53:3, 297-306. Available at: http://www.sciencedirect.com/science/article/pii/S0378720615001238.

Jones, M.C., Cline, M. \& Ryan, S., 2006. Exploring knowledge sharing in ERP implementation: an organizational culture framework. Decision Support Systems, $41: 2$,

411-434.

Available

at: 
http://linkinghub.elsevier.com/retrieve/pii/S0167923604001630 [Accessed August 20, 2012].

Jones, T.M. \& Wicks, A.C., 1999. Convergent stakeholder theory. Academy of management review, 24:2, 206-221.

Jones, T.M., 1980. Corporate social responsibility revisited, redefined. California Management Review, 22:2, 59-67.

Jonsson, K., Holmström, J. \& Lyytinen, K., 2009. Turn to the material: Remote diagnostics systems and new forms of boundary-spanning. Information and Organization, 19:4, 233-252. Available at: http://dx.doi.org/10.1016/j.infoandorg.2009.07.001.

Jorgensen, M. \& Phillips, L.J., 2002. Discourse Analysis as Theory and Method, London: Sage Publications.

Kaler, J., 2002. Morality and strategy in stakeholder identification. Journal of Business Ethics, 39:1-2, 91-99.

Kamal, M., Weerakkody, V. \& Irani, Z., 2011. Analyzing the role of stakeholders in the adoption of technology integration solutions in UK local government: An exploratory study. Government Information Quarterly, 28, 200-210.

Kampath, N. \& Röglinger, M., 2010. Operational and work system-related success factors for customer relationship management in "product sales" and "solution sales"-a descriptive case study. In Proceedings of ECIS 2010, the 18th European Conference on Information Systems.

Karimi, J., Somers, T.M. \& Bhattacherjee, A., 2007. The Role of Information Systems Resources in ERP Capability Building and Business Process Outcomes. Journal of Management Information Systems, 24:2, 221-260. Available at: http://www.tandfonline.com/doi/abs/10.2753/MIS0742-1222240209.

Keating, P. \& Cambrosio, A., 2003. Biomedical platforms: Realigning the normal and the pathological in late-twentieth-century medicine, Cambridge, MA.: MIT Press.

Kietzmann, J., 2008. Interactive innovation of technology for mobile work. European Journal of Information Systems, 17:3, 305-320.

Klein, H.K. \& Myers, M.D., 1999. A Set of Principles for Conducting and Evaluating Interpretive Field Studies in Information Systems. MIS quarterly, 23:1, 67-93. Available at: http://www.jstor.org/stable/10.2307/249410 [Accessed January 27, 2013].

Koh, S.C.L. \& Simpson, M., 2007. Could enterprise resource planning create a competitive advantage for small businesses? Benchmarking: An International Journal, $\quad 14: 1, \quad 59-76 . \quad$ Available at: http://www.emeraldinsight.com/10.1108/14635770710730937 [Accessed July 17, 2012].

Korpela, M.M. et al., 2004. IS research and development by activity analysis and development: Dead horse or the next wave? In Relevant Theory and Informed Practice: Looking Forward from a 20-Year Perspective on IS Research 15-17 July 2004, Manchester. Kluwer Academic Publishers, 453-471. 
Kotter, J.P., 1982. What effective general managers really do. Harvard Business Review, 60:6, 156-167. Available at: ftp://87-104-13-156-dynamiccustomer.profibernet.dk/Qmultimedia/bøger/Arbejde/Generel ledelse og strategi/(Ebook Hbr) - Harvard Business School - Effective Managers.pdf [Accessed August 11, 2014].

Kuan, K.K.Y. \& Chau, P.Y.K., 2001. A perception-based model for EDI adoption in small businesses using a technology-organization-environment framework. Information and Management, 38:8, 507-521.

Laakso, M. et al., 2011. The development of open access journal publishing from 1993 to 2009. PLOS ONE, 6:6.

Lamberg, J.-A. et al., 2008. Stakeholder management and path dependence in organizational transitions. Management Decision, 46:6, 846-863.

Laplume, A.O., Sonpar, K. \& Litz, R.A., 2008. Stakeholder Theory: Reviewing a Theory That Moves Us. Journal of Management, 34:6, 1152-1189. Available at: http://jom.sagepub.com/cgi/doi/10.1177/0149206308324322.

Larsen, P.O. \& von Ins, M., 2010. The rate of growth in scientific publication and the decline in coverage provided by science citation index. Scientometrics, 84:3, 575 603.

Latour, B., 1983. Give me a laboratory and I will raise the world. In K. D. Knorr-Cetina \& M. J. Mulkay, eds. Science Observed. Beverly Hills: Sage, 141-170.

Latour, B., 1986. The Powers of Association. In J. Law, ed. Action and belief: A new sociology of knowledge?. London: Routlege \& Kegan Paul, 264-280.

Latour, B., 1996. On interobjectivity. Mind, culture, and activity, 3:4, 228-245.

Latour, B., 2005. Reassembling the Social: An Introduction to Actor-network Theory, Oxford: Oxford University Press.

Lauerbach, G., 2006. Discourse representation in political interviews: The construction of identities and relations through voicing and ventriloquizing. Journal of Pragmatics, 38:2, 196-215.

Laukkanen, S., Sarpola, S. \& Hallikainen, P., 2007. Enterprise size matters: objectives and constraints of ERP adoption. Journal of Enterprise Information Management, 20:3, 319-334. Available at: http://dx.doi.org/10.1108/17410390710740763.

Lave, J. \& Wenger, E., 1991. Situated Learning: Legitimate Peripheral Participation, Cambridge, UK: Cambridge University Press.

Law, J., 1991. Power, discretion and strategy. In J. Law, ed. A sociology of monsters: essays on power, technology and domination. London: Routledge, 165-191.

Lawrence, T.B. \& Suddaby, R., 2006. Institutions and Institutional Work. In S. R. Clegg et al., eds. Handbook of Organization Studies 2nd. Sage Publications, 215254.

Lee, A.S. \& Baskerville, R.L., 2003. Generalizing Generalizability in Information Systems Research. Information Systems Research, 14:3, 221-243. 
Leonardi, P.M. \& Barley, S.R., 2010. What's Under Construction Here? Social Action, Materiality, and Power in Constructivist Studies of Technology and Organizing. The Academy of Management Annals, 4:1, 1-51.

Leonardi, P.M., 2011. When flexible routines meet flexible technologies: Affordance, constraint, and the imbrication of human and material agencies. MIS quarterly, 35:1, 147-167. Available at: http://web.stanford.edu/group/WTO/cgibin/uploads/Leonardi 2011b.pdf [Accessed December 10, 2014].

Lincoln, Y.S. \& Guba, E.G., 2003. Ethics: The Failure of Positivist Science. In Y. S. Lincoln \& N. K. Denzin, eds. Turning points in qualitative research: Tying knots in a handkerchief. Walnut Creek: Altamira Press, 219-238.

Lindgren, I., 2013. Public e-service stakeholders - A study on who matters for public eservice development and implementation. Linköpings University.

Lindman, J., Rossi, M. \& Tuunainen, V.K., 2013. Open data services: Research agenda. In 46th Hawaii International Conference on System Sciences (HICSS). IEEE, 1239-1246.

Llewelyn, S., 2003. What counts as "theory" in qualitative management and accounting research? Introducing five levels of theorizing. Accounting, Auditing \& Accountability Journal, 16:4, 662-708.

Lofland, J. \& Lofland, L., 1995. Analyzing social settings: A guide to qualitative observation and analysis, Belmont, CA: Wadsworth.

Lucas, L., 2006. The Research Game in Academic Life, London: SHRE \& Open University Press.

Lyytinen, K. \& Hirschheim, R., 1987. Information systems failures: a survey and classification of the empirical literature. In Oxford Surveys in Information Technology. Oxford: Oxford University Press, 257-309.

Lyytinen, K., Newman, M. \& Al-Muharfi, A.-R.A., 2009. Institutionalizing enterprise resource planning in the Saudi steel industry: a punctuated socio-technical analysis. Journal of Information Technology, 24:4, 286-304.

Majchrzak, A. \& Markus, M.L., 2014. Methods for policy resarch: Taking socially responsible action 2nd ed., Sage Publications.

Malhotra, R. \& Temponi, C., 2010. Critical decisions for ERP integration: Small business issues. International Journal of Information Management, 30:1, 28-37.

Mann, F. et al., 2009. Open access publishing in science. Communications of the ACM, $52: 3,135-139$.

Markus, M.L. \& Benjamin, R.I., 1997. The magic bullet theory in IT- enabled transformation. Sloan Management Review, 38:2, 55-68. Available at: $\mathrm{http} / /$ layoftheland.net/archive/web/mis575/course_docs/topic_4/Markus.magicbullet.pdf [Accessed May 19, 2014].

Markus, M.L. \& Tanis, C., 2000. The Enterprise Experience - From Adoption to Success. In R. W. Zmud, ed. Framing the Domains of IT Research: Projecting the Future through the Past. Cincinnati, OH.: Pinnaflex Educational Resources Inc.

Mars, M.M., Bronstein, J.L. \& Lusch, R.F., 2012. The Value of a Metaphor: Organizations and Ecosystems. Organizational Dynamics, 41:4, 271-280. 
Available at: http://linkinghub.elsevier.com/retrieve/pii/S009026161200068X [Accessed February 3, 2013].

Mathiassen, L. \& Nielsen, P.A., 2008. Engaged Scholarship in IS Research. Scandinavian Journal of Information Systems, 20:2, 3-20.

Mathiassen, L. \& Pedersen, K., 2005. The Dynamics of Knowledge in Systems Development Practice. Proceedings of the 38th Hawaii International Conference on System Sciences.

Mengiste, S.A. \& Aanestad, M., 2013. Understanding the dynamics of learning across social worlds: A case study from implementing IS in the Ethiopian public health care system. Information and Organization, 23:4, 233-257. Available at: http://dx.doi.org/10.1016/j.infoandorg.2013.08.001.

Merchant, K.A., 1984. Influences on departmental budgeting: An empirical examination of a contingency model. Accounting, organizations and society, 9:3-4, 291-307.

Meyer, J.P. \& Allen, N.J., 1991. A three-component conceptualization of organizational commitment. Human Resource Management Review, 1:1, 61-89.

Meyer, J.W. \& Rowan, B., 1977. Institutionalized Organizations : Formal Structure as Myth and Ceremony. American Journal of Sociology, 83:2, 340-363.

Miller, D., 2007. Paradigm prison, or in praise of atheoretic research. Strategic Organization, 5:2, 177-184.

Mingers, J. \& Walsham, G., 2010. Towards ethical information systems: The contribution of discourse ethics. MIS Quarterly, 34:4, 833-854.

Mintzberg, H., 1978. Patterns in Strategy Formation. Management Science, 24:9, 934948 .

Mitchell, R.K., Agle, B.R. \& Wood, D.J., 1997. Toward a theory of stakeholder identification and salience: Defining the principle of who and what really counts. Academy of Management Review, 22:4, 853-886.

Mitchell, R.K., Agle, B.R. \& Wood, D.J., 1997. Toward a theory of stakeholder identification and salience: Defining the principle of who and what really counts. Academy of management review, 22:4, 853-886.

Morton, N. a. \& Hu, Q., 2008. Implications of the fit between organizational structure and ERP: A structural contingency theory perspective. International Journal of Information Management, 28:5, 391-402. Available at: http://linkinghub.elsevier.com/retrieve/pii/S0268401208000030 [Accessed November 6, 2012].

Mumford, E., 2006. The story of socio-technical design: reflections on its successes, failures and potential. Information Systems Journal, 16, 317-342. Available at: http://onlinelibrary.wiley.com/doi/10.1111/j.1365-2575.2006.00221.x/full [Accessed February 11, 2013].

Murray, J.B., Evers, D.J. \& Janda, S., 1995. Marketing, Theory Borrowing, and Critical Reflection. Journal of Macromarketing, 15:2, 92-106. Available at: http://journals.sagepub.com/doi/abs/10.1177/027614679501500207.

Murthy, V. \& Marjanovic, O., 2014. Understanding a Transformation Process from Product-Centric to Customer-Centric Services in a Financial Institution - A Work 
System Perspective. In J. G. Davis, H. Demirkan, \& H. R. Motahari-Nezhad, eds. Service Research and Innovation. ASSRI 2013. Lecture Notes in Business Information Processing, vol 177. Cham: Springer International Publishing, 29-43. Available at: http://dx.doi.org/10.1007/978-3-319-07950-9_3.

Myers, M.D., 2013. Qualitative Research in Business and Management 2nd ed., London: Sage.

Nadai, E. \& Maeder, C., 2008. Negotiations at all Points ? Interaction and Organization. Forum Qualitative Sozialforschung, 9:1, Art 32.

Nah, F.F., Lau, J.L. \& Kuang, J., 2001. Critical factors for successful implementation of enterprise systems. Business Process Management Journal, 7:3, 285-296.

Norman, D. a., 1999. Affordance, conventions, and design. Interactions, 6, 38-43.

Nwankpa, J.K., 2015. ERP system usage and benefit: A model of antecedents and outcomes. Computers in Human Behavior, 45:2015, 335-344. Available at: http://dx.doi.org/10.1016/j.chb.2014.12.019.

Oakley, A., 1981. Interviewing women: a contradiction in terms', in H. Roberts (ed.) Doing Feminist Research, London: Routledge. In H. Roberts, ed. Doing Feminist Research. London: Routledge, 30-61.

Oliveira, T. \& Martins, M.F., 2010. Understanding e-business adoption across industries in European countries. Industrial Management \& Data Systems, 110:9, 1337-1354. Available

at: http://www.emeraldinsight.com/10.1108/02635571011087428

[Accessed November 27, 2013].

Oliveira, T. \& Martins, M.F., 2011. Literature Review of Information Technology Adoption Models at Firm Level. The Electronic Journal Information Systems Evaluation, 14:1, 110-121.

Orlikowski, W.J. \& Barley, S.R., 2001. Technology and institutions: what can research on Information Technology and research on organizations learn from each other. MIS Quarterly, 25:2, 145-165.

Orlikowski, W.J. \& Hofman, J.D., 1997. An Improvisational Model for Change Management: The Case of Groupware Technologies. Sloan Management Review, $38: 1,11-21$.

Orlikowski, W.J. \& Iacono, C.S., 2001. Research Commentary : Desperately Seeking the "IT" in IT Research - A Call to Theorizing the IT Artifact. Information Systems Research, 12:2, 121-134.

Orlikowski, W.J. \& Robey, D., 1991. Information Technology and the Structuring of Organizations. Center for Information Systems Research. Decision Sciences, 2:2, 143-169.

Orlikowski, W.J. \& Scott, S. V., 2008. 10 Sociomateriality: Challenging the Separation of Technology, Work and Organization. The Academy of Management Annals, 2:1, 433-474.

Orlikowski, W.J., 1996. Improvising organizational transformation over time: A situated change perspective. Information systems research, 7:1, 63-92. 
Ostgaard, T. a. \& Birley, S., 1994. Personal networks and firm competitive strategy-A strategic or coincidental match? Journal of Business Venturing, 9:4, 281-305.

Pan, G. \& Pan, S.L., 2006. Examining the coalition dynamics affecting IS project abandonment decision-making. Decision Support Systems, 42:2, 639-655.

Pan, G.S.C., 2005. Information systems project abandonment: a stakeholder analysis. International Journal of Information Management, 25:2, 173-184.

Pan, M.-Y. \& Jang, W.-Y., 2008. Determinants of the Adoption of Enterprise Resource Planning within the Technology-Organization-Environment Framework: Taiwan's Communications Industry. Journal of Computer Information Systems, 48:3, 94 102. http://www.tandfonline.com/doi/abs/10.1080/08874417.2008.11646025.

Parker, C.M. \& Castleman, T., 2009. Small firm e-business adoption: a critical analysis of theory. Journal of Enterprise Information Management, 22:1/2, 167-182.

Parmar, B.L. et al., 2010. Stakeholder Theory: The State of the Art. The Academy of Management Annals, 4:1, 403-445. Available at: http://www.tandfonline.com/doi/abs/10.1080/19416520.2010.495581.

Patton, M.Q., 2002. Qualitative Research \& Evaluation Methods 3rd ed., Thousand Oaks, California: Sage Publications.

Pesqueux, Y. \& Damak-Ayadi, S., 2005. Stakeholder Theory in Perspective. Corporate Governance: The international journal of business in society, 5:2, 5-21.

Petersson, J., 2008. Work system principles. In Proceedings of the 3rd International Conference on the Pragmatic Web Innovating the Interactive Society - ICPW '08. 69-76. Available at: http://portal.acm.org/citation.cfm?doid=1479190.1479200.

Phillips, N., Sewell, G. \& Jaynes, S., 2008. Applying critical discourse analysis in strategic management research. Organizational Research Methods, 11:4, 770-789.

Phillips, R., 2003. Stakeholder Legitimacy. Business Ethics Quarterly, 13:1, 25-41.

Pishdad, A. et al., 2015. Identifying Gaps in Institutional Theory. In 25th Australasian Conference on Information Systems (ACIS), 8-10 Dec 2014, Auckland New Zealand. Auckland, New Zealand.

Poba-Nzaou, P. \& Raymond, L., 2010. Managing ERP system risk in SMEs: a multiple case study. Journal of Information Technology, 26:3, 170-192. Available at: http://www.palgrave-journals.com/doifinder/10.1057/jit.2010.34 [Accessed April 2, 2013].

Polydoratou, P. \& Moyle, M., 2008. Scientific journals, overlays and repositories: A case of costs and sustainability issues. Lecture Notes in Computer Science (including subseries Lecture Notes in Artificial Intelligence and Lecture Notes in Bioinformatics), 5362 LNCS, 154-163. Available at: http://www.scopus.com/inward/record.url?eid=2-s2.058049107849\&partnerID=40\&md5=bde18ca7c63c6fe483d19e91c5901375.

Potter, J. \& Mulkay, M., 1985. Scientists' interview talk: interviews as a technique for revealing participants' interpretative practices. In M. Brenner, J. Brown, \& D. Canter, eds. The research interview: uses and approaches. London: Academic Press, 247-271. 
Potter, J. \& Wetherell, M., 1987. Discourse and Social Psychology, London: Sage Publications.

Potter, J. \& Wetherell, M., 1994. Analyzing discourse. In A. Bryman \& K. Burgess, eds. Analyzing qualitative data. London: Routledge, 47-66.

Pouloudi, A. \& Whitley, E.A., 1997. Stakeholder identification in inter-organisational systems: gaining insights for drug use management systems. European Journal of Information Systems, 6:1, 1-14.

Pouloudi, A., 1999. Aspects of the stakeholder concept and their implications for information systems development. In Systems Sciences, 1999. HICSS-32. Proceedings of the 32nd Annual Hawaii International Conference on. IEEE, 17pp.

Rahayu, R. \& Day, J., 2015a. Determinant Factors of E-commerce Adoption by SMEs in Developing Country: Evidence from Indonesia. Procedia - Social and Behavioral Sciences, 195, 142-150. Available at: http://linkinghub.elsevier.com/retrieve/pii/S1877042815039026.

Rahayu, R. \& Day, J., 2015b. Determinant Factors of E-commerce Adoption by SMEs in Developing Country: Evidence from Indonesia. Procedia - Social and Behavioral Sciences, 195, 142-150. Available at: http://www.sciencedirect.com/science/article/pii/S1877042815039026.

Ramdani, B., Kawalek, P. \& Lorenzo, O., 2009. Predicting SMEs adoption of enterprise systems. Journal of Enterprise Information Management, 22:1/2, 10-24. Available at: http://dx.doi.org/10.1108/17410390910922796.

Riehle, D., 2007. The Economic Motivation of Open Source Software: Stakeholder Perspectives. IEEE Computer, 40:4, 25-32.

Robey, D. \& Sahay, S., 1996. Transforming Work Through Information Technology: A Comparative Case Study of Geographic Information Systems in County Government. Information Systems Research, 7:1, 93-110. Available at: http://dx.doi.org/10.1287/isre.7.1.93.

Robey, D., Boudreau, M.-C. \& Rose, G.M., 2000. Information technology and organizational learning: a review and assessment of research. Accounting, Management and Information Technologies, 10:2, 125-155.

Robey, D., Schwaig, K.S. \& Jin, L., 2003. Intertwining material and virtual work. Information and Organization, 13, 111-129.

Rogers, E.M., 1983. Diffusion of Innovations 3rd ed., New York: The Free Press.

Romm, C.T., Pliskin, N. \& Rifkin, W.D., 1996. Diffusion of E-mail: An organisational learning perspective. Information and Management, 31:1, 37-46.

Rowley, J., 2011. e-Government stakeholders-Who are they and what do they want? International Journal of Information Management, 31:1, 53-62. Available at: http://www.sciencedirect.com/science/article/pii/S0268401210000666.

Sahay, S. \& Walsham, G., 1996. Implementation of GIS in India: organizational issues and implications. International Journal of Geographical Information Systems, $10: 4,385-404$. 
Saldaña, J., 2009. The coding manual for qualitative researchers, Thousand Oaks, California: Sage Publications.

Salge, T.O., Kohli, R. \& Barrett, M., 2015. Investing in Information Systems: on the Behavioral and Institutional Search Mechanisms Underpinning Hospitals' Is Investment Decisions. MIS Quarterly, 39:1, 61-90. Available at: http://search.ebscohost.com/login.aspx?direct=true \&db=bth\&AN=100717559\&lan $\mathrm{g}=\mathrm{zh}$-cn\&site $=$ ehost-live.

Sarker, S. et al., 2012. Exploring Value Cocreation in Relationship Between an ERP Vendor and its Partners: A Revelatory Case Study. MIS Quarterly, 36:1, 317-338.

Saviotti, P.P., 1996. Technology Evolution, Variety and the Economy, Cheltenham, UK: Edward Elgar Publishing.

Sayer, A., 2010. Method in Social Science: A Realist Approach Revised 2n., New York: Routledge.

Scapens, R.W. \& Jazayeri, M., 2003. ERP systems and management accounting change: opportunities or impacts? A research note, Available at: http://www.tandfonline.com/doi/abs/10.1080/0963818031000087907 [Accessed November 7, 2014].

Scholl, J., 2004. Involving salient stakeholders. Beyond the technocratic view on change. Action Research, 2:3, 277-304.

Schonberger, R.J., 1980. MIS Design: a Contingency Approach. MIS Quarterly, 4:1, $13-20$.

Schryen, G., 2013. Revisiting IS business value research: what we already know, what we still need to know, and how we can get there. European Journal of Information Systems, 22:2, 139-169. Available at: http://link.springer.com/10.1057/ejis.2012.45.

Scott, S.V. \& Wagner, E.L., 2003. Networks, Negotiations, and New Times: The Implementation of Enterprise Resource Planning into an Academic Administration. Information and Organization, 13:4, 285-313. Available at: http://linkinghub.elsevier.com/retrieve/pii/S1471772703000125 [Accessed July 25, 2012].

Seale, C., 1999. The Quality of Qualitative Research, London: Sage Publications.

Sedara, D., 2009. Size Matters! Enterprise System Success in Medium and Large Organizations. In J. N. D. Gupta, S. Sharma, \& M. A. Rashid, eds. Handbook of Research on Enterprise Systems. Hershey, PA: Information Science Reference, 218-231.

Serrano, N. \& Sarriei, J.M., 2006. Open source software ERPs: a new alternative for an old need. IEEE Software, 23:3, 94-97. Available at: http://ieeexplore.ieee.org/lpdocs/epic03/wrapper.htm?arnumber=1628946 [Accessed April 2, 2013].

Shang, S. \& Seddon, P.B., 2000. A Comprehensive Framework for Classifying the Benefits of ERP Systems. In Americas Conference on Information Systems (AMCIS). 
Shiau, W., Hsu, P. \& Wang, J., 2009. Development of measures to assess the ERP adoption of small and medium enterprises Y. K. Dwivedi, ed. Journal of Enterprise Information Management, 22:1/2, 99-118. Available at: http://www.emeraldinsight.com/doi/abs/10.1108/17410390910922859.

Shibutani, T., 1955. Reference groups as perspectives. American Journal of Sociology, $60: 6,562-569$.

Siggelkow, N., 2007. Persuasion With Case Studies. Academy of Management Journal, 50:1, 20-24. Available at: http://amj.aom.org/cgi/doi/10.5465/AMJ.2007.24160882.

Silverman, D., 2014. Taking theory too far? A commentary on Avison and Malaurent. Journal of Information Technology, 29:4, 353-355. Available at: http://link.springer.com/10.1057/jit.2014.21.

Soares-Aguiar, A. \& Palma-dos-Reis, A., 2008. Why Do Firms Adopt E-Procurement Systems? Using Logistic Regression to Empirically Test a Conceptual Model. IEEE Transactions on Engineering Management, 55:1, 120-133.

Soeffner, H.-G., 1991. "Trajectory" as intended fragment: the critique of empirical reason according to Anselm Strauss. In D. R. Maines, ed. Social organization and socials process: Essays in honor of Anselm Strauss. Hawtorne, NY: Aldine de Gruyter, 359-371.

Soja, P., 2006. Success factors in ERP systems implementations: Lessons from practice. Journal of Enterprise Information Management, 19:4, 418-433. Available at: http://www.emeraldinsight.com/10.1108/17410390610678331 [Accessed August 2, 2012].

Solomon, D.J., 2007. Handbook of research on open source software: Technological, economic, and social perspectives K. St. Amant \& B. Still, eds., IGI. Available at: http://www.scopus.com/inward/record.url?eid=2-s2.084898207322\&partnerID=40\&md5=051d745c7d07e50e023c9ff39e924d40.

Son, J.-Y. \& Benbasat, I., 2007. Organizational Buyers' Adoption and Use of B2B Electronic Marketplaces: Efficiency- and Legitimacy-Oriented Perspectives. Journal of Management Information Systems, 24:1, 55-99.

Star, S.L. \& Griesemer, J.R., 1989. Institutional Ecology, 'Translations' and Boundary Objects: Amateurs and Professionals in Berkeley's Museum of Vertebrate Zoology, 1907-39. Social Studies of Science , 19:3, 387-420. Available at: http://sss.sagepub.com/content/19/3/387.abstract.

Star, S.L. \& Strauss, A., 1999. Layers of Silence, Arenas of Voice: The Ecology of Visible and Invisible Work. Computer Supported Cooperative Work (CSCW), 8:12, 9-30. Available at: http://link.springer.com/10.1023/A:1008651105359.

Star, S.L., 1991. Power, Technologies and the Phenomenology of Conventions: On Being Allergic to Onions. In J. Law, ed. A sociology of monsters: essays on power, technology and domination. London: Routledge, 26-56.

Steinke, I., 2004. Quality criteria in qualitative research. In U. Flick, E. von Kardoff, \& I. Steinke, eds. A Companion to Qualitative Research. London: Sage Publications, 184-190. 
Strand, R. \& Freeman, R.E., 2015. Scandinavian Cooperative Advantage: The Theory and Practice of Stakeholder Engagement in Scandinavia. Journal of Business Ethics, 127:1, 65-85. Available at: http://dx.doi.org/10.1007/s10551-013-1792-1.

Strauss, A. et al., 1963. The hospital and its negotiated order. Eliot Friedson, ed. The Hospital in Modern Society. In E. Friedson, ed. The Hospital in Modern Society. New York: Free Press of Glencoe, 147-169.

Strauss, A. et al., 1964. Psychiatric ideologies and institutions, New York: Free Press.

Strauss, A., 1982. Interorganizational Negotiation. Urban Life, 11:3, 350-367. Available at: http://jce.sagepub.com/cgi/doi/10.1177/089124168201100306.

Strauss, A.L. \& Corbin, J., 1998. Basics of Qualitative Research, Thousand Oaks, California: Sage Publications.

Strauss, A.L. et al., 1985. Social Organization of Medical Work, Chicago: The University of Chicago Press.

Strauss, A.L., 1978a. A Social World Perspective. In N. Denzin, ed. Studies in Symbolic Interaction Vol 1. Greenwich, CT: JAI press, 119-128.

Strauss, A.L., 1978b. Negotiations: varieties, contexts, processes, and social order, San Francisco: Jossey-Bass.

Strauss, A.L., 1991. Scientists and the evolution of policy arenas: The case of AIDS. In Stone symposium of the society for the study of symbolic interaction, San Francisco, $C A$.

Strauss, A.L., 1997. Masks and mirrors: The search for identity, New Brunswick, NJ: Transaction Publishers.

Strauss, A.L., 2008. Continual Permutations of Action, New Brunswick, NJ: Aldine Transactions.

Suddaby, R. \& Greenwood, R., 2005. Rhetorical Strategies of Legitimacy. Administrative Science Quarterly, 50:1, 35-67.

Suddaby, R., 2010. Challenges for Institutional Theory. Journal of Management Inquiry, 19:1, 14-20. Available at: http://jmi.sagepub.com/cgi/doi/10.1177/1056492609347564 [Accessed March 18, 2012].

Sullivan Mort, G. \& Weerawardena, J., 2006. Networking capability and international entrepreneurship: How networks function in Australian born global firms C. Styles, ed. International Marketing Review, 23:5, 549-572. Available at: http://www.emeraldinsight.com/doi/abs/10.1108/02651330610703445.

Taylor, S., 2001. Evaluating and applying discourse analytic research. In M. Wetherell, S. Taylor, \& S. J. Yates, eds. Discourse as data: A guide for analysis. London: Sage and The Open University, 311-330.

Teece, D., Pisano, G. \& Shuen, A., 1997. Dynamic capabilities and strategic management. Strategic management journal, 18:7, 509-533. Available at: http://www.jstor.org/stable/3088148. 
Tennert, J.R. \& Schroeder, A.D., 1999. Stakeholder analysis: a tool for network management. In Paper presented at the 60th Annual Meeting of the American Society for Public Administration, Orlando, Florida, April 10-14, 1999.

Teo, H.H., Wei, K.K. \& Benbasat, I., 2003. Predicting Intention to Adopt Interorganizational Linkages: An Institutional Perspective. MIS Quarterly, 27:1, $19-49$.

Teo, T.S.H. et al., 2011. A framework for stakeholder oriented mindfulness: case of RFID implementation at YCH Group, Singapore. European Journal of Information Systems, 20:2, 201-220. Available at: http://dx.doi.org/10.1057/ejis.2010.58.

The Economist, 2014. The Peter Pan syndrome. The Economist.

The Swedish Research Council's Expert Group on Ethics, 2011. Good Research Practice,

Thong, J.Y.L., 1999. An integrated model of information systems adoption in small businesses. Journal of Management Information Systems, 15:4, 187-214.

Timmermans, S. \& Berg, M., 1997. Standardization in Action: Achieving Local Universality through Medical Protocols. Social Studies of Science, 27:2, 273-305. Available at: http://journals.sagepub.com/doi/10.1177/030631297027002003.

Tracy, K., 1995. Action-implicative discourse analysis. Journal of Language and Social Psychology, 14:1-2, 195-215.

Unruh, D.R., 1980. The Nature of Social Worlds. The Pacific Sociological Review, 23:3, 271-296.

Uwizeyemungu, S. \& Raymond, L., 2012. Impact of an ERP system's capabilities upon the realisation of its business value: A resource-based perspective. Information Technology and Management, 13:2, 69-90.

Venkatesh, V. et al., 2003. User Acceptance of Information Technology: Toward a Unified View. MIS Qarterly, 27:3, 425-478.

Vidgen, R., 1997. Stakeholders, soft systems and technology: separation and mediation in the analysis of information system requirements. Information Systems Journal, 7:1, 21-46. Available at: http://doi.wiley.com/10.1046/j.1365-2575.1997.00003.x.

Vidgen, R., Wood-Harper, T. \& Wood, R., 1993. A Soft System Approach to Information Systems Quality. Scandinavian Journal of Information Systems, 5, 97112.

Wagner, E.L., Newell, S. \& Piccoli, G., 2010. Understanding project survival in an ES environment: a sociomaterial practice perspective. Journal of the Association for Information Systems, 11:5, 276-297.

Walsham, G. \& Sahay, S., 1999. GIS for district-level administration in India: problems and opportunities. MIS quarterly, 23:1, 39-65.

Walsham, G., 1995. Interpretive Case Studies in IS Research: Nature and Method. European Journal of Information Systems, 4:2, 74-81.

Walsham, G., 2006. Doing Interpretive Research. European Journal of Information Systems, 15:3, 320-330. Available at: http://www.palgrave- 
journals.com/doifinder/10.1057/palgrave.ejis.3000589 [Accessed October 28, 2012].

Wang, H.-J. \& Lo, J., 2016. Adoption of open government data among government agencies. Government Information Quarterly, 33:1, 80-88. Available at: http://www.sciencedirect.com/science/article/pii/S0740624X15300198.

Wareham, J., Fox, P.B. \& Cano Giner, J.L., 2014. Technology Ecosystem Governance. Organization Science, 25:4, 1195-1215.

Wastell, D.G. \& Newman, M., 1993. The Behavioral Dynamics of Information System Development: A Stress Perspective. Accounting, Management and Information Technology, 3:2, 121-148.

Wastell, D.G., 1999. Learning Dysfunctions in Information Systems Development: Overcoming the Social Defenses with Transitional Objects. MIS Quarterly, 23:4, 581-600.

Weber, R., 2003. Still Desperately Seeking the IT Artifact. MIS Quarterly, 27:2, iii-xi.

Wedlin, L., 2006. Ranking business schools: Forming fields, identities and boundaries in international management education, Cheltenham, UK: Edward Elgar Publishing.

Westelius, A., 2003. Errors help users learn? In B. Sundgren et al., eds. Exploring Patterns in Information Management. Stockholm: The Economic Research Institute, Stockholm School of Economics, 117-130.

Westelius, A., 2006. Images and imaginators in virtual organising - the NPO Friluftsfrämjandet and www.frilufts.se. International Journal of Public Information Systems, 2:1, 11-37.

Westelius, A., 2006c. Muddling through The life of a multinational, strategic enterprise systems venture at BT Industries,

Westelius, A., 2009. The business logic and the enterprise system - the enterprise system as a political tool. In ANZAM 2009.

Wetherell, M. \& Edley, N., 1999. Negotiating Hegemonic Masculinity: Imaginary Positions and Psycho-Discursive Practices. Feminism \& Psychology, 9:3, 335-356. Available at: http://fap.sagepub.com/cgi/doi/10.1177/0959353599009003012 [Accessed April 2, 2014].

Wetherell, M. \& Potter, J., 1988. Discourse analysis and the identification of interpretive repertoires. In C. Antaki, ed. Analysing Everday Explanation: A Casebook of Methods. London: Sage Publications, 168-183.

Wetherell, M. \& Potter, J., 1992. Mapping the Language of Racism: Discourse and the legitimation of exploitation, London: Columbia University Press.

Wetherell, M., 2003. Racism and the analysis of cultural resources in interviews. In $\mathrm{H}$. van den Berg, M. Wetherell, \& H. Houtkoop-Steenstra, eds. Analyzing Race Talk. New York: Cambridge University Press, 11-31.

Whitley, R., Gläser, J. \& Engwall, L. eds., 2010. Reconfiguring Knowledge Production, New York: Oxford University Press. 
Whittle, A., Mueller, F. \& Mangan, A., 2009. Storytelling and "Character": Victims, Villains and Heroes in a Case of Technological Change. Organization, 16:3, 425442. Available at: http://org.sagepub.com/cgi/doi/10.1177/1350508409102305 [Accessed November 12, 2012].

Willinsky, J., 2005. Open Journal Systems S. P. Muir, ed. Library Hi Tech, 23:4, 504519. Available http://www.emeraldinsight.com/doi/abs/10.1108/07378830510636300.

Winn, M.I., 2001. Building Stakeholder Theory with a Decision Modeling Methodology. Business and Society, 40:2, 133-166. Available at: http://bas.sagepub.com/cgi/doi/10.1177/000765030104000202.

Wodak, R., 2001. The discourse-historical approach. In R. Wodak \& M. Meyer, eds. Methods of Critical Discourse Analysis. London: Sage Publications, 63-94.

Worren, N.A., Moore, K. \& Elliott, R., 2002. When theories become tools: toward a framework for pragmatic validity. Human Relations, 55:200209, 1227-1250. Available at: http://dx.doi.org/10.1177/0018726702055010082.

Xue, Y., Liang, H. \& Boulton, W.R., 2008. Information technology governance in information technology investment decision processes: The impact of investment characteristics, external environment, and internal context. MIS Quarterly, 32:1, 67-96.

Yen, H. \& Sheu, C., 2004. Aligning ERP implementation with competitive priorities of manufacturing firms: An exploratory study. International Journal of Production Economics, 92, 207-220.

Yen, T.S. et al., 2011. A Framework for Classifying Misfits between Enterprise Resource Planning (ERP) Systems and Business Strategies. Asian Academy of Management Journal, 16:2, 53-75.

Yin, R.K., 2009. Case Study Research: Design and Methods 4th ed., Thousand Oaks, California: Sage Publications.

Yoon, T.E. \& George, J.F., 2013. Why aren't organizations adopting virtual worlds? Computers in Human Behavior, 29:3, 772-790.

Yusuf, Y., Gunasekaran, A. \& Abthorpe, M.S., 2004. Enterprise information systems project implementation: A case study of ERP in Rolls-Royce. International Journal of Production Economics, 87:3, 251-266. Available at: http://linkinghub.elsevier.com/retrieve/pii/S0925527303002974 [Accessed July 15, 2012].

Zammuto, R.F. et al., 2007. Information Technology and the Changing Fabric of Organization. Organization Science, 18:5, 749-762. Available at: http://pubsonline.informs.org/doi/abs/10.1287/orsc.1070.0307 [Accessed March 19, 2014].

Zhu, K. \& Kraemer, K.L., 2005. Post-adoption variations in usage and value of ebusiness by organizations: Cross-country evidence from the retail industry. Information Systems Research, 16:1, 61-84. 


\section{THESES IN ECONOMIC INFORMATION SYSTEMS}

\section{DOCTORAL THESES}

1. Savén, Bengt, 1995, Verksamhetsmodeller för beslutsstöd och lärande - En studie av produktionssimulering vid Asea/ABB 1968-1993. Doktorsavhandling 371, IDAEIS, Universitetet och Tekniska Högskolan i Linköping.

2. Villegas, Jaime, 1996, Simulation Supported Industrial Training from an Organizational Learning Perspective - Development and Evaluation of the SSIT Method. Doktorsavhandling 429, IDA-EIS, Universitetet och Tekniska Högskolan i Linköping.

3. Nilsson, Fredrik, 1997, Strategi och ekonomisk styrning - En studie av hur ekonomiska styrsystem utformas och används efter företagsförvärv. Doktorsavhandling 475, IDA-EIS, Universitetet och Tekniska Högskolan i Linköping.

4. Moberg, Anna, 1997, Närhet och distans - Studier av kommunikationsmönster $i$ satellitkontor och flexibla kontor. Doktorsavhandling 512, IDA-EIS, Universitetet och Tekniska Högskolan i Linköping.

5. Lindström, Jörgen, 1999, Does Distance Matter? On Geographical Dispersion in Organisations. Doktorsavhandling 567, IDA-EIS, Universitetet och Tekniska Högskolan i Linköping.

6. Tjäder, Jimmy, 2000, Systemimplementering i praktiken - En studie av logiker $i$ fyra projekt. Doktorsavhandling 618, IDA-EIS, Universitetet och Tekniska Högskolan i Linköping.

7. Petri, Carl-Johan, 2001, Organizational Information Provision - Managing Mandatory and Discretionary Use of Information Technology. Doktorsavhandling 720, IDA-EIS, Universitetet och Tekniska Högskolan i Linköping.

8. Gäre, Klas, 2003, Tre perspektiv på förväntningar och förändringar i samband med införande av informationssystem. Doktorsavhandling 808, IDA-EIS, Universitetet och Tekniska Högskolan i Linköping.

9. Skåmedal, Jo, 2004, Telecommuting's Implications on Travel and Travel Patterns. Doktorsavhandling 869, IDA-EIS, Universitetet och Tekniska Högskolan i Linköping.

10. Askenäs, Linda, 2004, The Roles of IT - Studies of Organising when Implementing and Using Enterprise Systems. Doktors-avhandling 870, IDA-EIS, Universitetet och Tekniska Högskolan i Linköping.

11. Wang, Zhiping, 2004, Capacity-Constrained Production-Inventory Systems Modelling and Analysis in both a Traditional and an E-Business Context. Doktorsavhandling 889, IDA-EIS, Universitetet och Tekniska Högskolan i Linköping. 
12. Kald, Magnus, 2004, In the Borderland between Strategy and Management Control - Theoretical Frameworks and Empirical Evidence. Doktorsavhandling 910, IDAEIS, Universitetet och Tekniska Högskolan i Linköping.

13. Cäker, Mikael, 2005, Management Accounting as Constructing and Opposing Customer Focus - Three Case Studies on Management Accounting and Customer Relations. Doktorsavhandling 933, IDA-EIS, Universitetet och Tekniska Högskolan i Linköping.

14. Keller, Christina, 2007, Virtual Learning Environments in Higher Education - A Study of User Acceptance. Doktors-avhandling 1114, IEI-EIS, Universitetet och Tekniska Högskolan i Linköping.

15. Cöster, Mathias, 2007, The Digital Transformation of the Swedish Graphic Industry. Doktorsavhandling 1126, IEI-EIS, Universitetet och Tekniska Högskolan i Linköping.

16. Ahlström, Petter, 2008, Strategier och styrsystem för seniorboendemarknaden. Doktorsavhandling 1188, IEI-EIS, Universitetet och Tekniska Högskolan i Linköping.

17. Scheja, Mikael, 2009, Börsbolags redovisning av alternativa resultatbegrepp - En studie om hur, och varför, bolag noterade på Stockholmsbörsen redovisar 'NonGAAP measures'. Doktorsavhandling 1258, IEI-EIS, Universitetet och Tekniska Högskolan i Linköping.

18. Nilsson, Erik B., 2010, Strategi, styrning och konkurrenskraft - En longitudinell studie av Saab AB. Doktorsavhandling 1318, IEI-EIS, Universitetet och Tekniska Högskolan i Linköping.

19. Imre, Özgün, 2018, Adopting information systems - Perspectives from small organizations, Doktorsavhandling 1895, IEI-EIS, Universitetet och Tekniska Högskolan i Linköping. 


\section{LICENTIATE THESES}

1. Larsson, Rolf, 1992, Aktivitetsbaserad kalkylering $i$ ett nytt ekonomisystem. Licentiatavhandling 298, IDA-EIS, Universitetet och Tekniska Högskolan i Linköping.

2. Noghabai, Mehran, 1993, Värdering av strategiska datorinvesteringar - Med ett ledningsperspektiv på FMS- och KIS-investeringar. Licentiatavhandling 371, IDAEIS, Universitetet och Tekniska Högskolan i Linköping.

3. Moberg, Anna, 1993, Satellitkontor - En studie av kommunikationsmönster vid arbete på distans. Licentiatavhandling 406, IDA-EIS, Universitetet och Tekniska Högskolan i Linköping.

4. Carlsson, Peter, 1994, Separation av företagsledning och finansiering - Fallstudier av företagsledarutköp ur ett agentteoretiskt perspektiv. Licentiatavhandling 414, IDA-EIS, Universitetet och Tekniska Högskolan i Linköping.

5. Sjöström, Camilla, 1994, Revision och lagreglering - Ett historiskt perspektiv. Licentiatavhandling 417, IDA-EIS, Universitetet och Tekniska Högskolan i Linköping.

6. Poignant, Lars, 1994, Informationsteknologi och företagsetablering - Effekter på produktivitet och region. Licentiatavhandling 441, IDA-EIS, Universitetet och Tekniska Högskolan i Linköping.

7. Lind, Jonas, 1994, Creditor-Firm Relations: An Interdisciplinary Analysis. Licentiatavhandling 451, IDA-EIS, Universitetet och Tekniska Högskolan i Linköping.

8. Nilsson, Fredrik, 1994, Strategi och ekonomisk styrning - En studie av Sandviks förvärv av Bahco Verktyg. Licentiatavhandling 463, IDA-EIS, Universitetet och Tekniska Högskolan i Linköping.

9. Lagerström, Bo, 1995, Successiv resultatavräkning av pågående arbeten Fallstudier $i$ tre byggföretag. Licentiatavhandling 476, IDA-EIS, Universitetet och Tekniska Högskolan i Linköping.

10.Andersson, Jörgen, 1995, Bilder av småföretagares ekonomistyrning. Licentiatavhandling 522, IDA-EIS, Universitetet och Tekniska Högskolan i Linköping.

11. Larsen, Kristina, 1996, Förutsättningar och begränsningar för arbete på distans Erfarenheter från fyra svenska företag. Licentiatavhandling 550, IDA-EIS, Universitetet och Tekniska Högskolan i Linköping.

12. Lindström, Jörgen, 1996, Chefers användning av kommunikationsteknik. Licentiatavhandling 587, IDA-EIS, Universitetet och Tekniska Högskolan i Linköping.

13. Larsson, Annika, 1996, Ekonomisk styrning och organisatorisk passion - Ett interaktivt perspektiv. Licentiatavhandling 595, IDA-EIS, Universitetet och Tekniska Högskolan i Linköping. 
14. Ollinen, Jan, 1997, Det flexibla kontorets utveckling på Digital - Ett stöd för multiflex? Licentiatavhandling 623, IDA-EIS, Universitetet och Tekniska Högskolan i Linköping.

15.Zetterlund, Per-Ove, 1998, Normering av svensk redovisning - En studie av tillkomsten av Redovisningsrådets rekommendation om koncernredovisning, RR01:91. Licentiatavhandling 668, IDA-EIS, Universitetet och Tekniska Högskolan i Linköping.

16. Tjäder, Jimmy, 1998, Projektledaren \& planen - En studie av projektledning $i$ tre installations- och systemutvecklingsprojekt. Licentiatavhandling 675, IDA-EIS, Universitetet och Tekniska Högskolan i Linköping.

17. Wennestam, Christina, 1998, Information om immateriella resurser - Investeringar i forskning och utveckling samt i personal inom skogsindustrin. Licentiatavhandling 712, IDA-EIS, Universitetet och Tekniska Högskolan i Linköping.

18. Westin, Carl-Johan, 1998, Informationsförsörjning: En fråga om ansvar Aktiviteter och uppdrag $i$ fem stora svenska organisationers operativa informationsförsörjning. Licentiatavhandling 730, IDA-EIS, Universitetet och Tekniska Högskolan i Linköping.

19. Jansson, Åse, 1998, Miljöhänsyn - En del i företags styrning. Licentiatavhandling 731, IDA-EIS, Universitetet och Tekniska Högskolan i Linköping.

20. Bäckström, Anders, 1998, Värdeskapande kreditgivning - Kreditriskhantering ur ett agentteoretiskt perspektiv. Licentiatavhandling 734, IDA-EIS, Universitetet och Tekniska Högskolan i Linköping.

21. Ferntoft, Anders, 1999, Elektronisk affärskommunikation - Kontaktkostnader och kontaktprocesser mellan kunder och leverantörer på producentmarknader. Licentiatavhandling 751, IDA-EIS, Universitetet och Tekniska Högskolan i Linköping.

22. Alvehus, Johan, 1999, Mötets metaforer - En studie av berättelser om möten. Licentiatavhandling 753, IDA-EIS, Universitetet och Tekniska Högskolan i Linköping.

23. Skåmedal, Jo, 1999, Arbete på distans och arbetsformens påverkan på resor och resemönster. Licentiatavhandling 752, IDA-EIS, Universitetet och Tekniska Högskolan i Linköping.

24. Gäre, Klas, 1999, Verksamhetsförändringar $i$ samband med IS-införande. Licentiatavhandling 791, IDA-EIS, Universitetet och Tekniska Högskolan i Linköping.

25. Björkegren, Charlotte, 1999, Learning for the Next Project-Bearers and Barriers in Knowledge Transfer within an Organisation. Licentiatavhandling 787, IDA-EIS, Universitetet och Tekniska Högskolan i Linköping.

26. Askenäs, Linda, 2000, Affärssystemet - En studie om teknikens aktiva och passiva roll $i$ en organisation. Licentiatavhandling 808, IDA-EIS, Universitetet och Tekniska Högskolan i Linköping.

27. Nilsson, Håkan, 2000, Informationsteknik som drivkraft i granskningsprocessen En studie av fyra revisionsbyråer. Licentiatavhandling 788, IDA-EIS, Universitetet och Tekniska Högskolan i Linköping. 
28. Kald, Magnus, 2000, The Role of Management Control Systems in Strategic Business Units. Licentiatavhandling 842, IDA-EIS, Universitetet och Tekniska Högskolan i Linköping.

29. Cäker, Mikael, 2000, Vad kostar kunden? Modeller för intern redovisning. Licentiatavhandling 844, IDA-EIS, Universitetet och Tekniska Högskolan i Linköping.

30. Lindahl, Magnus, 2000, Bankens villkor i låneavtal vid kreditgivning till högt belånade företagsförvärv - En studie ur ett agentteoretiskt perspektiv. Licentiatavhandling 754, IDA-EIS, Universitetet och Tekniska Högskolan i Linköping.

31. Bergum, Svein, 2000, Managerial Communication in Telework. Licentiatavhandling 807, IDA-EIS, Universitetet och Tekniska Högskolan i Linköping.

32. Svarén, Stefan, 2001, Styrning av investeringar $i$ divisionaliserade företag - Ett koncernperspektiv. Licentiatavhandling 894, IDA-EIS, Universitetet och Tekniska Högskolan i Linköping.

33. Sandell, Niklas, 2001, Redovisning i skuggan av en bankkris - Värdering av fastigheter. Licentiatavhandling 915, IDA-EIS, Universitetet och Tekniska Högskolan i Linköping.

34. Odar, Susanne, 2002, IT som stöd för strategiska beslut, en studie av datorimplementerade modeller av verksamhet som stöd för beslut om anskaffning av JAS 1982. Licentiatavhandling 916, IDA-EIS, Universitetet och Tekniska Högskolan i Linköping.

35. Hansson, Emma, 2001, Optionsprogram för anställda - En studie av svenska börsbolag. Licentiatavhandling 917, IDA-EIS, Universitetet och Tekniska Högskolan i Linköping.

36. Sevenius, Robert, 2002, On the Instruments of Governance - A Law \& Economics Study of Capital Instruments in Limited Liability Companies. Licentiatavhandling 956, IDA-EIS, Universitetet och Tekniska Högskolan i Linköping.

37. Berglund, Fredrika, 2002, Management Control and Strategy - A Case Study of Pharmaceutical Drug Development. Licentiatavhandling 958, IDA-EIS, Universitetet och Tekniska Högskolan i Linköping.

38. Nilsson, Peter, 2003, Svenska bankers redovisningsval vid reservering för befarade kreditförluster - En studie vid införande av nya redovisningsregler. Licentiatavhandling 1033, IDA-EIS, Universitetet och Tekniska Högskolan i Linköping.

39. Stoltz, Charlotte, 2004, Calling for Call Centres - A Study of Call Centre Locations in a Swedish Rural Region. Licentiatavhandling 1084, IDA-EIS, Universitetet och Tekniska Högskolan i Linköping.

40. Sällberg, Henrik, 2004, On the Value of Customer Loyalty Programs - A Study of Point Programs and Switching Costs. Licentiatavhandling 1116, IDA-EIS, Universitetet och Tekniska Högskolan i Linköping.

41. Vascós Palacios, Fidel, 2005, On the Information Exchange between Physicians and Social Insurance Officers in the Sick Leave Process - An Activity Theoretical 
Perspective. Licentiatavhandling 1165, IDA-EIS, Universitetet och Tekniska Högskolan i Linköping.

42. Keller, Christina, 2005, Virtual Learning Environments in Higher Education - A Study of Students' Acceptance of Educational Technology. Licentiatavhandling 1167, IDA-EIS, Universitetet och Tekniska Högskolan i Linköping.

43. Ahlström, Petter, 2005, Affärsstrategier för seniorbostadsmarknaden. Licentiatavhandling 1172, IDA-EIS, Universitetet och Tekniska Högskolan i Linköping.

44. Cöster, Mathias, 2005, Beyond IT and Productivity - How Digitization Transformed the Graphic Industry. Licentiatavhandling 1183, IDA-EIS, Universitetet och Tekniska Högskolan i Linköping.

45. Horzella, Åsa, 2005, Beyond IT and Productivity - Effects of Digitized Information Flows in Grocery Distribution. Licentiatavhandling 1184, IDA-EIS, Universitetet och Tekniska Högskolan i Linköping.

46. Kollberg, Maria, 2005, Beyond IT and Productivity - Effects of Digitized Information Flows in the Logging Industry. Licentiatavhandling 1185, IDA-EIS, Universitetet och Tekniska Högskolan i Linköping.

47. Käll, Andreas, 2005, Översättningar av en managementmodell - En studie av införandet av Balanced Scorecard $i$ ett landsting. Licentiatavhandling 1209, IDAEIS, Universitetet och Tekniska Högskolan i Linköping.

48. Mihailescu, Daniella, 2006, Implementation Methodology in Action - A Study of an Enterprise Systems Implementation Methodology. Licentiatavhandling 1233, IDAEIS, Universitetet och Tekniska Högskolan i Linköping.

49. Park-Westman, Misook, 2006, Managing Competence Development Programs in a Cross-cultural Organisation - What are the Barriers and Enablers? Licentiatavhandling 1263, IDA-EIS, Universitetet och Tekniska Högskolan i Linköping.

50. Flodström, Raquel, 2006, A Framework for the Strategic Management of Information Technology. Licentiatavhandling 1272, IDA-EIS, Universitetet och Tekniska Högskolan i Linköping.

51. Fryk, Pontus, 2007, Beyond IT and Productivity - Effects of Digitized Information Flows in Health Care. Licentiatavhandling 1328, IEI-EIS, Universitetet och Tekniska Högskolan i Linköping.

52. Lundmark, Erik, 2008, Organisational Adoption of Innovations - Management Practices and IT. Licentiatavhandling 1352, IEI-EIS, Universitetet och Tekniska Högskolan i Linköping.

53. Anjou, Annette, 2008, Scanias framgång - Betydelsen av strategisk kongruens och integrerad styrning. Licentiatavhandling 1364, IEI-EIS, Universitetet och Tekniska Högskolan i Linköping.

54. Fagerberg, Jesper, 2008, Occupational Fraud-Auditors' Perceptions of Red Flags and Internal Control. Licentiatavhandling 1369, IEI-EIS, Universitetet och Tekniska Högskolan i Linköping. 
55. Arwinge, Olof, 2010, Internal Control - A Study of the Concept and Themes of Internal Control. Licentiatavhandling 1431, IEI-EIS, Universitetet och Tekniska Högskolan i Linköping.

56. Svensson, Martin, 2010, Routines for Engagement - Emotions and Routines when Communicating through ICTs. Licentiatavhandling 1444, IEI-EIS, Universitetet och Tekniska Högskolan i Linköping.

57. Gullberg, Cecilia, 2011, Puzzle or Mosaic? On Managerial Information Patterns. Licentiatavhandling 1483, IEI-EIS, Universitetet och Tekniska Högskolan i Linköping.

58. Styf, Elisabeth, 2011, Styrelsens ansvar för den interna koden. Licentiatavhandling 1491, IEI-EIS, Universitetet och Tekniska Högskolan i Linköping.

59. Granath, Malin, 2012, Kan professioner organiseras fram? - En fallstudie av den kommunala energi- och klimatrådgivningen. Licentiatavhandling 1519, IEI-EIS, Universitetet och Tekniska Högskolan i Linköping.

60. Eriksson, Emelie, 2017, Patterns of corporate visual self-representations in accounting narratives. Licentiatavhandling 1792, IEI-EIS, Universitetet och Tekniska Högskolan i Linköping. 



\section{The Swedish Research School of Management and Information Technology MIT}

The Swedish Research School of Management and Information Technology (MIT) is one of 16 national research schools supported by the Swedish Government. MIT is jointly operated by the following institutions: Blekinge Institute of Technology, Chalmers University of Technology, University of Gothenburg, Jönköping International Business School, Karlstad University, Linköping University, Linnaeus University Växjö, Lund University, Mälardalen University College, Stockholm University, Umeå University, Örebro University, and Uppsala University, host to the research school. At the Swedish Research School of Management and Information Technology (MIT), research is conducted, and doctoral education provided, in three fields: management information systems, business administration, and informatics.

\section{DISSERTATIONS FROM THE SWEDISH RESEARCH SCHOOL OF MANAGEMENT AND INFORMATION TECHNOLOGY}

\section{Doctoral theses (2003- )}

1. Baraldi, Enrico (2003), When Information Technology Faces Resource Interaction: Using IT Tools to Handle Products at IKEA and Edsbyn. Department of Business Studies, Uppsala University, Doctoral Thesis No. 105.

2. Wang, Zhiping (2004), Capacity-Constrained Production-Inventory Systems: Modelling and Analysis in both a Traditional and an E-Business Context. IDA-EIS, Linköpings universitet och Tekniska Högskolan i Linköping, Dissertation No. 889

3. Ekman, Peter (2006), Enterprise Systems \& Business Relationships: The Utilization of IT in the Business with Customers and Suppliers. School of Business, Mälardalen University, Doctoral Dissertation No 29.

4. Lindh, Cecilia (2006), Business Relationships and Integration of Information Technology. School of Business, Mälardalen University, Doctoral Dissertation No 28.

5. Frimanson, Lars (2006), Management Accounting and Business Relationships from a Supplier Perspective. Department of Business Studies, Uppsala University, Doctoral Thesis No. 119.

6. Johansson, Niklas (2007), Self-Service Recovery. Information Systems, Faculty of Economic Sciences, Communication and IT, Karlstad University, Dissertation KUS 2006:68. 
7. Sonesson, Olle (2007), Tjänsteutveckling med personal medverkan: En studie av banktjänster. Företagsekonomi, Fakulteten för ekonomi, kommunikation och IT, Karlstads universitet, Doktorsavhandling, Karlstad University Studies 2007:9.

8. Maaninen-Olsson, Eva (2007), Projekt i tid och rum: Kunskapsintegrering mellan projektet och dess historiska och organisatoriska kontext. Företagsekonomiska institutionen, Uppsala universitet, Doctoral Thesis No. 126.

9. Keller, Christina (2007), Virtual learning environments in higher education: A study of user acceptance. Linköping Studies in Science and Technology, Dissertation No. 1114.

10. Abelli, Björn (2007), On Stage! Playwriting, Directing and Enacting the Informing Processes. School of Business, Mälardalen University, Doctoral Dissertation No. 46.

11. Cöster, Mathias (2007), The Digital Transformation of the Swedish Graphic Industry. Linköping Studies in Science and Technology, Linköping University, Dissertation No. 1126.

12. Dahlin, Peter (2007), Turbulence in Business Networks: A Longitudinal Study of Mergers, Acquisitions and Bankruptcies Involving Swedish IT-companies. School of Business, Mälardalen University, Doctoral Thesis No. 53.

13. Myreteg, Gunilla (2007), Förändringens vindar: En studie om aktörsgrupper och konsten att välja och införa ett affärssystem. Företagsekonomiska institutionen, Uppsala universitet, Doctoral Thesis No. 131.

14. Hrastinski, Stefan (2007), Participating in Synchronous Online Education. School of Economics and Management, Lund University, Lund Studies in Informatics No. 6.

15. Granebring, Annika (2007), Service-Oriented Architecture: An Innovation Process Perspective. School of Business, Mälardalen University, Doctoral Thesis No. 51.

16. Lövstål, Eva (2008), Management Control Systems in Entrepreneurial Organizations: A Balancing Challenge. Jönköping International Business School, Jönköping University, JIBS Dissertation Series No. 045.

17. Hansson, Magnus (2008), On Closedowns: Towards a Pattern of Explanation to the Closedown Effect. Swedish Business School, Örebro University, Doctoral Thesis No. 1.

18. Fridriksson, Helgi-Valur (2008), Learning processes in an inter-organizational context: A study of krAft project. Jönköping International Business School, Jönköping University, JIBS Dissertation Series No. 046.

19. Selander, Lisen (2008), Call Me Call Me for some Overtime: On Organizational Consequences of System Changes. Institute of Economic Research, Lund Studies in Economics and Management No. 99. 
20. Henningsson, Stefan (2008), Managing Information Systems Integration in Corporate Mergers \& Acquisitions. Institute of Economic Research, Lund Studies in Economics and Management No. 101.

21. Ahlström, Petter (2008), Strategier och styrsystem för seniorboende-marknaden. IEI-EIS, Linköping universitetet och Tekniska Högskolan i Linköping, Doktorsavhandling, Nr. 1188.

22. Sörhammar, David (2008), Consumer-firm business relationship and network: The case of "Store" versus Internet. Department of Business Studies, Uppsala University, Doctoral Thesis No. 137.

23. Caesarius, Leon Michael (2008), In Search of Known Unknowns: An Empirical Investigation of the Peripety of a Knowledge Management System. Department of Business Studies, Uppsala University, Doctoral Thesis No. 139.

24. Cederström, Carl (2009), The Other Side of Technology: Lacan and the Desire for the Purity of Non-Being. Institute of Economic Research, Lund University, Doctoral Thesis, ISBN: 91-85113-37-9.

25. Fryk, Pontus, (2009), Modern Perspectives on the Digital Economy: With Insights from the Health Care Sector. Department of Business Studies, Uppsala University, Doctoral Thesis No. 145.

26. Wingkvist, Anna (2009), Understanding Scalability and Sustainability in Mobile Learning: A Systems Development Framework. School of Mathematics and Systems Engineering, Växjö University, Acta Wexionesia, No. 192, ISBN: 978-91-7636$687-5$.

27. Sällberg, Henrik (2010), Customer Rewards Programs: Designing Incentives for Repeated Purchase. Blekinge Institute of Technology, School of Management, Doctoral Dissertation Series No. 2010:01.

28. Verma, Sanjay (2010), New Product Newness and Benefits: A Study of Software Products from the Firms' Perspective, Mälardalen University Press, Doctoral Thesis.

29. Iveroth, Einar (2010), Leading IT-Enabled Change Inside Ericsson: A Transformation Into a Global Network of Shared Service Centres. Department of Business Studies, Uppsala University, Doctoral Thesis No. 146.

30. Nilsson, Erik (2010), Strategi, styrning och konkurrenskraft: En longitudinell studie av Saab AB, IEI-EIS, Linköpings universitet och Tekniska Högskolan i Linköping, Doktorsavhandling, Nr. 1318.

31. Sjöström, Jonas (2010), Designing Information Systems: A pragmatic account, Department of Informatics and Media, Uppsala University, Doctoral Thesis.

32. Numminen, Emil (2010), On the Economic Return of a Software Investment: Managing Cost, Benefit and Uncertainty, Blekinge Institute of Technology, School of Management, Doctoral Thesis. 
33. Frisk, Elisabeth (2011), Evaluating as Designing: Towards a Balanced IT Investment Approach, IT University, Göteborg, Doctoral Thesis.

34. Karlsudd, Peter (2011), Support for Learning: Possibilities and Obstacles in Learning Applications, Mälardalen University, Doctoral Thesis.

35. Wicander, Gudrun (2011), Mobile Supported e-Government Systems: Analysis of the Education Management Information System (EMIS) in Tanzania, Karlstad University, Doctoral Thesis. Karlstad University Studies 2011:49.

36. Åkesson, Maria (2011), Role Constellations in Value Co-Creation: A Study of Resource Integration in an e-Government Context, Karlstad University, Doctoral Thesis. Karlstad University Studies 2011:36.

37. Nfuka, Edephonce N. (2012), IT Governance in Tanzanian Public Sector Organisations, Department of Computer and Systems Sciences, Stockholm University, Doctoral Thesis.

38. Larsson, Anders Olof (2012), Doing Things in Relation to Machines: Studies on Online Interactivity, Department of Informatics and Media, Uppsala University, Doctoral Thesis.

39. Andersson, Bo (2012), Harnessing Handheld Computing: Framework, Toolkit and Design Propositions, Lund University, Doctoral Thesis.

40. Erixon, Cecilia (2012), Information System Providers and Business Relationships: A Study on the Impact of Connections, Mälardalen University, Doctoral Thesis.

41. Svensson, Martin (2012), Routes, Routines and Emotions in Decision Making of Emergency Call Takers, Blekinge Institute of Technology, Doctoral Dissertation Series No. 2012:04.

42. Svensson, Ann (2012), Kunskapsintegrering med informationssystem I professionsorienterade praktiker, Institutionen för tillämpad IT, Göteborgs universitet, Doktorsavhandling.

43. Pareigis, Jörg (2012), Customer Experiences of Resource Integration: Reframing Servicescapes Using Scripts and Practices, Karlstad University, Doctoral Thesis. Karlstad University Studies 2012:38.

44. Röndell, Jimmie (2012), From Marketing to, to Marketing with Consumers, Department of Business Studies, Uppsala University, Doctoral Thesis No. 155.

45. Lippert, Marcus (2013), Communities in the Digital Age: Towards a Theoretical Model of Communities of Practice and Information Technology, Department of Business Studies, Uppsala University, Doctoral Thesis No. 156.

46. Netz, Joakim (2013), Diffusa spänningar eller spännande tillväxt? Företagsledning i tider av snabb förändring, Mälardalens högskola, Doktorsavhandling nr 135. 
47. Thorén, Claes (2013), Print or Perish? A Study of Inertia in a Regional Newspaper Industry, Karlstad University, Doctoral Thesis. Karlstad University Studies 2014:10 (Ny uppl.).

Stockhult, Helén (2013), Medarbetare i dialog: en studie om viljan att göra mer än det formellt förväntade, Örebro universitet, Örebro Studies in Business Dissertations, 4.

48. Mihailescu, Daniela (2013), Explaining the Use of Implementation Methodology in Enterprise Systems Implementation Context: A Critical Realist Perspective, Lund University, Doctoral Thesis.

49. Ghazawneh, Ahmad (2012), Towards a Boundary Resources Theory of Software Platforms, Jönköping International Business School, Doctoral Thesis.

50. Shams, Poja (2013), What Does it Take to Get your Attention? The Influence of InStore and Out-of-Store Factors on Visual Attention and Decision Making for FastMoving Consumer Goods, Karlstad University, Doctoral Thesis. Karlstad University Studies 2013:5.

51. Osowski, Dariusz (2013), From Illusiveness to Genuineness: Routines, Trading Zones, Tools and Emotions in Sales Work, Department of Business Studies, Uppsala University, Doctoral Thesis No. 160.

52. Höglund, Linda (2013), Discursive Practises in Strategic Entrepreneurship: Discourses and Repertoires in Two Firms, Örebro University, Doctoral Thesis.

53. Persson Ridell, Oscar (2013), Who is the Active Consumer? Insight into Contemporary Innovation and Marketing Practices, Department of Business Studies, Uppsala University, Doctoral Thesis.

54. Kask, Johan (2013), On business relationships as Darwinian systems: An exploration into how Darwinian systems thinking can support business relationship research, Örebro University, Doctoral Thesis.

55. Paulsson, Wipawee Victoria (2013), The Complementary Use of IS Technologies to Support Flexibility and Integration Needs in Budgeting, Lund University, Doctoral Thesis.

56. Kajtazi, Miranda (2013), Assessing Escalation of Commitment as an Antecedent of Noncompliance with Information Security Policy, Linnaeus University, Doctoral Thesis.

57. Hasche, Nina (2013), Value Co-Creating Processes in International Business Relationships: Three empirical stories of co-operation between Chinese customers and Swedish suppliers, Örebro University, Doctoral Thesis.

58. Pierce, Paul (2013), Using Alliances to Increase ICT Capabilities, Lund University, Doctoral Thesis. 
59. Mansour, Osama (2013), The Bureaucracy of Social Media: An Empirical Account in Organizations, Linnaeus University, Doctoral Thesis.

60. Osmonalieva, Zarina (2013), Factors Determining Exploitation of Innovative Venture Ideas: A study of nascent entrepreneurs in an advisory system, Mälardalen University, Doctoral Thesis.

61. Holmberg, Nicklas (2014), The Purity of Separation of Concerns: The Service Oriented Business Process - a Design Approach for Business Agility, Lund University, Doctoral Thesis.

62. Poth, Susanna (2014), Competitive Advantage in the Service Industry. The Importance of Strategic Congruence, Integrated Control and Coherent Organisational Structure: A Longitudinal Case Study of an Insurance Company, Department of Business Studies, Uppsala University, Doctoral Thesis.

63. Safari, Aswo (2014), Consumer Foreign Online Purchasing: Uncertainty in the Consumer-Retailer Relationship, Department of Business Studies, Uppsala University, Doctoral Thesis.

64. Sandberg, Johan (2014), Digital Capability: Investigating Coevolution of IT and Business Strategies, Umeå University, Doctoral Thesis.

65. Eklinder Frick, Jens (2014), Sowing Seeds for Innovation: The Impact of Social Capital in Regional Strategic Networks, Mälardalen University, Doctoral Thesis.

66. Löfberg, Nina (2014), Service Orientation in Manufacturing Firms: Understanding Challenges with Service Business Logic, Karlstad University, Doctoral Thesis. Karlstad University Studies 2014:30.

67. Gullberg, Cecilia (2014), Roles of Accounting Information in Managerial Work, Department of Business Studies, Uppsala University, Doctoral Thesis No. 171.

68. Bergkvist, Linda (2014), Towards a Framework for Relational-Oriented Management of Information Systems Outsourcing: Key Conditions Connected to Actors, Relationships and Process, Karlstad University, Doctoral Thesis. Karlstad University Studies 2014:31.

69. Tavassoli, Sam (2014), Determinants and Effects of Innovation: Context Matters, Blekinge Institute of Technology, Doctoral Thesis No. 2014:10.

70. Högström, Claes (2014), Fit In to Stand Out: An Experience Perspective on Value Creation, Karlstad University, Doctoral Thesis. Karlstad University Studies 2014:44.

71. Jansson, Tomas (2015), Agila projektledningsmetoder och motivation, Karlstads universitet, Doctoral Thesis. Karlstad University Studies 2015:9.

72. Ryzhkova, Natalia (2015), Web-Enabled Customer Involvement: A Firms' Perspective, Blekinge Institute of Technology, Doctoral Thesis. 
73. Sundberg, Klas (2015), Strategisk utveckling och ekonomistyrning: Ett livscykelperspektiv. Företagsekonomiska institutionen, Uppsala universitet, Doctoral Thesis No. 173.

74. Nylén, Daniel (2015), Digital Innovation and Changing Identities: Investigating Organizational Implications of Digitalization, Umeå University, Doctoral Thesis.

75. Chowdhury, Soumitra (2015), Service Logic in Digitalized Product Platforms: A Study of Digital Service Innovation in the Vehicle Industry, Gothenburg University, Doctoral Thesis.

76. Jogmark, Marina (2015), Den regionala transformationsprocessens sociala dimension. Karlskrona 1989-2002, Blekinge Tekniska Högskola, Doctoral Thesis.

77. Sundström, Angelina (2015), Old Swedish Business in New International Clothes: Case Studies on the Management of Strategic Resources in Foreign-Acquired Swedish R\&D Firms, Mälardalen University, Doctoral Thesis.

78. Öbrand, Lars (2015), Information Infrastructure Risk: Perspectives, Practices \& Technologies, Umeå University, Doctoral Thesis.

79. Brozović, Danilo (2016), Service Provider Flexibility: A Strategic Perspective, Stockholm University, Doctoral Thesis.

80. Siegert, Steffi (2016), Enacting Boundaries through Social Technologies: A Dance between Work and Private Life, Stockholm University, Doctoral Thesis.

81. Linton, Gabriel (2016), Entrepreneurial Orientation: Reflections from a Contingency Perspective, Örebro University, Doctoral Thesis.

82. Akram, Asif (2016), Value Network Transformation: Digital Service Innovation in the Vehicle Industry, Department of Applied Information Technology, Chalmers University of Technology and University of Gothenburg, Doctoral Thesis.

83. Hadjikhani, Annoch (2016), Executive Expectation in the Internationalization Process of Banks: The Study of Two Swedish Banks Foreign Activities, Department of Business Studies, Uppsala University, Doctoral Thesis No. 177.

84. El-Mekawy, Mohamed (2016), From Theory to Practice of Business-IT Alignment: Barriers, an Evaluation Framework and Relationships with Organizational Culture, DSV, Stockholm University, Doctoral Thesis.

85. Salavati, Sadaf (2016), Use of Digital Technologies in Education: The Complexity of Teachers' Everyday Practice, Linnaeus University, Doctoral Thesis.

86. Pashkevich, Natallia (2016), Information Worker Productivity Enabled by IT System Usage: A Complementary-Based Approach, Stockholm Business School, Stockholm University, Doctoral Thesis.

87. Stone, Trudy-Ann (2016), Firms in Global Value Chains, Blekinge Institute of Technology (BTH), Doctoral Thesis. 
88. Saarikko, Ted (2016), An Inquiry into the Nature and Causes of Digital Platforms, Umeå University, Doctoral Thesis.

89. Tona, Olgerta (2017), The Journey of Mobile Business Intelligence: From Vision to Use, Lund University, Doctoral Thesis.

90. Fredin, Sabrina (2017), History and Geography Matter: The Cultural Dimension of Entrepreneurship, Blekinge Institute of Technology, Doctoral Thesis.

91. Giovacchini, Elia (2017), Weaving the Symbiotic Relationship: A Longitudinal Study of a Firm-Sponsored Open Source Community Relationship Maintenance, Stockholm Business School, Stockholm University, Doctoral Thesis.

92. Gillmore, Edward (2017), Four Essays on Subsidiary Evolution: Exploring the Antecedents, Contexts and Outcomes of Mandate Loss, School of Business, Mälardalen University, Doctoral Thesis.

93. Crawford, Jason (2017), Regulation's Influence on Risk Management and Management Control Systems in Banks, Department of Business Studies, Uppsala University, Doctoral Thesis.

94. Von Schantz, Hanna (2017), Well, that makes sense! Investigating opportunity development in a technology start-up, Stockholm Business School, Stockholm University, Doctoral Thesis.

95. Wass, Sofie (2017), The Importance of eHealth Innovations: Lessons about Patient Accessible Information, Jönköping International Business School, Doctoral Thesis.

96. Imre, Özgün (2018), Adopting Information Systems: Perspectives from Small Organizations, Department of Management and Engineering (IEI), Linköping University, Doctoral Thesis. 